Blackboard/Whiteboard:

The Discursive Construction of the International Baccalaureate in Canada

by

Saira Fitzgerald

A thesis submitted to the Faculty of Graduate and Postdoctoral Affairs in partial fulfillment of the requirements

for the degree of

Doctor of Philosophy

in

Applied Linguistics and Discourse Studies

Carleton University

Ottawa, Ontario

(C) 2017

Saira Fitzgerald 


\begin{abstract}
The International Baccalaureate (IB) is a series of educational programs for students aged 3 to 19 offered in schools around the world. Originally created for a transient population in need of a portable and recognized curriculum, it has evolved to become an alternative to local curricula in countries such as Australia, the United States, the United Kingdom and Canada. This manuscript dissertation includes four articles that examine perceptions of the IB in Canada and the implications these perceptions might have for the wider society (e.g., publicly funded education or real estate). The study was conducted in two parts: (i) online survey and semi-structured interviews to gain insight into how admissions personnel at Canadian universities view the IB in relation to other curricula; and (ii) corpus linguistics combined with aspects of critical discourse analysis to examine a 1.5 million word corpus of Canadian newspapers on how the IB is represented in the public domain. Results from both domains showed consistently positive views, suggesting that there exists a dominant (hegemonic) discourse surrounding the IB.
\end{abstract}

Results also suggested that the positive view of the IB tends to create a negative view of things non-IB (programs, students, schools). Since one is constructed as "better", there is an implied comparison that seems to go unnoticed. Using corpus-based critical discourse analysis, patterns of language use were analyzed to make visible values and assumptions that discursively construct the IB as superior. The linguistic patterns and strategies identified appear to bear a striking resemblance to discourses of discrimination and difference, such as (1) collectivization of people into a homogeneous group, (2) attribution of particular qualities or characteristics to the group as a whole, and (3) perpetuation of the stereotype through repetition, and eventually "common sense knowledge" which is taken for granted and more 
assumed than stated explicitly. In the context of Canada's publicly funded education system, where the IB has grown increasingly popular, this positive view is problematic as it privileges a select few while disadvantaging the rest (e.g., by preferred admission into universities), thereby creating a context of insiders and outsiders. 


\section{Acknowledgements}

I would like to express my deepest thanks to my husband Michael Fitzgerald, for his boundless energy, good humour, optimism and unconditional support every step of the way, even when so many other responsibilities demanded his attention. I am especially thankful to him for teaching me two most important words: not necessarily. I am also deeply grateful to my supervisor, Graham Smart, for his thoughtful guidance and constant encouragement over the last four years, fascinating conversations, unfailing trust and incredible generosity of time. You made this journey a real pleasure, thank you so much. And thank you also for introducing me to the profound thoughts of Jerry and the soft thesis whispers of the Wilster, both of whom worked wonders for flagging spirits.

To my Advisory Committee, Guillaume Gentil and Lynne Young, it has been a tremendous honour and a pleasure working with you. Thank you for all that you have taught me, which goes well beyond this dissertation, for always being interested and supportive, for your inspiration and unbelievable energy, and for making everything seem possible.

I am extremely honoured and deeply grateful to Tony McEnery and Tim Pychyl for agreeing to be the examiners for my defence, for reading my dissertation with such keen interest and enthusiasm, and for their thought-provoking questions which have opened up new avenues of enquiry.

To my professors and mentors, Janna Fox and Natasha Artemeva, thank you for always believing in me and for starting me down the path of doctoral research. I couldn't have done it without you. Thank you to my classmates for all their support and good cheer. And thank you to all the wonderful people at SLaLS, where I've spent the better part of two 
decades. Thank you also to the tireless staff at the Carleton University library who were always available to lend a helping hand.

I would also like to express heartfelt thanks to Lancaster University for their incredible generosity in offering the fantastic MOOC on Corpus Linguistics, for creating and sharing such a huge amount of knowledge and providing support, encouragement and unbelievable resources and doing it all without asking for anything in return.

And last but definitely not least, thank you to my family and friends for putting up with my neglect, bad moods and lack of coherent speech all these years. 


\section{Preface}

This manuscript dissertation includes four peer-reviewed journal articles $(2$ published, 1 in press, 1 under review). Each article is reproduced in full in the dissertation, with no changes made to either the published or the under review versions. Bibliographic details for each article, as well as information on how to cite material from these articles, are provided below.

1. Fitzgerald, S. (2015). Perceptions of the International Baccalaureate (IB) in Ontario universities. Canadian Journal of Education, 38(3), 1-34.

Use full journal reference when citing material from this article (see Chapter 5).

2. Fitzgerald, S. (in press). Perceptions of the International Baccalaureate (IB) in Canadian universities. Canadian Journal of Higher Education.

Use full journal reference when citing material from this article (see Chapter 6).

3. Fitzgerald, S. (2017). Murderers, moonwalkers and markets: A corpus based critical discourse analysis of the International Baccalaureate (IB) in Canadian newspapers. Critical Approaches to Discourse Analysis across Disciplines, 9(1), 1-26.

Use full journal reference when citing material from this article (see Chapter 7).

4. Fitzgerald, S. (2017). When you're in with the in-crowd: The discursive construction of the International Baccalaureate (IB) in a corpus of Canadian newspapers. Manuscript submitted for publication.

Reference this dissertation when citing material from this article (see Chapter 8). 


\section{Table of Contents}

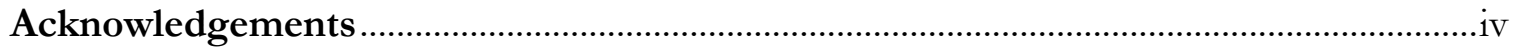

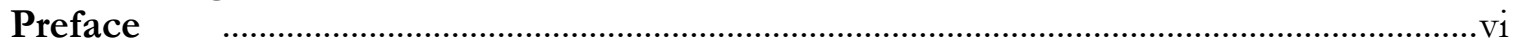

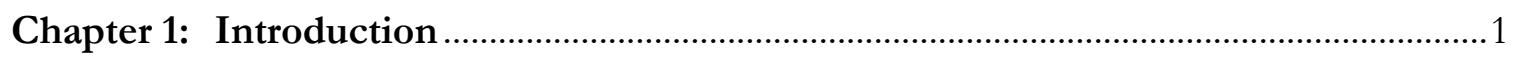

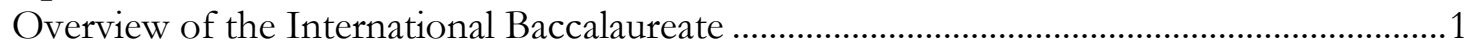

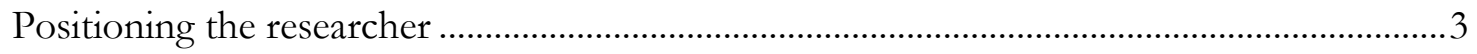

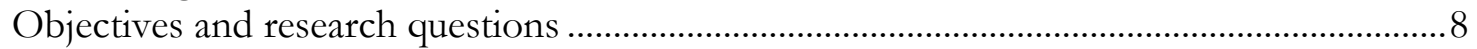

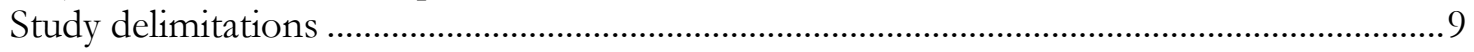

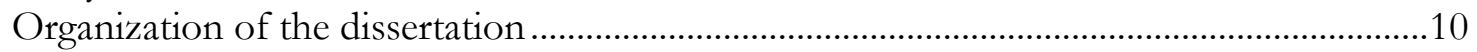

Chapter 2: Theoretical and methodological framework ....................................................12

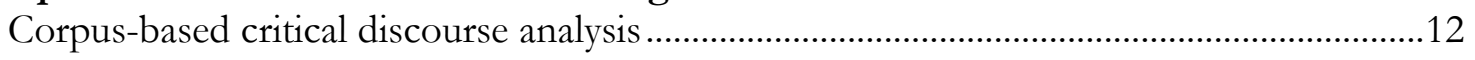

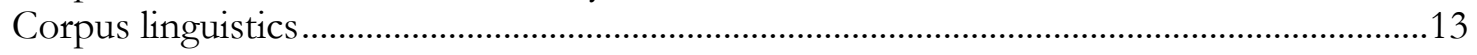

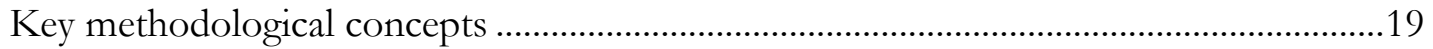

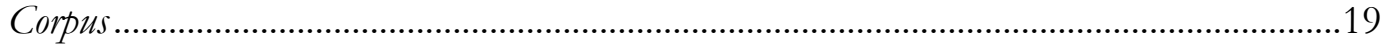

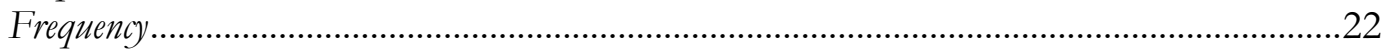

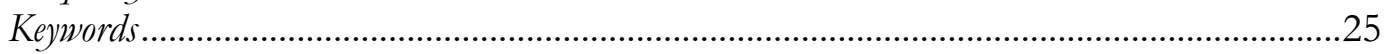

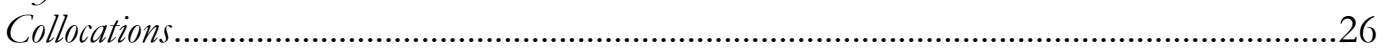

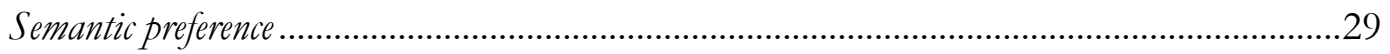

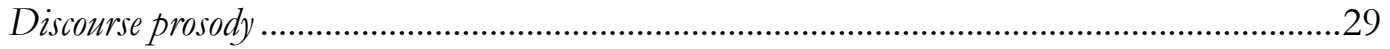

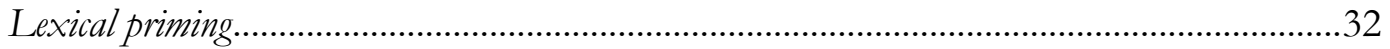

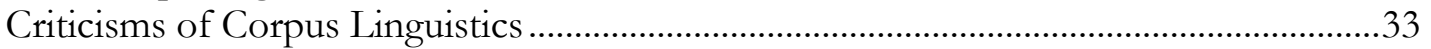

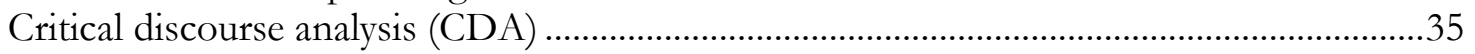

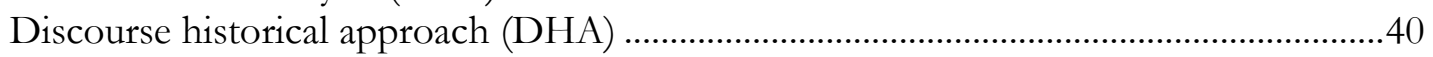

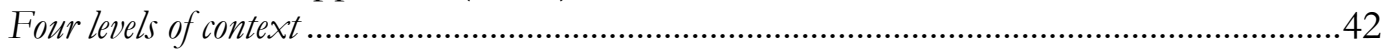

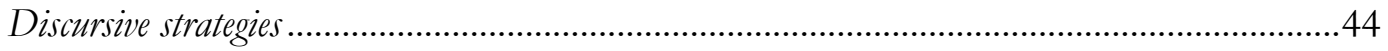

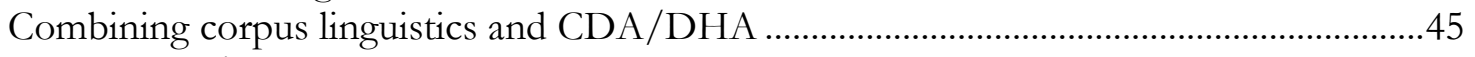

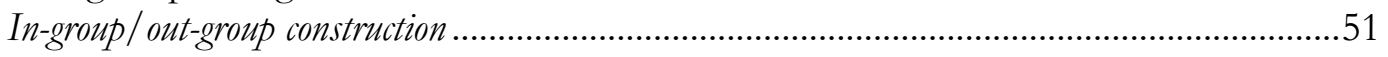

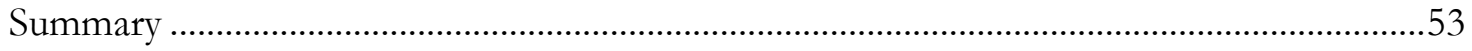

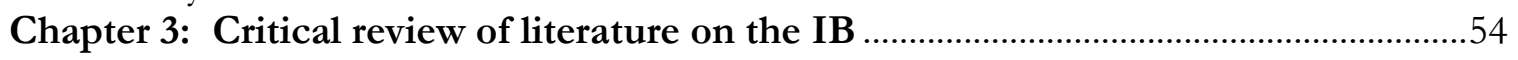

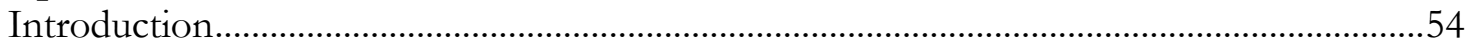

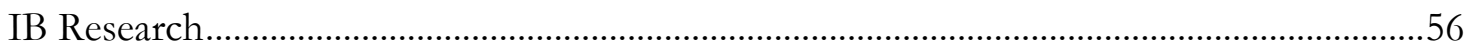

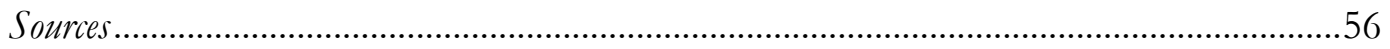

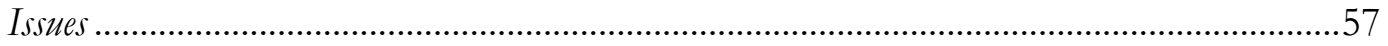

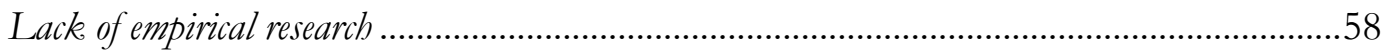

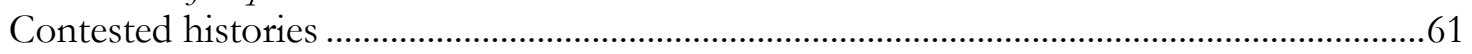

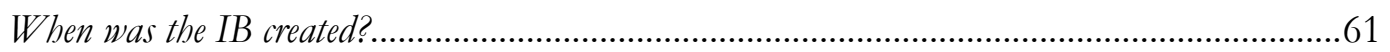

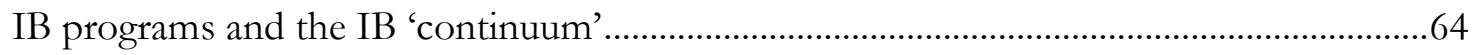

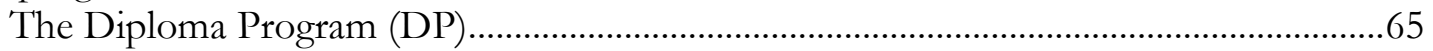

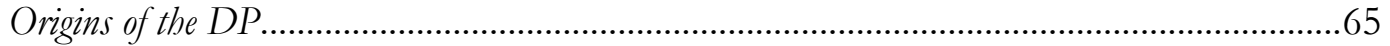

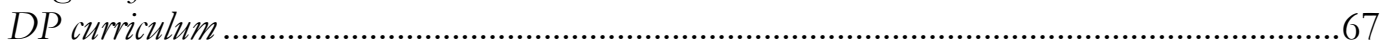

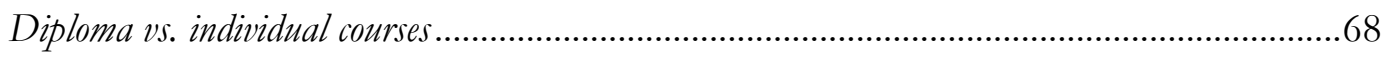

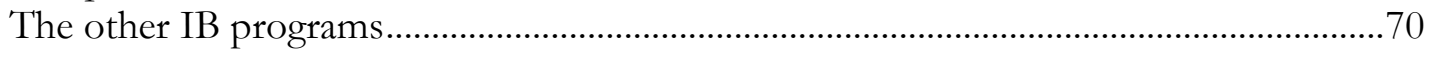

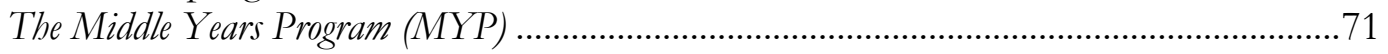

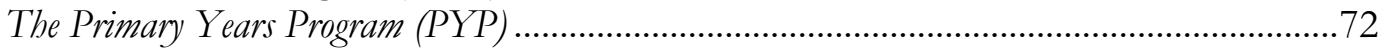

Disambiguating the IB 'continuum': rebranding/conflation ...............................................72 


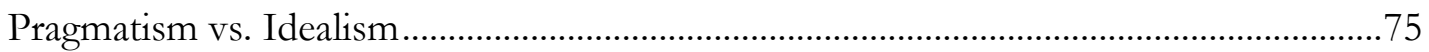

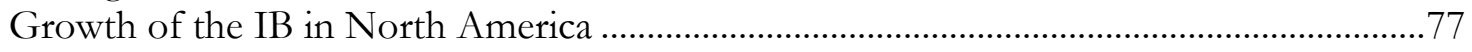

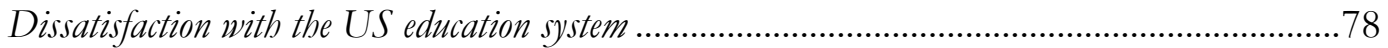

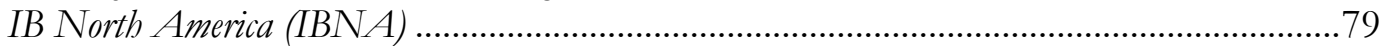

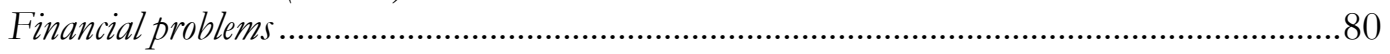

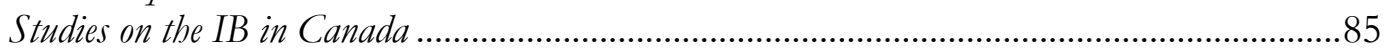

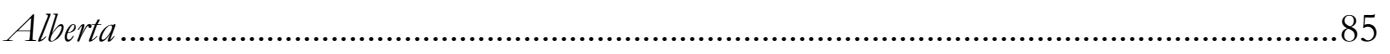

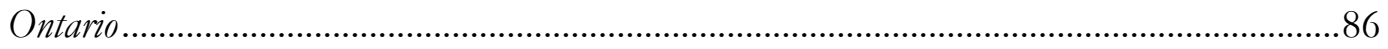

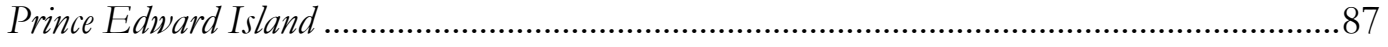

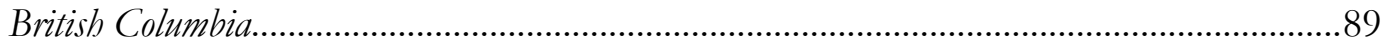

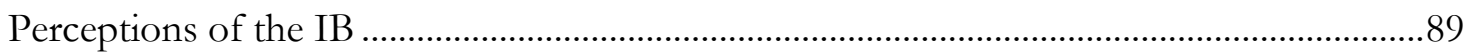

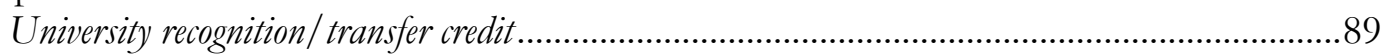

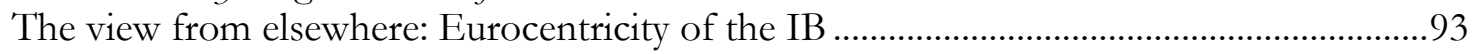

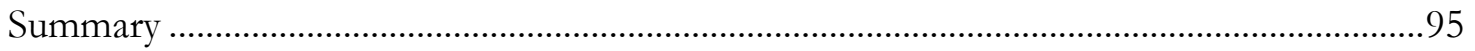

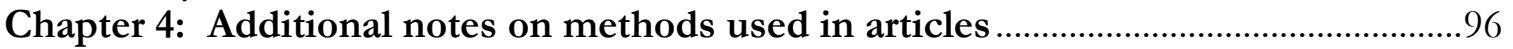

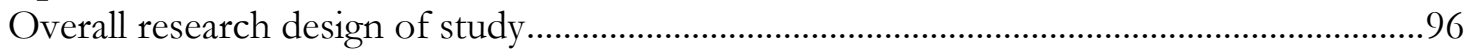

Part 1: Perceptions of university admissions personnel..........................................................98

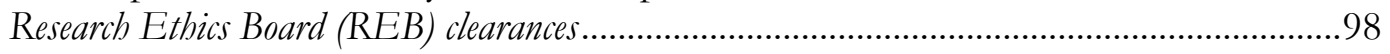

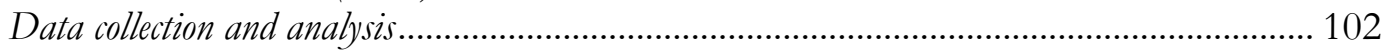

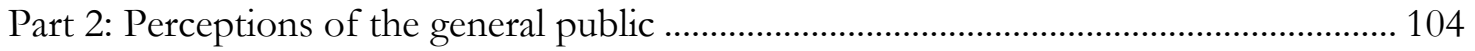

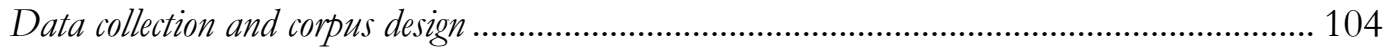

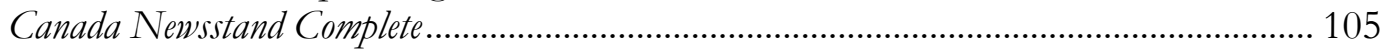

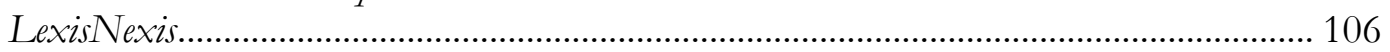

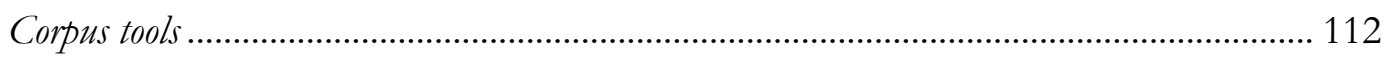

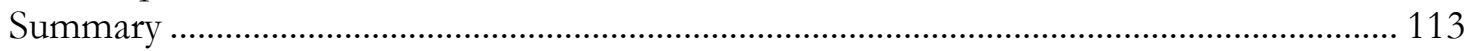

Chapter 5: Perceptions of the International Baccalaureate (IB) in Ontario

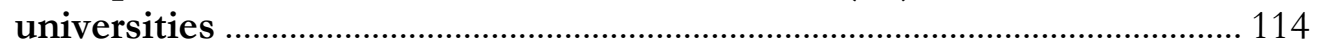

Chapter 6: Perceptions of the International Baccalaureate (IB) in Canadian

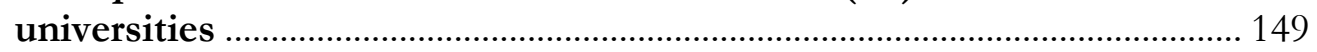

Chapter 7: Murderers, moonwalkers and markets: A corpus based critical discourse analysis of the International Baccalaureate (IB) in Canadian newspapers .............................................................................. 185

Chapter 8: When you're in with the in-crowd: The discursive construction of the International Baccalaureate (IB) in a corpus of Canadian newspapers

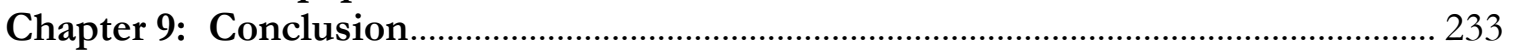

Summary of findings from journal articles (Chapters 5-8) ............................................... 235

Contributions, limitations and directions for further research …...................................... 239

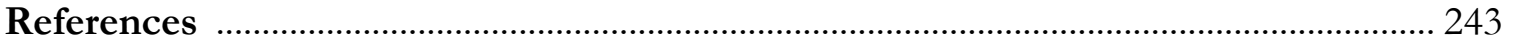




\section{List of Tables}

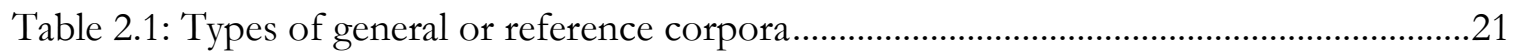

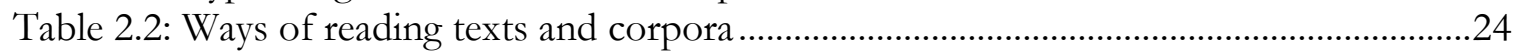

Table 4.1: Specific research questions ………….......................................................................... 


\section{List of Figures}

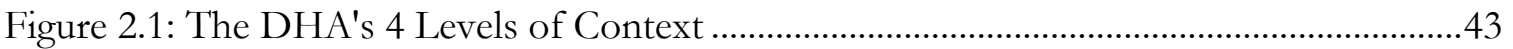

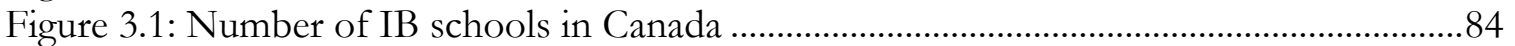

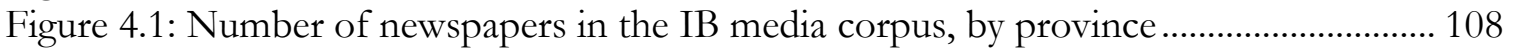

Figure 4.2: Number of articles in the IB media corpus, by province ...................................... 109

Figure 4.3: Number of articles in the IB media corpus, by year (1977 - Feb. 2016) ............ 111 


\section{Chapter 1}

\section{Introduction}

Founded in 1968, the International Baccalaureate ${ }^{\circledR}$ (IB) is a non-profit educational foundation offering four highly respected programmes of international education that develop the intellectual, personal, emotional and social skills needed to live, learn and work in a rapidly globalizing world. Schools must be authorized, by the IB organization, to offer any of the programmes... (IBO, 2017a)

\section{Overview of the International Baccalaureate}

The IB organization is headquartered in Geneva and has regional offices in The Hague (IB Africa/Europe/Middle East), Singapore (IB Asia-Pacific), the US, and Argentina (IB Americas). The IB is a series of educational programs for students aged 3 to 19 offered in schools around the world. According to the IB website, these programs have "unique academic rigour" and "aim to do more than other curricula" (IBO, 2017b). When it was originally created almost 50 years ago, it was a niche product for the children of diplomats who needed a portable and recognized curriculum to serve as their "academic passport" (Blackburn, 1991) as they moved from country to country. As "global nomads" (Langford, 1998) with disparate credentials from different education systems, these students were often disadvantaged when seeking admission into universities of their choice, usually located in North America or Europe. In order to serve this transient diplomatic population, the IB was located in private international schools around the world.

The picture of the IB today is very different. Instead of international private schools as its milieu, with the purpose of assisting students unable to access the educational benefits available to those who are settled at home, the IB has grown in popularity in publicly funded schools in Australia, the UK, the US and Canada, such that Canada and the US now have the highest number of IB schools in the world. As of March 10, 2017, the number of "IB 
World Schools" is 4,655, offering 6,068 programs. By far the greatest number is in the Americas (60.9\% of schools, $57 \%$ of programs) (IBO, 2017c). Such schools must be authorized by the IB organization, a process that "typically takes between two and three years" (IBO, 2017d).

This growth of the IB is somewhat ironic, since one of the reasons the IB was originally created was to assist those who were unable to access North American schools. In the US, the use of public money to support a "foreign" enterprise has been subject to an attack from a conservative group called "Truth About IB (TAIB)", ', who see the IB as antiAmerican and a covert way to promote UN values and agenda. While many of these views seem a bit extreme, the opposition grew strong enough to force the IB organization into issuing explicit statements disavowing any connection to the UN (IBO, 2014a, 2014b). What is notable about this is that TAIB has no issue with the IB in private schools, but objects to public money being used to support programs it does not agree with. There appears to be no such objection to the growth of the IB in Canadian public schools, where there seems to be near unanimous praise for IB programs, with universities privileging students with IB qualifications by offering them preferred admission, special scholarships and transfer credits to reduce their degree requirements and financial burdens. Given the extent of public money being diverted to the IB instead of provincial programs, then, it is surprising that there is little research on the growth of the IB in Canada. One of the aims of the present study is to begin to address this gap in the hope that it will serve as a basis for further discussion on this important but seemingly neglected topic.

\footnotetext{
${ }^{1}$ http://www.truthaboutib.com/

2 A recent article on the BBC news website (August 2, 2017) referred to Canada as an "education superpower"
} 


\section{Positioning the researcher}

I became interested in the IB as a result of my participation in an international development project on curricular reform at a local school in Tanzania. The aim of the project was to implement IB programs alongside the Tanzanian national curriculum so as to provide educational opportunities that the administration perceived to be lacking at this school, which happened to be marking its centenary the year I was there. What little knowledge I had about the IB prior to this experience I had obtained from the IB organization's website, which explained in great detail all the admirable qualities and benefits for students enrolling in IB programs and the virtuous cycle this perpetuates in terms of ultimately benefitting entire nations. I was therefore unprepared for the conflicts that can arise when IB programs are introduced in tandem with already existing local educational systems.

In retrospect, it is not surprising that the project was a failure, not least because, in one fell swoop, the world of this Tanzanian school was divided into "IB" and "non-IB", referring not just to the curriculum, but also to students and teachers. This newly constructed "dichotomous world of insiders and outsiders" (Reisigl \& Wodak, 2001, p. 105) manifested itself in the physical world of the school grounds by a chainlink fence, separating "national" from "international", and in the classrooms, with blackboards for one and whiteboards for the other. A further previously less visible aspect became evident as a result of the high cost of the IB program, i.e., the division between richer students who could afford the additional fees and the poor who could not. Furthermore, long-serving teachers suddenly found themselves identified as "unqualified" because they lacked "IB training" and were therefore excluded from participating in the new "IB World School”. Instead, "IB 
teachers" were recruited from the UK, Australia, the US and Canada. At this time, those considered to be qualified or capable of teaching IB courses tended to be white, while the others were black or brown, highlighting a racial component that was reflected in the physical arrangement of the school (e.g., IB teachers had desks in the air-conditioned and computerized "Teaching Resource Centre" whilst the non-IB teachers worked in the common staff room). What was particularly notable was the gulf between the claims that were routinely made about qualities of the IB (e.g., respect, tolerance, peace) and the apparent lack of these values in the daily operation of the school (discussed below).

In the context of this project, the IB was presented as a solution to the problem of the outdated education model supposedly manifest in the Tanzanian national curriculum. Not only would the IB allow students to gain admission into universities around the world instead of restricting them to Tanzanian institutions but, as one guidance counsellor told the audience at an information meeting, "the IB makes you one hundred times a better person". Interestingly, the speaker had very little knowledge about the IB yet seemed certain of the veracity of this claim. Moreover, in saying this, she seemed to fail to recognize that since the IB had not yet been implemented, her statement in effect excluded everyone at the school and grouped them into an inferior or lesser category in relation to the IB. What was also noticeable in this context of IB implementation was the frequent repetition of statements such as "the IB makes you think" followed by "national students can't think" or "national teachers can't think". The situation that unfolded at the school thus brought to mind the notion of "underdeveloped", a word coined by US President Truman and later described by Gustavo Esteva (1995):

Underdevelopment began, then, on January 20, 1949. On that day, two billion people became underdeveloped. In a real sense, from that time on, they ceased being what they 
were, in all their diversity, and were transmogrified into an inverted mirror of others' reality: a mirror that belittles them and sends them off to the end of the queue. (p. 7)

In a similar way, students at this school were transformed from being clever students lucky enough to have a place in a prominent secondary school in a country where such opportunities are scarce, to being poor non-thinkers and not worthy of the international world. As I was to discover, this type of "discourse of difference" (Hall, 1989; KhosraviNik, 2010; Wodak, 1996), which distinguishes between groups based on specific traits, was not unique to the Tanzanian context.

Upon returning to Canada, I resumed work as a university admissions officer, and was surprised to find that a similar attitude towards the IB seemed to have taken hold here. What had once been regarded as a relatively unfamiliar international credential that needed to be judged against Canadian provincial standards seemed to have become not only much more popular (evidenced by the greater number of applications and transcripts that were being received by the department), but also viewed as somehow superior to all Canadian provincial systems. Assumptions about the level of curricular difficulty and capabilities of students were routinely made, whether in passing or during departmental meetings, echoing the words I had heard in the Tanzanian context (e.g., "it is a very rigorous and challenging program" and "IB students are really smart"). Although my experience at a single school in a developing country could perhaps have been attributed to other factors (institutional growing pains, lack of resources, etc.), the IB organization claimed a level of standardization for its programs that made such an idea problematic. If one school could have such difficulties, didn't it raise the possibility that this might happen elsewhere?

Prior to my experience of the IB in Tanzania, I had not given much thought to this curriculum, but now became interested in why there seemed to be such a uniformly positive 
view of the IB and, in particular, why the same language was used to express this approbation. This view was surprising given not only that Canada's education system regularly scored high on international rankings (e.g., PISA [Programme for International Student Assessment]), ${ }^{2}$ but also that provincial curricula are exported internationally, extolled as providing the means for gaining entry into the best universities around the world. So, for example, an Ontario or British Columbia curriculum described as excellent in China or Egypt and presented perhaps on an equal footing with other international curricula such as the UK A Levels or the IB, in Canada itself was now viewed as inferior.

In order to understand this IB phenomenon, I spent the next six years (prior to embarking on this doctoral research) gathering information and reading widely on the subject. At first, I approached the research in terms of comparative and international education, assessment, curriculum and pedagogy, and followed several false trails that tended to focus on the many different variables at play in different contexts, none of which seemed to get at the aspect I was interested in, which was not about how the IB worked in a particular school or whether it was better than the Ontario or BC curriculum (all of which are important and interesting questions) but rather what the IB was imagined to be, i.e., what made people in diverse countries and contexts uniformly repeat the same qualities of the IB, using the same words. Evidence for this type of language use is easily found on websites of schools and universities, all of which position the IB curriculum and students as superior to the regular or traditional fare. A typical example can be found in one (publicly funded) school in Ottawa:

2 A recent article on the BBC news website (August 2, 2017) referred to Canada as an "education superpower" because it placed in the top tier on the most recent PISA tests (see http://www.bbc.com/news/business40708421). 
Colonel By Secondary School is proud to offer the International Baccalaureate Diploma Programme (IBDP). The IBDP is a rigorous pre-university course of studies and is offered to students over their grade 11 and grade 12 year. Preparation for the challenge of the IB Diploma is begun in grade 9 and grade 10 through the enrichment and acceleration of various courses.

Recognized around the world and offered at more than 3000 schools internationally, the IBDP has at its core the education of the whole student, challenging them to expand their horizons in the classroom, in their community, and the world. Noted Harvard University professor of educational psychology, Howard Gardner, has said that the IBDP curriculum allows students to "think critically, synthesize knowledge, reflect on their own thought processes and get their feet wet in interdisciplinary thinking." In recognition of the level of study demanded by the IBDP and the quality of the graduates that it turns out, universities will often grant advanced standing or university credit to students who have achieved the IB Diploma.

All successful recipients of the IB Diploma also receive their Ontario Secondary School Diploma. ${ }^{3}$

Descriptions of the IB tend to follow this general pattern, the main difference being the provincial credential that is given as part of the IB, almost as an afterthought. Articles in the media, websites of schools and universities, information evenings for parents organized by schools promoting IB programs, ${ }^{4}$ and Canadian university representatives touring the country on recruitment initiatives targetting IB students ${ }^{5}$ are effusive in their praise, repeating the same IB descriptions and qualities. Through further research, I became aware that simply saying "IB" seemed to be enough to trigger a positive and formulaic response. What also became apparent was that this view tended to be accompanied by a lack of knowledge about the specific nature of IB programs. In other words, IB seemed to be functioning as a label that was discursively constructed, with values and attitudes associated with it that seemed to be creating a divided world, as had been evident in the Tanzanian context and now seemed to be occurring in the Canadian public education context. When the IB existed only in the realm of private international schools in different parts of the

\footnotetext{
${ }^{3}$ http://www.ibcb.ca/

${ }^{4}$ https://www.elmwood.ca/event/ib-information-session-andrew-arida/

${ }^{5}$ http://www.ucc.on.ca/?s=Andrew +arida
} 
world, i.e., performing the function for which it was created, it remained the prerogative of wealthy parents who could afford to pay for this expensive brand of education. However, in the context of publicly funded education, this becomes problematic, as it introduces a twotier private-in-public school system, privileging some and disadvantaging others.

\section{Objectives and research questions}

This study combines corpus linguistics and critical discourse analysis (CDA) to examine how the IB is perceived and represented in Canada. As a result of my experience with the IB in multiple contexts, the discourse-historical branch of CDA was appealing because, with its focus on multiple sources and large amounts of data, and emphasis on the importance of the researcher's background (and insider) knowledge about the subject under investigation, it allows for different contexts to be brought into the research. However, as I was also keenly aware that my experience with the IB (and resulting bias) might lead me to pay more attention to things I agreed with and overlook diverging aspects, corpus linguistics provided a way to help mitigate (not eliminate - see Baker, 2012) my bias. Furthermore, corpus data can also reveal patterns and trends that lead to new avenues of enquiry.

To my knowledge, this study is the first since Bagnall's (1994) to focus on the IB in Canada as a whole, and the first to examine its discursive construction, i.e., the way that it is talked about throughout society (i.e., not just by schools or the IB organization itself), with a view to making explicit the values and attitudes associated with the IB and the implications this might have in terms of its impact on the wider society (e.g., publicly funded education or real estate markets). The research divides into two parts according to two different populations investigated: (i) university admissions personnel; and (ii) the general public. For 
the first part, an online survey and semi-structured interviews are used, while the second part employs a specialized corpus of Canadian newspapers as a window into public opinion (Karim, 2008; Mautner, 2008). As such, the study is guided by the following overarching research questions:

1. How is the IB perceived and represented in Canada?

2. What are the implications of this perception and representation? Initially, the primary aim of this research was to move beyond anecdote by systematically analyzing how the IB is perceived in Canada, in order to see whether my suspicion (or hunch) about the positive perception held up under systematic scrutiny. While one needs to be wary of confirmation bias in such cases (Baker, 2006), conducting research to provide evidence for what one suspects is important (Baker \& McEnery, 2015, Mautner, 2009b). However, as the research progressed, particularly during the corpus data analysis, what became evident was that, through repeated patterns of language, a "non-IB other" is constructed to which negative attributes and disadvantages seem to be linked, not always overtly or explicitly but often by implication and inference. In this way, an IB stereotype (or in-group) is discursively constructed. Such patterns may not be noticed if looking at a few selected texts - indeed, I had not noticed them as being quite so frequent or systematic despite my wide reading on the IB.

\section{Study delimitations}

1. The present research examines the IB as a discursive phenomenon, i.e., how it is thought and talked about in different domains of Canadian society, and as such does not evaluate or validate IB curricula or how it is operationalized in specific contexts. In other words, 
this research is not about education per se, but rather about how the label $I B$ is constructed so that it seems to be more about social values than about one type of curriculum among many.

2. Although the present research draws on a specialized corpus of Canadian newspapers as an unsolicited window into public opinion, the focus is not on newspaper reporting and related issues of political and ideological biases in the depiction of different groups that thereby perpetuates stereotypes, as found in numerous other studies. The corpus used in this study includes not just powerful elite sources, but letters and opinion pieces from different members of the public in an effort to be maximally representative. The unsolicited nature of this data provides an important contrast to the elicited responses of the first part of the study, which involved a survey and interviews.

\section{Organization of the dissertation}

This manuscript dissertation comprises nine chapters. Chapter 2 describes the theoretical and methodological framework used in this study, discussing key concepts and research in this relatively new approach to linguistic enquiry. Chapter 3 presents a critical review of the literature on the IB over its 50-year history, paying particular attention to how information is generated through intertextual references to other texts, as well as the conflation that becomes evident as a result. Chapter 4 provides additional details on the methods used in each of the four articles that were not included due to space constraints imposed by academic journals. Chapters 5-8 present the research findings as reported in four articles. The research reported in these articles can be divided into two parts: the first part (Chapter 5 and Chapter 6) focuses on perceptions of university admissions personnel in 
Canada with a view to determining whether a dominant (or hegemonic) discourse surrounding the IB does in fact exist (Baker, 2005); the second part (Chapter 7 and Chapter 8) examines how the IB is perceived and represented in the public domain to determine what values and assumptions are associated with the IB label and what the implications of such a perception or representation might be. Chapter 9 presents a summary of the study, offers some concluding remarks, and discusses avenues for future research. 


\section{Chapter 2}

\section{Theoretical and methodological framework}

This chapter describes the theoretical and methodological framework that guides the research presented in this study. The chapter begins with a brief overview of corpus-based critical discourse analysis and its rise in popularity. This is followed by a discussion of key concepts of each approach and how they combine to provide a "useful methodological synergy" (Baker et al., 2008).

\section{Corpus-based critical discourse analysis}

This framework combines corpus linguistics and critical discourse analysis, and is used here to examine how the IB is discursively constructed in the Canadian context. Such a combination is a relatively new approach, ${ }^{6}$ but one that is becoming increasingly popular and more mainstream (Adel \& Reppen, 2008; Baker \& Levon, 2015; Baker \& McEnery, 2015). It has been described variously as "the marriage between the two methodologies" (Gabrielatos \& Baker, 2008, p. 8), a “"best-of-both-worlds' scenario hardly achievable through the use of purely qualitative CDA" (Mautner, 2009b, p. 125), and as a way to engage in "fruitful dialogue" between a "macro and a micro approach to language, allowing access to data aggregates as well as close attention to detail" (Mautner, 2007, p. 66). Baker (2009) gives an account of the increasing popularity of this approach in terms of the change evident within his department from 1995, when there was little overlap between corpus linguistics and other research, to the present, where it is used by the majority of researchers.

\footnotetext{
${ }^{6}$ Following Lee (2008), approach refers to "a set of theoretical positions and beliefs about the nature of language and how we can study it" (p. 87).
} 
Although corpus analysis was carried out by some researchers in the 1960s and 1970s, it did not gain prominence until the introduction of personal computers in the 1980s and 1990s, which fuelled its increasingly widespread use in the study of language. As Baker (2006) points out, the arrival of personal computers ironically also coincided with an epistemological shift in the social sciences from the positivist or structuralist view (i.e., with emphasis on objective measurement and categorization of facts or truths) to the social constructionist (i.e., knowledge is not fixed but constructed through daily social interaction; see e.g., Burr, 1995). Quantification was thus less attractive to social scientists interested in concepts of language, ideology and hegemony (pp. 8-9), so that the use of corpus linguistics for discourse analysis was far less common. Flowerdew (2012) points out that while both discourse analysis and corpus linguistics make use of naturally occurring data, their "intrinsic ontological and epistemological differences" (p. 174) makes them appear ill-suited or, as Baker (2006) says, "retrograde and incompatible" (p. 9). However, it seems that this incompatibility has proven to be a strength, and corpus-based (critical) discourse analytical studies have become increasingly popular. To understand how this approach works, it is helpful to first discuss corpus linguistics and critical discourse analysis separately and then discuss their "useful methodological synergy" (Baker et al., 2008).

\section{Corpus linguistics}

A common key assumption in corpus-based studies is that the study of language is empirical, based on observing naturally occurring data (Tognini-Bonelli, 2001, p. 2). According to McEnery and Wilson (2001), corpus linguistics is "the study of language based on examples of real life language use” (p. 1). Such examples are collected into a corpus, 
which is generally large (often consisting of millions of words), and analyzed using software tools. As Baker (2006) explains, while corpus linguistics provides a "more quantitative" measure to the analysis because it uses frequency and statistical measures, qualitative analysis is also necessary for interpreting the patterns and trends found in the data. Mautner (2009b) describes corpus linguistics as "a methodology that uses computer support - in particular, software called 'concordance programs' - to analyse authentic, and usually very large, volumes of textual data" (p. 122). ${ }^{7}$ Thus corpus linguistics involves the study of language through the use of computers and large amounts of data (corpora) with a view to observing linguistic patterns and trends.

Although nowadays associated with computers, corpus-based research has a long history, with concordance work dating back to $13^{\text {th }}$ century biblical scholars. Today, as O’Keeffe and McCarthy (2010) point out, “computer concordancing programs replicate the work of 500 monks in micro-seconds" (p. 3). It is understandable, then, that prior to the advent of computers, this type of research was limited. Access to data (i.e., attested or authentic language) was also a challenge, so researchers relied on extracts or a small number of examples to test their theories. Claims were often based on "native speaker intuition" (Coffin, Hewings \& O’Halloran, 2004, p.8; Tognini-Bonelli, 2004, p. 11) which, together with a small data set, increased the potential for bias, i.e., the tendency of analysts to focus on aspects that confirm their suspicions and possibly disregard other results as anomalies. Or, as Kuhn (1962) discusses, researchers may not even notice the anomalies since awareness may come only through repeated encounters. As such, because the work was so

\footnotetext{
7 There are also smaller corpora which are purpose-built by individual researchers to investigate specific research questions, as in the present study, for example. The smaller the corpus, however, the more important it becomes to validate interpretations against a larger one (Mautner, 2009b, pp. 131-133). Baker (2006) provides a useful discussion about using a small corpus consisting of twelve tourist brochures (pp. 47-69).
} 
painstaking and laborious, anomalies could easily be missed. In addition, because of their infrequent occurrence, a small data set might not even include such anomalies which would therefore remain unknown or unnoticed (Stubbs, 1997; Tognini-Bonelli, 2004).

Corpus linguistics makes it possible not only to minimize bias by using large corpora but also to allow for unexpected discoveries about the patterns of language (see Partington et al., 2013, on the importance of "serendipity" that can lead to new questions). For example, in a study connected to the teaching of vocabulary and understanding synonyms, TogniniBonelli (2004) examined the linguistic behaviour of two adverbs, largely and broadly, and discovered that although the two words are often considered synonyms, largely carried a negative connotation because, in the corpus analyzed, it co-occurred (or collocated) primarily with negative words, whereas broadly co-occurred with words of similarity or agreement. Since there is no grammatical rule that accounts for this type of occurrence, such an observation "often comes to the analyst as totally unpredicted" (p. 16). These kinds of discoveries are possible with the help of alphabetized concordance tables afforded by corpus tools. And Biber \& Conrad (2001) note that quantitative corpus-based techniques allow researchers to entertain new kinds of research questions (p. 335). Hence the evident excitement in the corpus linguistics literature and the notion of a revolution in the way we understand language:

The revolution has resulted in a different quality of linguistic evidence which has enabled us to make new, exciting and unexpected discoveries...The change came about because of the move...from basically observing and describing a single communicative event, a text, to accessing, with the help of a computer, a whole collection of texts, a corpus, and observing the repeated lexical and grammatical choices of a certain community of language users. Unlike researchers from the past, this new methodology does not rely on native-speaker intuition but is equally available to anyone with an attentive eye for detail. (Tognini-Bonelli, 2004, p. 11)

According to Lee (2008), a corpus-based linguistic approach assumes a "set of theoretical positions and beliefs about the nature of language and how we can study it" (p. 87). This 
involves three components: (i) a particular orientation towards language (real language in use); (ii) a particular view of language data (more data is better); and (iii) familiarity with a set of techniques (e.g., concordancing, keyword analysis). Observing naturally occurring language as opposed to relying on introspection and native speaker intuition, as McEnery and Wilson (2001) discuss, reflects a fundamental division between a rationalist and empiricist approach. The rationalist approach advocated by Chomsky focused on language competence and relied on artificial examples, introspection, and the intuitions of native speakers rather than the observation of naturally occurring language as evidenced in a corpus (McEnery \& Wilson, 2001; Tognini-Bonelli, 2001).

Although intuition does of course play an important part in the analysis of language, testing such intuitions against a multi-million word corpus can provide the evidence for hypotheses which goes beyond one or two examples that simply confirm presuppositions. As O’Halloran and Coffin (2004) point out, intuition can be unreliable and result in “overinterpretation" (i.e., subjective impressions) or "underinterpretation" (i.e., not noticing nuances) (pp. 275-279). For example, Fairclough's (1995) analysis of the depiction of the poor interpreted the verb flock as referring to sheep, thereby reinforcing the notion that poor people are passive and helpless. However, his interpretation was based on intuition, and was not borne out by Widdowson's (2000) corpus analysis of the word, which found that the verb flock usually associated (collocated) with active roles (e.g., journalists or golf spectators). For such reasons, Stubbs (2004) warns that "[c]omments on individual words and phrases should always be made against the background of comparative data from a corpus" (p. 248). Hardt-Mautner (1995) suggests that "[d]rawing on corpus evidence fundamentally redefines 
the nature of 'interpretation', turning it from an introspective undertaking into an empirical one" (p. 22).

While there are certain methods and procedures that tend to be followed in corpusbased analyses (e.g., analyzing concordance lines or obtaining frequency lists), the field is heterogeneous, comprising different types of research and approaches to studying language. Furthermore, although quantitative and computer-based, corpus linguistics is not simply an automated process, as it depends on a considerable number of decisions made by the researcher. For example, as McEnery \& Hardie (2012) discuss, studies in corpus linguistics can vary by mode of communication (e.g., spoken, written, visual), whether it is corpusbased (i.e., using the corpus as a repository of examples to support or disconfirm prior hypotheses), corpus-driven (i.e., allowing hypotheses to emerge from the corpus data) or a combination of both, and also the type of corpus data used (e.g., whether it is already available or constructed from scratch as a specialized corpus, whether it is annotated for parts of speech or left unmarked, and whether it is multilingual or monolingual).

Lee (2008) describes three principle ways that corpora are used for analyzing discourse, although these distinctions are not precise and are only meant to illustrate the variety of discourse research that can be done with corpora: (i) "corpus informed" (i.e., mainly qualitative, where corpus data serves as a source of examples); (ii) "corpussupported" or "corpus-driven" (i.e., both qualitative and quantitative, where the degree of reliance on the corpus varies); and (iii) "corpus induced" (i.e., mainly quantitative, where corpora are used in large scale studies that conduct automated analyses requiring frequencies or grammar, an area still relatively new at the time of Lee's writing). According to Lee's distinction, then, the present study can be called "corpus supported" and "corpus driven" as 
it combines both quantitative and qualitative approaches (see Chapter 7 and Chapter 8). Such studies are often referred to as "corpus-based", a term that includes both meanings (e.g., McEnery et al., 2006).

Another reason there is such variety in corpus linguistics is that different researchers have different ways to approach the analysis, as illustrated by Marchi and Taylor (2009) and Baker (2015). In Marchi and Taylor's study, although both researchers used the same corpus and software tools, one began with a more corpus-driven approach (using frequency data to direct the analysis) while the other began with introspection and background reading on the subject being investigated that gave rise to some initial hypotheses prior to analyzing the corpus data. Baker (2015) conducted a similar experiment involving five researchers tasked with analyzing the same corpus with the same research question, and also showed a range of approaches to the data, including the type of tool and the analytical procedures used, with some researchers using up to five different techniques and others only two. Based on these two studies, a further experiment was conducted with 10 different researchers examining the same corpus data and research questions (Baker \& Egbert, 2016). Interestingly, even though each researcher in this case was deliberately restricted to using a single primary technique, differences still occurred due to decisions taken by researchers about the parameters for different techniques (e.g., cut-off points or whether the corpus was annotated or not). These studies provide evidence that counters notions about corpus linguistics being a fully automated approach. As Baker (2010) says, "corpus linguistics is not like Star Trek: we do not say 'Computer, tell me about change in the use of modal verbs over the past hundred years' and receive an immediate answer" (p. 11). For these reasons, as Sinclair (2004) argues, it is important to document all the decisions that are made (either during corpus 
construction or analysis), as well as the opportunities and/or problems encountered by the corpus and tool.

Debate is ongoing as to whether corpus linguistics is a theory or method (e.g., Baker, 2010; Hardie \& McEnery, 2010; McEnery \& Gabrielatos 2006; Partington et al., 2013; Taylor, 2008). Some argue that it is a unique discipline separate from other forms of linguistic enquiry and thus a theory (Tognini-Bonelli, 2001; Teubert, 2005). Others maintain that it is a methodology that can be fruitfully employed in diverse areas of linguistic research (e.g., Flowerdew 2012; Lee, 2008; O’Keeffe \& McCarthy 2010; McEnery \& Wilson, 2001), but also note that it is more than a methodology because it has changed the types of research questions that can be asked, thus transforming our understanding of the nature of language (e.g., Biber \& Reppen, 2015). For the purposes of the present study, however, this debate is largely academic.

\section{Key methodological concepts}

There are a number of key concepts in corpus-based (critical) discourse analysis (Baker, 2006; Baker et al., 2008; Gabrielatos \& Baker, 2008). Here I discuss those that are particularly relevant for the present study: corpus; frequency; concordance; keywords; collocations; semantic preference; discourse prosody; and lexical priming.

Corpus

Although the word "corpus" is sometimes used to refer to any collection of written texts, in the context of corpus linguistics it refers to a large body of naturally occurring language data stored on computers. As well, a corpus is designed according to specific principles pertaining to the data collected, with the aim of making it as representative as 
possible of the linguistic variety or topic in question (e.g., Baker \& McEnery, 2015). What is important is the natural occurrence of the data, i.e., that it is language in actual use rather than examples artificially constructed for abstract linguistic analysis, and thus is a representative sample of language as used in a particular society or societies (e.g., Mahlberg, 2009; Mautner, 2009a; Frankenberg-Garcia et al., 2011). By employing specialized software tools to analyze the data, linguistic patterns can be revealed that point the researcher to further areas of enquiry and a broader view of how discourses surrounding a particular object might be constructed, thereby making visible the values and attitudes of the societies in which they originate. As Tognini-Bonelli (2004) puts it, "the way we can now look at text shows up the link between the individual instance of communication and the social tendency for a community of speakers to use particular patterns of language" (p. 11). However, as McEnery and Hardie (2012, p. 15) note, a corpus only ever presents a partial or finite view, since it is only a sample and therefore cannot be said to be representative of the entire language. Any claims that are made about linguistic behaviour based on corpus analysis must therefore take this into account.

There are many different types of corpora, ranging from millions of words (e.g., British National Corpus [BNC], Corpus of Contemporary American English [COCA]) to now billions of words (e.g., ententen12/13, GloWbE). A summary of some of these is presented in Table 2.1 below. 


\begin{tabular}{|l|l|l|l|}
\hline Corpus & Size & Region & Range \\
\hline COCA & 520 million words & American & $1990-2015$ \\
\hline BNC & 100 million words & British & 1980 s-1993 \\
\hline Strathy Canada & 50 million & Canadian & 1970 s-2000s \\
\hline GloWbE & 1.9 billion & 20 countries & $2012-2013$ \\
\hline enTenTen12 & 12 billion & Web & $2012-2013$ \\
\hline enTenTen13 & 19.7 billion & Web & 2013 \\
\hline
\end{tabular}

Table 2.1: Types of general or reference corpora

These corpora contain texts from a wide range of contexts (e.g., written, spoken, fiction, non-fiction) and provide information on language norms such as British English or American English. They are usually referred to as "general" or "reference" corpora, and are often used as a means of comparing the findings from one's own data or specialized corpus (discussed below) with "general" usage. They can also be used as a source of linguistic data in themselves, thereby alleviating the need to build a corpus from scratch.

As Baker (2006) notes, reference corpora may not contain sufficient examples of the type of language one is interested in. In such cases, it is necessary to build a "specialized" (p. 26) or "purpose-built" (Mautner, 2009a, p. 35) corpus. These tend to be smaller, containing texts selected by the researcher according to specific criteria such as a focus on particular genres and/or topics (e.g., British newspapers containing references to political correctness [Johnson et al., 2003] or Canadian newspapers containing references to International Baccalaureate as in the present study). One issue with a specialized corpus is how large it needs to be (e.g., in terms of representativeness), although Baker (2006) argues that for the purposes of discourse analysis, substance, i.e., whether the corpus contains enough references for the item being analyzed, matters more than size. Another issue in designing a new corpus is sourcing texts, although this has become easier with the internet and ready 
access to electronic texts. The corpus one uses depends on one's research question and what one wants to do with it. As McEnery and Hardie (2012) put it, there is no point in trying to find out about Swahili adverbs in the BNC. Therefore, it is important that the questions posed can be answered by the corpora selected and/or designed.

\section{Frequency}

Frequency refers to the number of times a single word, phrase, cluster, or expression occurs in a corpus. As Baker and McEnery (2015) note, "the concept of frequency drives many of the techniques associated with corpus linguistics, giving the field a quantitative flavour" (p. 2). Frequency can direct a researcher to specific parts of a corpus (e.g., looking at where highly frequent words occur) and provide a starting point for analysis. To obtain frequency counts, a wordlist can be generated that lists all the words in the corpus according to the number of times they occur, and provides the total number of words (tokens) and the number of different types (unique words). Depending on the corpus tool used, a wordlist can be sorted in different ways (e.g., ascending or descending order, or alphabetically), and may also provide a word's percentage contribution towards the corpus. Frequencies are often expressed in terms of occurrences per million or per thousand words (i.e., normalized) so that corpora of different sizes may be meaningfully compared (Baker, 2006, 2010). Another concept associated with frequency is that of range or dispersion, i.e., the extent to which a lexical item occurs throughout the corpus or is concentrated in only a handful of texts. For example, if a certain word occurs very frequently throughout the corpus, it might suggest a dominant discourse. However, if it occurs very frequently in only one or two articles, it might indicate a more idiosyncratic usage. Dispersion plots provide a visual representation of where in the corpus a search term occurs (Baker, 2006, 2010). One way 
these have been used has been to obtain a smaller representative sample of articles (i.e., downsample) for more in-depth CDA/DHA analysis (see e.g., Freake et al., 2011).

As Baker (2006) notes, language is not random but occurs in predictable ways (see also Kilgarriff, 2005), yet there are many different ways to say the same thing. The notion of "language as a set of rules" and "language as free choice" makes frequency an important way to get at underlying assumptions and intentions because it highlights the (conscious or unconscious) linguistic choices made by a speaker (Baker, 2006, pp. 47-48). By examining the frequency of words and phrases and identifying repeated patterns and trends, it becomes possible to see how values and assumptions are reified, i.e., have become naturalized and taken for granted. Discovering such repeated patterns can make visible how a society's (or discourse community's) particular values and attitudes are discursively constructed. However, as Baker (2006) and Mautner (2009a) point out, powerful or hegemonic discourses are not always indicated by frequency. Sometimes what is not said may be a sign of a hegemonic discourse (e.g., mature student or male nurse suggest that student generally means young and nurse generally means female). In other words, a hegemonic discourse "can be at its most powerful when it does not even have to be invoked, because it is just taken for granted" (Baker, 2006, p. 19). And it is through frequently repeated action that patterns emerge, become taken-for-granted routines, and are more objectified over time until they are understood as "this is how things are done" (Berger \& Luckmann, 1966, p. 77).

\section{Concordance (KWIC)}

A concordance, often referred to as "key word in context (KWIC)", is a list of all the occurrences in a corpus of a search term or "node". These are presented in their contexts with a few words to the left and right of the node. Concordance lines are aligned around the 
search term, arranged vertically, and can be sorted alphabetically to the left or right of the search term, making it possible for the researcher to identify patterns (see Chapter 7 and Chapter 8 for examples of concordance lines). Once a pattern has been identified, detailed analysis of the line in its larger context is necessary. Mautner (2007) argues that a research design should combine analysis of patterns across large corpora with in-depth analysis of a smaller sample of longer texts, "mediat[ing] between a macro and a micro approach to language, allowing access to data aggregates as well as close attention to detail" (pp. 65-66). The analysis can iterate between quantitative (e.g., frequency information) and qualitative (e.g., individual concordance lines or entire article/text), with the KWIC providing the link between quantification and interpretation. As Gabrielatos \& Baker (2008) suggest, "[c]oncordance analysis is where corpus-based and CDA methodological approaches overlap" (p. 15).

Examining concordance lines requires a different type of reading than is usual when analyzing individual texts, as outlined in Table 2.2 below:

Table 2.2: Ways of reading texts and corpora

\begin{tabular}{|c|c|}
\hline A text & A corpus \\
\hline $\begin{array}{l}\text { - } \text { read whole } \\
\text { - } \text { read horizontally } \\
\text { - } \text { read for content } \\
\text { - } \text { read as a unique event } \\
\text { - } \text { read as an individual act of will } \\
\text { - } \text { coherent communicative event }\end{array}$ & $\begin{array}{l}\text { - } \text { read fragmented } \\
\text { - } \text { read vertically } \\
\text { - } \text { read for formal patterning } \\
\text { - } \text { read for repeated events } \\
\text { - } \text { read as a sample of social practice } \\
\text { - } \text { not a coherent communicative event }\end{array}$ \\
\hline
\end{tabular}

Table 2.2: Ways of reading texts and corpora (Source: Tognini-Bonelli, 2004, p. 18) 
As O'Keeffe and McCarthy (2010) explain, this type of reading requires the reader to understand meaning through vertical as well as left-to-right and right-to-left reading. It demands new micro-cognitive skills as the reader moves from identifying patterns to forming hypotheses and making inferences. Since this type of reading cannot be assumed to be automatic, it has implications for language pedagogy (p. 8), and thus further reinforces the notion of corpus linguistics as transformational for our understanding of language.

\section{Keywords}

Although keywords are not used in the present study, they are important for much corpus linguistic analysis. Therefore, a brief overview is provided here. Scott (1997) defines a keyword as any word that occurs "with unusual frequency" (p. 236) in one corpus when compared to another (a reference corpus). This is different from simple frequency, which only tells us how often a word occurs in one corpus. For example, although grammatical or function words such as the or and tend to be very frequent in most corpora, they will not usually be identified as "key" since they are equally frequent among corpora. When such words are identified as key, it tells us something about the unusual occurrence of the word, as was found by McEnery (2006) in a specialized corpus on bad language and British media, where and was used as a way to express underlying moralistic attitudes. Keywords, thus, give an idea of the preoccupation or "aboutness" (Baker et al., 2006) of a corpus, thereby pointing to avenues for further research. They generally consist of three types: (i) proper nouns (e.g., Obama, Trudeau); (ii) lexical words (e.g., baccalaureate, transgender); and (iii) grammatical words that may be an indication of style (e.g., shall, because) (Baker, 2004).

Keywords are determined by statistical methods (e.g., log-likelihood or chi-square), through which a "keyness" value is assigned to each word. The higher the keyness score of a 
word, the stronger its "saliency" (Baker, 2006, p. 125). However, a number of decisions must be made by the researcher before a keyword list can be obtained. For example, the researcher needs to establish cut-off points, such as number of keywords to be examined (e.g., top 10, 50, or 100 keywords), the minimum frequency required (e.g., a word must occur 20 times before it is a keyword), and distribution criteria (e.g., it must occur in at least 20 texts). The amount of researcher input required in the different aspects of corpus analysis helps counter the view that this is a purely "mechanistic or positivist approach" (Tenorio, 2011, p. 198). Keywords obtained through statistical measures (i.e., keyness strength) are described as being more corpus-driven (Baker \& Egbert, 2016), because the corpus directs the researcher to specific aspects for further enquiry.

\section{Collocations}

Collocation was important for the analyses in Chapter 7 and Chapter 8 of the present study. Here, I provide some additional information about this concept not included in those chapters.

Collocation refers to words that tend to occur near or next to each other more often than we might expect if the words were in random order, such as innocent bystander (Baker et al., 2006).. Collocation analysis can provide an initial focus for the analysis or a shortcut into the data, which is helpful when the researcher is faced with hundreds of concordance lines to sort through, and gives the most salient and obvious lexical patterns associated with a particular subject (Baker, 2006, p. 114). Although collocation has been defined in different ways (McEnery \& Hardie, 2012, p. 122), the concept is often introduced in corpus linguistics by reference to the statement made by Firth (1957), "You shall know a lot about a word from the company it keeps” (e.g., Baker, 2006, p. 96; Stubbs, 1993, p. 14; Stubbs, 1996, p. 
173). The notion here is that the meaning of a word does not reside in the individual word itself but rather is influenced or affected by the words that tend to occur with it.

A traditional means for identifying collocates (i.e., words that co-occur) is through native speaker intuition, as a way to test whether such co-occurrences are possible, but this has been shown to be unreliable and is therefore inadequate on its own (e.g., Stubbs, 1996; Tognini-Bonelli, 2004). A more reliable means is by counting the number of times words cooccur in the data, which can be done manually but becomes a challenge when the corpus is very large. Collocates can also be identified through an automated process using statistical measures and corpus tools, although different tools and different statistical measures can yield different types of collocates. For example, using frequency as a measure, i.e., identifying collocates in terms of how often they co-occur with a word, tends to highlight grammatical or function words such as the or and, which are less illuminating for discourse analysis than content words. Furthermore, as Baker (2006) points out, frequency is not the same as saliency, i.e., a word such as said may be identified as a frequent collocate of a node word, but the relationship is not exclusive because said also occurs frequently with other words.

For this reason, other statistical measures that highlight strong bonds between lexical items are often used. There are a number of these, which may also depend on the software tool. For example, Mutual Information (MI) measures collocational strength, i.e., the tendency of words to occur together rather than separately, even when they are not very frequent. This is a very useful feature for discourse analysis because it identifies collocates that have a strong bond with the node word. Other statistical measures, such as loglikelihood, tend to favour high frequency function words. As such, in some studies researchers have combined more than one statistical measure to strengthen their 
interpretation, identifying strong bonds as well as high frequency collocates (e.g., Gabrielatos \& Baker, 2008; Germond et al., 2016). Baker (2006) provides a useful summary of how different tools produce different types of collocates and the importance of how collocation analysis should be conducted depending on the research questions involved, and suggests that "[e]ach technique gives some sort of trade-off between frequency and saliency" (p. 102). Thus the choice of statistic will depend on the focus of the research.

Collocation is important for discourse analysis since strong bonds suggest that the co-occurring words are linked in people's minds, acting as triggers for unconscious associations. As such, they can provide insight into the kind of ideological work that words are doing. For example, Baker and Gabrielatos (2008) found that some collocates associated with the terms refugees, asylum seekers, and immigrants, such as country of origin, seemed to be fairly unproblematic descriptions, whereas collocates such as scroungers tended to be evaluative. In newspapers, when referring to refugees, asylum seekers, or immigrants, frequent use of such words helps to strengthen these negative associations. Understanding words in relation to the company they keep is thus useful in discovering the kinds of attitudes or assumptions they embody, and how these attitudes "imbue words with meaning" (Baker 2016: 140). It also assists in detecting discourses that may be powerful in the way they frequently link certain words together, thus contributing to stereotypes.

Observing the behaviour of words in relation to their collocates also allows for unexpected or surprising findings about seemingly innocuous words, as for example, in Tognini-Bonelli's (2004) study mentioned previously. What might appear at first glance to be a neutral description could turn out to be more evaluative. In addition, as Hunston (2002) argues, collocations can become "fixed phrases that represent a packaging of information" 
(p. 119) and, as they get picked up and repeated, thereby contributing to what Baker (2006) calls the "incremental effect of discourse" (pp. 13-14), more difficult to challenge or perhaps even notice. Furthermore, when such phrases become fixed or used repeatedly, they can influence how we come to think about them (a concept referred to as lexical priming (Hoey, 2005), discussed below).

\section{Semantic preference}

Semantic preference refers to the co-occurrence of a lexical item with "a class of words which share some semantic feature" (Stubbs, 2001, p. 88; see also Mautner, 2007; Partington, 2004). In other words, the focus is on the relationship to a group rather than a single word. For example, Mautner (2007) found that the word elderly tended to co-occur with groups of words related to the semantic domain of disability, frailty and care, thereby giving the word what she refers to as a "negative semantic load" (p. 59), as well as revealing attitudes and assumptions that have little to do with chronological age. Baker (2006) found that the word refugee showed a semantic preference for quantity terms, making them appear more alarming due to their large numbers. Moving beyond individual words to semantically related groups allows for the identification of habitual ways of talking about particular groups, i.e., what is typical in the wider society. Such recurring patterns often point to dominant discourses that reinforce stereotypes further. Baker (2006) notes that semantic preference "denotes aspects of meaning which are independent of speakers" (p. 87), which can provide some insight into the underlying values of a given society.

\section{Discourse prosody}

Although the difference between discourse prosody and semantic preference is not always clear-cut, Stubbs (2001) distinguishes them by describing discourse prosody as 
evaluative and expressing speaker attitude. Some researchers also use the terms "semantic prosody" (Louw, 1993; Sinclair, 1991) and "semantic aura" (Mautner, 2009b, p. 135). There is some overlap between these terms, with the choice largely depending on the user (Baker, 2006, pp. 86-87). However, although semantic prosody seems to be more widely used in the literature, it appears to be a more contentious term, as some researchers object to the notion that words are empty until they get "imbued" (Louw, 1993) ${ }^{8}$ with meaning by their collocates (Whitsitt, 2005) or that meaning becomes fixed and unchanging regardless of the context in which it is used (Hunston, 2007). Semantic prosody seems to be related to individual words; therefore, some researchers (e.g., Hunt, 2015; and also the present study) prefer discourse prosody because it relates to speaker attitude and holds that meaning is built up through repeated and shared usage, i.e., it refers to "an attitude associated with a lexical item over time and across texts" (Potts, 2015, p. 287). Examining trends and patterns built up through repeated usage can make it possible to identify societal value judgements associated with lexical items that give them an evaluative aura of meaning which is "an indication that something is good or bad" (Hunston, 2004, p. 159). For example, Mautner (2009b) analyzed the frequency and collocations of the word unemployed as it occurred in a corpus of British newspapers, and found that it collocated with negative attributes such as desperate, disadvantaged, divorced, homeless, which have more to do with societal attitudes than with a description of joblessness. Rather than performing a factual function, then, such collocates contribute to a negative discourse prosody. In this way, discourse prosody contributes to meaning (Baker, 2014, p. 223) and becomes evident from the analysis of numerous examples made possible by a large corpus (Partington, 2004). However, prosodies

\footnotetext{
${ }^{8}$ Louw (1993) defines semantic prosody as "a consistent aura of meaning with which a form is imbued by its collocates" (p. 157).
} 
are not always realized explicitly in a text, as they can involve other means of evoking positive or negative evaluations, such as allusion, metaphor or intertextual reference, which shift the burden of interpretation to the recipient (Reisigl \& Wodak, 2001, p. 105), i.e., leave the reader/listener to draw conclusions based on their own understanding.

A number of studies using corpus methods have identified prosodies associated with words or phrases that might not have been detected through a small sample of texts. For example, Stubbs (2001) found that the lemma ${ }^{9}$ CAUSE occurred most frequently with words denoting unpleasant events, thereby indicating a negative discourse prosody. As such, when we encounter the word, we may be predisposed to expect something unpleasant. Similarly, Tognini-Bonelli (2004) discovered that in her corpus the adverb largely collocated primarily with negative words and, as such, tended to have an "aura of negativeness" (p. 16). In his study of bachelor and spinster, Baker (2006) noted that while both refer to unmarried adults and could therefore be viewed as semantic equivalents, each carries a different discourse prosody, one more positive than the other. Through a word's collocational profile, it is possible to gain insight into the kinds of values and attitudes associated with it. Over time, these may become entrenched and taken for granted through our repeated encounters with the word and its collocates. This type of cumulative or "incremental effect of discourse" (Baker, 2006, p. 13) may lead to an unconscious predisposition towards words, so that when we see one (e.g., bystander), we might expect to see the company it keeps (e.g., innocent) (Baker et al., 2006, p. 38; see also Gabrielatos \& Baker, 2008, p. 34; Tognini-Bonelli, 2004, p. 16).

\footnotetext{
9 A "lemma" refers to the baseline or uninflected word form, e.g., WALK, which would include walk, walked, walking, walks in the analysis (Baker, 2006, p. 55).
} 


\section{Lexical priming}

Frequently co-occurring words can influence or become part of the meaning of a word, acting as triggers for unconscious associations. Identifying such triggers can provide insight into underlying ideologies. What might appear at first glance to be a straightforward description could turn out, in fact, to be evaluative (see Chapter 7 on collocations). When such pairings of words occur frequently enough, we may be unconsciously predisposed or “primed" (Hoey, 2005) to think of particular meanings as a result of our previous encounters with these words:

...if particular lexical and grammatical choices are regularly made, and if people and things are repeatedly talked about in certain ways, then it is plausible that this will affect how they are thought about. (Stubbs, 1996, p. 92)

Hoey (2005) argues that "every word is primed for use in discourse as a result of the cumulative effects of an individual's encounters with the word" (p. 13). This is important since repeated patterns are reflective of the wider society and can trigger cultural stereotypes (Stubbs, 2001, p. 215). But as Baker (2006, p. 19) points out, this is often unconscious and therefore difficult to verify. Furthermore, different people interpret things differently, and thus may have different lexical primings around the same words.

Although there is some debate about lexical priming in the literature, the argument being that we cannot know what goes on in people's heads (see Baker, 2006, p. 20; Baker, 2010, p. 333; Teubert, 2005), a recent study by Durrant and Doherty (2010) which aimed to test Hoey's thesis found that words did appear to trigger the thought of other words, e.g., parish church but not feature church, or spoken word but not lower word. A more recent study on artificial intelligence and machine learning conducted by Caliskan et al. (2017) found that machines learning human language also learnt human biases, for example, that flowers are more pleasant than insects, as are musical instruments compared to weapons. They also 
found stereotypical and/or prejudicial notions about race and gender. European names tended to be more associated with pleasant than unpleasant terms compared to African American names. As the study reports, machine learning absorbs stereotypes only through words and their collocates, with no direct experience of the world, thus providing further evidence that the meaning of a word is informed by its association with other words and that words do trigger cultural stereotypes. This lends further credence to the idea that language is social practice. The implications of this study are a concern that in building automated decision-making systems (e.g., for screening job applications), such cultural biases may also be learned and result in prejudicial outcomes.

\section{Criticisms of Corpus Linguistics}

According to Baker (2006), the use of corpus-based methods for discourse analysis at first faced some resistance because they were thought to be too broad, to discount native speaker intuition, to take words out of context, to be limited to studying only what appeared in the corpus with no way to address items that may not appear, and to tend to focus on synchronic data rather than the change of meanings over time. Corpus-based methods also tend to be viewed as purely quantitative, giving rise to objections such as that frequencies can be reductive and generalizing, oversimplify, or focus on comparing differences and obscure more interesting interpretations (Baker 2006, p. 47). While it is important to keep such limitations in mind, also important is Mautner's (2009b) comment on the disapprobation towards corpus linguistics:

It makes as much, or as little, sense to criticize corpus linguistic methods for not permitting more contextually embedded analysis, or a static, ten-year-old corpus for being silent on the latest neologisms, as it does to criticize a screwdriver for being no good at hammering in nails. (p. 141) 
The benefits of corpus linguistics in reducing bias, aiding with triangulation, and allowing for a more representative sample have some attraction (e.g., Baker, 2006, pp. 12 16), but scholars for whom language or discourse and context are inextricable object to the idea of mechanically counting isolated and decontextualized words (e.g., Widdowson, 2000; see also Baker et al., 2008). For Critical Discourse Analysis (CDA), context is the key to understanding any text, and the only way in which to reveal hidden ideologies and power relations. However, the notion that corpus linguistics is decontextualized is itself subject to criticism. Partington (2014) attributes such criticisms to a narrow and restricted understanding of corpus linguistics as "quantitative data crunching" (p. 142) which seems to assume that other sources of data are not used in the analysis. As he points out, external data providing social, political, historical and cultural context is routinely used and forms an integral part of corpus-assisted discourse studies (CADS). And Gabrielatos and Duguid (2015) argue that hundreds of concordance lines do provide useful contextual information. Thus, access to context is not a domain privileged for CDA but somehow denied to corpus linguistics.

However, it is important to keep in mind that corpus data are decontextualized in terms of the necessary removal of visual and other semiotic aspects of the texts, all of which are important for discourse analysis. Due to limitations with existing computer software, all non-textual features, such as images, graphics, layout, etc., usually need to be eliminated, thereby removing vital cues that contribute to the overall meaning. In order to mitigate this shortcoming, familiarity with one's corpus is critical, as is consulting full texts repeatedly during the analysis (Mautner, 2009a). The researcher should also guard against focussing only on frequent occurrences or counting what is easy to count (Baker, 2010), thereby missing 
rare but important instances of language use. Awareness of such shortcomings allows the researcher to take steps to counter them by a clear focus on what she wants to know and what the software and method can do.

Another criticism (and potential pitfall) of corpus-based analysis is that findings may simply confirm things that are already known. For example, in her study of the lexical item unemployed, Mautner (2009b) found that it carried a negative discourse prosody because it frequently collocated with words such as angry, demoralized, destitute, disabled, dreary, drunk, excluded, poor, struggling, underprivileged. As Mautner points out, some critics may say that this is not news, i.e., we did not need a large corpus or software tools to tell us that being unemployed may be a less than positive experience. However, as Mautner and other researchers (e.g., Baker et al., 2013; Baker \& McEnery, 2015; Partington et al., 2013) have emphasized, finding evidence for something that was merely a hunch is itself an important aspect of research. In addition, corpus-based analysis gives us an idea of how widespread and systematic "discursive structures" (Mills, 2004) might be, providing further evidence of their naturalization through repetition. The other side of this coin is, of course, the surprising or minority discourses that corpus analysis may discover (Baker \& McEnery, 2015, p. 10), and which (traditional) CDA approaches may not detect.

\section{Critical discourse analysis (CDA)}

The field of discourse analysis (also referred to as discourse studies - see Angermuller, Maingueneau, \& Wodak, 2014; Wodak \& Meyer, 2016) is diverse, as can be seen from an example such as The handbook of discourse analysis (Schiffrin et al., 2001). This handbook comprises 41 different topics, of which critical discourse analysis (CDA) is only 
one and the discourse historical approach (DHA) another. As the editors point out, discourse analysis involves different approaches, as reflected in types of data used (e.g., political speeches or conversations), different contexts (e.g., institutional or community) and different theoretical paradigms (e.g., systemic-functional linguistics). CDA is usually distinguished from the broader field of critical discourse studies (e.g., Blommaert, 2005; Hart \& Cap, 2014; Rogers et al., 2005), and refers to a group of scholars who represent different approaches within this research paradigm: (i) Norman Fairclough (dialectical-relational approach); (ii) Teun van Dijk (sociocognitive approach); (iii) Siegfried Jager and Florentine Maier (dispositive analysis); (iv) Theo van Leeuwen (social actors approach); and (v) Ruth Wodak and Martin Reisigl (discourse historical approach). However, in the introduction to their latest edition of a key CDA text, Wodak and Meyer (2016) use the term "critical discourse studies" (CDS) instead, arguing that "CDA....was the term used in the 1990s and 2000 s" (p. 4) (even though many of the articles contained in the collection continue to refer to CDA). In their introduction to a special issue of the journal Discourse \& Society, Krzyżanowski and Forchtner (2016) also refer to CDS as the broader version of CDA, which came about as CDA researchers began to recognize the limitations of their ideas and analyses (p. 254)..$^{10}$

The group of scholars generally associated with CDA emphasize that it is not homogeneous and does not constitute a standardized set of methods or theories (e.g., Wodak, 2001; Reisigl \& Wodak, 2009; Wodak \& Weiss, 2005). Wodak and Meyer (2009) state that

...it is important to stress that CDA has never been and has never attempted to be or to provide one single or specific theory. Neither is one specific methodology characteristic of

\footnotetext{
10 To avoid confusion, the articles included in this dissertation refer to "critical discourse analysis (CDA), also known as CDS".
} 
research in CDA. Quite the contrary, studies in CDA are multifarious, derived from quite different theoretical backgrounds, oriented towards different data and methodologies...Thus any criticism of CDA should always specify which research or researcher they relate to.

Hence, we suggest using the notion of a 'school' for CDA... (Wodak \& Meyer, 2009, 2016, p. 5)

Despite such heterogeneity, CDA is generally characterized by its problem-oriented interdisciplinary approach that aims at de-mystifying ideologies and power (Wodak \& Meyer, 2009, p. 3). CDA sees language as "social practice" (Fairclough \& Wodak, 1997) and the context of language use to be crucial (Wodak \& Meyer, 2009, p. 5), such that the relationship between any discursive event and the social structures framing it is dialectical, i.e., the event is shaped by, but also shapes social structures:

\footnotetext{
...discourse is socially constitutive as well as socially shaped: it constitutes situations, objects of knowledge, and the social identities of and relationships between people and groups of people. It is constitutive both in the sense that it helps to sustain and reproduce the social status quo, and in the sense that it contributes to transforming it. (Fairclough \& Wodak, 1997, p. 258)
}

The notion of discourse operative in CDA differs from other approaches in which discourse may mean, for example, language above the sentence level, or the view that discourse analysis should be approached in a detached (or objective) manner (Sinclair, 2004, cited in McEnery \& Hardie, 2012, p. 134). CDA practitioners are neither objective nor detached. Rather, they take an explicit stance against forms of inequality enacted in societal structures (van Dijk, 2001), though see Smith (2010, p. 32), who attempts to be both detached and objective in his CDA study by stating that he is disinterested in and personally unaffected by his subject, Hugo Chavez.

Although CDA studies tend to be diverse in terms of methods and objects of investigation, Fairclough and Wodak (1997) present eight key principles for CDA in general:

1. CDA addresses social problems.

2. Power relations are discursive.

3. Discourse constitutes society and culture.

4. Discourse does ideological work. 
5. Discourse is historical.

6. The link between text and society is mediated.

7. Discourse analysis is interpretative and explanatory.

8. Discourse is a form of social action. (pp. 271-280)

The starting point for CDA studies, then, is with a social problem and its dialectical manifestation or enactment within social structures. The link between language and society is through context, meaning that CDA studies are more interested in social phenomena than in linguistic units per se (KhosraviNik, 2009; Wodak \& Meyer, 2009). One of the key aims of CDA is to uncover hidden power and ideology as manifested in everyday language, as well as to make explicit how access to different public spheres contributes to power (e.g., Wodak, 2007, p. 210). "Ideology" here refers to underlying or latent beliefs of everyday interaction, behaviours, and expected or typical ways of conducting activities in a given society. This is an important aspect for the present study, which began as a result of becoming aware, through everyday interaction, of a dominant ideology that had appeared to be natural and neutral. As Wodak and Meyer (2009) explain,

In daily discussion, certain ideas arise more commonly than others. Frequently, people with diverse backgrounds and interests may find themselves thinking alike in startling ways. Dominant ideologies appear 'neutral', holding on to assumptions that stay largely unchallenged... (p. 8)

Systematic and repeated action incorporating a dominant ideology is linked to power as constituted in social structures, where it is enacted and further reinforced through daily interaction. For CDA, therefore, power and ideology are not overt so much as covert, unnoticed because taken for granted in everyday interaction. Through the analysis of discourse, inequality or systematic discrimination against certain parts of the population may be detected. Such dominant or hegemonic worldviews continue to exist through the participation of the society as a whole, i.e., dominant views are co-constructed by different societal domains rather than in a uni-directional or imposed way. Through repetition, 
qualities can become entrenched or naturalized, leading to stereotypes, where reference to a particular group, e.g., immigrants, might trigger qualities frequently associated with the term, e.g., illegal. These qualities are often presented as fixed or stable, with a simple cause-effect or uni-directional type relationship rather than a more complex and actively co-constructed one.

This notion is neatly illustrated by Berger and Luckmann (1966) in their example of how knowledge is transmitted in a given society (i.e., making a distinction between "knowers" and "non-knowers"), which then comes to be taken for granted and objectified. In their illustration, transmission of knowledge (i.e., from knower to non-knower) may be done through a tradition such as that between a maternal uncle and a nephew reaching a certain age. The maternal uncle is the knower who transmits knowledge to the nephew. What is less visible in this practice is the social apparatus that accompanies or makes this enactment possible; the idea that maternal uncles do not transmit knowledge because they know it but rather know it because they are maternal uncles, is masked or less visible (p. 88). Two things are happening here: (i) categories or labels are constructed (e.g., "maternal uncle", "nephew", indicating a particular segment of population or society); and (ii) capabilities or values are assigned (“knower", "non-knower”). In order for this to take place, social structures that construct the notion of maternal uncle as knowing are required. That is, there is active or collective dialectical participation in making such a notion exist, which may not be visible as it comes to be taken for granted through labels or associated assumptions. In other words, a stereotyped image is constructed, perpetuated and reproduced through multiple layers of interaction (e.g., political, economic, legal), not necessarily intentionally but as part of social practice, often in terms of in-groups and out-groups. According to Wodak 
(2009, p. 319), this type of construction necessarily implies the use of strategies of positive self and negative other presentation (see also Reisigl \& Wodak, 2001).

\section{Discourse historical approach (DHA)}

The discourse historical approach (DHA) is a branch of CDA and, as such, adheres to the principles listed above but also offers some distinctive features that give it a different perspective. The DHA was developed in the late 1980s by Ruth Wodak and her colleagues at the University of Vienna, hence it occasionally gets referred to as "the Vienna School of CDA" (Wodak, 2002, p. 18). The defining characteristics of the DHA were developed by combining historical, socio-political and linguistic dimensions to explore social phenomena such as racist discourse (Reisigl \& Wodak, 2001), the discursive construction of national identity (Wodak, de Cillia, Reisigl \& Liebhart, 2009), structural discrimination in different European countries (Wodak, 2009, p. 323), and organizational decision-making and team meetings (Kwon, Clarke, \& Wodak, 2014; Clarke, Kwon, \& Wodak, 2012; Wodak, Kwon, \& Clarke 2011; Wodak, 2014). According to some of its proponents, since the 1990s the DHA has evolved to become one of the main currents in CDA (Wodak, Krzyżanowski \& Forchtner, 2012, p. 160) and one of the major tools for systematic and in-depth analysis of collective identities (Krzyżanowski, 2005, p. 142). Furthermore, through its multimethodical and interdisciplinary approach, it is also having a significant impact on the research focus of other disciplines such as political science and policy studies (Oberhuber, 2005, p. 166). The analytical methods used in the DHA vary according to the type and size of the data, where, for example, the study of political speeches may focus on argumentation strategies more than does the study of a poster campaign, which would draw on other methods (e.g., KhosraviNik et al., 2012). 
The main features that distinguish the DHA are its integration of multiple genres surrounding a particular issue, use of large data sets, interdisciplinary analysis, and attention to multiple layers of socio-political and historical context (Wodak, 2009, p. 311). The first study for which the DHA was developed, which traced how an antisemitic stereotyped image emerged in public discourse during Kurt Waldheim’s 1986 Austrian presidential campaign, provides a way to understand key features of this approach. One of the aims of this study was to address a "research deficiency" (Reisigl \& Wodak, 2001, p. 94) on antisemitism. Up until that time, research in this area had been largely quantitative, consisting of statistical surveys designed to measure antisemitic prejudice. But such studies were not able to detect more subtle and hidden forms of antisemitic prejudice. For this reason, "a linguistic, discourse-analytical approach" (p. 94) was thought to be more useful. Analysis of the discourse about the "Waldheim Affair" involved working with authentic communicative data comprising "different strata of the Austrian public sphere" (Wodak, 2011, p. 352), such as TV, news broadcasts, newspapers, journals, political speeches, everyday conversations on the street, and opinion polls. The research team involved in the study came from three different fields - linguistics, psychology and history - which had an impact on the analytical methods used in the interpretation of the data. The categories developed by this interdisciplinary team "ultimately...led to the 'discourse-historical' approach" (Reisigl \& Wodak, 2001, p. 99).

What was also notable about the antisemitic stereotyped image was that, although antisemitic utterances were officially unlawful and considered taboo, such sentiments were widely circulating in various guises, whether through allusions, metaphors and other such indirect (or coded) means in the public domain, or explicitly in private conversations and 
political meetings. With the help of their large and diverse dataset, the researchers discovered that the type of antisemitic statements depended on the context. In other words, they observed a "coded discourse of antisemitism" that was context-dependent (Reisigl \& Wodak, 2001, p. 92), produced and reproduced by different segments of society that collectively perpetuated and co-constructed the stereotyped image (de Cillia et al., 1999; Reisigl \& Wodak, 2001).

\section{Four levels of context}

The DHA has been referred to as a "context-sensitive theory" (Reisigl \& Wodak, 2001, p. xii) and a "context-dependent approach" (Wodak, 2011, p. 360), indicating the central role played by the concept of context. According to Wodak and Matouschek (1993), the importance of the analysis of context emerged from the variety of data (media texts, interviews, conversations) in their study of racist discourse against foreigners in Austria. Context therefore had to be defined in various ways to account for the many layers of discourse being analyzed (e.g., the legality of racist utterances in post-war Austria, historical attitudes towards foreigners, and specific events such as the Waldheim affair and the Viennese election campaign of 1991). The importance of context was further highlighted in a study on the discursive constitution of national identities, which showed how collecting data from different social contexts (political speeches, advertising campaigns, press articles, group discussions, and interviews) revealed processes of co-construction of national identity as well as relationships between official, semi-official, and quasi-private discourse and social practice (de Cillia et al., 1999, p. 23).

In order to conduct a systematic analysis of context as well as to help minimize bias by means of triangulation and multiple sources of data, the DHA proposes a four-level 
model of context as a heuristic: (i) the language of the text; (ii) intertextual and interdiscursive relationships between texts; (iii) institutional frames of the specific context of a situation; and (iv) broader socio-political and historical contexts (Wodak, 2001, p. 67; Wodak, 2012, p. 529) (see Figure 2.1). These are not hierarchical, nor does analysis have to proceed in any particular order, as contextual analysis can occur on many levels. Switching repeatedly between levels (i.e., between textual and contextual aspects) allows for exploration of the way discourses change according to socio-political context, reveals conflicting narratives, and shows how perceptions may have changed over time.

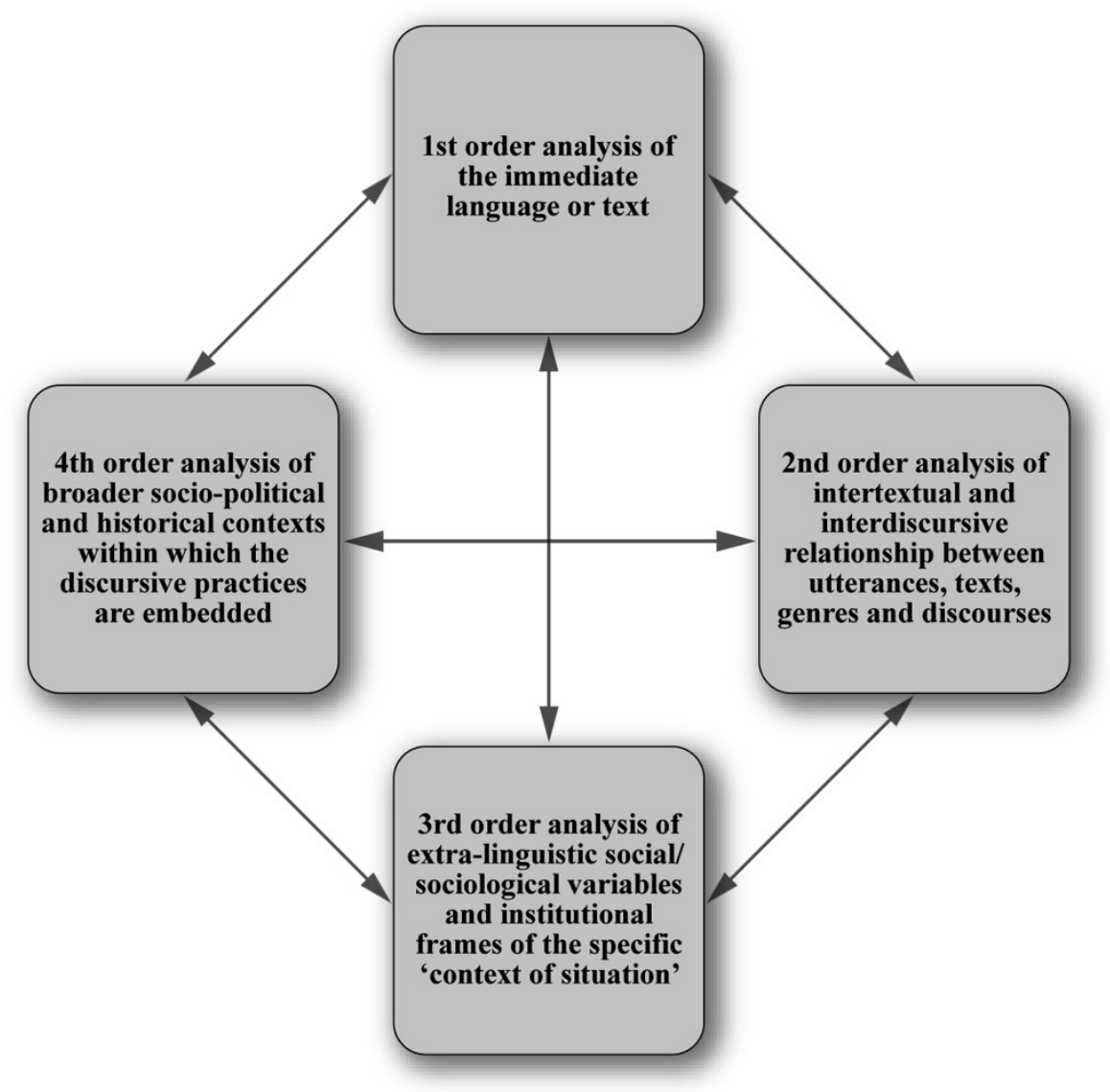

Figure 2.1: The DHA's 4 Levels of Context (adapted from Wodak 2014, p. 47) 
The analysis of a diverse range of genres according to the four levels of context thus differentiates the DHA from other CDA approaches (Titscher et al., 2000, p. 158). Studies utilize this model in different ways, not necessarily proceeding in any sequential order but considering all aspects as a whole and viewing them as different dimensions (see e.g., Engstrom \& Paradis, 2015). For example, in their study on immigration in Austria, van Leeuwen and Wodak (1999) analyzed a range of texts that included the application documents involved, the laws relating to these, the broader context of immigration, and the debates on this issue in the media and in parliament. Such multi-dimensional analysis allows for the exploration of how discursive practices are interconnected with social structures (Wodak et al., 2009, p. 9), i.e., data from different social contexts allows for the unpacking of underlying agendas and ingrained attitudes (Wodak, 2014, p. 47).

\section{Discursive strategies}

In order to discover how a particular group is represented in the wider social context, the DHA examines how discursive strategies (i.e., systematic ways of using language) are used to construct in-groups and out-groups, leading to social exclusion or discrimination. As noted by Wodak and her colleagues, while discourses of difference and discrimination may vary in terms of the specific group in question, the discursive strategies and linguistic realizations tend to be very similar (KhosraviNik, 2010, p. 24; Reisigl \& Wodak, 2001, p. 44), with construction of the "other" generally taking the form of a "they" group with negative qualities and a "we" group embodying positive ones. The term "strategy" refers to varying degrees of intentionality, from automatic to conscious depending on the context and purpose (see de Cillia et al., 1999). Furthermore, the DHA also assumes that the discursive construction of a particular group does not occur in a unidirectional top- 
down way (Reisigl \& Wodak, 2001, p. 24), but rather is co-constructed by different segments of society (official, public, semi-private) through interaction in different domains, with each segment shaping and being shaped by others in a dialectical relationship (de Cillia et al., 1999; Reisigl \& Wodak, 2001). In other words, the stereotyped image is perpetuated and reproduced through multiple levels of interaction (e.g., political, economic, legal), not necessarily intentionally but as social practice.

In order to discover how a particular group is represented in the wider social context, the DHA focuses on five types of discursive strategy used in the construction of ingroups and out-groups: (i) nomination/referential (how are groups named?); (ii) predication (what qualities are ascribed to them?); (iii) argumentation (how are these claims justified?); (iv) perspectivation (from what point of view are these claims made?); (v) intensification/mitigation (are these overt or implied?). These strategies are closely related and often overlap. For example, nomination may encompass predication strategies in situations where the label already carries with it a negative or positive connotation (Reisigl \& Wodak, 2001, p. 45 - see Chapter 7 of the present study). In other words, nomination on its own may be sufficient (i.e., used metonymically), making further attributions unnecessary. This can be seen in cases where things are alluded to or implied rather than mentioned explicitly.

\section{Combining corpus linguistics and CDA/DHA}

Combining qualitative and quantitative techniques within a single framework has grown in popularity and has been referred to as a "'third approach'... where the very nature of interpretation is redefined" (Creswell \& Plano Clark, 2007; see also Marchi \& Taylor, 2009). 
Combining corpus linguistics and CDA was pioneered by Hardt-Mautner (1995) in her study of $\mathrm{EC} / \mathrm{EU}$ discourse in the British press, where a clear mismatch between the qualitative approach (CDA) and the quantity of data to be analyzed required the use of corpus tools to aid the analysis. She initially intended to draw on CDA exclusively but

the mainly qualitative methodology used in CDA proved ill-suited to handling the sizeable
corpus that formed the basis of the study. It was this mis-match between the chosen
framework and the nature of the data that led to the development of an alternative analytical
procedure, combining the use of concordance programmes with CDA's traditional
qualitative analysis. (Hardt-Mautner, 1995, p. 1)

Hardt-Mautner's incorporation of corpus analysis into her CDA-oriented study demonstrated how the quantitative aspect lends credence to the findings as well as charts new paths for further exploration (see also Koller \& Mautner, 2004).

In another early study that combined corpus linguistics and CDA, Krishnamurthy (1996) investigated the use of the words ethnic, racial, and tribal in British newspapers, and the way repeated occurrences in particular contexts can influence public attitudes and opinions (p. 147). Salama (2011) used the "methodological synergy" of corpus linguistics and CDA to examine how different texts represent the topic of Wahhabi-Saudi Islam in different ways, revealing ideological representations. And Piper (2000) used a 950,000-word corpus to present a concordance-based analysis comparing individuals with people in the official literature of "lifelong learning" in Britain. The latter study revealed divergent agendas and power relations that only became evident through corpus analysis. Piper's rationale for adopting the corpus-based approach here was to "enable the analysis to reach beyond an intuitive interpretation, based on one human brain's reading of sampled texts, to the discovery of significant collocational patterns retrieved and presented from a much wider range of texts" (p. 520). Although not working explicitly within a CDA framework, the study design was informed by the criticisms levelled against CDA with respect to "over-generalized claims and 
paucity of actual data" (p. 517). As a result, the study contributes in important ways to data collection and processing methods which are "clear, replicable, and...comprehensive in their coverage" (p. 538).

Other studies using this combined approach have looked at the discursive construction of various groups, such as refugees and asylum seekers in UN and newspaper texts (Baker \& McEnery, 2005), gay men (Baker, 2005), higher education (Mautner, 2005), the elderly (Mautner, 2007), refugees, asylum-seekers, immigrants and migrants (RASIM) in the UK press (Baker et al., 2008; Gabrielatos \& Baker, 2008), nationhood and belonging in Quebec (Freake et al., 2011), and Muslims in the UK press (Baker et al., 2013a, 2013b). All of these studies report on the unique strengths of each approach, which when combined provide a much broader understanding of the subject under investigation, more confidence in the claims made about it, and even allow researchers to entertain new kinds of research questions through the use of a much larger dataset than would be possible using traditional CDA methods alone (Biber \& Conrad, 2001, p. 335). For example, through corpus data, it becomes possible to observe how patterns of language are systematic and recurrent and help uncover ideologies of disadvantage. Thus, it is now possible to study "notions of typicality" (Koller \& Mautner, 2004, p. 218), i.e., how widespread a phenomenon might be, in a given society (as was done in the present study) with more confidence due to a more representative dataset. Going beyond single texts to a large corpus allows for the exploration of quantitative patterns both synchronically and diachronically.

A large dataset thus helps to address one of the most frequent criticisms levelled against CDA, namely that the analysis and generalized claims tend to be based on a handful of samples chosen by the researcher to prove their point (O’Halloran \& Coffin, 2004, p. 279; 
Widdowson, 2000, p. 17), and thus say more about the analyst than about the discourse being analyzed (Stubbs, 1994, 1997; Widdowson, 2000, 2004). A large corpus of thousands of texts allows researchers to gather more evidence for their claims and also helps guard against “cherry-picking” particular texts that confirm the researchers' biases (Baker, 2006, 2012; Baker \& Levon, 2015).

These studies also report on aspects of the data that might have been overlooked or lost were it not for the combination of approaches. For example, Freake et al. (2011) would not have found the minority (i.e., rarer or less frequent but salient) discourse if they had relied solely on corpus data and not conducted an in-depth CDA analysis on a downsampled collection. On the other hand, Baker et al. (2008) found elements of a positive prosody or aura in their corpus data that was not found in the downsampled collection being analyzed by the CDA team. Thus, combining the analysis of large corpus data with in-depth CDA analysis can realize the benefits of both while mitigating some of the limitations.

This may be one reason why there has recently been a growing interest in combining corpus linguistics with CDA. Using corpus-based analysis is one way to provide CDA with the broad base of evidence it otherwise lacks. Although at first glance the two approaches seem incompatible, i.e., "quantitative dissection of text appears to be at odds with CDA's commitment to analysing coherent discourse at all linguistic levels" (Hardt-Mautner, 1995, p. 3), it is this very difference that seems to make them such great allies. For example, if a research project is interested in discovering how a particular word is used in newspapers, corpus linguistics can be used to find the instances of use, whereupon CDA can be used on a selected sample for in-depth analysis, with the results of the two approaches confirming one another (or not) (see Baker et al., 2008). Corpus-based analysis also offers explicit 
methods of data collection and the ability for results to be corroborated by other researchers (Stubbs, 1997), both of which are seen as lacking in CDA. Mautner (2009b) observes that as neither qualitative nor quantitative evidence speak for themselves but require interpretation, “surely, any improvement in CDA's empirical credentials ought to be welcome” (p. 133).

In their study of the discursive construction of refugees and asylum seekers in the UK, Gabrielatos and Baker (2008) argue that while corpus linguistics helps address criticisms of CDA methodology (i.e., arbitrary selection of texts, small number of texts or text fragments, subjective interpretations rather than analysis), corpus linguistics by itself would not be sufficient and should be used together with CDA:

Corpus analysis does not usually take into account the social, political, historical, and cultural context of the data... we would recommend that such a methodology only form part of the analysis, informing and being informed by a critical discourse analysis approach. (pp. 33-34)

Since then, a more integrated framework for corpus-based critical discourse analysis has been developed, in which corpus data works with a CDA interpretive framework as a combined (hybrid) approach, drawing on both rather than each working independently or one being subservient to the other. For example, in their study on the representation of Muslims and Islam in the British press, Baker et al. (2013) use CDA concepts to inform their interpretation of corpus data, moving from a broad descriptive stage to a more interpretive and explanatory stage that draws on wider social, political and historical information to gain deeper understanding of how groups may be systematically marginalized. Another study that illustrates this integrated approach well is Hunt's (2015) analysis of how male and female body parts are written about in J. K. Rowling's Harry Potter series. Using concepts of collocation and discourse prosody, Hunt is able to draw out how female characters are depicted as lacking power in relation to males through seemingly innocuous descriptions of various body parts. Hunt argues that such patterns are revealed through large corpus data 
(i.e., three books comprising 324,287 words) and might be missed using smaller samples for textual analysis. The move to a more integrated approach combining corpus and (critical) discourse analysis is reflected in the title of Baker and McEnery's (2015) book Corpora and discourse: Integrating discourse and corpora. ${ }^{11}$

The number of studies combining these two approaches continues to increase, with researchers using both corpus-driven and corpus-based methods, rather than operating under a strictly binary distinction. That is, researchers begin with a more exploratory corpusdriven approach and then become more corpus-based as the analysis gets more focused (e.g., Ädel, 2010; Baker, 2011; Baker et al., 2013a; Germond et al., 2016). This movement from broad frequency-based questions to more in-depth qualitative forms of analysis is also reflected in Baker and Egbert (2016), where the 10 studies discussed are organized on a continuum beginning with the most corpus-driven and moving to more corpus-based analysis, although the authors do reiterate the point made by McEnery et al. (2006) that the distinction between the two is "fuzzy" (p. 11) and that most analysis falls somewhere in between the two extremes.

\footnotetext{
${ }^{11}$ It should be mentioned that there appears to be a distinction in the literature between studies that are positioned within corpus-based CDA and those that are under the corpus-assisted discourse studies (CADS) branch, a name coined by Partington (2004). While this distinction is often not clear-cut, with studies considered corpus-based CDA being subsumed under the larger CADS umbrella term (e.g., McEnery et al., 2015; Salahshour, 2016), a clear distinction is made by Partington et al. (2013), who emphasize that "CADS is not tied to any particular school of discourse analysis, certainly not, for instance to critical discourse analysis (CDA). Unlike CDA, it has no overarching political agenda" (p. 10, emphasis in original). A distinction is also noted by Baker and McEnery (2015), who highlight the absence of "critical" in CADS, which seems to position it as different from other corpus based CDA studies. Rejecting the word "critical" may be a way to distance CADS research from CDA, perhaps because, as discussed by Partington (2004), CDA has been "bitterly lambasted for a cavalier approach to data and for allowing political commitment to obfuscate analytical methodology" (p. 13). Baker et al. (2008), draw attention to the word "assisted" in the CADS name, saying that neither should be "subservient to the other" (p. 274) as this word implies. Rather, each should contribute equally to the methodological synergy.
} 
In-group/out-group construction

A number of studies have used the DHA and corpus linguistics together to explore how in-groups and out-groups are discursively constructed. For example, Potts (2015) focused on the use of nomination and predication strategies to explore how American newspapers reported on the impact and aftermath of Hurricane Katrina, which hit the US in 2005. One of her main aims was to gain a deeper understanding of American ideologies by analyzing how a group of social actors is constructed in the wake of a major natural disaster, based on the assumption that ideological systems and values are enacted through institutionalized communication. Nomination strategies used to construct in-groups and outgroups were first identified, followed by the analysis of predication strategies which attributed positive or negative values to the different groups through the use of adjectival collocations. The study found emphasis on ethnicity and poverty, rather than the emotional states that one might expect in a context of disaster, and concluded that such construction "strongly favours objectification, segregation and othering" (p. 302). Such values were not always realized explicitly but often by association with other out-groups.

Another study combining DHA tools and corpus analysis investigated in-group and out-group construction in articles and policy documents of two British political parties (Engström \& Paradis, 2015). For this study, the discursive strategies were integrated with the DHA's model of context and used in the analysis as a whole, i.e., moving from the descriptive micro level of particular words and phrases in the corpus to the broader macro level of the social context. Nomination strategies focussed on how the parties referred to themselves (i.e., the in-group) and how they constructed immigrants (i.e., the out-group). In both cases, membership categorization through naming was found to be the most 
fundamental discursive strategy. In-group membership was signalled primarily through the use of the party name, which served not only to identify the parties but also to differentiate them, i.e., helping them to stand out as different from the other parties. Out-group membership was signalled through the use of the words refugees, immigrants and asylum seekers. The study found that predication strategies were used to construct unique competencies of both political parties, as well as to deny accusations of racism or extremism. However, for the out-group, a negative discourse prosody was found through the use of negative premodifying collocates (e.g., illegal, unskilled, unemployed). Through collocation analysis, the study found that the out-group was constructed negatively in three main ways: legal status, quantification and origin. In this way, both political parties used the same type of language to construct an "us" (the political parties and the "true" British people) and "them" (the notreally-British) scenario.

Studies exploring such discourses of difference and discrimination have tended to focus on those in which minority or vulnerable groups are out-groups, while the majority is the in-group. In contrast, the present study looks at a situation in which it is the minority that is constructed as the in-group while the majority emerge as the out-group. Although this appears to be a reversal of the usual positive-self and negative-other construction, the same sorts of discursive strategies can be found (see Chapter 8 for details). The present study also combined corpus-driven and corpus-based methods to identify salient features (e.g., the construction of in-group/out-group) that emerged from the corpus data, which were then analyzed in more depth. 


\section{Summary}

This chapter has described the theoretical and methodological framework for the present study, which combines corpus linguistics and CDA. Key concepts in corpus linguistics, CDA (and in particular, the DHA branch of CDA) were discussed, as was the relatively new approach of integrating the two, illustrated with reference to some of the studies that have used such an approach. The next chapter provides a critical review of the historical development of the IB over the past 50 years. In keeping with the DHA's key principle, it examines multiple genres from different public spaces to investigate the intertextual relationships in order to "detect and depict disfiguring of facts and realities" (Wodak, 2001, p. 70). 


\section{Chapter 3}

\section{Critical review of literature on the IB}

\section{Introduction}

This chapter provides a detailed and critical summary of the IB from its beginnings in the 1960s to the present day, both to expand on some of the aspects of the IB that were beyond the scope of the four articles that constitute the present study, and to provide the documentary and contextual evidence upon which a combined corpus-based discoursehistorical analysis (DHA) depends. Of particular note here are the discrepancies between various accounts of the history of the IB, on the one hand, and the intertextuality that much IB information relies on, on the other, which helps to make "distortion[s]...complete and systematic" (Wodak, 2001, p. 70).

As discussed in the previous chapter, in addition to working multimethodically, an important aspect of the DHA is to "integrate a large quantity of available knowledge about the historical sources and the background of the social and political fields in which discursive 'events' are embedded” (Wodak, 2001, p. 65), i.e., to draw on multiple sources of information surrounding a particular issue to focus on its historical dimension. In this way, important relationships with other texts (intertextuality), as well as the social, historical and political dimensions of the issue may be discovered. Furthermore, drawing on multiple sources and intertextual relationships helps to guard against presenting "simplistic and strongly biased historical narratives" (Blommaert, 2005, p. 240).

The chapter comprises six sections. Section one outlines the different sources for the social, historical and political dimensions of the IB. One of the problems with the IB literature is that much of it is produced by the IB organization itself or by practitioners, 
which raises the concern of bias. It is important, then, to look at multiple sources, including dissertations/theses and the popular press (see Bunnell, 2015; Cambridge, 2008), to gain a better understanding of the issues. This section also discusses some issues with IB research.

Section two provides a historical overview of the IB and its development over five decades, identifying key figures and texts, as well as the broader social and political context from which the IB emerged, which plays an important part in the way the IB is viewed today more as a UN-type humanitarian agency than a curriculum for kindergarten to grade 12 (K12) students. This section also highlights the variation evident in different accounts of IB history.

Section three seeks to disambiguate "the IB program" into its three component parts: Diploma Program (DP), Middle Years Program (MYP), and Primary Years Program (PYP). ${ }^{12}$ These often get lumped together under the IB label, giving the impression that they were developed together and evince a natural progression that forms the "IB continuum". However, they were in fact developed independently. Therefore, it is important to examine their particular histories and how they came to be part of the IB, to highlight the ways in which they differ from the DP.

Section four discusses the spread of the IB from its initial niche as a curriculum for international schools to the global enterprise it is today, identifying recurring themes in the literature and key research on the IB in North America.

Section five discusses perceptions of the IB and some of the key studies frequently cited in the literature, paying particular attention to the relationship between the IB and university admission.

\footnotetext{
12 The IB organization introduced a fourth program in 2012 called the Career-related program (IBCP). Little is known about it and when mentioned in the literature, tends to be referred to in passing without further discussion.
} 
Finally, section six discusses one criticism of the IB that has emerged, particularly from non-Western contexts, namely, that it is Eurocentric.

\section{IB Research}

Sources

The primary source of publicly available information on the IB is material published on the IB website (www.ibo.org), which comprises many different types of documents, such as program information; research studies; information for schools, universities, students, parents, researchers, governments, and media; magazines and newsletters; and information specific to each of its regions. A password-protected section for members houses detailed information on curriculum and assessment, as well as other resources and discussion groups.

As many researchers have noted (e.g., Bunnell, 2011d; Doherty \& Shield, 2012; Hill, 2013; Elliott, 2014; Tarc \& Beatty, 2012), much of the research available on the IB is generated by the organization itself, with a dearth of peer-reviewed and independent research. This was also noted in the research review the IB organization published for its $40^{\text {th }}$ anniversary, in which the author stated that most of the sources identified in his initial search turned out to have been published by the organization itself. As such "the majority of these have been rejected for inclusion because they cannot be seen as impartial" (Cambridge, 2008, p. 5) and also because many were simply descriptive, with no critical evaluation. As the author of the report explains, the primary source of data for the IB therefore came from the “growing body of literature that is reported in unpublished master's and doctoral 
dissertations and theses" (p. 5). Nine such dissertations were included, dating from 1992 to $2006 .{ }^{13}$

Issues

Bunnell (2011d) states that the IB has always been difficult to study and analyze because of its rapid growth and because the major authors are IB protagonists. For this reason, he cautions the researcher to "tread carefully through the literature for signs of bias or exaggeration...in particular to separate 'facts' from the 'myths', and the IB has its fair share of the latter" (p. 166). When reviewing different studies on the IB, then, researchers need to be aware that such studies may unwittingly rely on information that may not be impartial (see Daly, 2012; Elliott, 2014; Hill \& Saxton, 2014, for examples of biased references).

The IB organization is heavily involved in research activity and continually produces reports on studies, either completed or in-progress, which are posted in the research section of their website. ${ }^{14}$ However, these studies are not independent and therefore, as Cambridge (2008) stated, cannot be seen as impartial. The same could be said about research produced by the International Baccalaureate Research Unit (IBRU) at the University of Bath and the Journal of Research in International Education (JRIE) (IBO, 2006). The first issue of this “international peer-reviewed journal” was published in September 2002 with a logo stating "in cooperation with the IBO", and began with an editorial by Jeff Thompson, Professor of Education at the University of Bath and Academic Director of the IB organization.

Although the IB website currently lists JRIE on its "Research resources" page, it also states

\footnotetext{
${ }^{13}$ It is unclear why a number of earlier studies were not included in the report (e.g., Remillard, 1978; Wagner, 1978; Crouch, 1979; Salomon, 1981; Rowell, 1983; Kroll, 1984; Bagnall, 1994). Since 2010, the IB organization has issued a similar report every year, showing a steady increase in the number of articles and dissertations, which provides one indication of the increasing interest in IB programs.

${ }^{14}$ See http://www.ibo.org/research/research-resources/
} 
that the journal is not affiliated with the IB organization but frequently contains research articles relating to the IB (IBO, 2017i). The editorial board, however, consists of a number of IB-affiliated personnel (e.g., Jeff Thompson, George Walker (former Director General), Ian Hill (former Deputy Director General)).

\title{
Lack of empirical research
}

In their study of the IB in Australia, Doherty and Shield (2012) also noted another problem with research on the IB:

\begin{abstract}
There has been little rigorous empirical research on the IB. Published work tends to be practice- or advocacy-based, anecdotal, small scale survey with convenience samples or essayist critique. What empirical research is available is limited by sampling only IB graduates or students without any comparative foil, and failing to account for the effect of selectivity when reporting its outcomes. (p. 314) ${ }^{15}$
\end{abstract}

The author of the 2008 research review, published "in response to demand from a wide variety of stakeholders" (Cambridge, 2008, p. 2), noted that "[a]t present, the profile of research relating to the IB Diploma Programme in the academic literature is not high and the extent of published literature relating to the IB Diploma Programme is sparse” (Cambridge, 2008, p. 5). Following this, the IB organization published a similar review for 2010, which stated that "[i]t is the first attempt of what we hope will become a regular update of the research available in the field" and that "[a]s we tried to be as inclusive as possible when compiling these references, no value judgments were made on the validity of the findings or rigour of the studies included here" (IBO, 2011, p. 1). For this second review, the IB Research Department found 41 pieces of research on the IB. Similar statements introduce the research reviews for 2011 (75 pieces of research), 2012 (97), 2013 (101), 2014 (114), 2015

\footnotetext{
${ }^{15}$ For example, Xi (2015) uses a case study approach to examine the IB and power relations enacted amongst students, teachers and managers at one school in China. The study does not seek to be representative, but invites readers to vicariously experience the events and determine whether it is applicable to their own unique situation.
} 
(117), and 2016 (116). These reports appear to include all the available research, not only that produced by the IB, and thus are a useful resource.

However, despite such an abundance of research activity, the scarcity of empirical research to support IB claims regarding curricular outcomes is a constant refrain in the academic literature (Bunnell, 2008a; Frank-Gemmill, 2013; Green \& Vignoles, 2012; Kyburg et al., 2007; Panich, 2001; Rhodes, 2007; Tarver, 2010; Tarc \& Beatty, 2012). Furthermore, there is also concern about possible bias in those empirical studies that are commissioned by the IB organization (Hanover Research, 2010; Tarver, 2010; Tarc \& Beatty, 2012). This can be illustrated by comparing two different studies on the impact of the DP on student outcomes in Florida. The first, Caspary and Bland (2011) and Caspary (2011), commissioned by the IB organization, suggests a positive correlation, whereas the second report by May et al. (2013), an independent study, found that the selection bias regarding student participation in IB programs was so large that "comparing IB and non-IB students in this statewide context is like comparing apples and oranges" (p. 6). Yet the 2011 IB-commissioned studies, both available on the IB website, are regularly cited in IB publications as evidence for curricular outcomes (e.g., IBO, 2010a, 2014c, 2016a).

Cambridge (2008) also highlights problems with validity and reliability in studies that attribute a cause-effect relationship between student participation in the DP and academic performance, such as Hinrichs's (2002, 2003) study comparing DP (Diploma Program) and AP (Advanced Placement) students, which found that the DP did increase students' international understanding. Cambridge suggests that

[1] inking participation in the IB Diploma Programme to observed outcomes can be naive and simplistic because it is methodologically unclear whether participation in a given programme of study is a direct antecedent of outcomes, or whether both participation and outcomes are confounded with another variable. Students following the IB Diploma Programme may be viewed as a self-selecting 
group... [t] here is currently a dearth of valid and reliable knowledge addressing the 'value-added' effects of participation in the IB Diploma Programme. (Cambridge, 2008, pp. 22-23)

However, a three-page report issued by the IB organization called Preparation for University

Success appears to have somewhat altered the import of Cambridge's comments:

The IB literature review on the Diploma programme indicated that, although existing research on University outcomes for IB students is sparse and piecemeal, it is suggestive of the fact that IB graduates tend to be successful in University (Cambridge, 2008). (IBO, 2010b)

Hayden and Wong (1997), from the IB Research Unit (IBRU) at the University of Bath, also questioned the relationship between participation in the IB and subsequent student performance:
...our research suggests that perhaps rather more caution should be exercised in making claims directly relating to the curriculum itself. All of those questioned confirmed the view that becoming more international in outlook is an attribute generally associated with students who have followed an IB programme. What is not clear, however, is the extent to which such attributes develop as a result of the IB programme. (p. 358, emphasis in original)

Furthermore, a report published by the IB organization on Canadian high school students enrolled in the IB cautioned that
...many schools have instituted criteria for admission into the IBDP at their school...This indicates that students are admitted into the program because they are intelligent and highly motivated. Individuals should take this into account when comparing IB students to the overall population. (IBO, 2003, p. 6)

Yet a 2011 press release issued by the organization claimed that a new (IBcommissioned) study showed that not only do IB students perform better at universities, but are also more likely to gain higher-paying employment (IBO, 2011), implicitly attributing this to the IB. The question of whether enhanced student performance results from participation in the IB is often raised, yet despite the cautionary statements made by its own research department, the IB publishes numerous reports, brochures and promotional publications implying that there is such a relationship. The contradictions between IB promotional 
material and statements in its research reports are often hidden by the sheer volume of the material involved, and only become evident through close intertextual examination.

\section{Contested histories}

Key texts on the history of the IB often cited in the literature come from those who were involved in the early development of the IB: Alec Peterson $(1972,1987)$, the first Director General (1968-1977) and usually referred to as the founder of the IB; Gerard Renaud (1974), the second Director General (1977-1983); Robert Leach (1969), from the International School of Geneva (Ecolint), who created the first IB syllabus for history; Martin Mayer (1968), from the Twentieth Century Fund, which provided crucial financial support for the IB in its early years; and Elizabeth Fox (1985) from the United Nations International School (UNIS) in New York. Since 2001, the key source for historical information has been Ian Hill (2010), Deputy Director General of the IB from 2000 to 2012. These accounts vary, however, in regard to the historical development, key figures, and origins of the different programs. Such inconsistencies are widely reported in the literature (see e.g., Clissold, 2012). In some cases, discrepancies arise not just between accounts from different authors (e.g., Fox, 1998; Hill, 2001, regarding main architects of the IB), but also between different accounts by the same author, as will be discussed below.

\section{When was the IB created?}

Even a fairly straightforward question as to when the IB was created gets different answers depending on the source. Most documents indicate that the organization was founded sometime in the 1960s, although the specific years vary (e.g., Berkey, 1994; Bunnell, 2008a, 2015, 2016). In terms of origins, a few authors have even traced the beginning of the 
IB as far back as the end of the "Great War of 1914-1918” (e.g., Hill, 2001, p. 11) or to 1950, "in the aftermath of the horrors of the Second World War" (Hill \& Saxton, 2014, p. 43).

This origination story is notable in that it links the IB to war and conflict, perhaps to give the IB a humanitarian aura.

One reason for this variation in founding dates seems to be the change in name and legal status of the organization. It first started out as the International Schools Examination Syndicate (ISES), registered in Switzerland in 1963 (Fox, 1985, p. 56; Postlethwaite, 1970, p. 505). As Tarc (2009) points out, the name reflected the centrality of assessment to the IB, which was the way it could ensure a common curricular framework (p. 47). Referred to by its founder as "an unfortunate name" (Peterson, 1972, p. 11), the IB was seen by some to be a traditional subject and exam-driven curriculum (e.g., Remillard, 1978) rather than innovative in terms of its pedagogical approach.

Bunnell (2008a) views Peterson's (1972) account as “one of the most comprehensive, and probably accurate, for this period" (p. 411), although Peterson himself notes that his version of the history of the IB is personal rather than official, since he was intimately involved and is therefore not able to be detached or objective. For this reason, he suggests that Mayer's (1968) book provides "the only objective, though sometimes very critical, description of the early days of the IB" (Peterson, 1987, p. xii).

According to Fox (1998), the IB arose out of a practical concern among parents frequently required to move from country to country as a result of diplomatic or other types of international work, and whose children, therefore, had to move schools and change curricula. This resulted in students with fragmented and disparate credentials, which meant that these "global nomads" (Langford, 1998) had difficulty gaining admission into 
universities of their choice (i.e., in their home or other western countries). Such students were also disadvantaged by lack of access to the high standards of education available in their home countries. It became clear to teachers, parents, and "a number of highly placed international civil servants grouped in Geneva" (Hill, 2002, p. 20) that what was needed was an "internationally acceptable school-leaving credential whose standards reflected the highest common factor in all subjects required by admissions policies of universities in different countries" (Fox, 1998, p. 65). Since the universities of choice were primarily British, French, German and North American, the new curriculum was designed with these in mind, resulting in what is arguably a Eurocentric bias to the DP curriculum (discussed further below). This has been a focus for a number of researchers, who point out that although the DP claims to be international, it remains western in its epistemology (e.g., vanOord, 2007), and its adoption in non-western cultural traditions may in fact lead to "cultural dissonance" (Drake, 2004).

Over its 50-year history, the IB has grown increasingly popular in the publicly funded education systems of Australia, the United States, the United Kingdom ${ }^{16}$ and Canada (e.g., Bagnall, 1994, 2010; Bunnell, 2011a, 2011b, 2012; Daly, 2012; Paris, 2003; Tarc \& Beatty, 2012). With this move into publicly-funded schools, issues of equity (i.e., only some have access) and the associated debasing of local/national curricula have come to light (e.g., W. Baker, 2014; Doherty, 2009; Resnik, 2012; Tarc, 2009; Whitehead, 2005). Across diverse countries, from Tanzania to Canada, Singapore to Australia, the consensus seems to be that the IB is better than anything else on offer. This is somewhat surprising, given the difficulty in achieving a consensus about something as emotionally charged and ideologically divisive

\footnotetext{
${ }^{16}$ In a recent article, Bunnell (2015) reports on a sudden decline of the IB in the UK after experiencing momentous growth placing the UK as the third highest in number of IB schools (after the US and Canada).
} 
as education. But the IB manages to cut across these political and cultural divides and seems to achieve a level of unity not evident in any other system of education/curriculum. For example, as noted by Conner (2008), the IB diploma manages to satisfy two highly contested areas of education reform in the US, the more conservative view of standards-based highstakes testing and the progressive idea of educating the whole person. Another early study of the IB in US schools noted how the need for education reform had been pressing but only the IB was able to bring all the different stakeholders - students and parents, teachers and administrators, policy makers, the business community and the community at large - to the table in agreement (Gilliam, 1997).

\section{IB programs and the IB 'continuum'}

Another issue evident in the literature is that the three different IB programs are often lumped together as "the IB program", giving the impression that they were developed together, or suggesting that the requirements for the diploma program apply to the other programs (e.g., Chichekian, 2011; Resnik, 2009; Spahn, 2001). The Diploma Program was the only IB program for 30 years (Hayden \& Thompson, 2011), and its multi-faceted curriculum has been described in detail frequently. Since it was the only IB program for such a long time, the early literature tends not to distinguish between "IB" and "DP", often using both interchangeably. This has resulted in some confusion (conflation) after the addition of other IB programs, which are all often referred to with the same "IB" acronym. As Bunnell (2011c) notes, many commentators refer to "IB" when they mean "DP" (p. 263). In order to fully understand how these programs differ, they need to be examined separately, as discussed below. 


\section{The Diploma Program (DP)}

Origins of the DP

According to Peterson (1972), the idea of the IB (DP) was first conceived by a group of teachers at the International School of Geneva (Ecolint) and the International Schools Association (ISA) in 1962, which he describes as that "of an international university entrance examination which could be taken in any country and recognized in any country" (p. 9). He refers to a $\$ 75,000$ grant from the Twentieth Century Fund in 1963 to investigate the possibility of such an international examination (p. 11). In his later book, Peterson (1987) states that the IB "breakthrough" happened when "it ceased to be a pipe-dream at the International School of Geneva and began to become a reality" as a result of a $\$ 75,000$ grant from the Twentieth Century Fund in 1965 (p. xii). In both accounts, emphasis is firmly placed on the IB as a vehicle for university admission.

The Twentieth Century Fund was represented by Martin Mayer, who was charged with conducting a feasibility study of the IB project. Mayer's (1968) report states that the need for an international examination arose out of the diverse student population at one international school and the university admission requirements they had. Mayer argues that the IB was not "an exercise in international cooperation" (p. 10) but rather a way to cope with the multiplicity of national university entrance examination requirements. Furthermore, he points out that although everyone is committed to world peace and understanding, governments are more likely to be motivated by national interests, such as the strengthening of American schools for the US, than being "wholly international in their purpose" (p. 14). Emphasis in this account of the IB again seems to be on the pragmatic aspect. 
Mayer's description of the situation at Ecolint during this time provides an important and rare critical perspective, which "caused quite a sensation in America" (Peterson, 1987, p. xii). The teachers at Ecolint, it appears, were fixed in their ideas and not open to the opinions of other participants. At conferences discussing different IB subjects, "People were invited not as bargainers for their own national systems, but as sympathizers with the Geneva project" (p. 218). As such, there was a lost opportunity to achieve valuable insights through discussion. Instead, the meetings seemed to draw only those who were dissatisfied with their own national systems and therefore supported the IB: "Participants in the meetings who raised objections based on national experience...were considered hostile and were not invited back” (p. 219). Interestingly, Mayer accused the IB organization of "parochialism" (p. 219), a term which IB representatives themselves have on occasion used to refer to national education systems (e.g., Walker, 2002). Mayer argues that the organization's parochialism "created false perceptions of reality" with their use of the term "international education" to describe "struggling and confused schools" searching for a better procedure. As such, international education in the form of the IB became presented as "an established procedure intrinsically better than any national system of education" (p. 219, emphasis in original). Assertions were made in the absence of any comparative analysis with existing national examinations, despite the existence of much research in such areas. Mayer, therefore, calls into doubt the IB organization's “claim to embody the best of national systems" (p. 232).

Another oft-cited source for IB history is Fox (1985), which provides an important North American perspective on the reasons for the IB's increasing popularity. Fox also emphasizes the ideals of internationalism, as might be expected from a school for UN 
students. Berkey (1994) alludes to similar ideals with reference to Ecolint by linking its history with that of the IB: "The origin of the International Baccalaureate can be traced to Ecolint, the International School of Geneva...established in 1924...to serve the children of employees of the League of Nations" (p. 11), which suggests the origins of the IB lie in the interwar period. On the other hand, Bunnell (2011d) locates IB roots "in the Cold War, in 1962, at the peak of the Cuban missile crisis" (p. 167).

\section{DP curriculum}

When the International Schools Examination Syndicate (ISES) became the International Baccalaureate in 1968, there was only one IB program: the two-year diploma designed for the final two years of secondary school, which involved the completion of six subjects, three at a higher level and three at a subsidiary level. In addition, three core components were also required, the Theory of Knowledge (ToK), Extended Essay (EE), and Creative, Aesthetic, Social Service (CASS). ToK was designed to critically evaluate assumptions underlying different disciplines; the Extended Essay was an original piece of

independent research on a topic chosen by the student and supervised by a school teacher; and CASS required students to engage in community service activities. According to Fox (1998), the inclusion of these three special requirements "give the IB Diploma Programme its character as a total, integrated curriculum" (pp. 68-69). By providing students with opportunities for reflection, critical thinking, research, and community service, the IBDP aimed at educating "the whole person" (Fox, 1998, p. 68). Berkey (1994) adds that the IB curriculum was based on the notion that every student should receive a broad liberal arts education, with the three core components being part of this idea. The "IB curriculum" is thus understood to mean all the components required by the DP, i.e., six courses plus the 
three core components. In completing these, students obtain breadth and depth as well as the other key aspects (e.g., critical thinking, community service, independent research) that together make for a comprehensive curriculum.

As Director of the Department of Educational Studies, Oxford, one of Alec Peterson's areas of research dealt with upper secondary curricula. In creating the DP, Peterson maintained that recognition of this new qualification was highly important. Peterson's military service in the Second World War provided him with government contacts "that greatly assisted the acceptance of the IB by ministries of education and governments" (Hill \& Hayden, 2010, pp. 66-67). Gérard Renaud, the second Director General of the IB organization (1977-1983), worked closely with Peterson to develop the DP. Together, Peterson and Renaud identified the expectations of universities along with what they believed were the key competencies for education, and therefore developed a curriculum incorporating what they took to be the best elements of different educational systems. The resulting DP curriculum was thus a synthesis of French, British, German and American concepts that was felt to achieve a balance between national and international perspectives, and which combined an emphasis on both depth and breadth of knowledge, on the one hand, and theoretical and practical learning on the other. The DP was thus considered a "comprehensive curriculum" because it was designed to be acceptable for university admission and incorporated elements from different systems to meet university requirements (Berkey, 1994, p. 6; Peterson, 1972; Renaud, 1974).

\section{Diploma vs. individual courses}

In one of the first studies conducted on the IB in Canada, Bagnall (1994) reported that less than $1 \%$ of the student population in his sample completed the full diploma, while a 
much higher percentage took individual courses. Although this is considered an option, the IB organization sees the IB as consisting of the full diploma, with individual courses being an alternative for students "unlikely to be proceeding on with tertiary studies" (p. 119). According to Mathews \& Hill (2005), however, the only way that the IB could achieve success in North America was by allowing students to take individual courses rather than the full diploma since individual course selection was the style they were accustomed to as a result of the system in place in US high schools. As they report, the prevailing view was that "less ambitious students" (p. 39) would opt for individual courses rather than the full diploma.

In an early and frequently cited source on the IB in the US by Thomas Grexa (1988), assistant dean of admissions and international student specialist at the University of Virginia, describes how the IB diploma's different components could address deficiencies in the American education system. However, he also mentions that students were permitted to take fewer than six subjects and thus qualify for individual course certificates. These certificates were also awarded to those who "fail to meet all the [diploma] requirements" (p. 3). A report for the IB organization issued that same year by Philip B. Thomas (1988a, 1988b), a counsellor and IB coordinator at the International School of Geneva, stated that one issue particular to the US and Canada was that a large number of students, rather than taking the diploma, were taking individual IB courses on subjects such as Psychology and Economics that were generally not found in their high school curriculum. In addition, there were also students who failed to complete all their diploma requirements and thus qualified for only individual certificates for each course successfully completed, and were categorized as "certificate candidates" (Thomas, 1988a, p. 7). It is notable that both Grexa and Thomas 
associate IB benefits with the completion of all diploma requirements, not with single courses. Indeed, as Thomas notes, students were being encouraged to complete the diploma by the IB organization so that they could enjoy the related benefits. What is significant here is the notion that those students who do not manage to complete the diploma, i.e., fail to do so, or those who do not intend on proceeding to university, are then awarded certificates for courses they do complete. This aspect tends to be absent in current IB literature, where individual courses are generally referred to as the "IB Certificate Program" or the "partial IB program", which shifts the focus from "individual course" to "program" thereby helping to maintain the link with the diploma and its curricular benefits (see Chapter 8).

\section{The other IB programs}

The idea of students as "creative, critical and reflective thinkers" (IBO, 2014d) was expanded in 1994 to encompass students aged 11-16 in the Middle Years Program and, in 1997, students aged 3-12 in the Primary Years Program (the DP is for students aged 16-19). According to the IB organization, this "continuum of international education" available to students from age 3-19 is "unique because of its academic and personal rigour...promoting the education of the whole person through an emphasis on intellectual, personal, emotional and social growth" (IBO, 2014d). The expansion of the DP curriculum is often presented as a natural progression for the IB, since the organization claims that in order to develop the skills necessary for success, students must not only become the kinds of active learners and critical thinkers envisioned but do so from an early age: "The IB must begin at age three. Without the foundations of the primary years the later years will never yield their full potential” (Bartlett, 1998, p. 90). However, a significant difference between the DP and these later additions is that they were not developed for students interested in university entry, as 
noted by Barnes (1998): "both the MYP and PYP are intended for all children in the specific age ranges...whereas the Diploma Programme can be described as appropriate for the hardworking, college-bound student” (p. 45).

\section{The Middle Years Program (MYP)}

The MYP is often described as "joining” or being "added to" the IB in 1994 as a curriculum for students aged 11-16, followed by the Primary Years Program (PYP) in 1997 (e.g., Bunnell, 2008b, 2011d; Powell, 2002). The impression conveyed in the literature is that they were developed by the IB and are closely linked to the DP, i.e., students naturally progress from one level to another. However, this appears not to be the case when the literature is examined in more depth. According to Stobie (2005), the MYP was developed in the late 1980s by the International Schools Association, a separate Swiss-based organization, as the International Schools Association Curriculum (ISAC) and was so named until the IB organization took over its management in 1994 (see also Hayden \& Thompson, 2011). Unlike the DP, therefore, it did not begin as an "IB product" (Bunnell, 2013), and interestingly, instead of Geneva as origin, this curriculum was first discussed at the 1980 ISA conference held at the International School Moshi in Tanzania.

One little-known aspect relevant to the IB in Canada is that "some 27 schools in Quebec had been doing the MYP as the former ISA curriculum and implemented it in French in 27 state schools...all of these schools have since been authorized as IB MYP schools" (Hill, 2010, p. 139). Despite over two decades under the IB emblem, however, Hayden and Thompson (2011) refer to it as "still a relatively new programme" which is as yet little researched (see also Bunnell, 2011c; Chapman, 2011). 
The Primary Years Program (PYP)

Like the MYP, the PYP did not begin as an IB product. As described on the IB website, the idea for a primary years program for students aged 3 to 12 was first discussed at a 1990 European Council of International Schools (ECIS) conference in Rome (IBO, 2015a). This program was called the International Schools Curriculum Project (ISCP) until it was "formally adopted by the IB in 1997" (Bunnell, 2011c, p. 261). As with the MYP, descriptions of the PYP tend to be attached to detailed descriptions of the DP and its history (e.g., Powell, 2002; Tarc \& Beatty, 2012).

\section{Disambiguating the IB 'continuum': rebranding/conflation}

A 2014 description of the IB 'continuum' on the IB website reads as follows:

What started life as a single programme for internationally mobile students preparing for university, has today grown into four programmes for students aged 3 to 19. (IBO, 2014e)

However, the version that appears on the website at present (May 2017) reads as follows:

The International Baccalaureate ${ }^{\circledR}$ (IB) offers a continuum of international education. The programmes encourage both personal and academic achievement, challenging students to excel in their studies and in their personal development. (IBO, 2017e, emphasis added)

In this later version, reference to different programs is erased. Shifting the focus to

"personal and academic achievement" and presenting the programs as a single unified whole or "continuum", gives the impression that a seamless and natural progression occurs from start to finish, with all programs sharing the same qualities.

The idea of a continuum of IB education has been questioned most frequently by Bunnell (e.g., 2008a, 2010, 2011a, 2011b), who points out that only a handful of schools around the world offer all three programs and that the "IB continuum, as a product, has been a global failure" (Bunnell, 2011b, p. 73). Nevertheless, in a later book responding to the attack on the IB by a conservative group in the US, he does say that "it is probably too soon 
to dismiss it as a 'failure"' (Bunnell, 2012, p. 30). Bunnell further states that the "IB as a system of education defies reality" (p. 31) and that each of the programs functions more as a standalone (Bunnell, 2011a, p. 175). Chapman (2011) also questions the concept of continuum or progression assumed by the three programs, which were "developed at different times and in relative isolation" (p. 195). Although the three programs are presented as a continuum by the IB organization, few schools offer all three, with the majority of schools offering only one program.

IB-related literature is notable for its inconsistent and conflationary use of the different names for programs. For example, Doherty (2009) refers to "Early Phase curriculum" and "Middle Years curriculum" (p. 77) instead of the Middle Years Program (MYP) and Primary Years Program (PYP). The use of acronyms for the different programs also tends to be inconsistent. For example, the IB diploma program is referred to variously as "IBDP”, "DP”, “IBD”, or "IB DP”. These acronyms are a veritable "alphabet soup" (Bunnell 2007, p. 357), which seems to have been recognized by the organization, as in 2007 it produced an "English to IBese dictionary: To help you communicate with the locals" (IBO, 2007a). To further complicate matters, the IB organization changed its name from "IBO" to simply "IB" in 2008 (Bunnell, 2011c, p. 262), launching "its new visual identity" and thereby becoming "a brand rather than an organization” (Bunnell, 2011a, p. 177). As a result, "IB" is now used to refer to (i) the organization itself; (ii) the whole system of education from kindergarten to diploma (also referred to as the IB Continuum); or (iii) any one of the programs (often the DP) without specification, thereby conflating different curricular requirements and standards. 
The DP and the other IB programs are further conflated in descriptions that mention the different components of the DP (i.e., six subjects plus three core components) even when the program being discussed is the MYP or PYP (see Chapter 8 for an example of this type of conflation). This misconception has on occasion been adverted to in the literature, with, for example, a distinction made between the MYP, described as a framework and the DP as having strict requirements for university entry (Hayden \& Thompson, 2011; Chapman, 2011; Bunnell, 2011c; Stobie, 2005). What becomes apparent is that the different components of the DP tend to be drawn on widely (if superficially), whilst very little information about the PYP or MYP is visible in IB descriptions. This may help explain why a recurring theme in the literature is that IB programs are either not clearly understood or are unknown (e.g., Hahn, 2003; Bunnell, 2011c, Spahn, 2001; Tarver, 2010; Daly, 2012).

Leach (1969) discusses the two very different approaches to international education found in the DP and the MYP, the former an "elite syllabus and examination structure at the conclusion of secondary international education" designed to meet the "rigorous selectivity of continental universities in their admissions policy", the latter a "child-centred projectoriented education" (p. 78). Furthermore, as Hayden and Thompson (2011) state, "the IB makes clear that schools should not expect to be supplied with detailed curriculum documents" but rather provides a framework "within which each school develops its own written curriculum" (pp. 16-17). They also point out that assessment of the MYP is purely internal (p. 16), making it fundamentally different from the externally assessed DP. The MYP and PYP have been referred to as "shell curricula" (Bagnall, 2010, p. 134), simply codifying good teaching practice (IST teacher, personal communication) without providing concrete content for the classroom. Evaluation of students is also only conducted internally 
by teachers. Given these differences, the only commonality that unites these three is their shared mission statement (Hayden \& Thompson, 2011, p. 14).

In summary, descriptions of the IB in different domains and by different stakeholders tend to present it as a single unified program, despite their different origins and requirements of the three component programs. Furthermore, the attributes of hard work and scholarly skills usually associated with the strict requirements of the DP get tagged to the IB label in general. The conflation that this gives rise to seems to be at the root of much of the misunderstanding about the IB. In her study on IB discourse, Hahn (2003) points to the difficulty in the understanding of the IB curriculum because of the room it offers for interpretation and the different ways it is incorporated into schools (p. 20). Others have also remarked on the lack of understanding of IB programs (e.g., Bunnell, 2011c; Daly, 2012; Kroll, 1984; Spahn, 2001; Tarver, 2010). Rowell (1983) makes an interesting observation in her study of IB implementation in Edmonton that a "veneer of consensus" (p. 132) was constructed by presenting an official point of view that excluded divergent views. She suggests that this was indicative of an absence of understanding of the program, and differences only emerged as understanding deepened. This may provide one possible explanation as to why the responses from participants surveyed in different studies are very similar, as found in this research project and also reported widely in the literature (e.g., Bagnall, 2010; Clissold, 2012; Duarte, 2012; Mayer, 2006; Verneuille, 2011; Poelzer, 1994 cited in Wilkerson, 2005).

\section{Pragmatism vs. Idealism}

Reviewing the historical sources, it becomes apparent that a subtle shift in emphasis seems to have occurred between the older sources and the newer ones, with the former 
emphasizing the more pragmatic aspect of the IB (i.e., university admission) and the latter a more idealistic version (i.e., world peace). Such differences are important as they are used in different studies to emphasize particular aspects (a notion Reisigl \& Wodak (2001) call "perspectivation" (p. 45)). In some cases, simply by referring to the source material used, a reader can predict the angle of the study. For example, according to Hill (2002) the idea for the diploma program came about as a result of an interest in the "promotion of world peace and international understanding” (p. 19). In another account of IB history, Hill begins by describing the aftermath of the "Great War of 1914-1918" and the "terrible manner...in which nations were distrustful and intolerant of each other" (2010, p. 15). Using the League of Nations and Ecolint for context, he presents the emergence of the IB in 1965 as the natural culmination of efforts of "unpaid enthusiasts for international education" (p. 46). The university admission aspect is less central than in either Peterson's or Mayer's accounts. Hill and Saxton (2014) list three main reasons for the creation of the IB:

- to develop critical thinking skills, holistic learning, life-long education, and affective education via community service;

- to foster international mindedness, an appreciation of multiple perspectives, promotion of intercultural understanding, and consideration of solutions to major global issues leading to world peace;

- to offer a globally recognised university entrance qualification, thus facilitating student mobility across frontiers. (p. 44)

The order in which they present their three main reasons places more emphasis on the idealistic aspect of the IB than on the pragmatic aspect of university admission, which is consistent with the other historical accounts authored by Hill, mentioned above.

Bunnell (2011d) argues that even the name "IB" suggests a compromise between the two conflicting reasons for its development, school leaving certificate or education for global peace, reflecting the dilemma plaguing its identity from the start, i.e., whether it was in fact a pragmatic university entrance qualification or an idealistic entity focussed on world peace (p. 
178). This issue has also been discussed by other researchers (e.g., Tarc 2007, 2009) and the

IB Research Unit (Cambridge \& Thompson, 2004). Spahn (2001) provides what he claims is the first official mission statement of the IB organization:

Through comprehensive and balanced curricula coupled with challenging assessments, the International Baccalaureate Organisation aims to assist schools in their endeavours to develop the individual talents of young people and teach them to relate the experience of the classroom to the realities of the world outside.

(IB Annual Report, 1996-1997, p. 2, cited in Spahn, 2001, p. 16)

This contrasts strikingly with the IB mission statement available on the website at present, which seems to focus more on ideals of intercultural understanding and world peace:

The International Baccalaureate aims to develop inquiring, knowledgeable and caring young people who help to create a better and more peaceful world through intercultural understanding and respect.

To this end the organization works with schools, governments and international organizations to develop challenging programmes of international education and rigorous assessment.

These programmes encourage students across the world to become active, compassionate and lifelong learners who understand that other people, with their differences, can also be right. (IBO, 2017f, emphasis added)

Once again, the shift in focus from curriculum and academic attainment, with words such as classroom and teach, to values and attitudes pertaining to international understanding, is clearly evident.

\section{Growth of the IB in North America}

\section{United States}

The US has the greatest number of IB schools in the world (38.9\%), with 1,809 as of July 2017 (IBO, 2017g). This has led some researchers to refer to an American "imbalance" (Bunnell, 2011b), and to argue that the IB's home is the US (Bunnell, 2011b; Spahn, 2001). Peterson (1987) gives three main reasons for the growth of the IB in North America: (1) public dissatisfaction with the public education system; (2) the IB North America (IBNA) 
office in New York operating as an independent organization with its own budget; and (3) the extremely efficient promotion of the IB conducted by the IBNA in the region through workshops and presentations (p. 137).

\section{Dissatisfaction with the US education system}

The adoption of the IB in the US is generally attributed to dissatisfaction with the existing education system, which was seen as providing choice and flexibility at the expense of academic rigour (Bunnell, 2008a; James, 2005; Matthews, 1989; Mathews \& Hill, 2005). For example, Grexa (1988) first states that "American public education is being criticized" (p. 2) and then explains how the different components of the IB diploma are of value and can address the deficiencies found in the American education system. According to Berkey (1994), interest in the IB grew as a result of recognition and concern about "the problem of apathy in American high schools" and a resulting "call for excellence" (p. 8). He notes that there was significant growth between 1982 and 1993, and attributes this increase to two factors: (i) the reform movement that arose as a result of a number of national reports (e.g., A Nation at Risk, 1983) stressing the need for curricular reform in American secondary schools that was evident from the decline in test scores; and (ii) a concern about the absence of intellectual challenge for university-bound students in the US. The IB curriculum was seen as able to address these different areas of concern (see also Conner, 2008, on her discussion of how the IB satisfies everyone).

H. Gilbert Nicol (1982), executive director of IBNA, in discussing the unexpected popularity of the IB in North America, indicates that secondary education reform was not part of its plan, which was rather to facilitate entrance to universities by students who completed their secondary education in another country. In other words, the plan had more 
to do with pragmatic university entrance requirements than with idealistic educational reform. The change in focus to domestic students stemmed from the interest in American education reform. Furthermore, the increase in recognition of the IB by universities in Canada and the US also provided students elsewhere with more institutions to which they could apply. However, the key factor for the IB's growth in these countries is that neither country has a national system of education, a point also noted by Peterson (1987, p. 134).

\section{IB North America (IBNA)}

The International Baccalaureate North America (IBNA) branch of the IB organization, an independently incorporated foundation located in New York and existed until 2009 (Bunnell, 2012), mounted a campaign in the early 1980s to promote the IB as a program of academic excellence providing a challenging curriculum for gifted students. According to O'Connor (2011), “[a] significant portion of the program’s growth is attributed to its effective marketing” (p.1), a point reiterated by Bunnell (2011b), who says that the IB "had a powerful marketing and training presence in the form of the IBNA" (p. 71). However, Abrioux and Rutherford (2013) claim that "[t]he IB has never yet run a marketing campaign to enroll more schools" (p. 5), a point that Bunnell, confusingly, also seems to agree with, stating that the IB "has never undergone any formal advertising or marketing and relies totally on word of mouth comment" (2011a, p. 185).

Peterson (1987) points out that this growth also occurred as a result of the decentralized US education system, in which education is a state rather than federal responsibility:

It is not difficult to see why in such an educational climate some high schools concerned for academic excellence began to think of introducing an IB track. Because of the decentralization of the American system they were free to do so. (p. 138) 
Walker (2005) also notes the importance of the absence of a national or centralized education system, but adds another reason for growth, i.e., the key role played by the regional associations in promoting the IB:

The United States and Canada share one very important advantage for the IB and that is the devolved nature of their public education systems. The more heavily centralized the system, the more difficult it is to penetrate (France provides a very good example of this principle) and here I want to acknowledge the importance of the different IB sub regional groups that do a huge amount of effective lobbying and explaining at a state and provincial level. There are no fewer than 6 in Canada and 15 in the US: societies, leagues, associations, organizations, coalitions and guilds. (p. 7)

Introductory seminars and workshops offered by the IBNA and its sub-regional groups

proved to be a key factor in generating interest from schools and increasing IB membership.

These workshops were gradually replaced by presentations made at gatherings of teachers

and administrators, a practice that continues to this day at conferences such as the Ontario

University Registrars' Association (OURA) conference held annually and the Association of

Registrars' of Universities and Colleges in Canada (ARUCC) conference held biannually. ${ }^{17}$

\section{Financial problems}

A lesser known aspect of this success story in North America is the financial

difficulties the IB organization experienced in its early years. Early studies on the

development, growth and change of the IB organization (Kroll, 1984; Remillard, 1978;

Wagner, 1978) provide a rare glimpse into the situation at that time depicting an organization

unable to function because of financial woes and experiencing great difficulty in gaining

traction in North America. Kroll (1984) focuses on this issue, arguing that support from

various foundations was insufficient to guarantee the organization's future and therefore led

\footnotetext{
${ }^{17}$ It is also interesting to note, for example, that the president of ARUCC until 2016, Andrew Arida, Associate Registrar, Student Recruitment \& Undergraduate Admissions from the University of British Columbia, is a member of the IB College and University Recognition Task Force (CURT) (ARUCC, 2014), whose mandate is to assist North American universities in "their strong desire to aggressively attract IB Diploma candidates to their campus" (IBO, 2014f).
} 
to cutbacks (p. 83). For this reason, the increase in the number of schools offering the IB was financially helpful (p. 84), as revenue is generated from examination fees and school subscriptions. According to Rowell (1984, p. 92) and Remillard (1978, p. 100), the financial crisis experienced by the IB organization in 1976 may have prompted the decision to "go public" and move away from the original focus on private international schools. They speculate that when UNESCO funds were not forthcoming, the IB organization's attention shifted to the "ambitious intellectual elite in the public sector" (p. 92; cf. Remillard, 1978, p. 100). These financial difficulties tend to be hidden or backgrounded in the predominantly “celebratory accounts” (Doherty, 2013, p. 381) of the IB usually presented.

Peterson (1987) also describes the financial difficulties of an organization continually having to solicit funds from other parties. The only way for it to avoid the threat of closure was to become financially independent:

...if IBO as a whole was to become financially viable...it must seek a swift and substantial
increase in the number of IB schools, and that under current conditions such an increase
could only be found in North America...There can be little doubt that without the $300 \%$
growth of North American IB schools between 1980 and 1985 , a period when the number
of IB schools in the rest of the world grew by approximately 33\%, IBO as a whole might
have foundered. (p. 147)

He goes on further to say that "it has to be remembered that it was only in the free and unregulated system of North America that expansion of this kind in the public system was possible and that it was from this expansion that the money was being provided" (p. 152). It seems ironic in light of this information that the IB is thought of as "Swiss-based", and is attacked by a conservative group in the $\mathrm{US}^{18}$ for being foreign or UN. However, as Peterson points out, it was primarily the IBNA's independent status and thus able to raise funds without ties to the parent organization, that made it grow in North America. This because

\footnotetext{
${ }^{18}$ See Truth about IB (TAIB) at http://www.truthaboutib.com/
} 
US donors who were willing to provide funds to support the IB also wanted their contributions to be used for the benefit of American education rather than an international organization in Geneva (p. 141). With the IBNA as a separate entity, they were reassured that their donations would remain in North America.

There is little discussion of the business and financial aspects of the IB organization in the literature. In most versions of IB history and the creation of the DP, emphasis is placed on the idealistic vision of the founders. However, implementation of IB programs is costly, which proved to be a serious handicap for the organization in its early days and a key reason for its difficulties in gaining a foothold in North America (see Kroll, 1984, and other early dissertations). Since the financial burden is prohibitive, this raises the question about who is paying for the IB in the public schools (see Baluja \& Hammer, 2012, the Globe and Mail investigation). In the purview of elite private schools, either internationally or incountry, wealthy parents are willing to pay the extra costs for the IB, but this becomes problematic in the context of publicly funded schools, where budget cuts to education are an ongoing issue.

While much of the literature focuses on the expansion and adoption of IB programs in schools, citing increasing numbers around the world, little is mentioned about schools that withdraw or decide to discontinue the program due to high cost and low student enrolment. For example, in the Regina School Board, since individual courses were more popular than entire programs, the Regina School Board decided that the US-based Advanced Placement (AP), which offers individual university or college academic credit courses for secondary students, was a more affordable option and made more sense than the expensive IB diploma that students were not choosing (Regina Board of Education, 2016). Spahn (2001) mentions 
that a number of schools (more than 138 since 1975) had withdrawn from the program after being granted authorization, the time span for this occurrence ranging from as little as a few months to as long as 17 years. He points to different reasons why schools decided to give up on the program, such as declining enrolment and lack of interest, lack of adequate support (i.e., among administration, faculty, students, parents, IB organization), high cost, school preparation, and frustration with the IB bureaucracy. He also describes problems with implementation of the program at schools, an issue that comes up in a number of studies (e.g., Rowell, 1983 in Alberta; Rodway, 2008 in Ontario; Connell, 2010 in PEI; Sills, 1996, in Cairo; Gilliam, 1997, Parker, 2000, Batey-Stepancic, 2006, Mayer, 2006, Pascoe, 2016, Meadows, 2017, in the US). Some studies mention the division resulting from "IB" and "non-IB" as a major negative effect of implementing the program, resulting in friction between students and faculty (e.g., Spahn, 2001; O’Conner, 2011; Parker, 2000; Doherty \& Shield, 2012).

\section{Canada}

Although the rate of IB growth in Canada was initially greater than that of the US (Thomas, 1988a), and Canada in 1974 already had an IB program in the country as a result of the United World College of the Pacific in British Columbia, there is relatively little written about it. For example, in his discussion about the exponential growth of the IB in the US, Bunnell (2011b) only glances at Canada even though the growth appears to be equally great (p. 72). The first (and, to my knowledge, only) study to focus on the IB in Canada as a whole (rather than in a particular province or specific school) was conducted by Bagnall (1994), and is frequently cited in the literature. Bagnall's research provides a basis of comparison for the present study, in terms of the development of the IB in Canada. At the 
time of Bagnall's study, there were 47 “IB schools”, whereas as of May 2017 there were 375 (see Figure 3.1). One of the contributions of the present study is thus to provide a more contemporary account that covers the country as a whole.

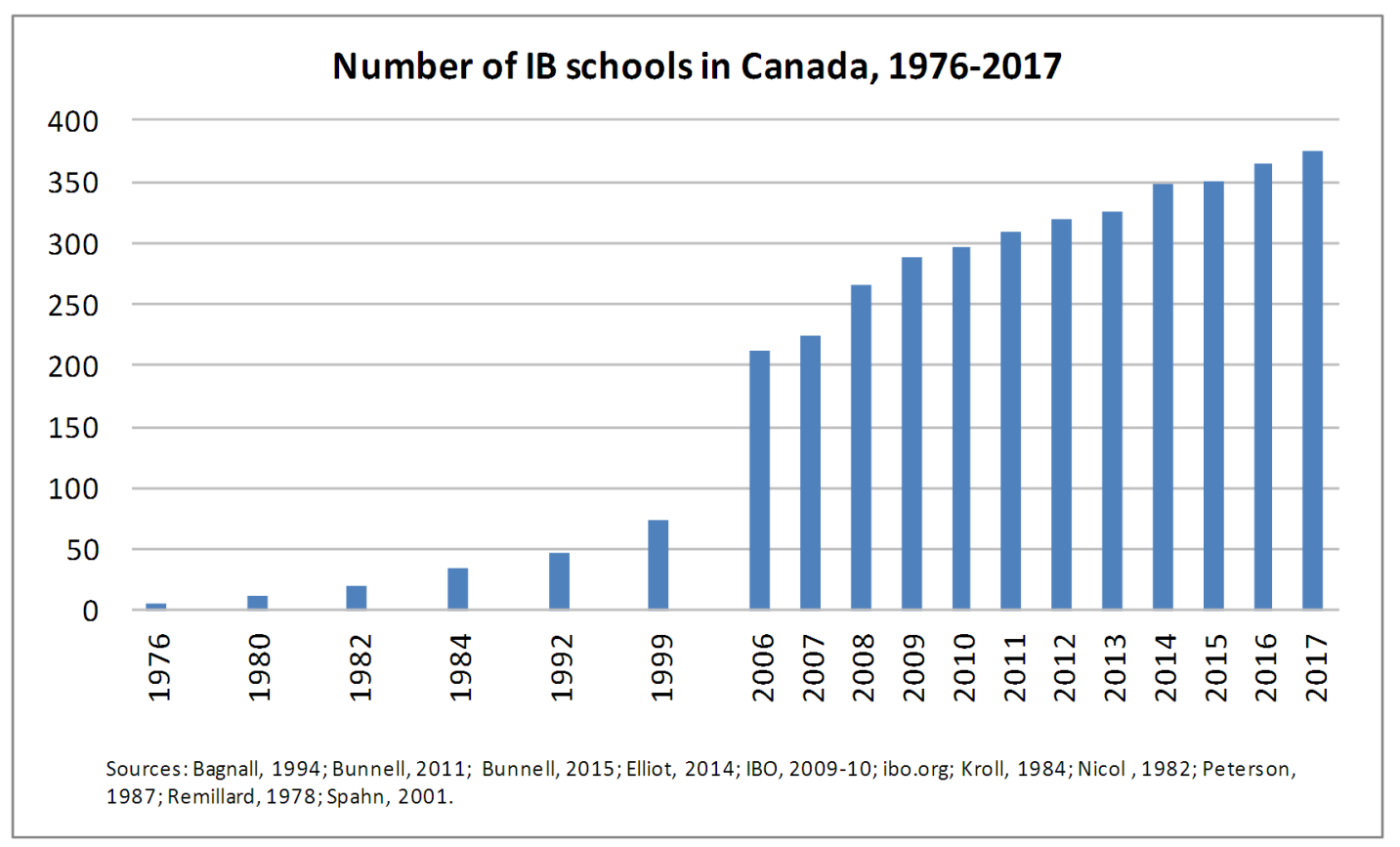

Figure 3.1: Number of IB schools in Canada

Of these 375 schools, 301 are public schools. The province of Prince Edward Island (PEI) was the last to introduce the IB into its schools (see DiGiorgio, 2010 \& Connell, 2010 for details of program implementation in this province).

When describing the popularity of the IB in North America, the general trend in the literature seems to be to subsume Canada under the US, thus making it appear that the dissatisfaction with the public education system in the latter was present in Canada as well. According to Bagnall (1994), there was a view in Canada that the standard of education was deteriorating (p. 116), on the basis of which the DP came to be considered as an alternative. However, Walker (2005) states that "[i]n Canada the situation was different and the quality of public education was much better regarded” (p. 2). Peterson (1987), for his part, notes 
that the expansion in Canada was initially faster due to the absence of the AP program in Canadian schools, and the existence of a United World College that served as a model that the US did not yet have (pp. 150-151). He also mentions that an annual grant to the IB organization of $\$ 5,000$ was made by Canada's External Affairs Department (p. 148), but attempts to obtain additional funding from the Council of Education Ministers of the provinces failed except for an individual contribution by Alberta (p. 148). However, growing interest in Canada as a result of the IBNA campaign through introductory seminars and teacher training workshops (cf. Rowell, 1983 on the importance of these workshops) brought additional funds from Gulf Canada and Imperial Oil (p. 149).

\section{Studies on the IB in Canada}

Alberta

Rowell's (1983) study of the IB in Edmonton schools is the first Canadian study available. Implementation of the IB was accompanied by a booklet used by the IB organization to advertise its program entitled Restoring Challenge to Secondary Education, which thus evoked the notion of deficiency and falling standards in schools. Rowell argues that the title of the booklet provided Edmonton trustees and administrators with the justification for adopting the program, and also addressed those who believed that the academically gifted were being neglected. In this way, public opinion regarding the quality of education in Edmonton was further reinforced (p. 143). A number of phrases, such as academically able, intellectual challenge, enrichment, international education, and prestigious program, came to be associated with the IB during the period under study. Such phrases created an image of success but did not describe what would actually happen in the classroom. However, they did serve to legitimize its adoption by the Edmonton public school district (p. 143). Furthermore, the 
credibility of the program was important for trustees, who were not prepared to gamble on an unknown program. This credibility came from "its wide acceptance by universities" and also "by its prestige as the curriculum of many multinational schools and private schools" (p. 68).

Ontario

Two studies have recently been conducted in Ontario. The first, Tarc and Beatty (2012), looks at perceptions of students enrolled in the DP at one school, to gain insight into how they viewed their experience in terms of (1) benefits and drawbacks of the DP; (2) how well it prepares students for further academic study; and (3) the degree to which it fosters international mindedness. As with other such perception studies frequently cited in the literature (e.g., Paris, 2003), they are more exploratory than evidentiary and tend to be closely tied to the specific school being studied, with results being "suggestive rather than numerically significant” (Tarc \& Beatty, 2012, p. 357).

The second study (W. Baker, 2014) examines the adoption of the IB in Ontario schools through the lens of neoliberal education reform, in which schools are forced to compete with one another in order to remain financially viable through increased student enrollment. One way they do this is by distinguishing themselves through offering the IB as a "curricular choice" (p. 12). The study explores (i) whether access to the IB is equitable across the province; (ii) the reasons that Ontario public schools choose the IB as an alternative curriculum; and (iii) how the DP differs from the Ontario curriculum. Important findings were that there is a policy vacuum regarding the IB in Ontario that allows local school boards to make diverging decisions (e.g., who can enrol and how much parents are charged), that access to the IB is not equitable, and that the DP offers advantages beyond 
those of the Ontario curriculum, "in effect creating a private school atmosphere in public education" (p. 127).

Echoing the idea of curricular choice is the more recent development of "niche programming" as one way to attract students and thereby forestall school closure due to declining enrolments. A recent article in an Ontario newspaper announced that a school in the neighbourhood was "on death row" and facing potential closure due to declining student enrolment (Leslie, 2017). The author suggested that one way to save the school would be by introducing "an IB program". By doing so, the author argues, the school would not only "stand out from the crowd" and have the potential to become a "top-notch community school", but would also "draw students from beyond its boundaries" and "attract local middle-class families". Similar reports can be found in other Canadian provinces where schools facing "the chopping block" are saved from closure by the introduction of IB programs. Not only do these programs boost a school's profile through increased enrolment and funding, but since students in IB programs are said to perform better than "non-IB students" (IBO, 2017h), the school itself can become a better performer through higher scores on provincial or international ranking systems.

\section{Prince Edward Island}

The adoption of the IB in PEI, the last Canadian province to take it up, was examined by DiGiorgio (2010) using ethnographic case study on two high schools in the province that were to receive funding for the implementation of the IB. The aim of the study was to understand the process of implementation through interaction with parents, students and educators by means of observations, interviews and document analysis. Interviews were carried out with parents, students, teachers, and administrators. Document 
analysis focused on communication between schools, home and the public through various media sources (newspapers, radio \& television, internet, school and department websites), and found that parents are the driving force behind students' decision to enrol in the program. Parents wanted the program for more stimulation and better preparation for university and used their position as taxpayers in public education to get their voices heard (p. 283). This echoes Resnik (2012), who also commented on the increase in viewpoints when public money is involved. DiGiorgio's study provides valuable insight into the types of issues that arise when the IB is introduced into schools, such as conflicts or differences of opinion about the program amongst teachers and students, which appears to depend on the type of leadership, the teachers, and how the IB works in relation to existing school programs. It also points to the potential exclusion of the rest of the school from the IB. DiGiorgio's conclusion was that "The application of IB to public schools-within-schools is quite different from the original IB goal of global citizenship and internationalization" (p. 290), which seems to contradict earlier statements by the IB which emphasized that it was not a competitor but rather an alternative to existing national curricula (Thomas, 1988b, p. 13).

This study is interesting because it examines two provincially funded schools located in close proximity, and shows how the IB worked very differently due to the particularities of each context. Throughout the literature, a recurring theme is that there is no typical IB school, that every school is unique (Conner 2007; Clissold 2012; Hara, 2011; Rodway 2008; Rowell 1983; Gilliam 1997; Spahn 2001; Samore 1992), and that success in every case depends on a number of factors, especially on the teachers (Peterson 1987; Bent 2009; 
Parker 1996). Yet dominant discourses surrounding the IB construct it as a single entity, whether in reference to IB schools, IB programs, or IB students (see Chapter 8).

\section{British Columbia}

A study that is frequently cited in the literature is Taylor and Porath (2006), conducted in BC, with DP graduates from two public schools. Participants were asked to respond to a survey consisting of 20 statements about the IB with Likert-scale responses ranging from strongly agree to strongly disagree and seven open-ended questions. The aim was to solicit from these graduates "their retrospective views of the DP experience", (p. 151), i.e., about whether they felt the program had benefited them. The two different groups represented those who had just graduated and were beginning their first year of postsecondary education and those who had finished university and were well into their careers. The majority agreed that the IB curriculum stimulated them intellectually, provided breadth and depth, critical thinking, and time management skills, and felt they were better prepared for their postsecondary studies than those who had not been in the DP (p. 155).

\section{Perceptions of the IB}

\section{University recognition/ transfer credit}

A change in university perception regarding the IB can be found in the 10 years between Kroll (1984) and Berkey (1994). Kroll stated that the DP was not recognized by most public universities in the US, primarily because they were only interested in the higher level courses rather than the other DP requirements, which he attributes to the lack of understanding about the nature of the diploma as a comprehensive program of study. However, by the time of Berkey's study, both American and Canadian universities 
recognized the DP as a credential for admission purposes and some even granted transfer credit or advanced standing for higher level DP courses. Some institutions granted transfer credit for individual “certificates" (p. 25), and some diploma holders could enter $2^{\text {nd }}$ year, depending on the institution. Tarver (2010) and Daly (2012), driven by a stated desire to see the IB treated on par with the AP, conducted studies on IB perceptions of US university admissions personnel and the transfer credits awarded for IB courses, as they both believed that the IB was not getting due recognition because of universities' lack of understanding of the IB. Interestingly, they also note the point made by earlier authors, namely that more students in the US take individual IB courses than the full diploma, showing that while perceptions of universities might have changed, student preferences have not.

The IB organization also regularly issues reports on perceptions of admissions officers which are published on their website. For example, on June 25, 2015, in reference to a report by ACS International Schools on its survey of university admissions officers at 80 UK institutions, the organization issued a press release, University Admissions Officers suggest DP as best preparation for workplace and university, which stated that this was the 10th annual report to show such results and that the views of admissions officers had remained constant for over a decade (IBO, 2015b). The report also noted that the study was conducted in partnership with the IB organization. On October 11, 2016, another press release, University admissions officers favour DP over A Levels was issued, referring to the $11^{\text {th }}$ annual report on UK admissions officers' ranking of three exam systems against factors such as "encouraging independent inquiry”, “encouraging citizenship", and "developing self management skills". According to this report, the DP ranked at the top and "all UK university admissions officers surveyed agreed that being able to think and learn independently is the most 
important element in students being ready and equipped to thrive at university" (IBO, 2016b). The press release reports that "all surveyed" were of the view that, compared to the DP, some qualifications are "single minded" and do a poorer job of developing other qualities valued by universities (such as independent study, time management, essay writing and referencing). The press release further adds that

A high proportion of admissions officers (63 percent) say they would accept a DP student even if they hadn't completed every aspect of the programme because they appreciate the value of the all-round academic education that the DP offers, and they value the contribution these students will make to the university course. (IBO, 2016b)

The results presented in the press release are then legitimized by reference to another official body in the UK, the Higher Education Statistics Agency (HESA):

The results of the report are supported by figures released earlier this year from a study conducted by the Higher Education Statistics Agency (HESA), which revealed that DP students have a 57 percent greater likelihood of attending one of the top $20 \mathrm{UK}$ universities than their peers who study A Levels. (IBO, 2016c)

However, the HESA report was itself produced for the IB organization (HESA, 2016; IBO, 2016c). In other words, one IB-affiliated report makes claims about perceptions and comparisons and than cites another IB report to support its claims. This type of intertextual "bootstrapping" is evident in much of the literature that is generated by the IB, where opinions and anecdotes about the IB expressed in one document are then cited as "evidence" of the DP's superiority, thus constructing an image of a curriculum superior to all others.

For example, although there are issues in linking student performance to participation in the IB (e.g., Green \& Vignoles, 2012; May et al., 2013), studies purporting to show such causal links continue to be done and cited, leading to advantages and characteristics being associated with IB students. Berkey (1994) cites Sjorgen and Vermay (1986), who examined records of three groups of students at one college in the US: an AP 
group $(\mathrm{n}=64)$, a French Baccalaureate group $(\mathrm{n}=18)$, and an IB diploma group $(\mathrm{n}=15)$.

Based on this study, the authors identified six advantages that IB students have "over students who have studied under less demanding programs” (Berkey, 1994, p. 26).

According to the authors, not only do IB students have these advantages, secondary schools also benefit by establishing a reputation for sending better students to universities (see also Torre-Halscott, 1992, for a list of IB student characteristics).

However, an earlier study is far less definitive in ascribing higher levels of academic performance to IB students. Grexa (1988) charted the progress of 100 students divided into three groups at the University of Virginia - AP, IB, and neither - and found it was reasonable to say that IB students performed "at least as well as their counterparts from the same or other schools that do not offer the IB" (p. 5). What is noticeably absent in this study is results showing that IB students outperformed other students.

An important aspect that tends to get overlooked in comparisons between students enrolled in IB programs and those who are not is that there are often strict admission criteria for entry into IB programs, with students required to be high academic performers as well as skilled in other extracurricular aspects. As such, students who gain entry into the IB are already high achievers. As mentioned previously, this point was noted by the IB organization in its study of IB students in Canada.

The issue of self-selection of students is often found in the literature, but tends to get mentioned and then brushed aside (e.g., Tarc \& Beatty, 2012) or ignored (e.g., the IB organization rephrasing Cambridge (2008) on this point). The repeated claim that IB students are high performers is thus one that seems to have become a stereotype. In Spahn's (2001) study of the IB in one school, teachers remarked that the students came into the 
program already motivated, and that "King Kong could teach these kids. You give them a little bit and they run with it" (p. 97). Thus, despite evidence that students come to the program already exhibiting particular qualities, these tend to get ascribed as if they are the result of participation in the IB.

\section{The view from elsewhere: Eurocentricity of the IB}

Another perception of the IB, particularly relevant for the present study, is that the curriculum is Eurocentric, and thus seems irrelevant or inappropriate for non-European parts of the world. This criticism has been raised by a few early researchers. For example, Uy (1988) points to the three languages (English, French and Spanish) of the IB as evidence of its Eurocentric bias, and argues that it is elitist and presents a monolithic compartmentalized view of the "third world". Furthermore, she argues that the IB is presented as "excellence" rather than "internationalism" in national schools, where students opt for individual courses rather than the diploma, thereby defeating the holistic purpose of the IB.

Drone (1988), in examining the IB in relation to the Kenya curriculum, also argued that the IB was Eurocentric (rather than international) and needed to incorporate African content. Her study showed that IB students entering the University of Nairobi were deficient in knowledge requisite for the Kenyan context, and suggested that Kenya be invited to advise the IB on curricular reform. Drone also states that there is "great discrepancy between what the IB purports and what it actually does" (p. 39) and that it is "outdated and not as effective as when it began" (p. 9 \& 24), since when its original plan was formulated “independence for most African countries...was a dream (p. 9). She also remarks on the tone of academic superiority and arrogance (p. 19). According to Drone, the communication she 
had with Renaud revealed that in 1978-79 the IB had tried and failed to gain entry into

Kenyan national schools for two reasons: the high cost of the program; and because the "IB was irrelevant to the needs of the national schools of Kenya” (p. 48).

Bunnell (2016) reports that the lack of IB activity in Africa was a major disappointment for Alec Peterson, who believed that it could prove valuable to countries of the "Third World" as it would be free of any colonial overtones (p. 183; Peterson, 1972, p. 105). Mayer (1968) offers a different view, stating that educational leaders in developing countries were "not in the least interested in a program which will make more efficient the selection of students to go off to American and European universities” (p. 231), and that those who do wish for educational change resent the European tie more than the colonial one (p. 234). According to Bunnell (2016), the IB's mode of operation in Africa has not changed since the 1970s, largely existing in private international schools catering to a British or American expatriate community. Furthermore, the numbers of schools offering the IB are spread out such that 12 countries have only one IB school while "half the continent remains an IBDP wilderness" (Bunnell, 2016, p. 186). A very different picture was presented by the IB organization in a recent press release proclaiming "40 years of the IB in Africa", suggesting greater success in that part of the world than appears in the literature:

As IB presence in Africa approaches its 40th anniversary in 2017, we take a look at developments across the continent and the growing appetite to offer an IB education. Since the first school in Africa offered an IB programme in 1977, at the International School of Moshi in Tanzania, 128 IB programmes are now offered by 80 schools in 28 countries across the continent - that's an IB World School in more than half of the 54 African countries. (IBO, 2016d)

Given the number of countries and the population in the continent (1.2 billion), it is difficult to see these figures as indicators of success. For example, the number of IB schools in Africa is less than $2 \%$ of the global total. 
Hahn (2003) also found elements of colonial discourse present in her analysis of IB documents, where a non-academic emphasis (vocational, agricultural, technical) associated with a lower educational standard appeared to be directed towards developing countries. According to Hahn, the theme of "lower standard" was only mentioned with regard to the “Third World” (p. 109).

Hayot (1984) examines the IB in France on three different levels: international, national and local. At the international level, she discusses the IB in relation to the "Third World" and criticism of its Eurocentricity. On the national level, i.e., in France, it is also criticized for being elitist. And on the local level, i.e., in three Paris schools, government funding plays an important role. Hayot's study provides an important window into the IB in France, where it has had relatively little success, and the analysis of the IB within its larger social, historical and political context provides important insights into how the construction of perceptions of the IB is multifaceted.

\section{Summary}

This chapter has looked at development of the IB from its beginning in the 1960s to the present day to highlight some of the discrepancies evident in the literature. Of particular note was the contested histories of the IB, the conflation that seems to be prevalent, where different IB programs get grouped together under a single IB label, thereby making it appear as a unified coherent whole, and the growth of the IB in the US and Canada. The next chapter gives some additional detail on methods used in the present study. 


\section{Chapter 4}

\section{Additional notes on methods used in articles}

This chapter describes the research design of the four articles presented in the following chapters and the research questions the study sought to address. Each article includes information on the methods used at that stage of the research. To avoid repetition, this chapter simply provides some additional detail on the research methods that was not included in the articles themselves.

\section{Overall research design of study}

The research design of the present study is multimethodical and sequential, as reflected in the four articles. Each article represents a different stage in the research process, with the results of each stage informing the next. The four stages are: (i) survey of perceptions of a target population in Ontario; (ii) survey of perceptions of a target population in Canada; (iii) newspaper corpus representing perceptions of the general population in Canada; (iv) in-depth analysis of a smaller random sample from the newspaper corpus. The research questions guiding the study as a whole were:

1. How is the IB perceived and represented in Canada?

2. What are the implications of this perception and representation? In addition to these overarching questions, each article also sought to answer a research question specific to that stage (see Table 4.1). Based on the results of the Ontario survey (Chapter 5), the study was expanded to include all 10 provinces in Canada (Chapter 6). Results from this nationwide survey indicated the importance of extending the study beyond universities to the general population (Chapter 7). The values and assumptions associated with International Baccalaureate (IB) found in this stage led to the detailed analysis, in a smaller 
random sample, of the discursive strategies evident in the construction of $I B$ as a positive label (Chapter 8). The two parts of the research design are described in more detail below.

\begin{tabular}{|l|l|l|}
\hline Articles & Research questions for each article & Data/Tool \\
\hline Chapter 5 & $\begin{array}{l}\text { How do Ontario university admissions personnel } \\
\text { view the IB? }\end{array}$ & $\begin{array}{l}\text { Online survey }+ \\
\text { interviews results }\end{array}$ \\
\hline Chapter 6 & $\begin{array}{l}\text { How do Canadian university admissions personnel } \\
\text { view the IB? }\end{array}$ & $\begin{array}{l}\text { Online survey }+ \\
\text { results }\end{array}$ \\
\hline Chapter 7 & $\begin{array}{l}\text { How does the Canadian public view the IB? } \\
\text { What values and attitudes are associated with IB? }\end{array}$ & $\begin{array}{l}\text { Specialized corpus } \\
\text { AntConc }\end{array}$ \\
\hline Chapter 8 & $\begin{array}{l}\text { How is the dominant view of IB discursively } \\
\text { constructed? } \\
\text { What are the implications of this representation? }\end{array}$ & $\begin{array}{l}\text { Specialized corpus } \\
\text { Sketch Engine }\end{array}$ \\
\hline
\end{tabular}

\section{Table 4.3: Specific research questions}

The research design divides into two parts according to the two different populations investigated, i.e., university admissions personnel and the general public. While the overall research design continued to use mixed methods by combining both quantitative and qualitative analyses of the data at each stage, different tools and techniques were used in each of the two parts. In the first part, the research used a two-phase explanatory sequential design (Creswell \& Plano Clark, 2011): a first phase involving the collection and analysis of quantitative data, followed by a second qualitative phase to help explain the results of the first phase. In this way, it was possible to obtain both a general and a detailed understanding of the issue.

First, quantitative data was collected through an anonymous online survey and analyzed. Second, qualitative data was obtained through follow-up interviews with interested respondents and analyzed with a view to providing more depth to the survey responses. To an extent, this first part replicated previous studies conducted on perceptions of the IB 
among university admissions personnel in the UK (Jenkins, 2003) and Australia/New Zealand (Coates et al., 2007). In the second part, the research followed a corpus-based CDA/DHA design involving a specialized IB media corpus and software tools to conduct quantitative and qualitative analyses. Together, the two parts provided a means of triangulation, i.e., multiple types of data and analyses are brought to bear on the subject being investigated (Baker, 2006; Wodak, 2001).

\section{Part 1: Perceptions of university admissions personnel}

Detailed presentation of the methods used for the first part of this study can be found in Chapter 5 and Chapter 6. Here I present details on the process of research ethics clearance that was not covered in those articles due to space limitations, as well as additional information on data collection and analysis.

\section{Research Ethics Board (REB) clearances}

In order to deploy the online survey to university personnel, clearance was first required from Carleton University's Research Ethics Board (REB), which was received on December 20, 2013 after the submission of a 25 page application detailing the research design, methods, instrument, informed consent forms and invitations, potential risks, length of time commitment, etc. Furthermore, to recruit participants directly from other institutions across the country, it was necessary to seek clearance from their own REBs (a total of 97). However, if the survey were simply advertised on national and regional listservs, such clearance from other institutions was not required.

For this reason, the survey was posted to a national listserv on January 9, 2014, which proved to be unsuccessful as there were no responses. The survey was then posted to 
a regional listserv on February 4, 2014. Based on this advertising and word of mouth, 19 usable responses from eight universities in Ontario were obtained. The survey was live until March 8, 2014. In addition to those responses, two one-hour semi-structured interviews were conducted with respondents who indicated an interest in discussing the IB further. These were done face to face, recorded, and transcribed.

Results from the Ontario survey (see Chapter 5) made it important to expand the research nationwide to all 10 provinces. Universities were selected from the Universities Canada website (formerly AUCC) for each province, to include only those that were English-medium, and to exclude any affiliates (colleges or religion-based) as well as specialized institutions (e.g., art and design). From a total of 55 universities that met these criteria, 54 were contacted regarding REB clearance procedures. Contact information for one university could not be located but it managed to participate in the survey nevertheless and is included in the total number.

The procedure for obtaining permission from an institution's REB first required an email of enquiry to the appropriate person identified on the website. This was not always obvious and required several attempts via emails to various people until the right person was located. In two cases, there was no reply to repeated attempts and those institutions had to be excluded.

The initial enquiry explained that I was an external researcher with clearance for the project from my own institution and was seeking permission to contact their staff to participate in an anonymous online survey. I asked for information on what I would need to do in order to obtain such permission from their REB. The response from each university was different, which was surprising given that all are signatories to the Tri-Council Policy 
Statement: Ethical Conduct for Research Involving Humans (TCPS2, 2010), and thus abide by the same principles, one of which is to encourage the sharing of information in order to reduce the duplication of effort. Responses were generally of three types: (1) no permission was required as only publicly available information (i.e., contact details from the institution website) would be used; (2) an application was required but would be expedited based on the review and approval of the Carleton University REB clearance; and (3) a full application was required (similar to the 25 page application for Carleton's REB), which upon receipt was scheduled for their next Board meeting (sometimes several weeks later). A number of institutions also required a certificate of completion for the TCPS2 Course on Research Ethics as part of the application. This is an online course that takes approximately 3-4 hours to complete, at the end of which a certificate is issued. It is worth noting that obtaining REB approval did not mean that staff at that institution were obliged to participate in the survey, which was strictly voluntary. It simply allowed invitations to be sent directly to individuals at that institution. Given the time and effort required for each REB clearance, it was a source of some disappointment in those cases that resulted in no response.

Of the 54 universities contacted, final REB approval was granted by 48 . Of the remaining six, one institution refused to participate in the study (but did indicate an interest in receiving the results) and another required that the research be supervised or "signed off" by one of its own faculty members, despite the researcher not being a student there. Since this was not possible, the institution had to be excluded. Two universities did not reply, and two required extensive applications and therefore were not pursued further.

Additional challenges arose during the process, both before and after clearance was obtained. For example, in three cases, after several months of communication back and 
forth around REB application requirements, when permission was finally granted and email invitations were sent, one admissions department declined to participate and the other two failed to respond. In another case, the head of the office responded to the survey by saying that one such response would be sufficient, participation of others in the office was not required and therefore, further invitations should not be sent. One institution initially refused permission because of a concern that the survey platform being used was US-based, which meant that data storage would not be protected to Canadian standards. This was not the case, however, and after a series of email exchanges providing details from the survey platform company, the institution was finally reassured and granted permission. One institution required submission of all documents in hardcopy format sent by regular mail in addition to sending pdfs by email attachment, and another required the signing and witnessing of a separate confidentiality agreement in addition to the usual clearance procedures.

A further complicating factor at this time was the transition at several institutions from email attachments to an online portal system for ethics applications. This required an additional level of communication with the institutions' computing services departments to obtain usernames and passwords to access the systems such that the application could be submitted. Once access was granted, all documents had to be uploaded onto these systems. In a few cases, forms were rigid in the information they required and would not allow moving to another section until all required fields were completed. In other cases, the information required was not relevant to an external researcher (e.g., name of faculty member or department) and, therefore, a workaround had to be found (sometimes in consultation with the REB contact person), which was then explained either in an email or in 
a free text box provided. Furthermore, the signature of a supervisor was also often required, which meant printing the application forms, getting the signature, scanning and submitting the signed forms.

All REB clearances obtained were valid for a set period, ranging from 3 months up to one year. As with the application process, the requirements governing continuance, such as annual reports on progress, further renewal application, or closure of research, differed at each institution. Since each institutional clearance had been obtained at different times depending on the length and type of procedure involved, such reports were an ongoing concern as notices of expiry and demands for reports came in from the various institutions. Once these were submitted, a new certificate of approval was issued, detailing the project number and length of clearance, with a further expiry date set. In addition, all external REB documents had to be submitted to the Carleton REB in the annual report required to renew clearance for another period (e.g., the first report was 70 pages, comprising emails and/or clearance certificates from all external REBs received up to the time of submission). The entire process for conducting this nationwide survey (i.e., obtaining permission, deploying the survey, processing responses, keeping all the REB clearances open and valid by completing individual institutional requirements, etc.) took a period of three years (February 2014-May 2017) from start to finish.

\section{Data collection and analysis}

As discussed above, for the Ontario study, 19 responses from eight universities were received. In addition, one-hour individual interviews were conducted with two respondents. These were recorded with the participants' permission, transcribed and analyzed for recurring themes. Although the number was too small to serve as a means of triangulation 
(as noted by one of the anonymous reviewers), the two interviews provided a valuable supplement to the survey results. Details for the Ontario study are reported in Chapter 5: Perceptions of the International Baccalaureate (IB) in Ontario universities (Fitzgerald, 2015).

For the Canada-wide study, approximately 550 individual email invitations were sent to admissions personnel at 48 institutions using contact details obtained from institutional websites. In some cases, these were not clearly identified on the website, and therefore emails were sent to people assumed to be in those roles, based on reading the descriptions about the services offered by departments, such as Registrarial or Student Services. In such cases, for the most part, if the wrong person had been contacted, they would either let me know and point me in the right direction or would forward the email on to the appropriate department.

Due to the nature of REB clearance procedures, survey data was obtained intermittently over a long period as permissions were obtained and invitations sent. The survey was live until February 1, 2016. Responses were collected as they came in and imported into Microsoft Excel for analysis. Only those responses that were complete were included in the analysis. Once cleaned and sorted, there were 78 participants from 40 institutions in 10 provinces.

Unlike the Ontario study, the semi-structured interview component of the research design had to be abandoned due to lack of uptake (only three individuals expressed an interest) combined with the time it would have taken to obtain additional REB clearance from each of the three institutions. Instead of interviews, the open-ended comments provided by 63 participants were used for qualitative analysis. Details of this study are 
reported in Chapter 6: Perceptions of the International Baccalaureate (IB) in Canadian universities (Fitzgerald, in press).

\section{Part 2: Perceptions of the general public}

The second part of the study shifts from the specific context of university admission to discovering how the general public in Canada perceives the IB. For this purpose, newspapers were examined as a place/space in which the IB is constructed by different segments of society, from parents and students to schools and governmental representatives.

\section{Data collection and corpus design}

To gain insight into the dominant perceptions of the IB in Canada found in the country's newspapers as an unsolicited window into public opinion (Mautner, 2008), a specialized corpus was created. A preliminary search of existing corpora showed that none provided enough references to the IB in the Canadian context. Readily-available large corpora (e.g., COCA, BNC) were dominated by the US, UK and Australia, and even the corpus of Canadian English (Strathy Canada, 50 million words) contained only eight references to the IB. Thus, a specialized corpus on Canadian perceptions was necessary (Baker, 2006).

In practical terms, obtaining data for a specialized newspaper corpus is relatively unproblematic nowadays, since most such texts already exist in digital form and can be accessed through a variety of databases. To allow for the broadest possibility of voices/perspectives, i.e., maximum representation of public attitudes and perceptions, all types of newspaper texts were included in the corpus, such as letters to the editor, opinion

pieces, obituaries, news and sports. In addition, only articles from Canadian sources 
(national, regional, local) that were found on two databases (Canada Newsstand Complete and LexisNexis Academic) using the search terms international AND baccalaureate, ib AND diploma OR student were selected. The aim was not to examine the newspapers themselves (e.g., in terms of their political stance and/or readership) but rather to gain a window into the way the IB is viewed by different social domains as represented by the different types of newspaper texts.

Articles from the two news databases were collected in two stages, first from Canada Newsstand Complete (CNC) and then from LexisNexis (LN). It is important to note that each news database provided articles not available in the other (e.g., community newspapers were available on $\mathrm{CNC}$ but not on $\mathrm{LN}$ ). For this reason, both databases were required for maximum coverage.

\section{Canada Newsstand Complete}

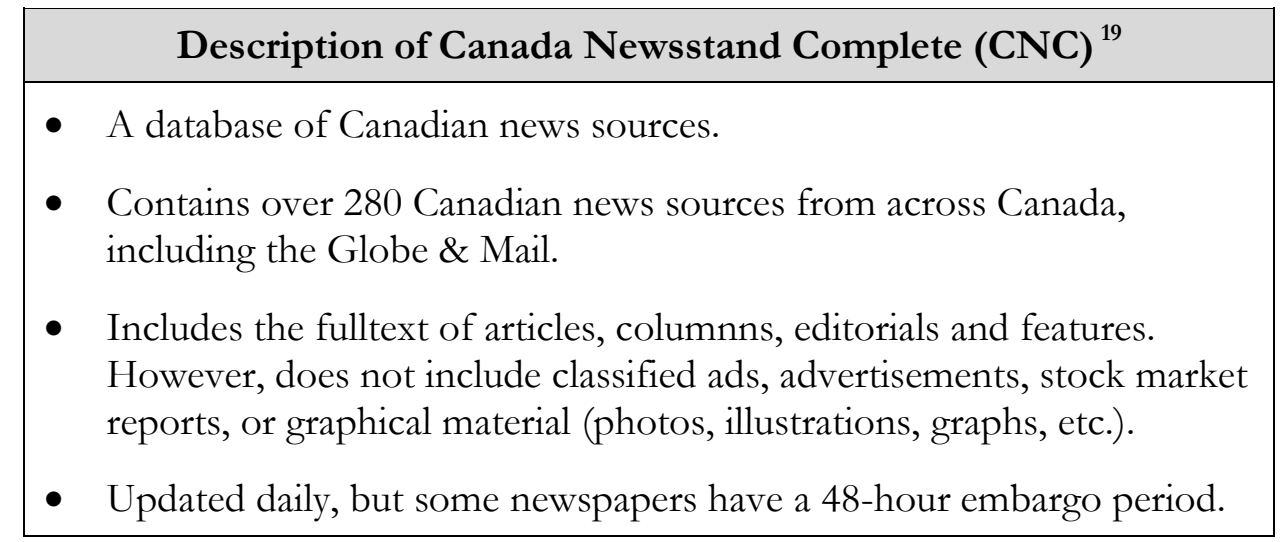

A search was conducted on international baccalaureate (955) and ib and diploma or student (467). Articles were downloaded for all newspapers listed in this database and saved according to individual newspaper in both pdf and txt formats. For example, all articles found for Ottawa Citizen were downloaded as a single pdf file and a single txt file. Once all

\footnotetext{
${ }^{19}$ https://library.carleton.ca/find/databases/canadian-newsstream
} 
the articles had been downloaded, they were then grouped by province. Articles were not sorted by genre (e.g., editorial opinion, letters, features, etc.; see Baker et al., 2013) but grouped together according to newspaper since the focus of the study was to establish overall trends rather than those found in specific contexts. However, a detailed record was created for each article to help facilitate future analysis based on individual articles (e.g., sorting by year, province, newspaper or section).

\section{LexisNexis}

\section{Description of LexisNexis $(\mathrm{LN})^{20}$}

- Provides access to news, business and legal information.

- LexisNexis Academic provides searchable access to a comprehensive spectrum of fulltext information from over 6,000 sources, selected to meet academic research needs, including:

- News: National and regional newspapers, wire services, broadcast transcripts, international news, and non-English language sources

- Law: U.S. Federal and state case law, codes, regulations, legal news, law reviews, and international legal information; Shepards Citations for all U.S. Supreme Court cases back to 1789

- Business: Business news journals, company financial information, SEC filings and reports, and industry and market news

The search through LN was more targetted than the one through CNC. Despite its name, $\mathrm{CNC}$ was not complete and, therefore, once newspapers were found on $\mathrm{CNC}$ they were also searched for on LN. For example, having obtained the result from $\mathrm{CNC}$ for Prince Edward Island (PEI) (Charlottetown Guardian), a search was then conducted on this particular source to ensure the greatest number of articles possible were included in the corpus. In other words, a wide net was cast on the Canada news database, followed by a more targetted search of individual news sources through LN. Articles found there were also downloaded in

\footnotetext{
${ }^{20}$ https://library.carleton.ca/find/databases/lexisnexis-academic
} 
both pdf and txt formats. At times, full text articles were not available from $\mathrm{CNC}$, only abstracts. LN proved to be very useful in filling in these gaps. In addition, the $\mathrm{CNC}$ archives began at 1981 whereas LN went back to 1977, which was very important for information on how the IB was viewed in the early days before it became so well known. Combining CNC + LN with specific search was thus necessary to obtain maximum yield.

In some cases, full text articles were not available through either database. These were obtained either by searching the newspaper website itself (which had only limited success as papers tend to be behind a pay wall and have only a small number of articles available for view) or by request through the Carleton University library. The latter were scanned copies of the newspaper article which then had to be converted into a txt file through optical character recognition (OCR) or by manually typing the text.

The numbers of newspapers differs markedly from province to province. For example, Alberta has four newspapers, PEI one, while BC has 48, and Ontario and BC have a large number of community papers whereas others have a smaller number of papers but with broader coverage (see Figure 4.1). This provided an additional layer of information, with the different numbers of newspapers available in different provinces indicating a more restricted source of information in some cases than in others. The large number in BC resulted from community newspapers which focussed on particular towns, such as Abbotsford or Kamloops. While the difference in numbers is not relevant for the 


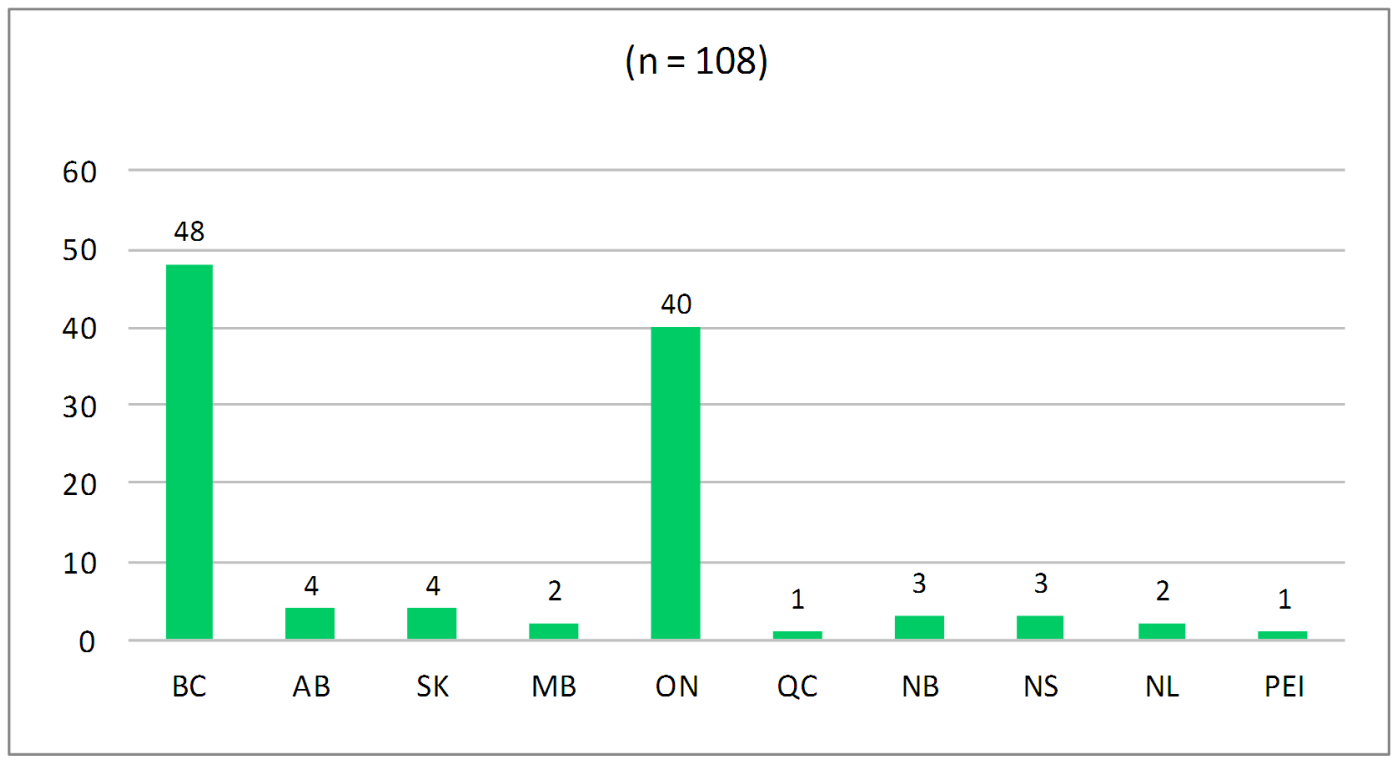

Figure 4.1: Number of newspapers in the IB media corpus, by province

present research study, which looks at the corpus as a whole, such variation would need to be borne in mind for future research focusing on provincial comparisons, and caution would need to be exercised in drawing conclusions. For example, the Quebec subcorpus consists of only one (English) newspaper, which cannot be claimed to be representative of that province. As well, the PEI and Newfoundland subcorpora are small and repetitive, providing the same type of information in their few articles (see Figure 4.2 for number of articles per province).

A detailed record was created for each newspaper, indicating important information such as name of newspaper, province, date, title, author of article, and section of paper (e.g., sports, entertainment). This detailed record was crucial in helping ensure that no information was lost, and articles could be accurately and systematically located and referenced. Access to the complete original text was especially important 


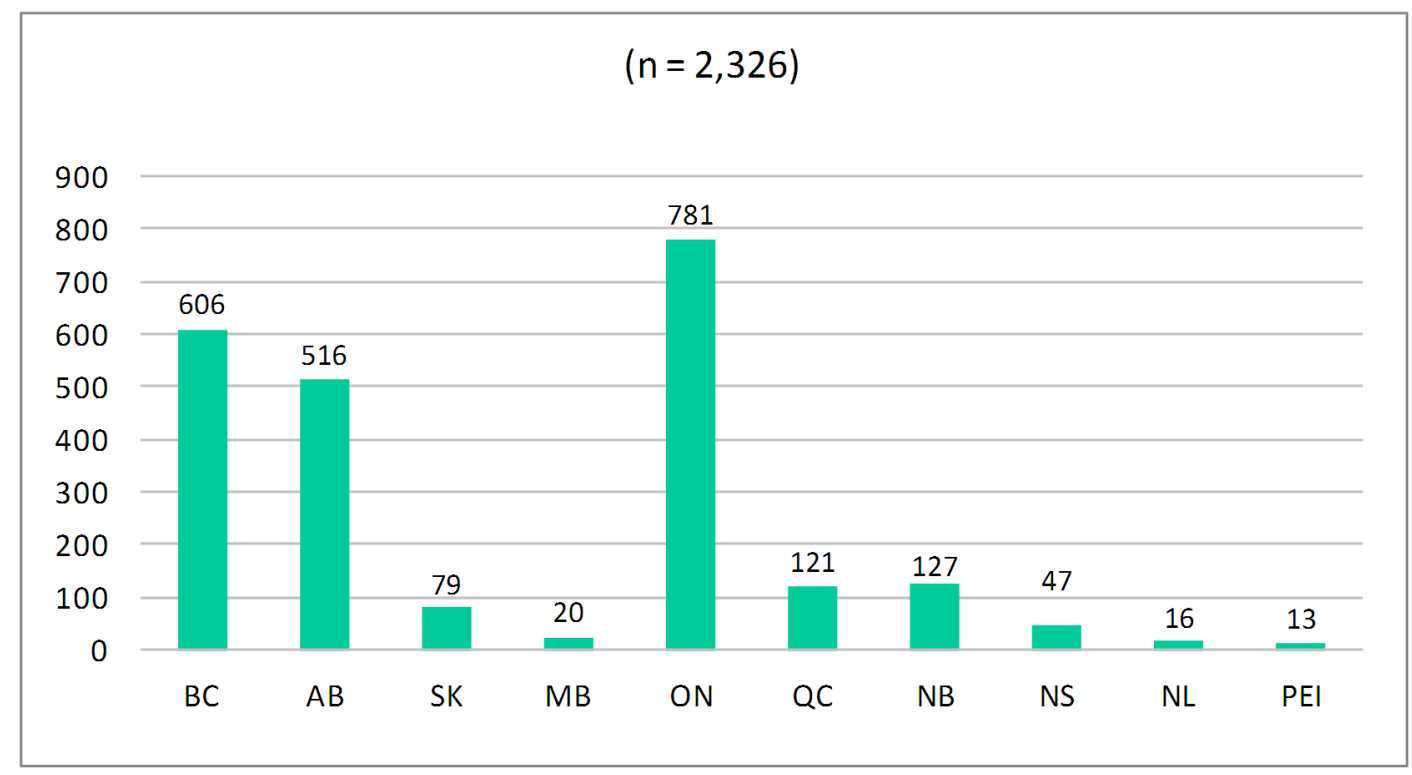

Figure 4.2: Number of articles in the IB media corpus, by province

when data were cleaned and some information deleted (e.g., date of article or name of author). The record also indicated which database the article came from.

When all the articles had been collected, i.e., maximum representation as provided by the two databases had been achieved, all the articles were read in order to (i) exclude repeats (e.g., the same article appearing in early and final editions of a newspaper; the same article appearing in different newspapers or in both databases); (ii) exclude non-IB articles that were pulled up through search terms (e.g. section 1B of a newspaper or "ib" as a person's name); (iii) clean the data by removing non-relevant material (e.g., name of newspaper; article number, byline, section, number of words, abstract, load date, language, copyright; see Baker 2004, 2013). The title and captions were retained; (iv) correct misfiled articles due to newspapers with similar names (e.g., BC and Ontario both have newspapers titled The Record which are unaffiliated); (v) keep a detailed log by newspaper of all articles included in the corpus to ensure that cleaned-up text files could be linked back to original articles; and (vi) correct errors in the data, e.g., French accents or hyphens that came out as spurious 
characters, typos, and errors in the OCR-converted texts (e.g., IB read as 18). By the time the IB media corpus was assembled and ready for analysis, I had "got to know my data" (Kilgarriff, 2012), an important benefit associated with creating a specialized corpus. As discussed by Baker (2006), building a corpus from scratch provides the researcher an important means not only to become familiar with the data, but also to notice patterns that may emerge as the corpus gets built. In this way, knowing what is in one's corpus aids analysis and also helps to mitigate concerns about the suitability of corpus data for discourse analysis (i.e., that it is decontextualized).

All types of articles containing the search terms were included in the corpus. I decided to include community events and other articles that only mention the IB in passing (based on Baker et al, 2013), as this allowed for a wider view on how the IB is represented even when it is not the focus. This led to documenting the diverse sections of the newspapers in which the IB was mentioned, such as crime, sports, letters, real estate, health, obituaries, and financial, as well as other more expected ones such as education and news. It is important to keep in mind that while this IB media corpus is maximally representative, it contains only those articles that get picked up by the two databases and constitutes a realworld limitation on the data.

Selecting all the articles provided by the two databases avoided the possibility of selection bias, i.e., inadvertently focussing only on articles that suited my purposes. In addition, selecting all the papers - national, regional, local and/or free community papers allowed for a greater unsolicited window into public opinion (Mautner, 2008), not just powerful elite sources but parents, students, and other members of the public writing in through letters and opinions. As such, the IB media corpus is varied, and the analysis focuses 
not on individual papers but rather on the entire corpus as a way to understand the dialectic, i.e., "constitutive effect of discourse" (Mautner, 2008, p. 32) and the shaping of shared views. The final IB media corpus consists of the following:

\section{Summary of IB Media corpus:}

- Total number of articles: 2326

- Total number of words: $1,521,796$

- Total number of newspapers: 108 (10 provinces)

- Range: 1977-2016

- Search conducted February 2016

The IB media corpus contains articles ranging from 1977 to February 2016. The number of articles by year is presented in Figure 4.3.

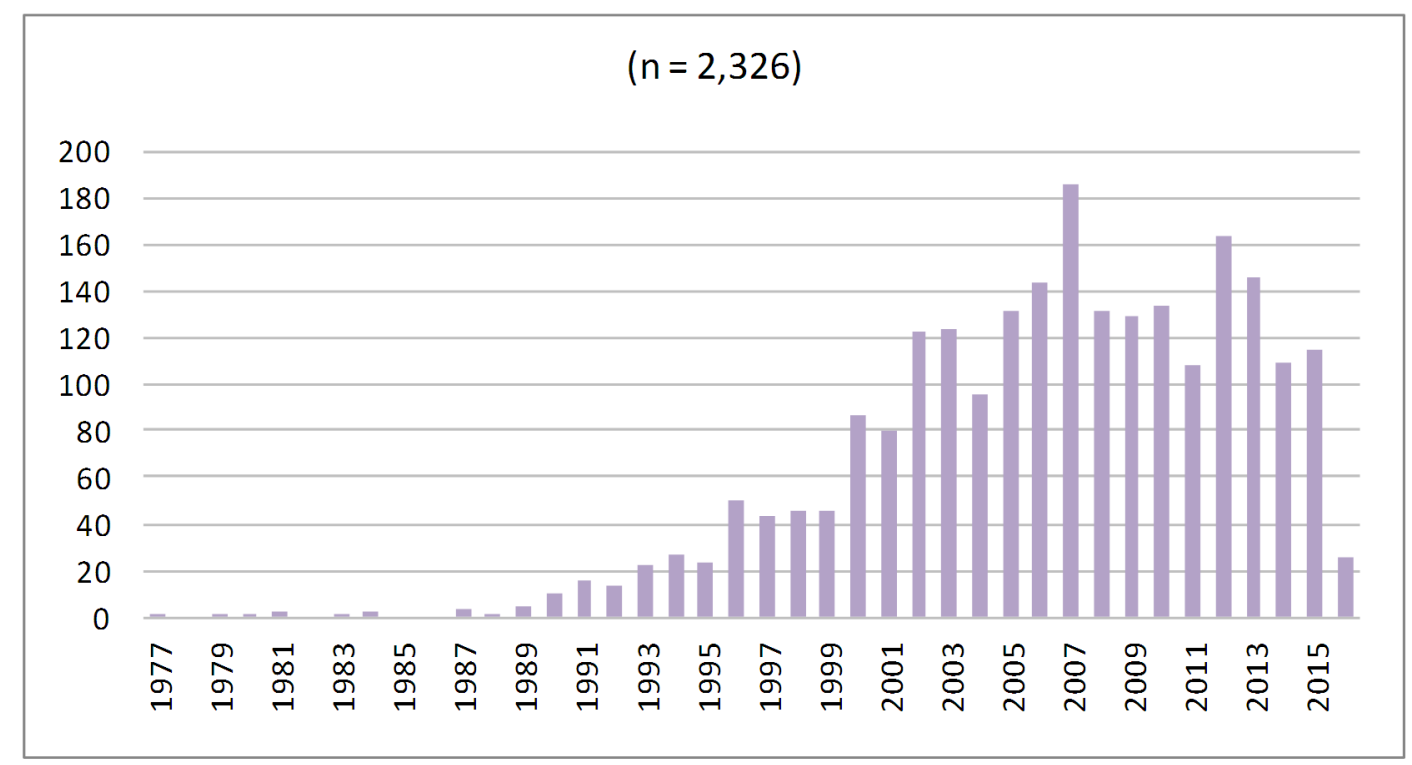

Figure 4.3: Number of articles in the IB media corpus, by year (1977 - Feb. 2016) 


\section{Corpus tools}

The importance of corpus tools in the analysis has been discussed by Anthony (2009, 2013) and Taylor (2010). The choice of tool may depend on the type of information the researcher wishes to extract from the corpus data, as different tools vary in terms of the affordances or functionality they provide, or it may simply be that the tool is freely available and easy to use. The development of corpus tools since the 1960s is described by McEnery and Hardie (2012) as consisting of four generations, with the popular WordSmith Tools (Scott, 2017) and AntConc (Anthony, 2014) referred to as third generation. The fourth generation tools were created in response to the limitations of the third, which have difficulty processing the increasingly prevalent larger corpora of billions of words. Furthermore, issues of copyright make it difficult for researchers to obtain and store data on personal computers. Therefore, fourth generation corpus tools are web-based and accessed through different online platforms, for example, Sketch Engine (Kilgarriff, et al., 2014) and the Corpus of Contemporary American English (COCA; Davis, 2015).

To explain the relationship between the corpus data and the corpus tool, Anthony (2013) provides a helpful analogy to astronomy and the way different tools allow us to see the same phenomenon with different levels of detail, e.g., the view of Saturn as observed by (i) the human eye; (ii) through binoculars; and (iii) the Hubble telescope. Each tool provides very different types of information on the same object. The level of detail required depends on the research questions. More is not necessarily better and might even be considered “overkill” (Anthony, 2013) for the purposes of a simple analysis. For the present research, AntConc, COCA (see Chapter 7), and Sketch Engine (see Chapter 8) were chosen not only because they provide different functionalities, but also as a further means of triangulation, as 
different tools offer different windows into the data, allowing for a more complete picture (Taylor, 2010).

\section{Summary}

This chapter has presented some additional details on research methods used in the present study. The next four chapters present the results of this study, in the form of four separate articles. 


\section{Chapter 5}

Perceptions of the International Baccalaureate (IB) in Ontario universities

A fully edited, peer-reviewed version of this article was first published by the Canadian Journal of Education, 2015, Volume 38, Issue 3, Page 1 to Page 34. 


\title{
Perceptions of the International Baccalaureate (IB) in Ontario Universities
}

\author{
Saira Fitzgerald \\ Carleton University
}

\begin{abstract}
This article presents the results of the first phase of a research project on perceptions of the International Baccalaureate Diploma Program (IBDP) in Canadian universities. Establishing explicit university recognition policies for IBDP students has been an ongoing task for the International Baccalaureate Organization (IBO), which conducted two studies on university perceptions of the IBDP in the UK (2003) and Australia/New Zealand (2007). The present study replicates these studies in the Canadian context, to discover how admissions officers in Ontario universities perceive the IBDP in relation to other curricula. Preliminary results reveal a high degree of uniformity in responses, consistent with the previous studies. The IBO is indicated as being the primary source of information, suggesting that it plays an important part in forming perceptions of the IBDP.

Keywords: International Baccalaureate Diploma Program, IBDP, university recognition, admissions officer perception, comparative education, international education
\end{abstract}

Canadian Journal of Education / Revue canadienne de l'éducation 38:3 (2015) C) 2015 Canadian Society for the Study of Education/ Société canadienne pour l'étude de l'éducation

www.cje-rce.ca 


\section{Résumé}

Cet article présente les résultats de la première phase d'un projet de recherche sur la perception du Programme du diplôme de l'IB (PDIB) dans les universités canadiennes. Établir des politiques de reconnaissance universitaire explicites pour les étudiants inscrits dans ce programme demeure une tâche permanente de l'Organisation du Baccalauréat International (IBO), qui a mené deux études sur les perceptions qu'ont les universités du PDIB au Royaume-Uni (2003) et en Australie / Nouvelle-Zélande (2007). La présente étude reprend ces travaux dans le contexte canadien afin de découvrir comment les responsables des admissions dans les universités de l'Ontario perçoivent le PDIB par rapport aux autres programmes. Les résultats préliminaires révèlent un degré élevé d'uniformité dans les réponses, en accord avec les études antérieures. L'IBO est répertorié comme la principale source d'information, ce qui suggère qu'il joue un rôle important dans la formation des perceptions du PDIB.

Mots-clés : Programme du diplôme du baccalauréat international (PDIB), reconnaissance par les universités, perception des responsables des admissions, éducation comparée, éducation internationale 


\section{Introduction}

College-admissions officers at many schools say that...IB [has] acquired the status of [a] backstage pass at a rock concert. Selective universities begin to ask questions if they see that applicants have not taken the tests available at their high school. (Mathews, 2003, quoted in IBO 2007a, pp. 4-5)

The recent growth of the International Baccalaureate Organization's (IBO) International Baccalaureate Diploma Program (IBDP) ${ }^{1}$ as an alternate curriculum within national (publicly funded) schools in Canada, Australia, the United Kingdom, and the United States is well documented (e.g., Bagnall, 1994, 2010; Bunnell, 2011a, 2011b, 2012; Daly, 2012; Doherty, 2009; Paris, 2003; Tarc \& Beatty, 2012; Whitehead, 2005). Also well documented is the scarcity of empirical research supporting the IBO's claims regarding IBDP curricular outcomes (e.g., Hanover Research, 2010; Tarver, 2010; Tarc \& Beatty, 2012). Panich (2001) remarked on the absence of any empirical evidence to support the claims made by the IBO with respect to the IBDP as a preferred vehicle for university preparation:

The kudos for the I.B. Programme and its graduates are abundant and readily forthcoming from anyone who is familiar with the program. However, scholarly empirical validation for the success of its graduates is surprisingly scant. This is paradoxical for a program whose curriculum involves the generation of a research-based paper, the Extended Essay, by every graduating student. It is also an anomaly considering that statistical validation was an area of concern from the earliest days of the organization. (pp. 18-19)

Although studies have been done on particular aspects of IBO programs in the past, and are now appearing with increasing frequency, "there may be concerns about the biases of existing studies because of frequent ties to the IBO itself" (Hanover Research, 2010, p. $11)$.

1 The International Baccalaureate Diploma Program is referred to inconsistently in the literature as "IBDP," "DP," "IB," "IBD," or "IB DP." Here, the diploma program is referred to as "IBDP," except in quotations which have other usage; "IB" is used to refer to the IBO's whole system of education. 
The success of the IBDP depends on its acceptance as a suitable qualification for university admission. In fact, the impetus for the creation of the IBDP was a need "to develop for international schools a common curriculum and examination programme which would facilitate student admission to the university of individual choice" (Renaud, 1991, p. 7). Therefore, one of the IBO's ongoing tasks has been to provide information to universities to get them to establish explicit recognition policies governing IBDP students. To this end, it has produced numerous publications, brochures, conference presentations, and workshops to help university personnel understand the IBDP curriculum by creating a "common language" (Daly, 2012, p. 8). In North America, the IBO created the College and University Recognition Task Force (CURT) in 2003, whose mandate is to assist North American universities in "their strong desire to aggressively attract IB Diploma candidates to their campus" (IBO, 2014a, n.p.). By establishing close linkages with universities, CURT members aim to help "train recruiters, train admission, educate faculty, support policy development" (IBA Regional Council, 2009, p. 6). Universities are assured that by doing so they will not only simplify their recruitment efforts but will attract the best and brightest students to their institutions (Sjogren \& Campbell, 2003).

Of central importance to the IBO in this endeavour has been for the organization itself to obtain a clearer picture of how the IBDP is viewed in relation to other curricula. To this end, the IBO commissioned two studies on IBDP perception in universities, the first in the United Kingdom (2003) and the second in Australia/NZ (2007). Although Canada has been reported to have the largest number of IB schools next to the United States (IBO, 2014b), to date a similar study has not been conducted. The present study aims to replicate the UK and Australia/NZ studies with a view to discovering how the IBDP is perceived in relation to other curricula by admissions officers in Canadian universities.

\section{Theoretical Framework}

The wider research project, of which the present study is a part, uses the discourse-historical approach (DHA) developed and used by Ruth Wodak and colleagues (e.g., Wodak, 1999, 2001; Wodak \& Meyer, 2009; KhosraviNik, Krzyzanowski, \& Wodak, 2012; Richardson \& Wodak, 2009) to explore the historical, organizational, and political dimensions of IBO discourse. The main aim of the DHA is to work "multimethodically

Canadian Journal of Education / Revue canadienne de l'éducation 38:3 (2015) 
[i.e., using different approaches]...to integrate a large quantity of available knowledge about the historical sources and the background of the social and political fields in which discursive "events' are embedded" (Wodak, 2001, p. 65). By contextualizing discourse socially, institutionally and historically, the DHA helps to identify "particular discursive strategies that serve to present the arguments of an individual or a group either positively or negatively" (Richardson \& Wodak, 2009, p. 255). The use of a variety of empirical data, such as texts, websites, conference presentations, policy documents, journal articles, and reports not only help to minimize the risk of bias, but also make visible how different discourses work together to co-construct the image of the IB.

The present study also draws on Berger and Luckmann's (1966) discussion of institutionalization, which "occurs whenever there is a reciprocal typification of habitualized actions by types of actors" (p. 72), in its analysis of the IBDP as a discursive phenomenon. Berger and Luckmann argue that, as human actions are repeated, they develop into patterns, which then come to be perceived as such patterns. Viewed in this way, they come to control the behaviour of the actors and, over time, become institutions: "They cannot be created instantaneously. Institutions always have a history, of which they are the products. It is impossible to understand an institution adequately without an understanding of the historical process in which it was produced" (p. 72). This historical dimension then gives institutions an objective reality, as "unalterable and self-evident" (p. 77), distinguishing "institutionalization" from concepts such as "branding" and "marketing," which tend to occur in the immediate present and are concerned with the production and consumption of goods (see Cambridge, 2002). Further, Berger and Luckmann argue that the relationship between humans and their social product is also dialectical, in the way each interacts and shapes the other. Finally, institutions require "legitimation" (p. 79) through explanations and justifications to the next generation:

These will have to be consistent and comprehensive in terms of the institutional order, if they are to carry conviction to the new generation. The same story, so to speak, must be told to all the children... These legitimations are learned by the new generation during the same process that socializes them into the institutional order. (p. 79)

Together with the DHA, Berger and Luckmann's concept of institutionalization provides a valuable lens through which to understand how widespread, consistent views of the 
IBDP curriculum have been discursively constructed by the IBO through its transmission of the same IBDP story, such that the IBDP has become institutionalized as a superior curriculum in the perceptions of university personnel.

\section{History of the International Baccalaureate Diploma Program (IBDP)}

The IBDP was created by the IBO in 1968 as a program of study aimed at "internationally mobile students preparing for university" (IBO, 2013, n.p.), and was developed as a curriculum to be offered in private international schools around the world to serve the needs of "students disadvantaged by having to live and study abroad" (Bagnall, 1994, p. 5). Since these students were often living in parts of the non-Western world, where it was assumed that the local education was either inferior or inaccessible because of language barriers (Hayden, 1998), such international schools served a practical need by providing students with a "home" curriculum, in their own language, recognized by universities in their own countries.

According to Robert Blackburn (1991), the IBDP was thus created to meet the practical needs of international schools, i.e., to provide students with a single acceptable recognized qualification for university entry:

The IB was created as "an international passport to higher education" and it is clearly important that possession of an IB diploma should secure consideration by the university of a student's choice... It would clearly be intolerable (and unworkable) to offer IB students an excellent international curriculum... at the expense of their university entry ambitions. In fact, the worldwide recognition of the diploma is essential to the international credibility of the project... [emphasis added].

(Blackburn, 1991, p. 23)

Over the past decade, however, in addition to its continued expansion among private international schools around the world (e.g., Lee, Hallinger, \& Walker, 2012), the IB has also become a competitor curriculum at local (i.e., publicly funded state-run) schools in Canada, Australia, the United Kingdom, and the United States (Bunnell, 2011a). In conjunction with positioning the IB as a "national" curriculum, the IBO has devoted much 
effort to the institutionalization of the IBDP at universities in these countries. A key focus has been to determine how the IBDP is perceived in such institutions.

\section{Prior Research on Perceptions of University Representatives}

Given the importance of university admission in the creation of the IBDP, it is notable that the first formal study of how university personnel view this qualification only took place in 2003, in the UK. Based on this, a second study followed in Australia/NZ in 2007. These two studies, both commissioned by the IBO, provided a first look at how the IBDP was viewed by universities in relation to other curricula and whether it was considered suitable preparation for university study. Although both studies stated they were neither evaluating nor validating the IBDP program or actual student performance, they are cited in IBO publications as evidence for IBDP students' university capabilities (e.g., IBO, 2007b). As indicators of the global scope of IBDP research and acceptance, they are also frequently cited by other researchers on the IB (e.g., Tarc \& Beatty, 2012; Daly, 2012; Pook, 2009) and served as the basis for two small-scale studies on US college officials' perceptions of the IBDP (Daly, 2012; Tarver, 2010).

The growth of the IB in Canada is well documented (e.g., Bunnell, 2012; Tarc, 2009; Walker, 2005) and aspects of the program in Canadian schools have been researched (e.g., Bagnall, 1994; Chichekian, 2011; Rowell, 1983; Tarc \& Beatty, 2012). However, an examination of how the IBDP is viewed by admissions officers in Canadian universities has not been undertaken.

\section{The UK and Australia/NZ Studies}

In 2003, the IBO commissioned a survey of perceptions of the IBDP in UK universities, with the stated aims of (1) evaluating the IBDP as a suitable preparation for degree studies in the UK, (2) establishing the IBDP's strengths and weaknesses and the higher education sector's level of enthusiasm for the program, and (3) comparing the IBDP to predominant national qualifications (Jenkins, 2003, p. 7). As the report states, "anecdotal evidence... about the performance of students needed investigation" (p. 13), although it also states that "[t]he project did not set out to measure individual student performance...

Canadian Journal of Education / Revue canadienne de l'éducation 38:3 (2015)

www.cje-rce.ca 
[i]t set out to examine the response to the curriculum" (p. 26). UK universities had been accepting the IBDP since the 1970 s, but only in an ad hoc way, meaning that "IB enthusiasts spent countless hours in negotiations with university authorities countrywide promoting the new qualification" (p. 13), which had led to growing acceptance of the IBDP, as reflected in universities' admission requirements.

In the UK survey, questionnaires were distributed to all 225 institutions of higher education in the UK (Jenkins, 2003, p. 7), ${ }^{2}$ sent specifically to the pro-vice-chancellors (senior administrators). One hundred and twenty-two replies from 71 institutions were received, from which 20 (34 respondents) were selected for follow-up interviews. The survey was not anonymous and listed all institutions, names and titles of participants in the final report. Although results showed that " $97 \%$ were satisfied that DP students were well prepared for undergraduate courses" (p. 27), the study revealed ignorance on the part of university personnel about the IBDP itself. Furthermore, none of the universities included in the interview reports had any formal systems in place to track IBDP student performance, and so were unable to provide information in this regard.

A similar survey was commissioned by the IBO in 2007 for Australia and New Zealand. As with the UK study, a key aim was to determine what university representatives knew about the IBDP and how they viewed it in comparison to other school-leaving qualifications. One important contextual difference from the UK study, however, is that by this time the IBO had established an explicit IB Recognition Policy:

...the IBO encourages universities to develop a Recognition Policy, offers universities secure access to the IBO website, and works with tertiary admissions centres and directly with universities. The secure website contains... an IB recognition policy. The current analysis should be read with this context in mind. (Coates, Rosicka, \& MacMahon-Ball, 2007, p. 5)

The Australia/NZ study was designed to replicate and extend the UK study (Coates et al., 2007 , p. 7). A total of 644 paper survey forms were mailed out to senior academic and

2 According to Daly (2012), at the time of this study, these were called Selecting institutions, which meant that competition for places was high. There were also Recruiting institutions, which were less competitive. Only Selecting institutions were included in this study based on the assumption that IB students would more likely apply to a Selecting university. "All existing institutions of this type in the UK at the time of the study were included in the sample" (p. 56). However, such a differentiating factor was not mentioned in the published report. 
administrative staff: 573 to 40 Australian universities, and 71 to seven New Zealand institutions. A total of 159 usable responses were received: 146 from Australian universities and 13 from New Zealand. Eleven individuals from 11 institutions were selected for follow-up telephone interviews from those who had indicated willingness to be interviewed. Neither institutions nor personnel were identified in the report. While the limitations of this study were made explicit, e.g., that the survey was strictly about the perceptions of university representatives rather than being a validation of the IBDP, the systematic collection of data was seen as "an important move beyond anecdote" (p. 8). As with the UK survey, while the results suggested "a very high level of regard for the IB Diploma" (p. 6), the "study did not examine the actual academic performance of IB students" (p. 8). Furthermore, it also found that

much of what university representatives know about the IB Diploma and IB students is derived from anecdote or personal experience. Respondents frequently noted that their perceptions had been formed by having children or friends' children pass through the IB, or from knowledge of a student or group of students at their institution. A repeated point raised in the interviews and survey was that universities had little or no systematic information on which to base their perception of the IB. (Coates et al., 2007, p. 17)

Based on the findings of this study, the researchers recommended that

[t]he IBO should use a multifaceted approach to help university staff learn about the IB Diploma and IB graduates...providing senior university officials working in chancelleries with summary information and newsletters about the IB... and providing central administrative staff with information about IB operations and characteristics. (p. 17)

A key limitation of both the UK and Australia/NZ studies was that many of the respondents had no direct contact with the IBDP or with IB-related issues. According to Coates et al. (2007), "46 per cent of university representatives in Australasia had no contact with IB students in the last five years, or were not aware that they had such contact" (p. 14).

The present study explores, in the contemporary Ontario context, questions similar to those that informed the UK and Australia/NZ studies. It was designed to replicate 
and extend those studies to discover whether the pattern of responses would be the same. This study, then, reports the results of a survey similar to those conducted in the UK and Australia/NZ.

\section{Method}

This is a mixed method study using a two-phase explanatory sequential design (Creswell \& Plano Clark, 2011): a first phase involving the collection and analysis of quantitative data, followed by a second qualitative phase to help explain the results of the first phase. A mixed method design was necessary because the aim of the study is to provide both a general and a detailed understanding of the issue of Canadian perceptions of the IBDP. In the first phase, the collection of quantitative data was conducted through an online survey. Before submitting the completed survey, participants were asked whether they would be interested in a follow-up interview, with a contact email address provided. The second qualitative phase involved individual interviews with these respondents.

To recruit participants, an invitation to the survey was advertised on the Ontario University Registrars' Association (OURA) listserv due to the length of time required to obtain the Research Ethics Board (REB) clearances from each university necessary for direct recruitment of university personnel. The survey was conducted between January 9 and March 8, 2014, using an online survey tool (FluidSurveys, Chide.it Inc., Ottawa, Canada). Data were exported into Microsoft Excel (Redwood, CA, USA) for validation, analysis, and generation of charts.

\section{Instruments}

Phase 1: Online survey. The survey questions from the UK and Australia/NZ surveys were adapted for the Canadian context, and consisted of three main types: checklist, Likert-scale, and open-ended (Brown, 2001). These were grouped into five broad categories: (1) background information of the respondent; (2) general information about university applications; (3) specific information about IBDP applications; (4) comparison of the IBDP to other curricula; and (5) open-ended question and additional comments. A negative response to any of four questions at the start terminated the survey: informed 
consent, privacy statement, background information, and application assessment. The substantive questions were programmed to be optional; respondents were not required to provide answers to questions on one page before advancing to the next. The survey was field-tested and revised before it was posted online.

Phase 2: Semi-structured interview questions. At the end of the survey, respondents were asked if they were interested in a follow-up interview, with the researcher's email address provided. Based on these responses, two one-hour individual interviews were conducted, and recorded with the participants' permission. Interview questions were not provided in advance in order to try and capture the participant's perceptions, rather than prepared responses with possible "correct" answers (Fontana \& Frey, 2000). Semi-structured questions on aspects of IB admission policy, issues of transfer credit, and general impressions of IB students in relation to others served as a guide and framed the conversation. Recorded interviews were transcribed and analyzed for information that would help explain and add depth to the survey responses. Despite the small number of participants, the interviews provided a valuable supplement to the results from the survey.

\section{Participants}

A total of 19 usable responses from 8 out of 24 universities (33\%) in Ontario (AUCC, 2015 ) were received from respondents in various positions. While the number of responses was smaller than hoped for, making generalizations problematic, the target population was specific and deliberately chosen, i.e., it was a purposive sample (Vogt, 2007, p. 81). Unlike both the UK and Australia/NZ studies, ${ }^{3}$ the present study targets admissions officers whose duties include regular evaluation and interpretation of IB documents. To ensure that the sample remained specific, the survey was designed to terminate if respondents answered "No" to the question "Do you assess admissions applications from high school students?" Thus, although the sample size was small compared to both

3 The UK study targeted pro-vice-chancellors (Jenkins, 2003, p. 7) and, according to Coates et al. (2007), the Australia/NZ study "specifically targeted 'senior university representatives.' The views are therefore of people working in decision-making capacities within universities, and may not necessarily be the same as those people who have routine operational involvement with the IB Diploma or other senior secondary qualifications" (p. 8). 
previous studies, this limitation has been mitigated by the $100 \%$ contact respondents have with IB students, allowing a more reliable picture to emerge.

Of the 19 respondents, $8(42 \%)$ had been in their positions for more than 10 years, $6(32 \%)$ for 5 to 10 years, and $5(26 \%)$ for less than 5 years.

\section{Findings}

Survey results were grouped into four categories: (1) background and procedural information; (2) comparison of IBDP to other curricula; (3) open-ended questions and additional comments; and (4) interviews.

\section{Background and Procedural Information}

Respondents were first asked about the origin of the applications they assessed, to determine bases of comparison of different curricula. All 19 respondents (100\%) evaluated applications originating from: their home province, out of their home province but within Canada, the United States, and other international systems. To determine the proportion of $\mathrm{B}$ applications in relation to other types of applications (CEGEP, A-Levels, US high school, other international), respondents were asked to indicate the percentage they evaluated of each type over the previous year according to the following scale: (i) less than $5 \%$; (ii) 5-10\%; (iii) 10-15\%; (iv) more than 15\%; and (v) N/A, for which 19 responses were received (18 responses were received for "other international") (see Figure 1).

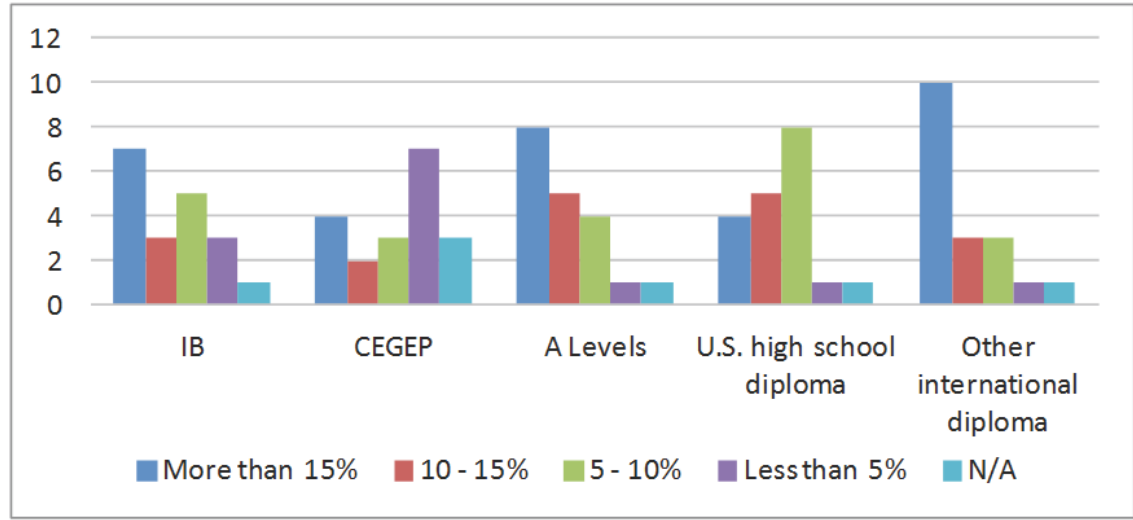

Figure 1. Percentage of applications assessed by origin $(n=19)$.

Canadian Journal of Education / Revue canadienne de l'éducation 38:3 (2015) www.cje-rce.ca 


\section{Comparison of the IB to Other Curricula}

Nine Likert-scale questions were adapted from the Australia/NZ study (Coates et al., p. 37), deliberately retaining the positive bias evident in that study. The questions asked respondents about specific aspects of the IBDP in relation to their own provincial high school curriculum, other Canadian high school curricula, US high school curricula, A-Levels (UK high school), and other international curricula. Each of the statements required a response ranging from "strongly agree" to "strongly disagree," or "cannot say." The responses to these substantive questions showed a high degree of consensus, with minimal variation among admissions officers across universities.

(i) The IB is more challenging than... As shown in Figure 2, the overwhelming majority of respondents (95\%) agreed that the $\mathrm{B}$ was a more challenging curriculum than all Canadian high school curricula. None disagreed and only one neither agreed nor disagreed. Almost as many (90\%) agreed that the IB was more challenging than US high school curricula, with one respondent neither agreeing nor disagreeing and one respondent unable to say. Again, no respondents disagreed with this statement. However, responses diverged more with respect to A-Levels and other international curricula. One respondent provided no response for either of the latter.

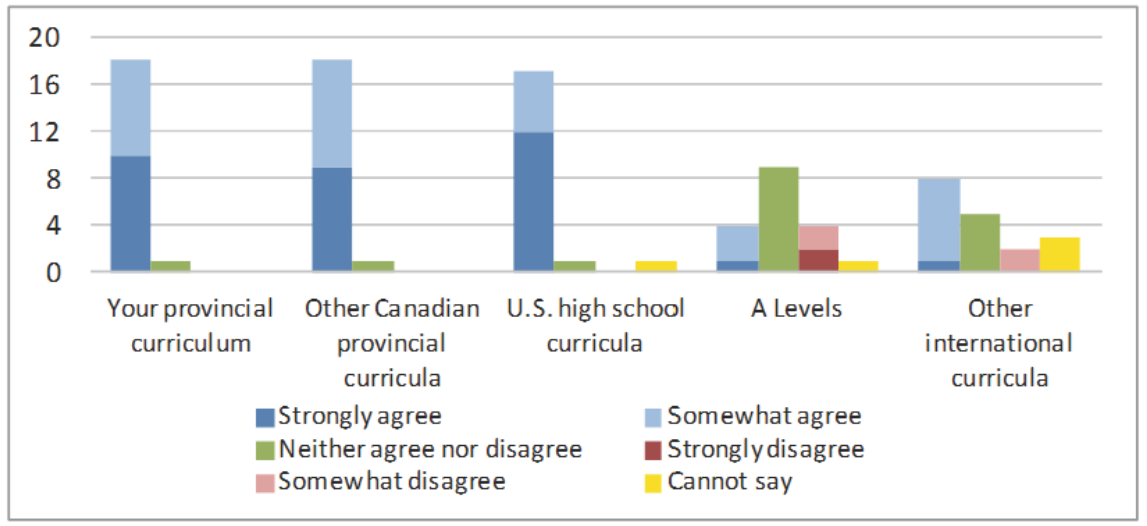

Figure 2. Comparison of challenge $(n=19)$.

(ii) The IB prepares students better for university studies than ... As shown in

Figure 3 , the overwhelming majority of respondents again (90\%) agreed that the IB better 
prepares students for university study than either Canadian or US high school curricula. Again, no respondents disagreed with this statement and only two neither agreed nor disagreed. Responses again diverged with respect to A-Levels and other international curricula. One respondent provided no response for A-Levels.

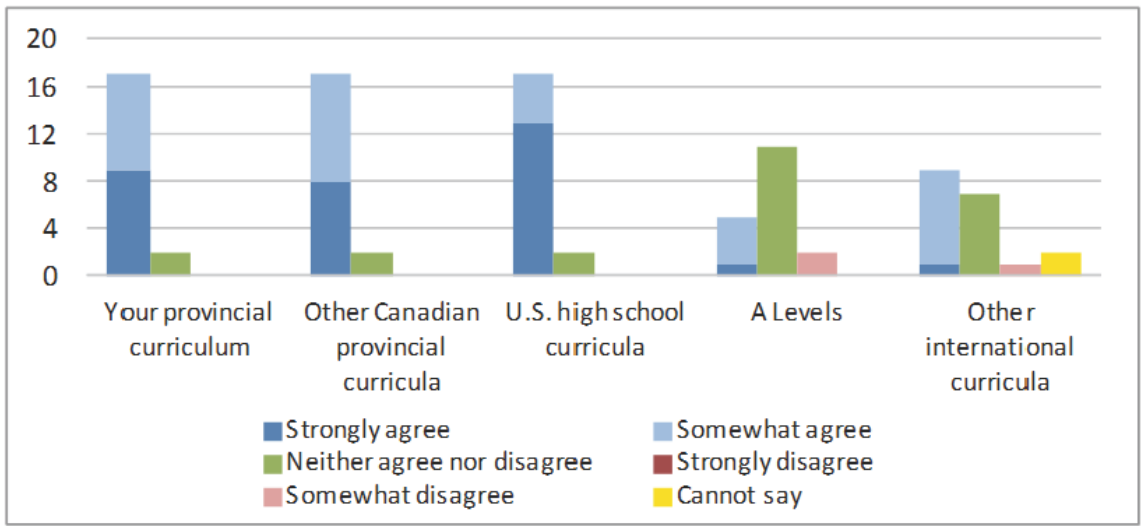

Figure 3. Comparison of preparation for university studies $(n=19)$.

\section{(iii) IB students make an easier transition to university than students who have}

taken... As shown in Figure 4, more than half of the respondents (53\%) agreed that $\mathrm{B}$ students make an easier transition to university than students from Canadian high school curricula, while half $(50 \%)$ agreed with respect to transitioning from US high school curricula. Only one respondent disagreed, whereas eight ( $42 \%$ for Canada, $45 \%$ for the US) neither agreed nor disagreed or could not say. One respondent provided no response for US high school curricula. With respect to A-Levels and other international curricula, the majority of respondents neither agreed nor disagreed, or were unable to say. 


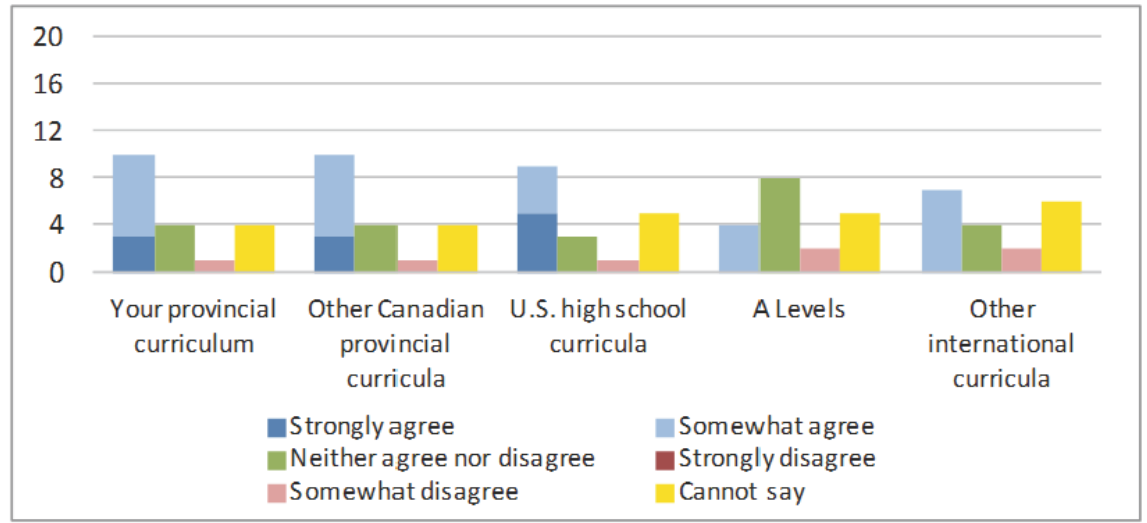

Figure 4. Comparison of transition to university $(n=19)$.

\section{(iv) IB students are more capable of independent research than students who}

have taken... As shown in Figure 5, less than half (44\%) of the respondents agreed that IB students are more capable of independent research than students from Canadian or US high school curricula. Only one respondent disagreed and half (50\%) neither agreed nor disagreed or could not say. Regarding A-Levels and other international curricula, the majority $(72 \%)$ neither agreed nor disagreed or were unable to say.

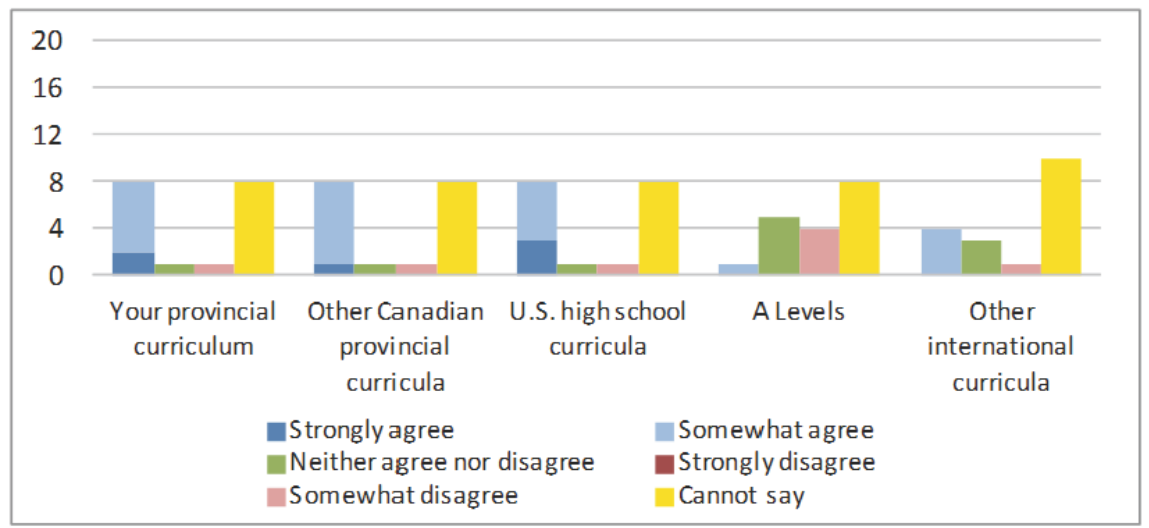

Figure 5. Comparison of independent research capability $(n=18)$.

(v) IB students have better research skills than students who have taken... As shown in Figure 6, again, less than half of the respondents agreed that IB students have 
better research skills than students from Canadian (39\%) or US (33\%) high school curricula, with half $(50 \%)$ unable to say. Regarding A-Levels and other international curricula, the majority $(77 \%)$ were either unable to say or neither agreed nor disagreed. One respondent provided no response for other international curricula.

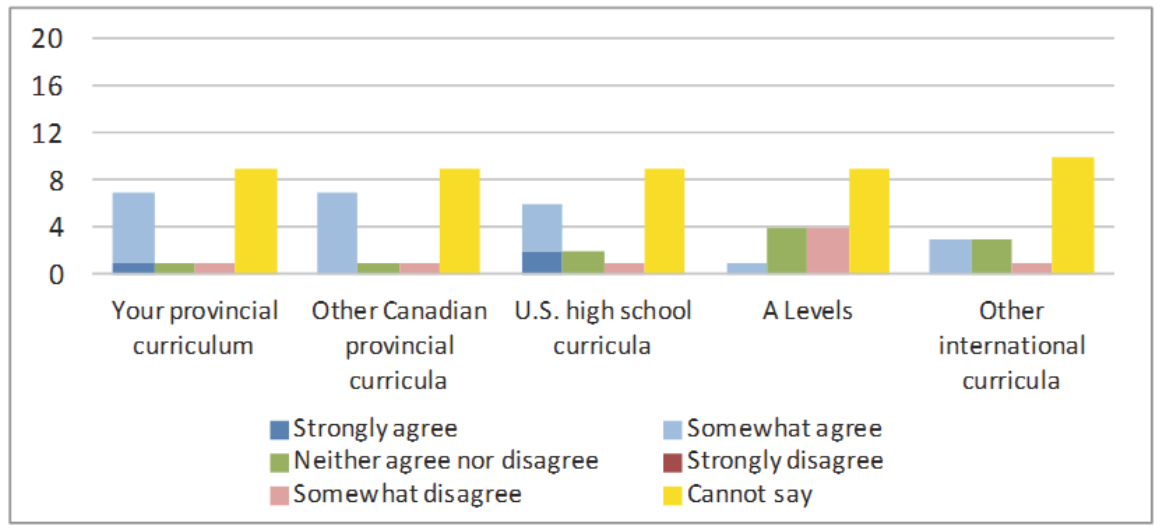

Figure 6. Comparison of research skills $(n=18)$.

\section{(vi) IB students have better written communication skills than students who}

have taken... As shown in Figure 7, less than half of the respondents agreed that IB students have better written communication skills than students from either Canadian (39\%) or US (45\%) high school curricula. Only one respondent disagreed with respect to Canadian curricula, and none disagreed with respect to US high school curricula. In all three, however, more than half $(56 \%)$ neither agreed nor disagreed, or were unable to say. Regarding A-Levels and other international curricula, the majority $(72-78 \%)$ were either unable to say or neither agreed nor disagreed. 


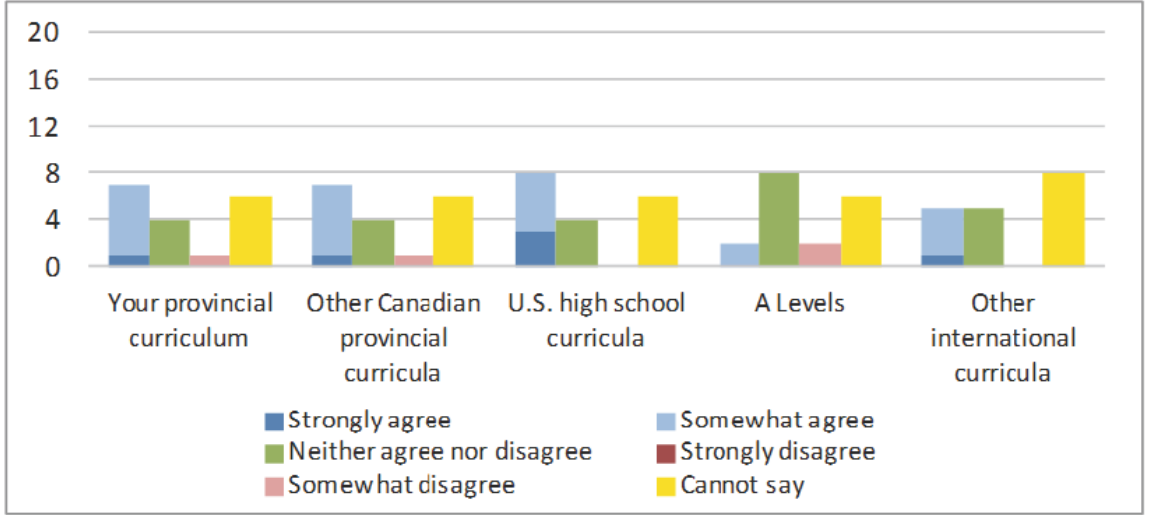

Figure 7. Comparison of written communication skills $(n=18)$.

(vii) IB students have better oral communication skills than students who have

taken... As shown in Figure 8, the majority ( $72-78 \%$ ) of respondents either could not say or neither agreed nor disagreed that IB students have better oral communication skills than students from Canadian or US high school curricula. Only two respondents disagreed with respect to Canadian curricula. Regarding A-Levels and other international curricula, the majority ( $83 \%)$ were either unable to say or neither agreed nor disagreed.

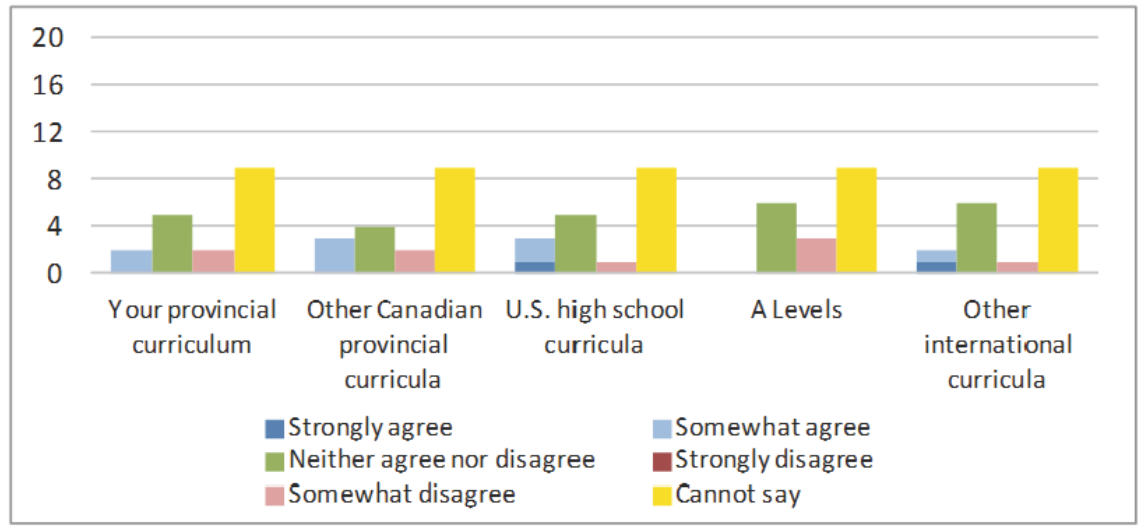

Figure 8. Comparison of oral communication skills $(n=18)$.

(viii) IB students are more active in university life than students who have

taken... As shown in Figure 9, the overwhelming majority (78\%) of respondents could 
not say that IB students were more active in university life than students from any other curriculum. Only one respondent agreed with respect to Canadian curricula and two with respect to US high school curricula.

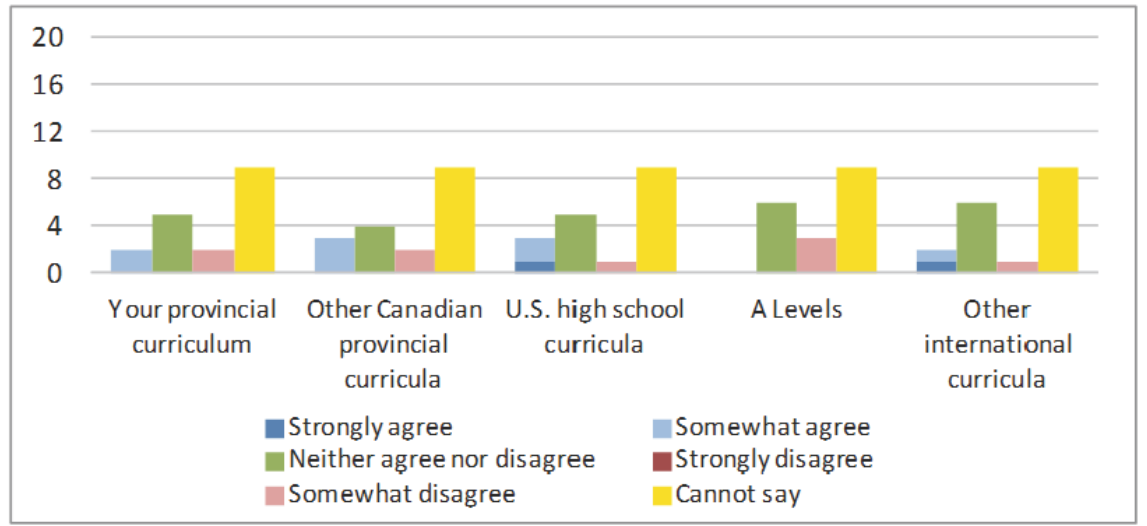

Figure 9. Comparison of activeness in university life $(n=18)$.

(ix) IB students are better problem solvers than students who have taken... As shown in Figure 10, the majority (67\%) of respondents could not say that IB students were better problem solvers than students from any other curriculum. Only a small number (17-22\%) agreed with respect to Canadian and US high school curricula. One respondent did not provide a response for other international curricula.

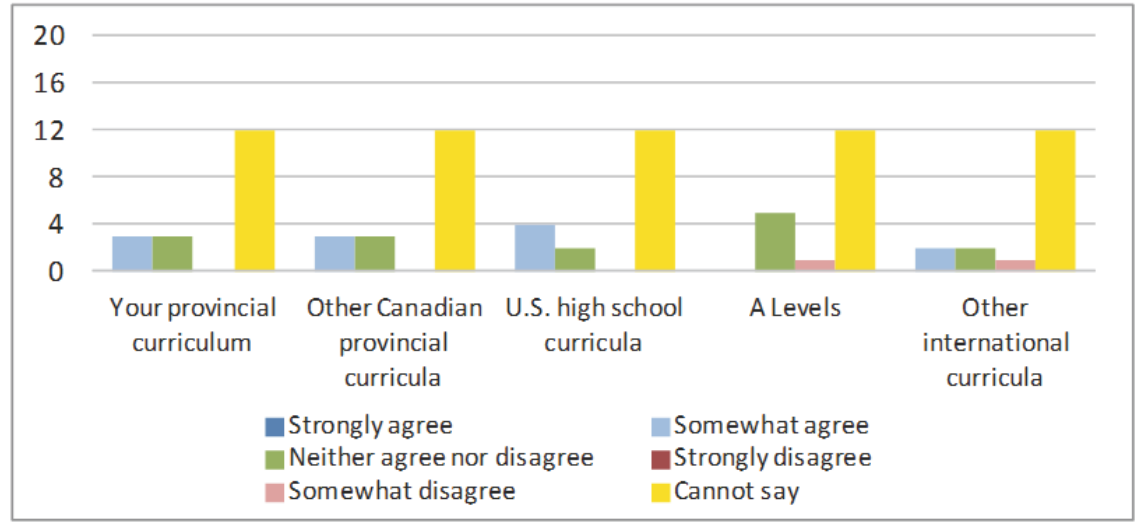

Figure 10. Comparison of problem-solving abilities $(n=18)$. 
(x) Overall opinion of IBDP versus Canadian high school. Respondents were asked whether, in their opinion, Canadian students graduating with an IB diploma had more advantages than their peers graduating with provincial certificates. Sixty-seven percent replied in the affirmative (Figure 11).

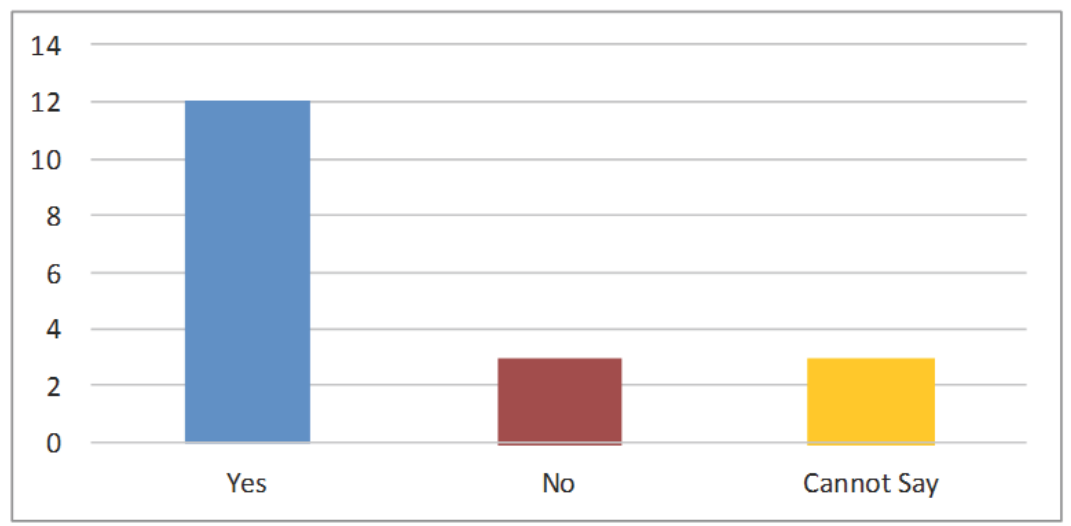

Figure 11. Opinion of IBDP advantage $(n=18)$.

(xi) Sources of information. Respondents were asked to indicate the sources of their information about the IB (see Figure 12). The majority of respondents indicated three common sources: IBO public webpages (94\%), internal documents (100\%), and external information sessions (78\%). Less than half (44\%) indicated use of IBO secure webpages. More than half (67\%) indicated use of their institution website and half (50\%) their institution calendar. No respondents declared any other source of information in the text field provided for this response. 


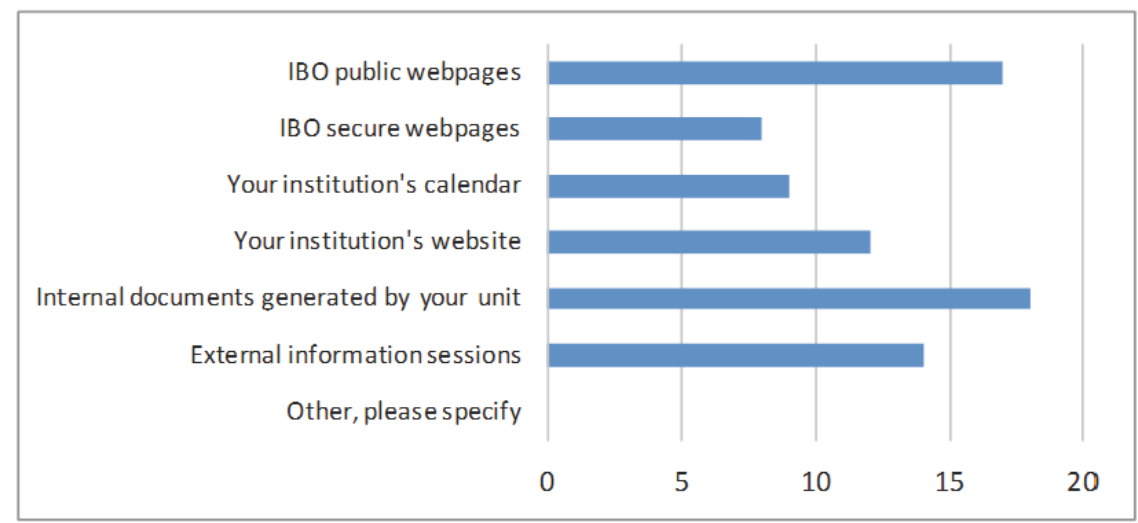

Figure 12. Sources of IB information $(n=18)$.

\section{Open-ended Questions and Additional Comments}

(i) Open-ended questions. Respondents were asked to provide their overall view of the IB diploma. Responses were coded according to broad themes that emerged. Fifteen responses were submitted, with all but one expressing a very positive view of the IBDP. Nine (60\%) noted specifically that the IB prepares students well for university/ post-secondary studies. Five (33\%) commented positively on the IB system of education as being standardized, available globally, well monitored by the IBO, and therefore providing "realistic grades." Two (13\%) mentioned the transfer credits awarded to IB students and one respondent stated that from an Admission Officer perspective, "the International Baccalaureate is a very straightforward curriculum. It is easy to understand." One respondent stated that "too much emphasis is put on the possible Advanced Credit aspect of the IB courses, especially by the parents of Canadian IB students. I believe that the IB schools are 'selling' the program in the wrong way."

(ii) Additional comments. At the end of the survey, respondents were provided with an opportunity to comment on the survey as a whole. A total of five comments were received. Of these, four expressed uncertainty about the questions and whether admissions officers were able to answer questions relating to university performance or research and problem-solving skills, since none of these are measured following admission 
and therefore respondents would not have the information necessary. One noted that both good teachers and good students could be found in any curriculum. One respondent reported having an impression from the survey that the researcher was very much "sold" on the IB program and that this bias showed.

\section{Interviews}

Semi-structured interviews with two participants provided additional information to supplement the survey data. The interviews were recorded, transcribed, and coded according to broad themes that corroborated survey data and that reflected respondent opinion and professional insight (Yin, 2009, p. 107).

One of the key themes that emerged in the interviews was the rigour of the IB curriculum as compared to other curricula, with IB courses described as emphasizing research, writing and presentation skills in a way that provincial curricula do not. The length of IB courses spanning two years as opposed to other curricula covering only the final year of high school was also mentioned. Participants stated that IB students did more than other students, thereby noting that the IB curriculum better equipped students for university study, and actually covered material equivalent to first year courses, which is why IB students were awarded transfer credits. However, interview participants also qualified their remarks by mentioning that poor students could be found in any system and that being an IB student did not necessarily mean that "that student is a stellar student compared to some other national curriculum."

When asked to what extent the number of IB applications had increased at their institutions, both participants commented that there had been a noticeable increase. The notion of standardization and the growing familiarity with the IBO in instilling confidence in admission officers was another theme that emerged in the interviews, echoing a response to the open-ended question in the survey ("It is easy to understand"). In terms of university recruitment strategies, the importance of IBO accreditation and its relationship to the Council of International Schools (CIS) was discussed. IB World Schools undergo "a very rigorous accreditation" and then get accredited by CIS, providing a further level of confidence and validation.

The awarding of transfer credits for IBDP courses was also a recurring theme, and was associated with the rigour of the program. This was given as one of the key 
advantages for IB students when compared to students from provincial curricula. However, participants also explained that there were no systems in place at their universities to track student performance by curriculum. In terms of communication with IB representatives, the primary source of information was the IBO website, and when necessary, the manager/director of admissions who usually served as the IB liaison person.

\section{Discussion}

The purpose of this study was to explore Ontario university admissions officers' perceptions of the IBDP in relation to other high school curricula. As with the UK and Australia/ NZ studies, the results show that respondents have a highly positive view of the IBDP as more challenging and preparing students better for university studies than local (i.e., Canadian or US) high school curricula. Although the sample size was much smaller than those in the UK and Australia/NZ studies, the results provide an important first view of perceptions of Canadian university admissions officers regarding the IBDP as a curriculum for university entry. Unlike the earlier studies, in which a large percentage of the sample had little or no contact with IB students, all respondents in this study regularly evaluate IBDP applications for university admission and are familiar with the various components of such evaluation.

What is noticeable is the consistency in the pattern of responses, not only with one another but also when compared to the previous studies. A clear trend is revealed in the survey responses and subsequently confirmed by the interviews: Canadian admissions officers are very positively disposed towards the IBDP, particularly when compared to Canadian provincial and US high school curricula. Yet, this certainty diminishes as questions about the IBDP curriculum become more specific (e.g., whether IBDP students have better writing skills, better research skills, better oral communication skills, etc.), suggesting that, while there appears to be no doubt on the part of the respondents that the IBDP is in fact more challenging and better prepares students for university in comparison to other curricula, most were unable to say how this is evident in specific skill areas, and commented that admissions officers simply could not know such details, as there is no system in place to track student performance by curriculum. This discrepancy between 
a unanimous and positive general view combined with an almost equally unanimous uncertainty regarding specifics raises the question as to the basis for the former.

This perception was also found in both the UK and Australia/NZ studies, where the IBDP rated higher than the local (State) curricula. In the UK study, the local curriculum (A-Levels) scored lower in all aspects (breadth, critical thinking, communication skills, self-management, motivation) except depth: "A majority (97\%) of respondents were satisfied that the DP prepares students well for degree studies, and $57 \%$ felt that it gives them an advantage over A-Level students" (Jenkins, 2003, pp. 22-23). Similarly, the Australia/NZ study asked respondents to rate different curricula according to six criteria: deep learning, broad learning, critical thinking, communication, research, and self management. The discussion of the results stated that "[t]he state certificates and New Zealand certificate tend to rate the lowest" (Coates et al., 2007, p. 27). The study also reported a large number of comments (60 from a total of 88 ) from respondents stating that they did not have sufficient information to answer the questions (pp. 44-46). Interestingly, in the Australia/NZ study, not only does the "IB Diploma tend to rate highly across all categories" but the "A' levels also tend to rate highly" (p. 27).

This pattern is repeated in the present study: the IBDP is unanimously rated higher than Canadian and US curricula, but variation starts to appear in reference to A-Levels and other international curricula. The majority of respondents were unable to make comparative statements in any of the nine categories with respect to A-Levels and other international curricula. This suggests that a higher regard may be given to those curricula considered to be "international," as opposed to simply "national," which is supported by the respondents' uniform overall view that Canadian and US curricula are less challenging that the IBDP. In her study of "how the IB is constructed for public consumption in Australia," Doherty (2009) argues that the absence of critique with respect to the IB "casts a shadow on others and intertextually builds an implicit criticism of local curricula... If the IB is seen to 'own' the qualities of 'academic rigour,' 'challenge,' 'well-roundedness,' such claims create and promote a perception of their absence in other curricula" (pp. 12-13).

Another important pattern in the present study is the consistency in sources of information about the IB. Almost all respondents relied heavily on information produced by the IBO (94\%) and all relied on internal documents generated by their departments $(100 \%)$. A large number (78\%) also obtained information from workshops and training 
sessions. Over the past decade, IBO representatives have given a number of information workshops at both national and regional association conferences (e.g., Association of Registrars of Universities and Colleges in Canada, 2004, 2006, 2008, 2010; Ontario University Registrars' Association, 2013). At the OURA 2015 conference in Toronto, the first scheduled information session for admissions personnel was a presentation on the IBDP as "international education for the 21st century" (OURA, 2015). The IBO has also produced publications aimed at higher education staff, such as The IB Diploma Programme: $A$ Guide for Universities and Colleges. This publication, intended to assist university personnel in their evaluation of IBDP documents and encourage the formulation of recognition policies, also includes a section called "Admissions officers around the world use some of the following assumptions about $\mathbb{B}$ diploma graduates to assist them in the admissions process," and provides descriptors for ten such "assumptions" ( $\mathbb{B O}, 2007 \mathrm{~b}$, p. 7). For example, the "Academic strength of curriculum" criterion states, "An admissions officer can be assured of the candidate's strong preparation in a cohesive and broad-based academic curriculum..." (p. 7). These assumptions were further modified and codified as 13 admission criteria in a 2008 publication authored by the IBO's College and University Recognition Task Force (IBO, 2008).

To further assist post-secondary institutions in Canada, in 2010, the IBO published a template entitled Setting an IB Policy that Works for Your Institution and Your Students in Canada. This document provides "suggested wording" for the formulation of IB policies governing admission, grades, English proficiency requirements, transfer credits, and scholarships, and even provides appropriate boiler-plate texts where the institution can simply insert its own name (see Figure 13).

\section{Policy components}

Suggested wording

[Your university] values the International Baccalaureate (IB) Diploma Programme and its engaging and challenging curriculum that encourages critical thinking, intercultural understanding and respect. We welcome applications from IB students.

Figure 13. IBO policy model for Canadian universities (IBO, 2010). 
Each of these publications, designed specifically for the use of university admissions personnel, provides important insight into the communication strategies of the IBO, a message reiterated at national and regional association conferences for admissions personnel, where IBO representatives deliver presentations and workshops. Having identified the information gaps revealed by the UK and Australia/NZ studies, the IBO is actively working to address them.

Although a detailed DHA analysis of the IBDP as a "discursive event" (Wodak, 2001, p. 65) is beyond the scope of this article, the historical evolution of the IBDP revealed in IBO publications, combined with the evidence from the present and previous studies, shows how these various texts work intertextually and interdiscursively such that "qualities/traits/attributes" (p. 75) come to be associated with the name. This helps explain, for example, the frequent occurrence of the words "rigorous" and "challenging" whenever the IBDP is mentioned. The "rigour" of the IBDP recurred frequently in responses to the survey's open-ended question and in the interviews for the present study. Such repetition is also found in IBO publications, including texts specifically designed to guide admissions officers in their understanding of what an IBDP student "personifies" (Sjogren \& Campbell, 2003, p. 56). The reciprocal nature of the relationship between the IBO and university personnel is also made evident in the texts where, for example, results and recommendations from one survey are used to refine existing documents, which then get transmitted as further evidence. Both the UK and Australia/NZ surveys revealed a lack of awareness about the IBDP curriculum amongst university personnel, which led to renewed efforts on the part of the IBO to address this deficiency by providing details on different aspects of the program and how it compares to other curricula. The core components of the IBDP (the Theory of Knowledge [TOK], the Extended Essay [EE], and the Creativity, Action, Service [CAS]) were the least known aspects of the IBDP in both surveys. Since this core is fundamental to the IBDP and is presented as the unique feature that is responsible for the very research and writing skills that IBDP students are supposed to have, the IBO began to emphasize this component in its information guides for universities by providing more description and making explicit the skills acquired as a result of this core and how these skills serve to prepare students for university study.

To better understand the consistent pattern of perceptions of the IBDP, it is also useful to consider Berger and Luckmann's (1966) concept of institutionalization, i.e., the idea that institutions are socially constructed through repeated actions over time. Berger

Canadian Journal of Education / Revue canadienne de l'éducation 38:3 (2015) www.cje-rce.ca 
and Luckmann describe how routines that arise from humans coexisting become institutions, thereby gaining an objective dimension that is eventually experienced by society as an external reality. Over time, institutional history gets transmitted to subsequent generations through stories, and according to Berger and Luckmann, "the same story...must be told to all the children" (p. 79). Considering the IBDP as an institution, or as a phenomenon in the process of being institutionalized, we can see that in the IBO's efforts to inform university personnel about the merits of the IBDP through its publications, workshops, and commissioned research studies, the IBDP and the qualities associated with it are being socially constructed. The characteristics attributed to the IBDP by university personnel, e.g., "rigorous," "challenging," "better preparation for university study," "promotes research and writing," have become institutionalized, so that the IBDP curriculum is perceived, in the absence of any empirical research on student performance, to demonstrate such characteristics. The shift in university admissions policies to favour the IBDP shows this institutionalization in practice. Analyzing documents produced by the IBO, university policy documents, and the survey results, makes visible the repetition of the claims about the IBDP that results in their no longer being perceived merely as claims, but as reality, socially, or in this case, discursively, constructed through the concerted efforts of the IBO to create and transmit this story.

\section{Limitations of the Study}

This study is ongoing; the results reported here are preliminary and restricted to Ontario. The sample, while purposive, is limited. Of the 24 Ontario universities listed on the AUCC website (not counting affiliated colleges), only eight (33\%) universities responded to the open invitation (with a total of 19 participants). In addition, while the interviews provided valuable supplemental information, the number is small, thereby limiting the qualitative data in this mixed-methods study. Furthermore, the survey questions retained the positive skew of the Australia/NZ survey, from which they were adapted. This bias was remarked on by the Carleton Research Ethics Board (REB) as well as by one of the survey participants. Since the present study was replicating the previous studies, it was important to retain the positive skew in order to see how Canadian university personnel would respond. 


\section{Conclusion}

This article presented the results of the first phase of an ongoing research project. Based on two previous studies conducted in the UK and Australia/NZ, the study aimed to explore the perceptions of admissions officers in Ontario universities. It was designed to replicate and extend the two previous studies but adapted for the Canadian context. Although the sample was limited in size and regional representation, i.e., the focus for this article is only on Ontario, the purposive aspect of the sample ensured that all those who responded were responsible for evaluating high school applications for admission into university. As such, the trends that emerge from the data provide an important first glimpse into how the IBDP is viewed by Canadian admissions officers. The overwhelming consistency of responses from Ontario universities has made further research involving a much larger sample from across Canada more important.

The results show a remarkable degree of consistency of perceptions across institutions, with a highly positive disposition towards the IBDP, particularly when compared to Canadian provincial and US high school curricula. However, this certainty diminishes as questions about the IBDP curriculum become more specific. This suggests that respondents have little doubt that the IBDP is more challenging and better prepares students for university than other curricula, but when pressed to identify how this manifests itself in specific skill areas, such as better writing and research skills, most respondents were unable to say and commented that admissions officers could not provide such details since there are no systems in place to track student performance by curriculum. One possible explanation for this discrepancy may be that the perception of the IBDP as a rigorous and challenging curriculum that prepares students better for university level studies is closely related to the IBO's efforts to form this view through its "powerful marketing and training presence" (Bunnell, 2011b, p. 71) via national and regional association conferences and workshops.

By employing the DHA and Berger and Luckmann's (1966) concept of institutionalization, the analysis of the different IBO texts combined with the results of the two previous surveys, and the present (small-scale) study helps make visible the intertextual dialectical nature of the IBDP phenomenon. By analyzing the different texts in relation to the historical and social context in which they are embedded, the reciprocal and repetitive actions are made evident.

Canadian Journal of Education / Revue canadienne de l'éducation 38:3 (2015) 
In sum, there are two key findings to this study: (1) the overwhelming consistency of responses in the absence of any empirical (i.e., not simply anecdotal) evidence, and (2) the current perception of the IBDP curriculum may be attributed to the IBO itself, with its active participation in and promotion of IBDP at conferences and publications aimed at university admissions officers. This provides further evidence that the view of the IBDP as a more challenging curriculum that prepares students better for university is socially and discursively constructed. The uniformity of responses across universities has suggested the value of expanding the research scope to obtain data from a larger sample of universities across Canada.

\section{Acknowledgements}

Many thanks to Dr. Janna Fox, Dr. Natasha Artemeva, and Dr. Michael Fitzgerald for their very helpful feedback in the writing of this article. I am very grateful to all the admissions personnel, without whom this study would not be possible. I would also like to thank the three anonymous reviewers for their valuable comments and suggestions in helping to improve this article.

Canadian Journal of Education / Revue canadienne de l'éducation 38:3 (2015)

www.cje-rce.ca 


\section{References}

Association of Universities and Colleges of Canada (AUCC). (2015). Our universities: Ontario. Retrieved from AUCC website: http://www.univcan.ca/ canadian-universities/our-universities/

Australian Council for Educational Research (ACER). (2006). Australian Certificate of Education: Exploring a way forward. Canberra, Australia: Commonwealth of Australia.

Bagnall, N. F. (1994). The International Baccalaureate in Australia and Canada: 1980 1993 (Unpublished doctoral dissertation). University of Melbourne, Melbourne, Australia.

Bagnall, N. F. (2010). Education without borders: Forty years of the International Baccalaureate, 1970-2010. Saarbrucken, Germany: VDM Verlag Dr Muller.

Berger, P. L., \& Luckmann, T. (1966). The social construction of reality: A treatise in the sociology of knowledge. New York, NY: Penguin Books.

Blackburn, R. (1991). The International Baccalaureate: A curriculum at upper secondary level and a university entrance examination. In P. Jonietz \& D. Harris (Eds.), World yearbook of education 1991: International schools and international education (pp. 6-14). London, England: Kogan Page.

Brown, J. D. (2001). Using surveys in language programs. Cambridge, England: Cambridge University Press.

Bunnell, T. (2011a). The growth of the International Baccalaureate $\mathbb{B}$ Diploma Program: Concerns about the consistency and reliability of the assessments. The Educational Forum, 75, 174-187.

Bunnell, T. (2011b). The International Baccalaureate in the United States: From relative inactivity to imbalance. The Educational Forum, 75, 66-79.

Bunnell, T. (2012). Global education under attack: International Baccalaureate in America. Frankfurt, Germany: Peter Lang.

Cambridge, J. (2002). Global product branding and international education. Journal of Research in International Education, 1(2), 227-243. 
Chichekian, T. (2011). The articulation of inquiry in research about teaching and learning in the International Baccalaureate (Unpublished MA thesis). McGill University, Montreal, QC.

Coates, H., Rosicka, C., \& MacMahon-Ball, M. (2007). Perceptions of the International Baccalaureate Diploma Programme among Australian and New Zealand Universities. Retrieved from the IBO website: http:/www.ibo.org/en/about-the-ib/ research/programme-impact-research/diploma-studies/

Creswell, J. W., \& Plano Clark, V. L. (2011). Designing and conducting mixed methods research. Thousand Oaks, CA: Sage.

Daly, K. (2012). An exploration of Virginia law on recognition, university officials, and perceptions of the International Baccalaureate Diploma Programme (Unpublished doctoral dissertation). George Mason University, Fairfax, VA.

Doherty, C. (2009). The appeal of the International Baccalaureate in Australia's educational market: A curriculum of choice for mobile futures. Discourse: Studies in the Cultural Politics of Education, 30(1), 73-89.

Fontana, A., \& Frey, J. (2000). From structured questions to negotiated text. In N. K. Denizin \& Y. S. Lincoln (Eds.), Handbook of qualitative research (2nd ed., pp. 645-672). Thousand Oaks, CA: Sage.

Fox, E. (1998). The emergence of the International Baccalaureate as an impetus for curricular reform. In M. C. Hayden \& J. J. Thompson (Eds.), International education: Principles and practice (pp. 65-76). London, England: Kogan Page.

Hanover Research. (2010). Current trends in International Baccalaureate programs.

Retrieved from Hanover Research website: http://www.ibsom.org/ uploads/9/0/6/3/9063770/current trends in international baccalaureate programs - membership.pdf

Hayden, M. (1998). International education in practice. In M. Hayden \& J. Thompson (Eds.), International education: Principles and practice (pp. 1-8). London, England: Kogan Page.

Hill, I. (1994). The International Baccalaureate: Policy process in education (Unpublished doctoral dissertation). University of Tasmania, Hobart, Tasmania, Australia. 
Hill, I. (2002). The history of international education: An International Baccalaureate perspective. In M. Hayden, J. Thompson, \& G. Walker (Eds.), International education in practice: Dimensions for national and international schools (pp. 18-29). London, England: Kogan Page.

Hill, I., \& Hayden, M. (2010). The International Baccalaureate: Pioneering in education. Woodbridge, England: John Catt Educational Limited.

IBA Regional Council. (2009). CURT in support of university recognition of the IB. Retrieved from IBA website: www.ibmidatlantic.org/CURT 11_09.pdf

International Baccalaureate Organization. (2007a). 2003 United States student survey of high school seniors participating in the International Baccalaureate Program. Retrieved from IBO website: https://web. archive.org/web/20130704085538/ https://www.ibo.org/ibna/research/documents/2003StudentSurvey.US.pdf

International Baccalaureate Organization. (2007b). The IB Diploma Programme: A guide for universities and colleges. Retrieved from IBO website: https://web.archive. org/web/20130117051410/https:/www.ibo.org/communications/publications/ documents/e uni recognition brochure 07.PDF

International Baccalaureate Organization. (2008). IB diploma candidates: Some college admission assumptions. Retrieved from IBO website: https://web. archive. org/web/20130510070758/http://www.ibo.org/ibna/recognition/documents/ CollegeAdmissionassumptions2008.pdf

International Baccalaureate Organization. (2010). Setting an IB policy that works for your institution and your students in Canada. Retrieved from IBO website: https://web.archive.org/web/20140715154440/http://www.ibo.org/recognition/ resourcesanddocumentlibrary/documents/ModelPolicyCanada.pdf

International Baccalaureate Organization. (2013). History of the International Baccalaureate. Retrieved from IBO website: http://www.ibo.org/en/about-the-ib/

International Baccalaureate Organization. (2014a). Resources for universities and applicants in the US and Canada: IB Americas College \& University Task Force (CURT). Retrieved from IBO website: https://web.archive.org/ web/20140713213328/http://ibo.org/informationfor/universitiesandgovernments/ universities/curt/ 
International Baccalaureate Organization. (2014b). IB Diploma statistical bulletin: May 2014 examination session. Retrieved from IBO website: http://www.ibo.org/ contentassets/bc850970f4e54b87828f83c7976a4db6/may-2014-stats-bulletin.pdf

Jenkins, C. (2003). Perceptions of the IB Diploma Programme. Retrieved from IBO website: http:/www.ibo.org/en/about-the-ib/research/programme-impact-research/ diploma-studies/

KhosraviNik, M., Krzyzanowski, M., \& Wodak, R. (2012). Dynamics of representation in discourse: Immigrants in the British press. In M. Messer, R. Schröder \& R. Wodak (Eds.), Migrations: Interdisciplinary perspectives (pp. 283-295). Vienna, Austria: Springer-Verlag.

Lee, M., Hallinger, P., \& Walker, A. (2012). Leadership challenges in international schools in the Asia Pacific region: Evidence from programme implementation of the International Baccalaureate. International Journal of Leadership in Education: Theory and Practice, 15(3), 289-310.

Mathews, J. (2003, June 2). The 100 best high schools in America. Newsweek, 141, $49-54$

Ontario University Registrars' Association (OURA). (2015). Admissions 1 - The IB Diploma Programme - International education for the 21 st century. Retrieved from OURA website: https://web.archive.org/web/20150222190544/http://oura. ca/conference/program.html

Paris, P. G. (2003). The International Baccalaureate: A case study on why students choose to do the IB. International Education Journal, 4(3), 232-243.

Panich, C. (2001). A study of the university performance of students with International Baccalaureate high school experience (Unpublished doctoral dissertation). Duquesne University, Pittsburgh, PA.

Pook, G. (2009). External examinations beyond national borders: The International Baccalaureate. In B. Vlaardingerbroek \& N. Taylor (Eds.), Secondary school external examination systems: Reliability, robustness and resilience (pp. 319336). Amherst, NY: Cambria Press.

Renaud, G. (1975). The International Baccalaureate. Prospects, 5(1), 111-119. 
Renaud, G. (1991). The International Schools Association (ISA): Historical and philosophical background. In P. Jonietz \& D. Harris (Eds.), World yearbook of education 1991: International schools and international education (pp. 6-14). London, England: Kogan Page.

Richardson, J. E., \& Wodak, R. (2009). Recontextualising fascist ideologies of the past: Right-wing discourses on employment and nativism in Austria and the United Kingdom. Critical Discourse Studies, 6(4), 251-267.

Rowell, P. M. (1983). Planning for the implementation of the International Baccalaureate Program: A situational study (Unpublished doctoral dissertation). University of Alberta, Edmonton, AB.

Sjogren, C., \& Campbell, P. (2003). The International Baccalaureate: A diploma of quality, depth and breadth. College and University Journal, 79(2), 55-58.

Tarc, P. (2009). Global dreams, enduring tensions: International Baccalaureate program in a changing world. New York, NY: Peter Lang.

Tarc, P., \& Beatty, L. (2012). The emergence of the International Baccalaureate Diploma in Ontario: Diffusion, pilot study and prospective research. Canadian Journal of Education, 35(4), 341-375.

Tarver, E. T. (2010). University admissions officers' perceptions of student performance within the International Baccalaureate Diploma Program (Unpublished Doctoral dissertation). Louisiana State University, Baton Rouge, LA.

Vogt, W. P. (2007). Quantitative research methods for professionals. Boston, MA: Pearson.

Walker, G. (2005). Looking back and looking forward: The next 30 years. Plenary Address to the IBNA Annual Regional Conference, Montreal, July 9. Retrieved from the IBO website: https://web.archive.org/web/20070930201614/http://www. ibo.org $/ \mathrm{dg} / \mathrm{emeritus} / \mathrm{speeches} /$ documents/ibna ju105.pdf

Whitehead, K. (2005). Advertising advantage. The International Baccalaureate, social justice and the marketisation of schooling. Paper presented at the Australian Association for Research in Education Annual Conference, University of Western Sydney, Parramatta. Retrieved from the Australian Association for Research in Education website: http:/www.aare.edu.au/05pap/whi05426.pdf 
Wodak, R. (1999). Critical discourse analysis at the end of the 20th century. Research on Language and Social Interaction, 32(1\&2), 185-193.

Wodak, R. (2001). The discourse-historical approach. In R. Wodak \& M. Meyer (Eds.), Methods of critical discourse analysis (pp. 63-94). London, England: Sage.

Wodak, R., \& Meyer, M. (2009). Critical discourse analysis: History, agenda, theory, and methodology. In R. Wodak \& M. Meyer (Eds.), Methods of critical discourse analysis (2nd ed., pp. 1-33). London, England: Sage.

Yin, R. K. (2009). Case study research design and methods (4th ed.). Thousand Oaks, CA: Sage. 


\section{Chapter 6}

\section{Perceptions of the International Baccalaureate (IB) in Canadian universities}

This chapter presents the study on how admissions officers in Canadian universities perceive the IB in relation to other curricula. Canadian Journal of Higher Education (in press). 


\title{
Perceptions of the International Baccalaureate (IB) in Canadian universities ${ }^{*}$
}

\author{
Saira Fitzgerald, Carleton University
}

\begin{abstract}
This article presents the results of the first Canada-wide survey on how university admissions personnel view the International Baccalaureate Diploma Program (IBDP) in relation to other curricula. The purpose of this study was twofold: (i) to move beyond anecdote and discover how Canada compares with universities in the UK and Australia/NZ, and (ii) determine whether a dominant or hegemonic discourse surrounding the IBDP exists. Building on a small-scale pilot of perceptions in Ontario universities, the present study replicates two IBO studies (UK 2003 and Australia/NZ 2007) in the Canadian context. Results reveal a pattern of responses consistent with the previous studies, i.e., a confident positive general view combined with uncertainty regarding specific aspects of the IBDP. Such widespread and consistent views suggest the existence of a dominant or hegemonic discourse surrounding the IBDP, constructing it as the standard of excellence in pre-tertiary education, which has important implications for publicly-funded education in Canada.
\end{abstract}

\section{Résumé}

Cet article présente les résultats de la première enquête pancanadienne sur la façon dont les admissions universitaires du personnel considèrent le Programme du diplôme du Baccalauréat International (PDIB) par rapport aux autres programmes. Le but de cette étude était double: (i) pour passer au-delà de l'anecdote et de découvrir comment le Canada se compare avec les universités au Royaume-Uni et en Australie / Nouvelle-Zélande, et (ii) de déterminer si un discours dominant ou hégémonique entourant le PDIB existe. Construire sur un pilote à petite échelle des perceptions dans les universités de l'Ontario, la présente étude reproduit deux études l' IBO (UK 2003 et Australie / NZ 2007) dans le contexte canadien. Les résultats révèlent un schéma de réponses cohérentes avec les études précédentes, à savoir, une vue générale positif confiant combinée à l'incertitude en ce qui concerne les aspects spécifiques du PDIB. Ces vues étendues et cohérentes suggèrent l'existence d'un discours dominant ou hégémonique entourant le PDIB, la construction comme la norme d'excellence dans l'enseignement pré-tertiaire, qui a des implications importantes pour l'éducation publique au Canada.

\footnotetext{
* In press, Canadian Journal of Higher Education.
} 


\section{Introduction}

Universities in Canada are tripping over each other trying to entice IB students to come to our institutions...

offering perks such as preferred residence rooms, priority enrollment in courses, special scholarships and full transfer credit to IB diploma holders...the domino effect is sweeping the country. Those who are not developing IB friendly policies are losing out on great students in an increasingly competitive market for outstanding prospective students...

- Wendy Loat Admissions policy adviser, University of Toronto \& Chair, College University Recognition Task Force

Although the International Baccalaureate Organization's (IBO) flagship IB Diploma Program $(\mathrm{IBDP})^{1}$ was originally designed to be offered in private international schools around the world for "students disadvantaged by having to live and study abroad" (Bagnall, 1994, p. 5), the past two decades have seen a growing adoption of the IBDP as an alternate curriculum within publicly-funded schools in Canada, Australia, the United Kingdom and the United States (e.g., Bagnall, 2010; W. Baker, 2014; Doherty, 2009; Tarc \& Beatty, 2012). One of the main reasons for this growth is the perception that the IBDP produces students who excel both academically and socially compared to other high school curricula.

In her analysis of IB discourse in Australia, Doherty (2009) argues that the appeal of the IB is linked to its portrayal as "all 'good news', with no whisper of critique" (p. 12). Such a positive view is evident in frequently repeated statements about the IBDP, referred to as "the Cadillac of college-prep programs" (Gehring, 2001), a "gold star" in secondary education (Byrd, Ellington, Gross, Jago, \& Stern, 2007), a "supertest" capable of transforming a failing education system (Matthews \& Hill, 2005), and an "international passport to higher education" (Blackburn, 1991). Furthermore, IBDP students are said to outperform students from other educational systems with respect to retention, degree-completion, and securing the highest-paying jobs upon graduation (Halic, 2013; HESA, 2011; IBO, 2015). This high 
esteem is not restricted to the education domain, but has also been extended to other areas, such as linking the rise in property values to districts having IB schools (Spahn, 2001; Verneuille, 2011) and to lowering the likelihood of juveniles taking up cigarette-smoking (Amuendo-Dorantes, Mach, \& Clapp, 2004; see also Cambridge, 2008). In one of the first doctoral dissertations to study the IBDP in Canada, Bagnall (1994) argued that "the IB is more than a qualification, it is a set of assumptions and a statement of the regard that society places on those who hold it" (p. 4). More recently, this idea of social and cultural capital has been expanded by linking the IBDP to the notion of "cosmopolitan capital" (Tarc, 2009; Weenink, 2008), thereby situating both the qualification and its holder in the global arena (Bagnall, 2010; Bunnell, 2010; Doherty, Luke, Shield, \& Hincksman, 2012; Gardner-McTaggart, 2016). The view that the IBDP is a premier qualification for university admission can also be found on the websites of many high schools and universities, and in the media, as newspapers report on the program in various public schools around the country. As well, the IBO recently issued a press release titled "University Admissions Officers suggest DP as best preparation for workplace and university," which stated that this is the tenth annual report that showed such findings, meaning that the views of admissions officers have remained constant for over a decade (IBO, 2015).

However, running parallel to the discourse of IBDP-praise is another recurring theme in the literature, that of a scarcity of empirical research that supports these claims, from both scholars outside the IBO (e.g., Bunnell, 2008, 2014; Daly, 2012; Doherty, 2009; Doherty et al., 2012; Frank-Gemmill, 2013; Green \& Vignoles (2012); Panich, 2001; Resnik, 2012; Tarc \& Beatty, 2012; Tarver, 2010; Whitehead, 2005) and from the organization's own research departments (Cambridge, 2002, 2008; Hayden \& Wong, 1997; IBO, 2003). For example, Bunnell (2010) remarks that it "seems strange after four decades of IB activity to comment upon the lack of empirical investigation" (p. 359). The main 
thrust of the argument focuses on selection bias in the research, and also that successful performance in university could well be a result of the characteristics of the students rather than the IBDP curriculum.

Another consistent thread in the literature is that universities tend not to track students'

performance based on curriculum, i.e., there are no systems in place to identify IB students and determine their level of achievement after they have been admitted. As such, when asked to comment on student performance, university admissions personnel routinely qualify their responses as being based on impressions or anecdotes rather than evidence (Barnes, 2004; Fitzgerald, 2015; Jenkins, 2003; Coates Rosicka, \& MacMahon-Ball, 2007; Daly, 2012; Tarver, 2010). Nevertheless, in Canada the IBDP has moved from relative obscurity in the 1990 s to being strongly endorsed as a premiere qualification by universities, schools, governments and the media, with the number of IB schools the second highest in the world next to the US.

For these reasons, to better understand how university personnel viewed the IBDP in relation to other curricula, the International Baccalaureate Organization (IBO) conducted two surveys of university personnel, one in the UK (Jenkins, 2003) and the second in Australia/New Zealand (Coates et al., 2007). Results from both showed that although the IBDP was viewed very favourably, knowledge about the program itself was either lacking or superficial, primarily based on anecdote or personal experience. No such survey had been conducted in Canada (except a small-scale pilot study in Ontario [Fitzgerald, 2015]). This paper presents the results of the first survey of university admissions personnel across Canada, replicating and extending the previous studies, and has a twofold purpose: (i) to move beyond anecdote and discover how Canada compares with universities in the UK and Australia/NZ, and (ii) determine whether a dominant or hegemonic discourse surrounding the IBDP exists. 


\section{Background of the IBDP in Canada}

The predominant view is that the introduction of the IBDP into North America came about as a result of dissatisfaction in the 1950s with the existing education system, which was seen as providing choice and flexibility at the expense of academic rigour (e.g., Bagnall, 1994; Bunnell, 2008; James, 2005; Matthews, 1989; Mathews \& Hill, 2005). A Nation at Risk, the 1983 US report produced by President Reagan's National Commission on Excellence in Education, was highly critical of the education system, thus further reinforcing that view. This environment paved the way for the IBDP to be introduced into US public schools: "It is not difficult to see why in such an educational climate some high schools concerned for academic excellence began to think of introducing an IB track. Because of the decentralization of the American system they were free to do so" (Peterson, 1987, p. 138).

While the growth of the IBDP in the US has been extensively discussed, the reason for the IBDP's rapid growth in Canada is less clear and seems to have taken the founders of the program themselves by surprise (Peterson, 1987, p. 143). Bagnall (1994) notes that in Canada there also existed a similar view that the standard of education was deteriorating (p. 116), on the basis of which the IBDP came to be considered as an alternative, but Walker (2005) states that while public education in the US may have been in crisis, in Canada "the situation was different and the quality of public education was much better regarded" (p. 2) and that the reasons for adopting the IBDP had more to do with Canada's multicultural outlook and interest in an international education. Yet another view is offered by Fox (1998), who attributes the growth to the promotional campaign of the International Baccalaureate North America (IBNA) branch of the IBO in New York (p. 73). Whatever the reason, the rapid growth of the IBDP in North America was unexpected, and in fact led to tensions within the IBO (Bunnell, 2011; Mathews \& Hill, 2005). 


\section{Prior research on perceptions of university representatives}

Given the importance of university admission in the creation of the IBDP, it is notable that the first formal study of how university personnel view this qualification only took place in 2003 , in the UK. Based on this, a second study followed in Australia/NZ in 2007. These two studies, both commissioned by the IBO, provided a first look at how the IBDP was viewed by universities in relation to other curricula and whether it was considered suitable preparation for university study. Although both studies stated they were neither evaluating nor validating the IBDP or actual student performance, they are cited in IBO publications as evidence of IBDP students' university capabilities (e.g., IBO, 2007). As indicators of the global scope of IBDP research and acceptance, they are also frequently cited by other researchers on the IB (e.g., O'Connor, 2011; Pook, 2009, Tarc \& Beatty, 2012). Using these studies as a basis, Daly (2012) and Tarver (2010) conducted surveys of US college admissions' perceptions and also discovered that while the IBDP was viewed very favourably by admissions personnel, knowledge about the program was superficial or lacking. A small-scale pilot study of perceptions in Ontario universities, the results of which form the basis of the present study, showed a similar trend.

\section{Theoretical \& Methodological Framework}

The wider research project, of which the present study is a part, employs the discourse historical approach (DHA) combined with corpus linguistics (CL) to examine IBDP discourse as it occurs in different public domains (see Baker et al., 2008, for details on the "synergy" between these two methodologies). As a branch of Critical Discourse Analysis (CDA), the DHA views language as social practice and the context of language use to be crucial (Fairclough \& Wodak, 1997). One of the main features that distinguishes the DHA from other CDA approaches, is its integration of multiple genres surrounding a particular issue, and its focus on the historical dimension of that issue. By contextualizing discourse socially, institutionally and historically, the DHA helps to identify "particular discursive 
strategies that serve to present the arguments of an individual or a group either positively or negatively" (Richardson \& Wodak, 2009, p. 255).

The success of the IBDP depends on its acceptance by universities as a suitable qualification for admission (Blackburn, 1991), which in turn depends on acceptance by schools, parents, students, provincial governments and the media. For this reason, the IBO has produced numerous publications, brochures, conference presentations and workshops to promote greater understanding of the IBDP in relation to other curricula. As this information gets picked up and repeated uncritically in various fora, a "common language" (Daly, 2012, p. 8) or hegemonic discourse of the IBDP starts to form, perpetuating a positive view of the curriculum across domains. This suggests a dialectical discursive construction that is shaped by, but also shapes, the social structures in which the IB operates (Fairclough \& Wodak, 1997) Through the analysis of IB-related texts from different contexts, linguistic patterns involved in the construction of discourses surrounding the IBDP as a preferred qualification may be discovered. Examining "multiple genres and multiple public spaces" (Wodak, 2001, p. 70) can allow for a broader understanding of how the IBDP is discursively represented in Canada, with the view that "language is not powerful on its own - it gains power by the use powerful people make of it" (Wodak, 2007, p. 209). However, as Baker (2005) argues, the first step is to determine whether a dominant or hegemonic discourse does in fact exist, rather than simply being a reflection of researcher bias. One possible method is to consult a representative set of people by means of surveys and focus groups (Baker, 2005).

\section{Method}

The survey results reported in this article form the first phase of a three phase mixed method study. Based on the results of a pilot study of Ontario universities, the survey was expanded to include universities from all ten provinces. Although the original study design consisted of survey responses followed by interviews with interested participants, the lack of uptake (only three individuals expressed 
an interest), combined with the time required to obtain additional Research Ethics Board (REB)

clearance from each institution, made the interview stage not feasible. For this reason, the open-ended comments provided by 63 participants are used to supplement the quantitative survey data.

\section{Instrument: online survey}

The survey questions from the UK and Australia/NZ surveys were adapted for the Canadian context, and consisted of three main types: checklist, Likert-scale, and open-ended (Brown, 2001). These were grouped into five broad categories: (1) background information about the respondent; (2) general information about university applications; (3) specific information about IBDP applications; (4) comparison of the IBDP to other curricula; and (5) an open-ended question and additional comments. A negative response to any of four questions at the start terminated the survey: informed consent, privacy statement, background information, and application assessment. The substantive questions were programmed to be optional; respondents were not required to provide answers to questions on one page before advancing to the next. The survey was field-tested and revised before it was posted online.

\section{Participants}

Universities were selected from the AUCC (Universities Canada) website for each province to include only those that are English-medium, and to exclude any affiliations (colleges or religion-based) as well as specialized institutions. From a total of 55 universities that fulfilled these criteria, 54 were contacted regarding REB clearance procedures. Contact information for one university could not be located but it managed to participate in the survey and is included in the total number. Of the 54 contacted, final REB approval was granted by 48 . Approximately 550 individual email invitations were sent to admissions personnel at these 48 institutions using contact details obtained from institutional websites. Of these, 78 participants from 40 institutions responded. In order to preserve anonymity of institutions, these have been grouped regionally (see Figure 1): 


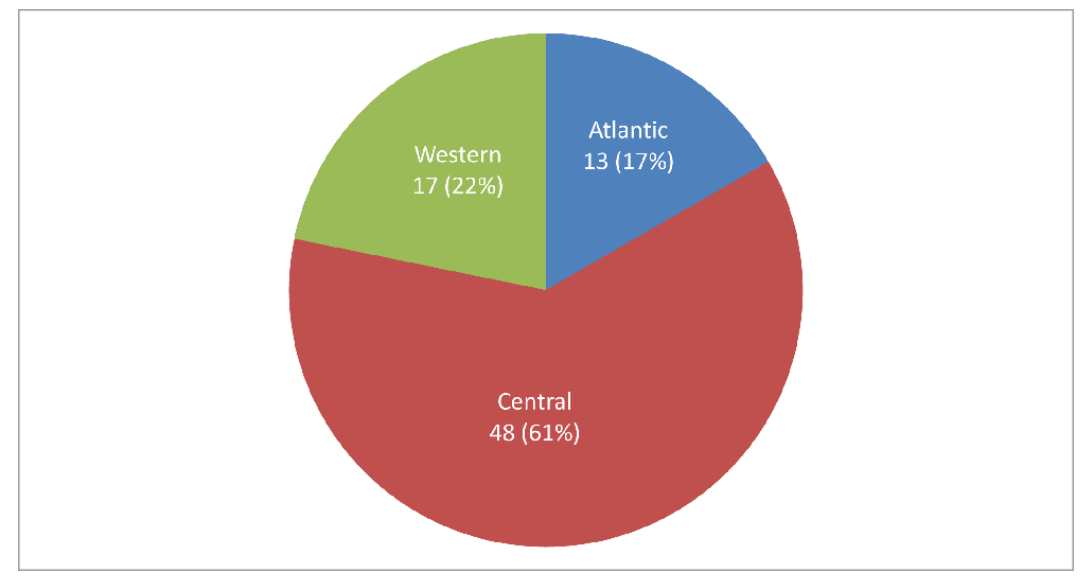

Figure 1. Regional representation of participants $(n=78)$

Atlantic (four provinces, 8 universities, $n=13$ ); Central (two provinces, 16 universities, $n=48$ ); Western (four provinces, 16 universities, $\mathrm{n}=17$ ).

The target population for this study was specific and deliberately chosen, i.e., a purposive sample (Vogt, 2007). Unlike both the UK and Australia/NZ studies, ${ }^{2}$ the present study targeted admissions officers whose duties include regular evaluation and interpretation of IB documents. To ensure that the sample remained specific, the survey was designed to terminate if respondents answered "No" to the question "Do you assess admissions applications from high school students?" Thus, although the sample size was small compared to both previous studies, this limitation is mitigated by the $100 \%$ contact respondents have with IB students, allowing a more reliable picture to emerge.

Of the 78 respondents, $20(26 \%)$ had been in their position for more than 10 years, 24 (31\%) for 5 to 10 years, and $33(42 \%)$ for less than 5 years. One respondent provided no information for this question.

\section{Findings}

Survey results have been grouped into four categories: (1) background and procedural information; (2) comparison of the IBDP to other curricula; (3) open-ended questions and (4) additional comments. 


\section{Background \& procedural information}

Respondents were first asked about the origin of the applications they assessed, to determine bases of comparison of different curricula. All 78 respondents (100\%) evaluated applications originating from: their home province, out of their home province but within Canada, the United States, and other international systems. To determine the proportion of IB applications in relation to other types of applications (CEGEP, A-Levels, US high school, other international), respondents were asked to indicate the percentage of each type they had evaluated over the previous year according to the following scale: (i) less than 5\%; (ii) 5-10\%; (iii) 10-15\%; (iv) more than 15\%; and (v) N/A, for which 78 responses were received (see Figure 2 ).

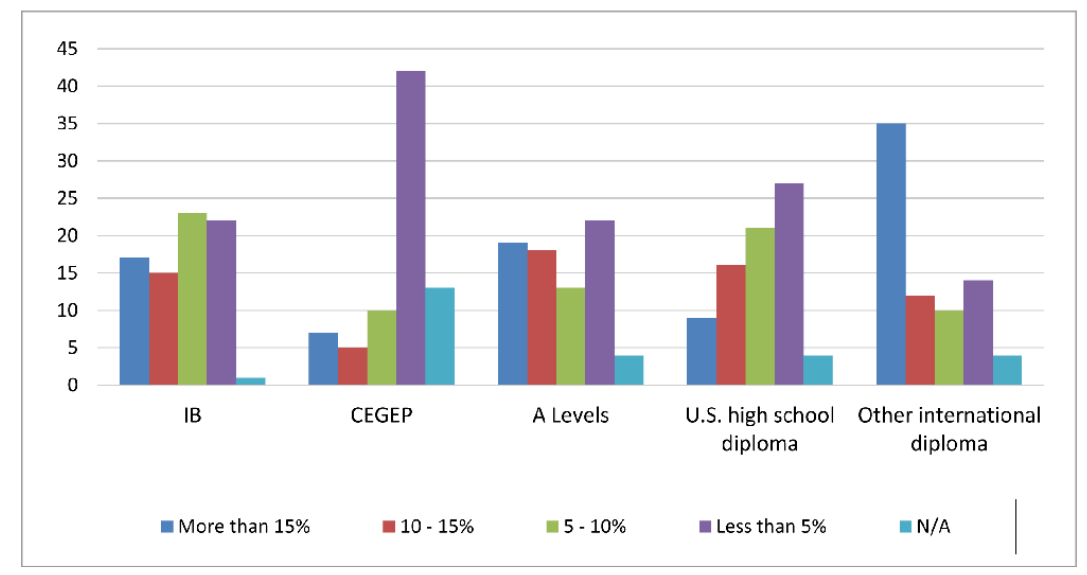

Figure 2. Percentage of applications assessed by origin $(n=78)$

\section{Comparison of the IBDP to other curricula}

Nine Likert-scale questions were adapted from the Australia/NZ study (Coates et al., p. 42), deliberately retaining the positive bias evident in that study. The questions asked respondents about specific aspects of the IBDP in relation to their own provincial high school curriculum, other Canadian high school curricula, US high school curricula, A-Levels (UK high school), and other international curricula. Each of the statements required a response ranging from "strongly agree" to "strongly 
disagree," or "cannot say." Although the responses to these substantive questions showed a similar trend as the Ontario pilot study, greater variation was evident among admissions officers across universities.

\section{(i) The IB is more challenging than...}

As shown in Figure 3, the overwhelming majority of respondents agreed that the IB was more challenging than their provincial curriculum (88\%), all other Canadian high school (82\%), and US high school curricula ( $79 \%)$. Only two respondents somewhat disagreed and seven neither agreed nor disagreed or could not say with respect to their provincial curricula. For other Canadian and US high school curricula, no respondents disagreed, whereas $18 \%$ (Canada) and $21 \%$ (US) neither agreed nor disagreed or could not say. Responses diverged more with respect to A-Levels (59\%) and other international curricula ( $41 \%$ ), where a much larger percentage of respondents neither agreed nor disagreed or were unable to say. Two respondents provided no information for other international curricula.

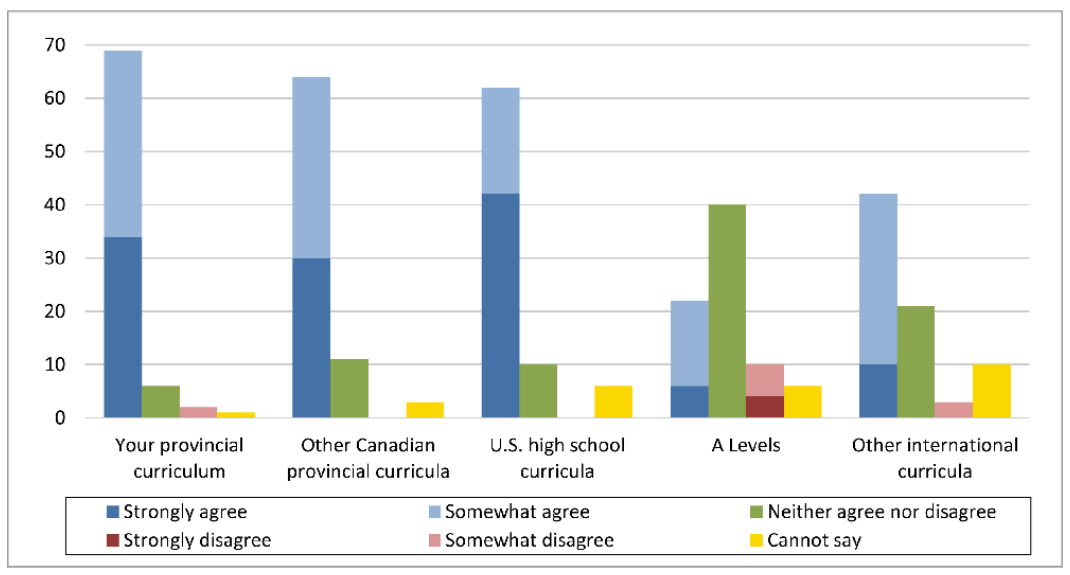

Figure 3. Comparison of Challenge $(n=78)$

(ii) The IB prepares students better for university studies than...

As shown in Figure 4, the majority of respondents (79\%) again agreed that the IB better prepares students for university study than all Canadian and US high school curricula. Only four disagreed in 
terms of provincial, two in terms of Canadian and one somewhat disagreed with respect to US high school curricula. Twelve respondents (16\%) for provincial, $14(18 \%)$ for other Canadian, and $15(20 \%)$ for US high school curricula neither agreed nor disagreed or could not say. Responses again diverged with respect to A-Levels (55\%) and other international curricula (44\%) where a larger percentage of respondents neither agreed nor disagreed or were unable to say. One respondent provided no information for US high school curricula or A-Levels.

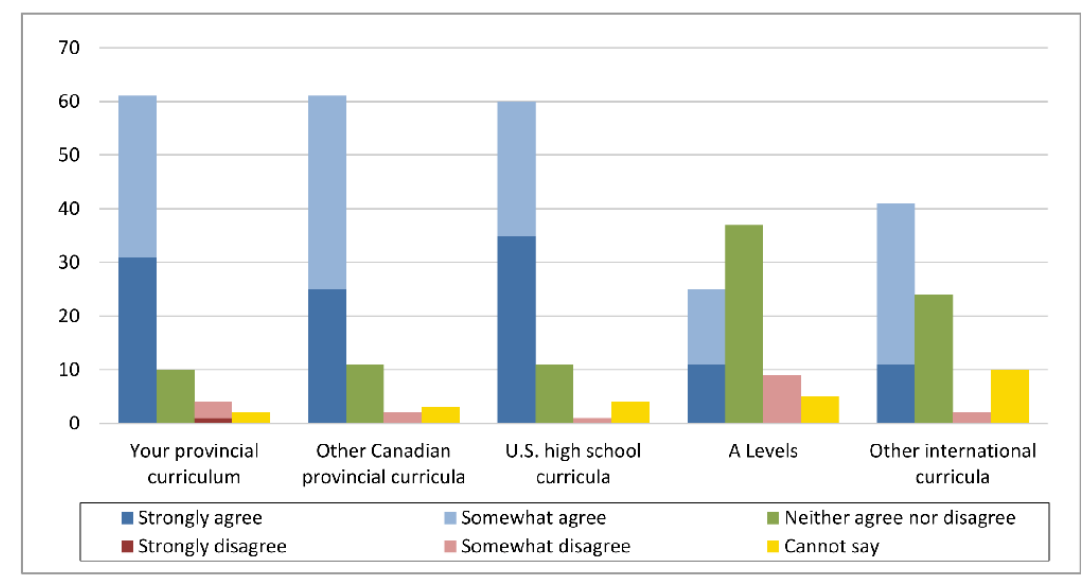

Figure 4. Comparison of preparation for university studies $(n=77)$

(iii) IB students make an easier transition to university than students who have taken...

As shown in Figure 5, 53\% of the respondents agreed that IB students make an easier transition to university than students from their provincial and US high school curricula whereas $54 \%$ agreed with respect to other Canadian high school curricula. Seven (9\%) disagreed with respect to their provincial curricula, five (6\%) disagreed in terms of other Canadian curricula, and four (5\%) disagreed regarding US high school curricula. Thirty respondents (38\%) for provincial, $31(40 \%)$ for other Canadian, and 33 (42\%) for US high school curricula neither agreed nor disagreed or could not say. With respect to ALevels and other international curricula, the majority of respondents (69\% and $53 \%$ respectively) neither agreed nor disagreed or were unable to say. One respondent provided no information for A-Levels. 


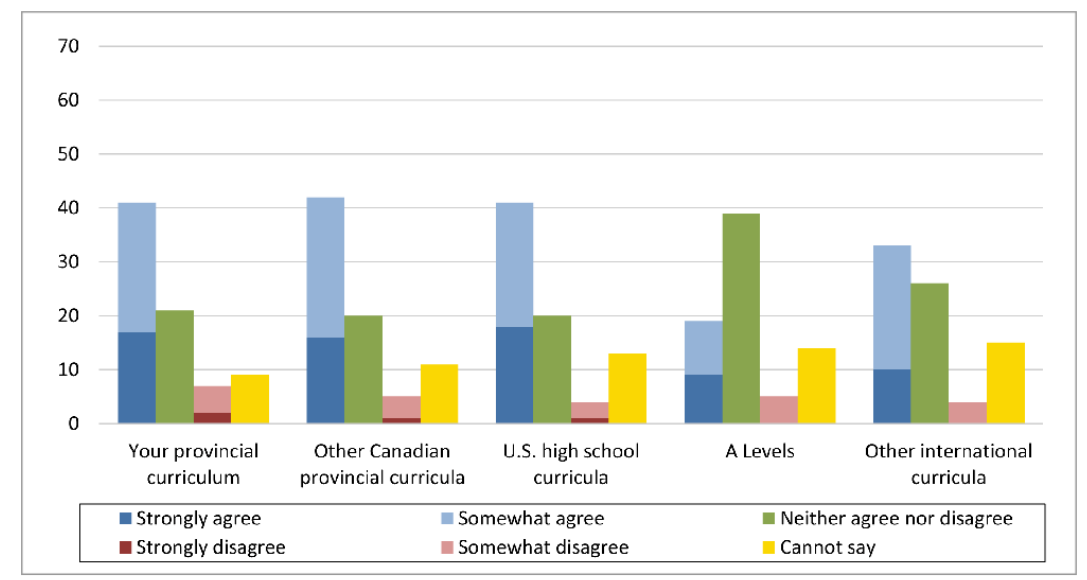

Figure 5. Comparison of transition to university $(n=78)$

(iv) IB students are more capable of independent research than students who have taken...

As shown in Figure 6, half the respondents (50\%) agreed that IB students are more capable of independent research than students from their provincial curricula, whereas $47 \%$ agreed with respect to other Canadian curricula and 49\% with US high school curricula. Only four respondents disagreed for all three whereas $45-47 \%$ neither agreed nor disagreed or could not say. Regarding A-Levels and other international curricula, again the majority of respondents (68\% and 59\% respectively) neither agreed nor disagreed or were unable to say. Two respondents provided no information for provincial curricula and A-Levels. 


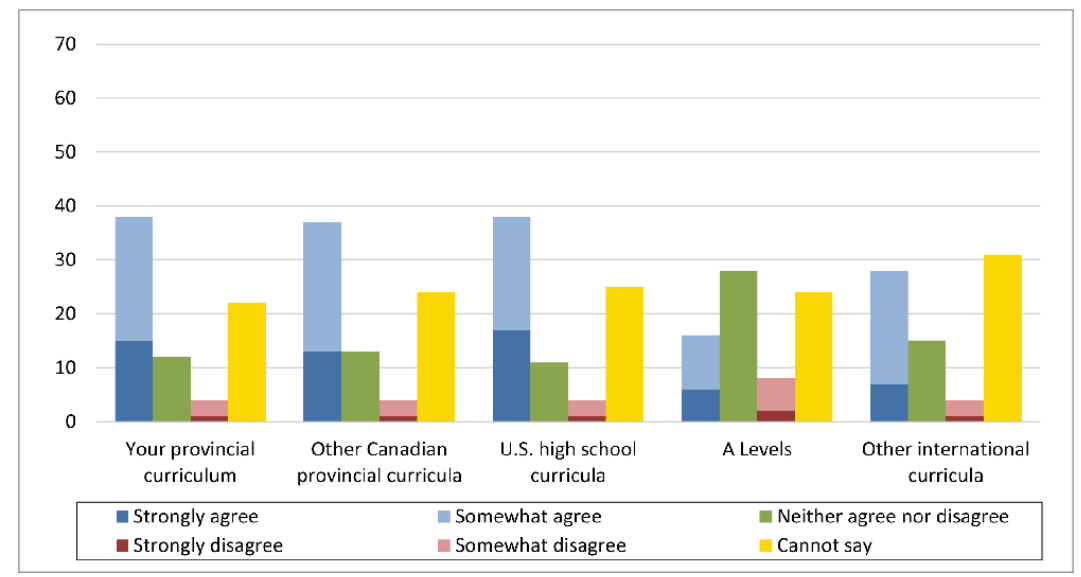

Figure 6. Comparison of independent research capability $(n=78)$

(v) IB students have better research skills than students who have taken...

As shown in Figure 7, less than half of the respondents agreed that IB students have better research skills than students from their provincial (48\%), other Canadian (45\%) or US (42\%) high school curricula. Only three respondents disagreed for all three, whereas $37(48 \%)$ respondents for provincial, $39(51 \%)$ for other Canadian, and $41(54 \%)$ for US high school curricula neither agreed nor disagreed or could not say. Regarding A-Levels and other international curricula, the majority of respondents (70\% and 64\% respectively) neither agreed nor disagreed or could not say. One respondent provided no information for US high school and other international curricula. 


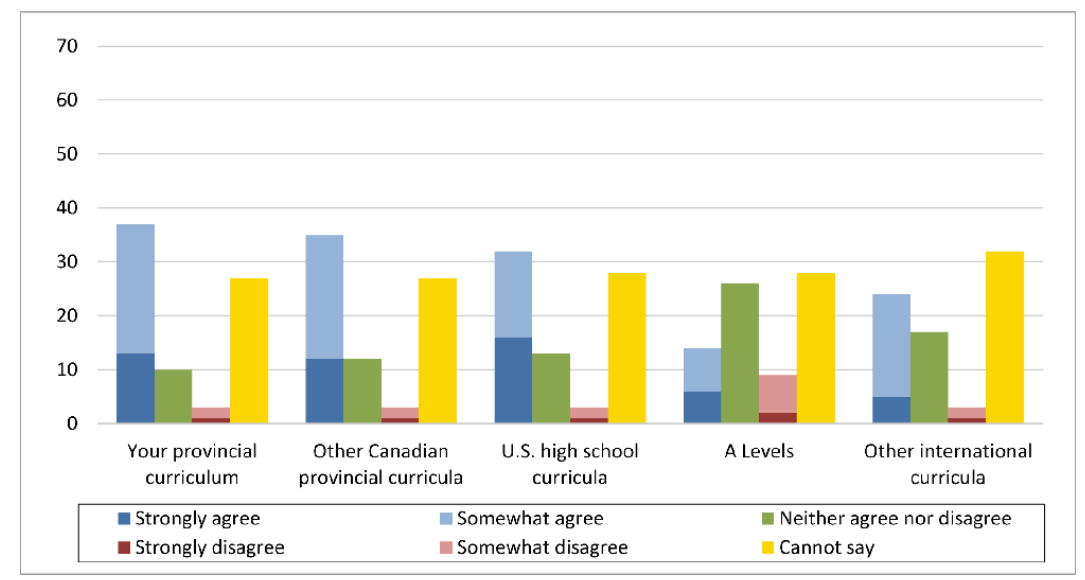

Figure 7. Comparison of research skills $(n=77)$

(vi) IB students have better written communication skills than students who have taken...

As shown in Figure 8, slightly more than half of the respondents (53\%) agreed that IB students have better written communication skills than students from their provincial curricula, half (50\%) agreed for other Canadian curricula and less than half (46\%) for US high school curricula. Only two respondents disagreed regarding provincial and other Canadian, and one disagreed for US high school curricula. Thirty-five (45\%) respondents for provincial, $37(47 \%)$ for other Canadian, and $41(53 \%)$ for US high school curricula neither agreed nor disagreed or were unable to say. Again, with respect to ALevels and other international curricula, the majority of respondents ( $70 \%$ and $60 \%$ respectively) neither agreed nor disagreed or could not say. One respondent provided no information for A-Levels and other international curricula. 


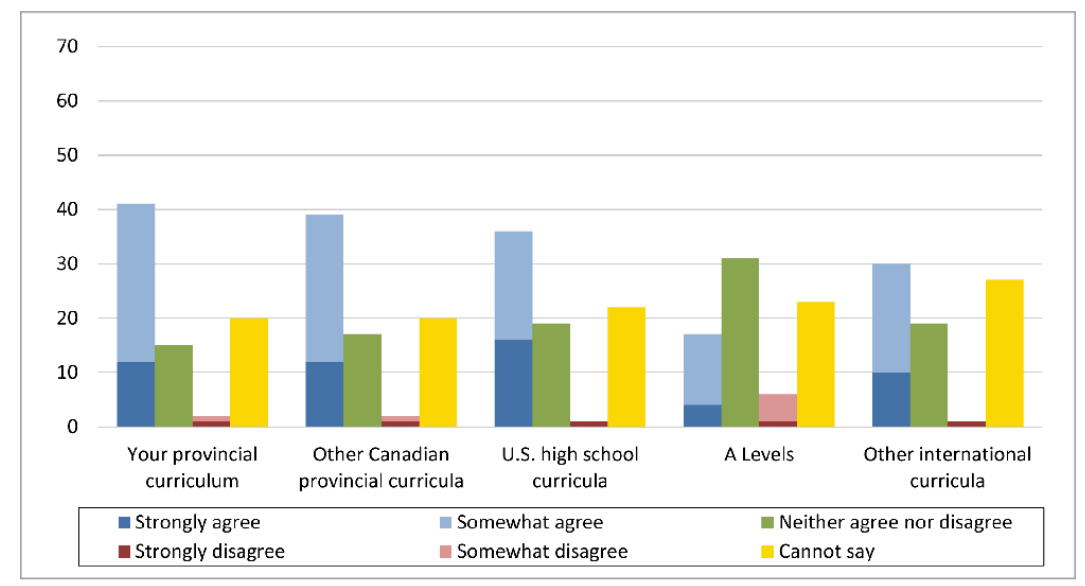

Figure 8. Comparison of written communication skills $(n=78)$

(vii) IB students have better oral communication skills than students who have taken...

As shown in Figure 9, the majority of respondents (68-69\%) either could not say or neither agreed nor disagreed that IB students have better oral communication skills than students from all Canadian and US high school curricula. Only five respondents disagreed with respect to Canadian and four with respect to US high school curricula, while 20 (26\%) agreed for all three. Regarding A-Levels and other international curricula, the majority ( $81 \%$ and $74 \%$ respectively) neither agreed nor disagreed or could not say. One respondent provided no information for US high school curricula. 


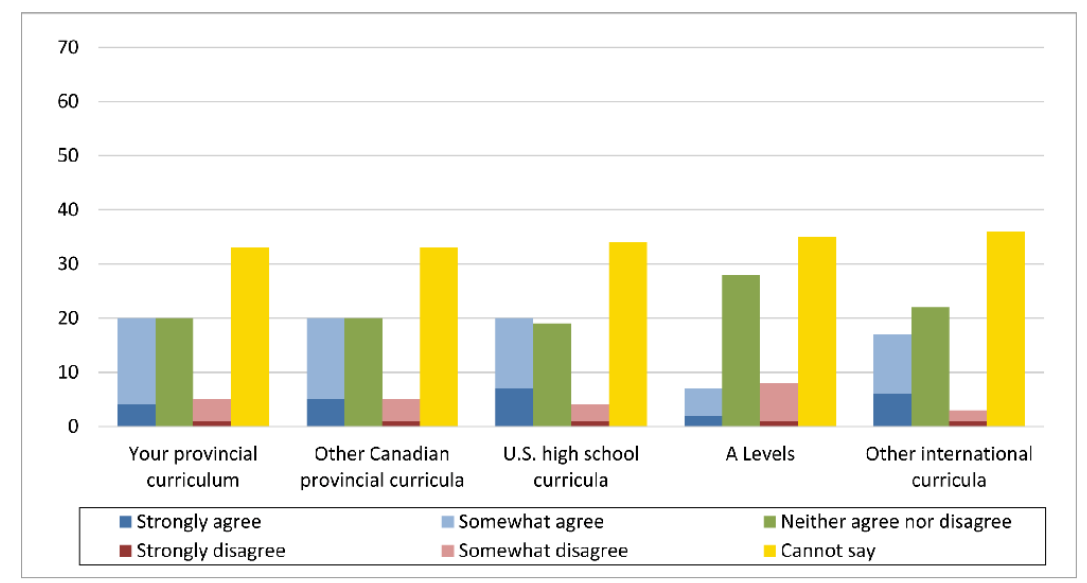

Figure 9. Comparison of oral communication skills $(n=78)$

(viii) IB students are more active in university life than students who have taken...

As shown in Figure 10, the overwhelming majority of respondents (81-88\%) either could not say or neither agreed nor disagreed that IB students were more active in university life than students from any other curriculum. Nine respondents agreed with respect to provincial and seven for other Canadian curricula. Six respondents agreed in terms of US, A-Levels and other international curricula. One respondent provided no information for other Canadian and US high school curricula.

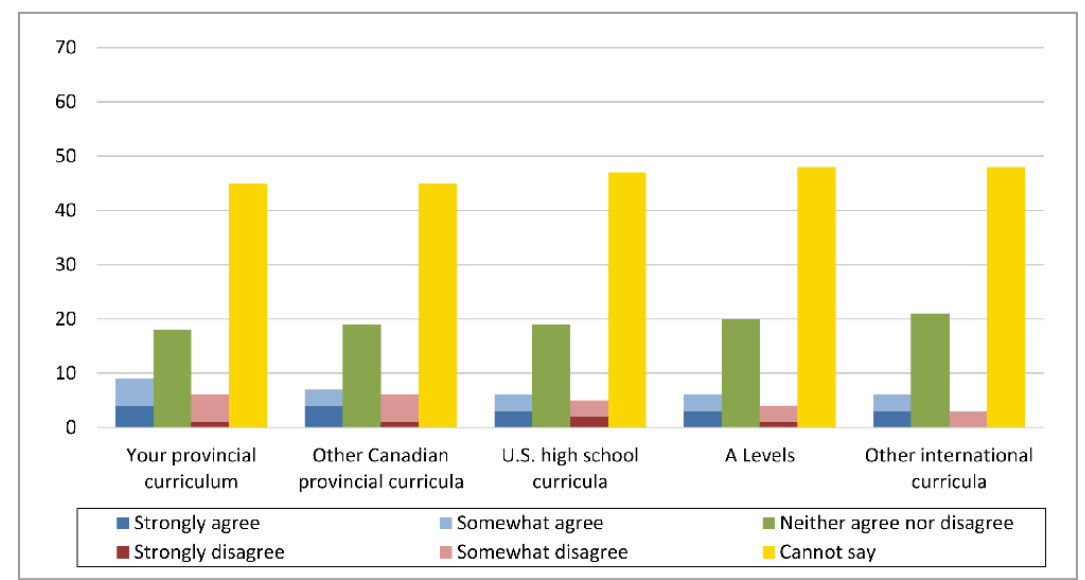

Figure 10. Comparison of activeness in university life $(n=78)$ 
(ix) IB students are better problem solvers than students who have taken...

As shown in Figure 11, the majority of respondents (68-69\%) either could not say or neither agreed nor disagreed that IB students were better problem solvers than students from all Canadian and US high school curricula. The number was much larger for A-Levels and other international curricula, at $83 \%$ and $77 \%$ respectively. Twenty-four respondents $(31 \%)$ agreed that IB students were better problem solvers than students from their provincial curricula, while $23(29 \%)$ agreed with respect to other Canadian and US high school curricula. The number drops noticeably for A-Levels $(9,12 \%)$ and other international curricula $(16,21 \%)$. One respondent provided no information for other international curricula.

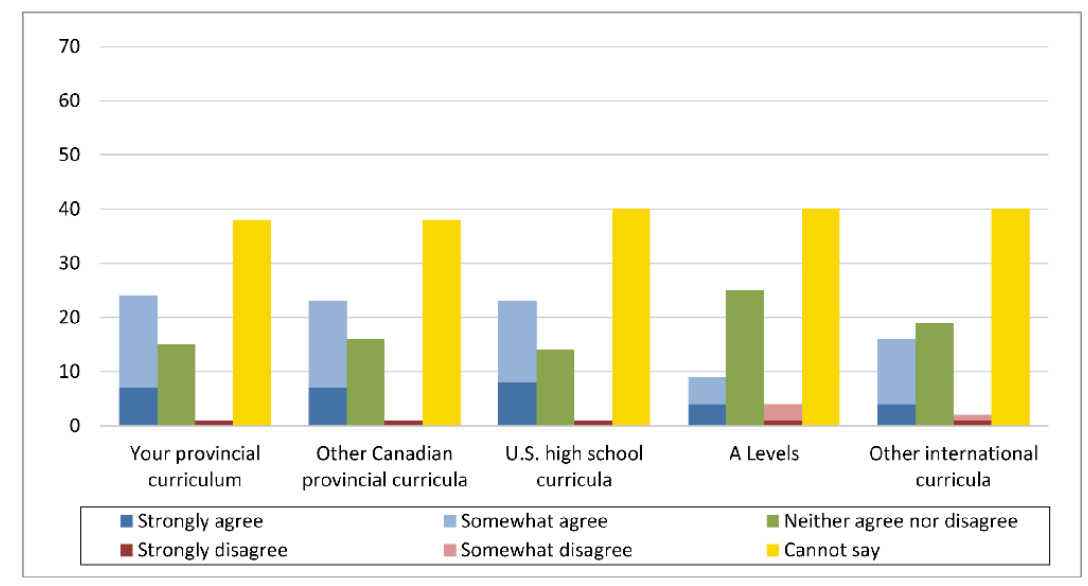

Figure 11. Comparison of problem-solving abilities $(n=78)$

\section{(x) Overall opinion of IBDP versus Canadian high school}

Respondents were asked whether, in their opinion, Canadian students graduating with an IB diploma had more advantages than their peers graduating with provincial certificates. Sixty-four percent replied in the affirmative (Figure 12). 


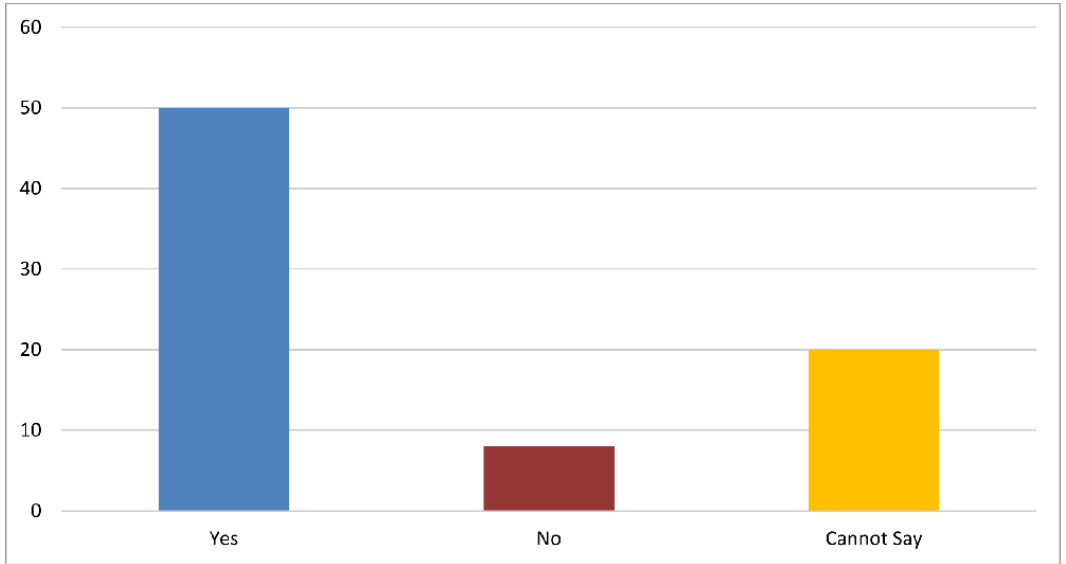

Figure 12. Opinion of IBDP advantage $(n=78)$

\section{(xi) Sources of information}

Respondents were asked to indicate the sources of their information about the IB (see Figure 13).

The majority of respondents $(81 \%)$ indicated two main sources: IBO public webpages and internal documents generated by their unit. The second major source indicated was the respondent's own institutional website (68\%), followed by the institution's calendar (64\%). Other sources were external information sessions (47\%) and IBO secure webpages (37\%). Nine respondents indicated other sources in the free text box provided, which included information from NARIC (National Academic Recognition Information Centre), official transcripts and guides, governmental and other institutional research, IB students, schools, counsellors, scholarly publications, and other colleagues. 


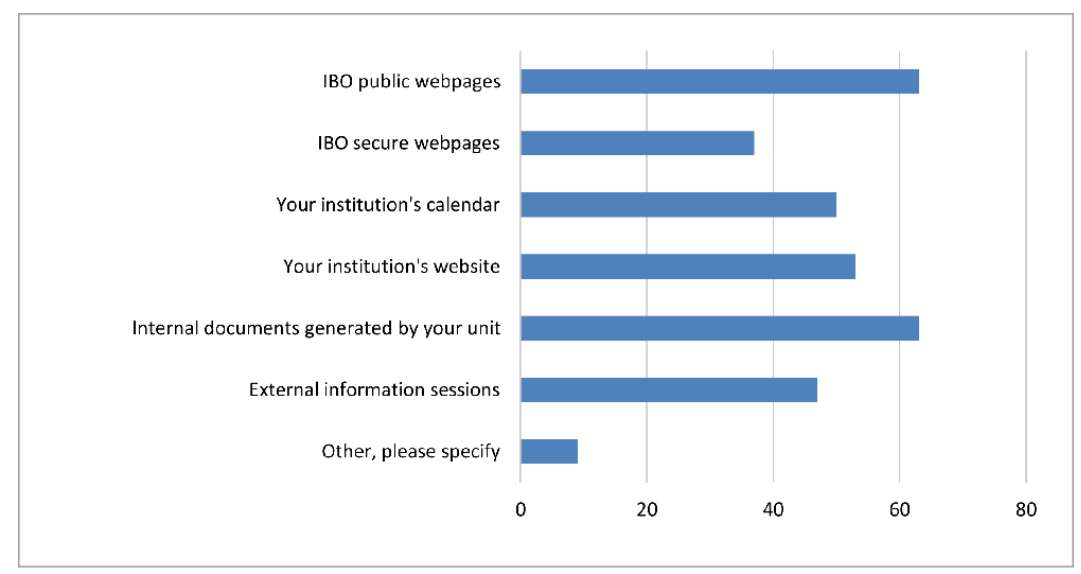

Figure 13 here: Sources of IB information $(n=78)$

\section{Open-ended questions}

Respondents were asked to provide their overall view of the IB diploma. A total of 63 responses were submitted which were coded according to seven broad themes that emerged (see Table 1).

\begin{tabular}{|l|c|}
\hline Theme & Number of responses \\
\hline 1. rigorous, etc., curriculum & $47(75 \%)$ \\
\hline 2. prepares for university & $26(41 \%)$ \\
\hline 3. comparative statements (19+/7-) & $26(41 \%)$ \\
\hline 4. good students (up for the challenge) & $15(24 \%)$ \\
\hline 5. transfer credit & $12(19 \%)$ \\
\hline 6. well-monitored (grades reliable, consistent teaching, etc.) & $11(17 \%)$ \\
\hline 7. available worldwide/widely recognized & $6(10 \%)$ \\
\hline
\end{tabular}

Table 1. Summary of open-ended responses $(n=63)]$

Due to the open-ended nature of the question, each response contained more than one theme. All but

three expressed a favourable view of the IBDP, and only one stated that the IBDP was the "same quality as a provincial credential." Forty seven (75\%) referred to the IBDP positively (e.g., as "rigorous," "strong," "challenging," "excellent," "solid," "well rounded," "enriched"), while 26 (41\%) noted specifically that the IBDP prepares students well for university/post-secondary studies. Seventeen (27\%) 
commented on the IB system of education as being widely recognized, well monitored by the IBO, consistent, standardized, easier for admissions officers to understand, and providing "realistic grades" which have not experienced the "massive grade inflation" seen in the public system. One respondent commented that "I tend to feel more confident about an applicant's potential success at our institution if they've completed the IB diploma with strong results." However, two remarked that IB grades are translated inconsistently, and one stated that IB predicted grades were "not standardized internationally" and were "unfortunately too frequently inaccurate."

Twenty six $(41 \%)$ commented on the IBDP in relation to other curricula. Nineteen of these were positive, indicating that the IBDP was better, more rigorous, a more advanced curriculum, provided students with additional preparation and was a better indicator of student success in post-secondary education. One respondent commented that "I believe it is the strongest curriculum that we receive in decent numbers." However, seven of the 26 respondents explained that they did not believe the IBDP to be better than provincial curricula or that all IB students are successful and that "it is more dependant on the student than the curriculum that they are studying" as well as "many other intersectional factors that come into play when determining which students will and which students will not be successful in the post-secondary system." Fifteen respondents commented on the qualities of students as being ready and academically strong to take on the challenge of extra work.

Another theme that emerged dealt with awarding transfer credits for IBDP courses, commented on by $12(19 \%)$ respondents. Most (10) referred to this dimension of the IBDP positively (e.g., bonus, advantage, better option) with one respondent stating that "a full year of advanced standing" is offered to IBDP students coming to their institution. However, two stated that the IBDP "should not be used to grant transfer credits" and that too much emphasis was being placed on this aspect of the program. 


\section{Additional comments}

At the end of the survey, respondents were provided with an opportunity to comment on the survey as a whole. A total of 22 comments were received. Of these, six expressed uncertainty about the questions and whether admissions officers were able to answer questions relating to university performance or research and problem-solving skills, since none of these are measured following admission and therefore respondents would not have the information necessary. Four stated that they found it difficult to compare different curricula since there was a great deal of variation not only across provinces but also internationally. Three commented on the nature of the questions and the possible bias, stating that "the assumption that all IB students are more committed is not accurate" and that "[s]trong, well-rounded students can come from any background or curriculum." One respondent noted that "[a]s an international admissions officer, I welcome the standardization of the IB program as it makes my job easier. I can be confident that the official transcript is an accurate representation of the applicants [sic] academic background and competency. This is not always the case with local curricula and inconsistent educational systems." The remaining eight comments related to policies and procedures governing IBDP transfer credits and English language requirements at particular institutions.

\section{Discussion}

The purpose of this study was twofold: (i) to move beyond anecdote and discover how Canada compares with universities in the UK and Australia/NZ, and (ii) determine whether a dominant or hegemonic discourse surrounding the IBDP exists. One thing that is noticeable in all the surveys is the consistency of responses regarding the IBDP curriculum even though comments by the participants state that information is not available to admissions officers and that there is an absence of empirical evidence notably tracking studies on student performance. Both UK and Australia/NZ surveys reported an overall positive view of the IBDP and at the same time, a lack of knowledge as to what the program actually 
was. Participants commented that they did not possess knowledge or information about the program or the relative performance of IB students. The same trend was reported in the two small-scale US studies on admissions personnel: an overall positive view of the program (It is a very rigorous and challenging program) and the students (I think the students in the IB program are really smart) followed by statements regarding knowledge about the program (I do not have enough familiarity with the IBDP to comment fully or pass judgement) or student performance (we do not track students once they are admitted so cannot comment on student performance). The uniformity of responses regarding the IB has been commented on by a number of researchers, notably one who attested to being "astonished" by the similarities given the open-ended nature of the questions (Mayer, 2006). This trend was echoed in the Ontario pilot study where a unanimous overall positive view gave way to uncertainty regarding specific aspects of the program. The same trend is also evident in the present study where the overall perception of the IBDP is positive, seeing it as more challenging and better preparation for university study than any Canadian or US high school curriculum. However, the view becomes more tentative and nuanced when specific aspects of the IBDP are considered. Comments by participants also state that such details on student performance are not available to admissions officers since these different skills (such as research, writing, oral) are not measured following admission. Interestingly, as Figure 14 shows, there appears to be slightly more agreement regarding transition to university and written communication skills. Since the knowledge base remains just as restricted as for other categories, this may have more to do with what respondents have heard about the IBDP. The "incremental effect of discourse" (Baker, 2006, pp. 13-14) becomes evident in how repeated phrases influence our perceptions and then often get reproduced, further contributing to the discourse. In just such a way, an IBDP image is built on assumptions and the impressions of others in the absence of rigorous research (Conner, 2008; May \& Perna, 2011), revealing an IB-ideology or "IBeology," i.e., everyone says that the IBDP is better and 
that IB students are obviously smart, but at the same time also say they do not know much about the program or about actual student performance.

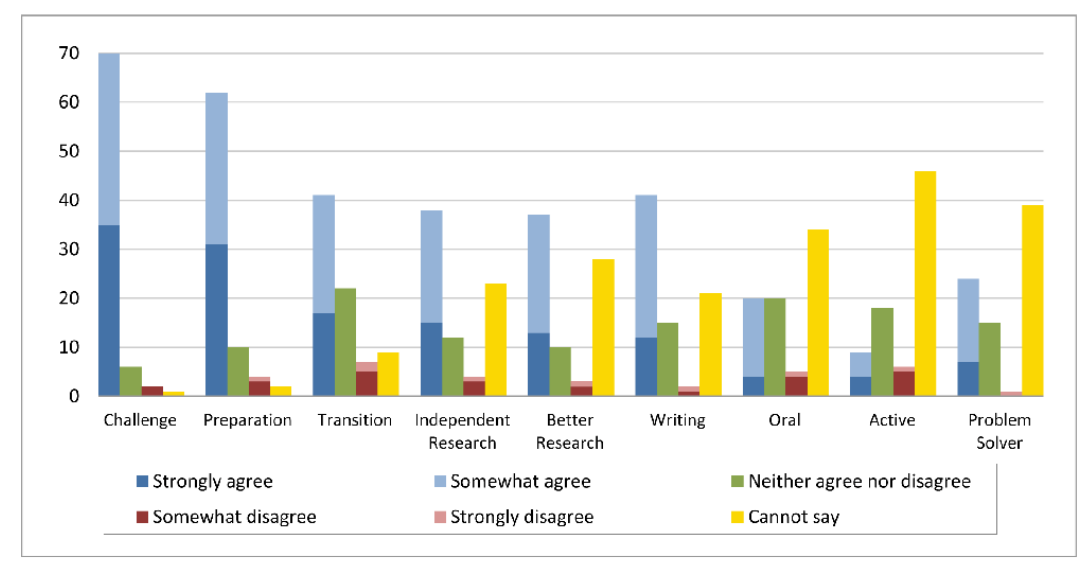

Figure 14 here: Perceptions of IBDP vs. provincial curriculum $(n=78)$

The consistent pattern evident in these different surveys of the IBDP suggests that a hegemonic discourse about the IBDP does exist, one that has become naturalized through repetition (Baker, 2010, p. 124) and has come to be taken for granted in the public domain, resulting in a stereotypical image. A number of researchers (e.g., Conner, 2008) have discussed how the media and other stakeholders (such as education administrators, policy makers, parents and students) play a role in shaping and conveying this impression. In this way, the IBDP as a premiere qualification for university study and also for "the workplace" (IBO, 2015) is discursively constructed, i.e., the image is collectively co-constructed by different segments of society such that the IBDP becomes reified as a superior curriculum. This type of perception can be seen in the remarks made by the 1983 Director of Curriculum of Alberta Education:

It's a known program. I believe the program has rigor, because of its acceptance by universities around the world. There is no question in my mind [emphasis added] that the student who graduates with an IB Diploma has had a more rigorous training than the student in Alberta who matriculates. It reflects the higher level examinations. (Director of Curriculum of Alberta Education, cited in Rowell, 1983, p. 55) 
Such certainty about the superiority of the IBDP in relation to other curricula is formed despite issues of self-selection and differences amongst students and schools. ${ }^{3}$ Perna et al. (2011) argue that the IB program at one school is not the same as the IB program at another school, which therefore raises questions about exactly what is being described in terms of the effects of the program (p. 26). Alec Peterson, founder of the IBDP, also stated that IB schools in North America have little in common (1987 p. 152).

As Fairclough \& Wodak (1997) argue, the relationship between a discursive event and the social structures that frame it is dialectical, i.e., the event is shaped by, but also shapes the social structures. Discourses surrounding the IBDP are often quite similar in the way the IBDP is regularly presented as the natural solution to the "problem" of moribund educational systems ill-suited for a competitive globalized world. Against this "discourse of derision" (Parker, 2011, p. 493), public/state schools and the local curriculum are relegated to an inferior status (Resnik, 2012). Such a perception was found in the surveys of university personnel in the UK, Australia/NZ, the US, Ontario, and as this study shows, across Canada.

An important aspect of IBDP discourse revealed by respondent comments in the survey is the construction of "IB students" as a homogeneous group (IB students do well academically) and as having particular qualities (IB students are academically able, well rounded, enriched, take on challenge, work harder, are high performing). ${ }^{4}$ Qualities attributed to IB students are not always mentioned explicitly, but draw on the "IB" label to bring related attributes to the fore. In constructing this type of in-group, there is a correlative out-group construction. Referring to "IB students" as a homogeneous group with associated characteristics is a discursive strategy that draws on evaluative binary terms and results in a polarization of positive and negative values attributed to the in-group and out-group. The repeated presentation of IB students as embodying such qualities implies that other, non-IB, students lack them. 
By creating this exclusive "us," those outside the group are marginalized, using a positive-us/negativeother discourse strategy (Reisigl \& Wodak, 2001).

A mythology of "the IB" seems to have been created, where the "IB World School" educates the "IB Learner" who embodies qualities described in the "IB Learner Profile" (Bunnell, 2010). Through such reification, "the IB" becomes a value-laden term which becomes associated with all the qualities discursively linked to it, thereby giving it a positive semantic/discourse prosody or aura (e.g., Stubbs, 2001). As the term becomes reified and more naturalized, it acts as a shortcut, "priming" (Hoey, 2005) us to unconsciously attribute these associated qualities.

\section{Limitations of the study}

The sample, while purposive, is limited in that only English-medium universities were selected and each required Research Ethics Board (REB) clearance before recruitment of participants could take place. In some cases, after lengthy REB processes were complete and the survey was deployed, no responses were returned. The survey questions retained the positive skew of the Australia/NZ survey, from which they were adapted. This bias was remarked on by the Carleton REB as well as by one of the survey participants. Since the present study was replicating the previous studies, it was important to retain the positive skew in order to see how Canadian university personnel would respond. Furthermore, only descriptive statistical methods were used in the interest of consistency, thereby limiting additional insights.

\section{Conclusion}

This article presented the results of the first phase of an ongoing research project on IB discourse in Canada. Based on two previous studies conducted in the UK and Australia/NZ, and building on a small-scale pilot study in Ontario, this study aimed to explore the perceptions of admissions officers in Canadian universities across ten provinces. It was designed to replicate and extend the two previous 
studies but was adapted for the Canadian context. Although the sample was smaller than the two IBOcommissioned surveys, the purposive aspect of the sample and the participation of universities from all ten provinces provide important first data of how the IBDP is viewed by Canadian admissions officers.

The results show a similar trend to previous studies, with a highly positive disposition towards the IBDP, particularly when compared to the local (in this case, Canadian provincial) curricula. At the same time, this certainty diminishes as questions about the IBDP curriculum become more specific. This suggests the existence of a dominant or hegemonic discourse surrounding the IBDP, one that presents the view that the IBDP not only produces students who excel academically and socially but also guarantees retention and degree-completion, and that IBDP students secure the highest-paying jobs upon graduation. This makes the recruitment of IBDP students an attractive financial prospect for fundstarved universities, for whom student retention is a key determinant of the level of funding they receive from the provincial government. Universities in Canada have been "tripping over each other trying to entice IB students to come to [their] institutions" (Loat, 2007) because of what appears to be a widely held view that the IBDP produces "great students" (Loat, 2007) and is an "excellent predictor of success" (Piper, 2006, p. 2).

The views and perceptions that arise from this discursive representation also have implications for education policy and the issue of equal access to publicly-funded education across the country. Adoption of the IBDP in high schools raises questions about why scarce provincial funds are being spent on a program that benefits a select few, rather than being used to benefit the whole school and to further strengthen Canada's already world-class education system. In addition, because of the high cost of running the IBDP, parents are often required to pay fees, meaning that only those who can afford it have the opportunity (W. Baker, 2014). Thus, the implication of the IBDP is that "public education" is becoming more exclusive, made up of insiders and outsiders. 


\section{Acknowledgements}

Many thanks to Dr. Michael Fitzgerald for his very helpful feedback in the writing of this article. I am also deeply thankful to all the admissions personnel for their participation. This study would not be possible without them. I would also like to thank the three anonymous reviewers for their valuable comments and suggestions in helping to improve this article.

\section{Notes}

1 The International Baccalaureate Diploma Program is referred to inconsistently in the literature as "IBDP," "DP," "IB,"

"IBD," "IBP" or "IB DP." Here, the diploma program is referred to as "IBDP," except in quotations which have other usage;

"IB" is used to refer to the IBO's whole system of education.

2 The UK study targeted pro-vice-chancellors (Jenkins, 2003, p. 7) and, according to Coates et al. (2007), the Australia/ NZ study "specifically targeted 'senior university representatives.' The views are therefore of people working in decision-making capacities within universities, and may not necessarily be the same as those people who have routine operational involvement with the IB Diploma or other senior secondary qualifications" (p. 8).

${ }^{3}$ In the Australian/NZ survey (2007), one participant adverted to this issue: "In my view IB students are very self-confident and self-motivated, with a broader view of the world...they have been high performers. I suspect that students like this select the IB, not that the IB produces students like this" (p. 44).

${ }^{4}$ According to the IB Learner Profile published by the IBO, IB students are (i) inquirers; (ii) knowledgeable; (iii) thinkers; (iv) communicators; (v) principled; (vi) open-minded; (vii) caring; (viii) risk-takers; (ix) balanced; and (x) reflective (IBO, 2016). 


\section{References}

Amuedo-Dorantes, C., Mach, T., \& Clapp, J. D. (2004). The impact of schools on juvenile substance initiation and use. Prevention Science, 5(2), 91-99.

Bagnall, N. F. (1994). The International Baccalaureate in Australia and Canada: 1980-1993 (Unpublished doctoral dissertation). University of Melbourne.

Bagnall, N. F. (2010). Education without borders: Forty years of the International Baccalaureate, 1970-2010. Saarbrucken: VDM Verlag Dr Muller.

Baker, P. (2005). Public discourses of gay men. London: Routledge.

Baker, P. (2006). Using corpora in discourse analysis. London, UK: Continuum.

Baker, P. (2010). Sociolinguistics and corpus linguistics. Edinburgh: Edinburgh University Press.

Baker, P., Gabrielatos, C., KhosraviNik, M., Krzyżanowski, M., McEnery, T., \& Wodak, R. (2008). A useful methodological synergy? Combining critical discourse analysis and corpus linguistics to examine discourses of refugees and asylum seekers in the UK press. Discourse \& Society, 19(3), 273-306.

Baker, W. (2014). "Curricular choice" in Ontario public secondary schools: Exploring the policy and practice of the International Baccalaureate Diploma Programme (Unpublished Master's thesis). The University of Western Ontario.

Barnes, R. (2004). Perceptions of the International Baccalaureate Programme. IB Research Notes, $4(1), 2-4$

Blackburn, R. (1991). The International Baccalaureate: A curriculum at upper secondary level and a university entrance examination. In P. Jonietz \& D. Harris (Eds.), World yearbook of education 1991: International schools and international education (pp. 6-14). London: Kogan Page.

Brown, J. D. (2001). Using surveys in language programs. Cambridge, England: Cambridge University Press.

Bunnell, T. (2008). The global growth of the International Baccalaureate Diploma Programme over the first 40 years: A critical assessment. Comparative Education, 44(4), 409-424.

Bunnell, T. (2010). The International Baccalaureate and a framework for class consciousness: The potential outcomes of a "class-for-itself." Discourse: Studies in the Cultural Politics of Education, 3l(3), 351-362.

Bunnell, T. (2011). The International Baccalaureate in the United States: From Relative inactivity to imbalance. The Educational Forum, 75, 66-79. 
Bunnell, T. (2014). The International Baccalaureate and its "Second Era" of ambitious rhetoric: Wider access and greater impact. In D. P. Hobson \& I. Silova (Eds.), Globalizing minds: Rhetoric and realities in international schools (pp. 137-157). Charlotte, NC: Information Age Publishing, Inc.

Byrd, S., Ellington, L., Gross, P., Jago, C., \& Stern, S. (2007). Advanced Placement and International Baccalaureate: Do they deserve gold star status? Washington, DC: Thomas B. Fordham Institute. Retrieved from http://edex.s3-us-west2.amazonaws.com/publication/pdfs/APIB 9 0. pdf

Cambridge, J. (2002). Response to Judy Hinrichs article. IB Research Notes, 2(1), 11. International Baccalaureate Organization. Retrieved from https://web.archive.org/web/20110105235113/http://www.ibo.org/programmes/research/ publications/documents/notesfebruary02.pdf

Cambridge, J. (2008). A review of research relating to the IB Diploma Programme. International Baccalaureate Organization (IBO). Retrieved from http://www.ibo.org/globalassets/publications/ib-research/dpresearchreview-1.pdf

Coates, H., Rosicka, C., \& MacMahon-Ball, M. (2007). Perceptions of the International Baccalaureate DiplomaProgramme among Australian and New Zealand Universities. Retrieved from http://www.ibo.org/contentassets/d1c0accb5b804676ae9e782b78c8bc1c/iboperceptionsre portfinal.pdf

Conner, J. O. (2008). From international schools to inner-city schools: The first principles of the International Baccalaureate Diploma Program. Teachers College Record, 110(2), 322351.

Daly, K. (2012). An exploration of Virginia law on recognition, university officials, and perceptions of the International Baccalaureate Diploma Programme (Unpublished $\mathrm{PhD}$ thesis). George Mason University, USA.

Doherty, C. (2009). The appeal of the International Baccalaureate in Australia's educational market: A curriculum of choice for mobile futures. Discourse: Studies in the Cultural Politics of Education, 30(1), 73-89.

Doherty, C., Luke, A., Shield, P., \& Hincksman, C. (2012). Choosing your niche: The social ecology of the International Baccalaureate Diploma in Australia. International Studies in Sociology of Education, 22(4), 311-332.

Fairclough, N., \& Wodak, R. (1997). Critical discourse analysis. In T. A. van Dijk (Ed.), Discourse as social interaction (pp. 258-284). London, UK: Sage.

Fitzgerald, S. (2015). Perceptions of the International Baccalaureate (IB) in Ontario universities. Canadian Journal of Education, 38(3), 1-34. 
Fox, E. (1998). The emergence of the International Baccalaureate as an impetus for curricular reform. In M. C. Hayden \& J. J. Thompson (Eds.), International education: Principles and practice (pp. 65-76). London, UK: Kogan Page.

Frank-Gemmill, G. (2013). The IB Diploma and UK university degree qualifications. Journal of Research in International Education, 12(1), 49-65.

Gardner-McTaggart, A. (2016). International elite, or global citizens? Equity, distinction and power: The International Baccalaureate and the rise of the South. Globalisation, Societies and Education, 14(1), 1-29.

Gehring, J. (2001). The International Baccalaureate: "Cadillac" of college-prep programs. Education Week, 20(32), p. 19. Retrieved from http://www.edweek.org/ew/articles/2001/04/25/32ib.h20.html

Green, F., \& Vignoles, A. (2012). An empirical method for deriving grade equivalence for university entrance qualifications: An application to A levels and the International Baccalaureate. Oxford Review of Education, 38(4), 473-491.

Halic, O. (2013). Postsecondary educational attainment of IB diploma candidates from US high schools. International Baccalaureate Organization. Retrieved from http://www.ibo.org/globalassets/publications/ibresearch/dp/nscpostsecondaryfullreportfinal.pdf

Hayden, M. C., \& Wong, C. S. D. (1997). The International Baccalaureate: International education and cultural preservation. Educational Studies, 23(3), 349-361.

Higher Education Statistics Agency (HESA). (2011). International Baccalaureate students studying at UK higher education institutions: How do they fare? Retrieved from http://www.ibo.org/contentassets/d74675437b4f4ab38312702599a432f1/hesaukpostsec f inal report.pdf

Hoey, M. (2005). Lexical priming: A new theory of words and language. London: Routledge.

International Baccalaureate Organization. (2003). 2003 Canadian survey of high school seniors participating in the International Baccalaureate Program. Retrieved from IBO website: https://web.archive.org/web/20130704093644/https://www.ibo.org/ibna/research/docume nts/2003StudentSurvey.Canada.pdf

International Baccalaureate Organization. (2007). The IB Diploma Programme: A guide for universities and colleges. Retrieved from IBO website:

https://web.archive.org/web/20130117051410/https:/www.ibo.org/communications/publi cations/documents/e_uni_recognition_brochure_07.PDF

International Baccalaureate Organization. (2015). University admissions officers suggest DP as best preparation for workplace and university. Retrieved from IBO website: http://www.ibo.org/en/news/news-about-the-ib/university-admissions-officers-suggestdp-as-best-preparation-for-workplace-and-university/ 
International Baccalaureate Organization. (2016). The IB Learner Profile. Retrieved from IBO website: http://www.ibo.org/en/benefits/learner-profile/

James, K. (2005). International education: The concept, and its relationship to intercultural education. Journal of Research in International Education, 4(3), 313-332.

Jenkins, C. (2003). Perceptions of the IB Diploma Programme. Retrieved from IBO website: http://www.ibo.org/contentassets/d1c0accb5b804676ae9e782b78c8bc1c/jenkinsukpercep $\underline{\text { tions.pdf }}$

Loat, W. (2007). Bridging the gap: The IB program as university preparation. AACRAO-SEM Newsletter. American Association of Collegiate Registrars and Admissions Officers. Retrieved from http://www4.aacrao.org/semsource/sem/index6861.html?fa=print\&id=3697

Mathews, J., \& Hill, I. (2005). Supertest: How the International Baccalaureate can strengthen our schools. Chicago: Open Court.

Matthews, M. (1989). The scale of international education. International Schools Journal, 17, 7 17.

May, H., \& Perna, L. (2011). A longitudinal analysis of student and school diversity in the International Baccalaureate (IB) diploma program in the U. S. Paper presented at the Annual Meeting of the American Educational Research Association, New Orleans. Retrieved from http://www.cpre.org/sites/default/files/meetingpaper/1373_aera2011ib.pdf

Mayer, A. P. (2006). Interrupting social reproduction: The implementation of an International Baccalaureate Diploma program in an urban high school (Unpublished doctoral dissertation). University of California.

O'Connor, R. P. (2011). Raising all boats? An examination of claims that the International Baccalaureate diploma program is good for all (Unpublished doctoral dissertation). University of Iowa.

Panich, C. (2001). A study of the university performance of students with International Baccalaureate high school experience (Unpublished PhD thesis). Duquesne University, Pittsburgh, PA.

Parker, W. C. (2011). "International education" in US public schools. Globalisation, Societies and Education, 9(3), 487-501.

Perna, L. W., May, H., Yee, A., Ransom, T., Rodriguez, A., \& Fester, R. (2011). The potential role of the International Baccalaureate (IB) Diploma Programme in improving academic preparation for college for all students. Paper presented at the Annual Meeting of the Association for the Study of Higher Education, Charlotte, North Carolina. Retrieved from http:/www.cpre.org/sites/default/files/meetingpaper/1372_ashe2011-ibpaper1232011.pdf 
Peterson, A. D. C. (1987). Schools across frontiers: The story of the International Baccalaureate and the United World Colleges. La Salle, IL: Open Court.

Piper, M. (2006). Universities and the IBO: Your mission is our mission. Peterson Lectures. International Baccalaureate Organization. Retrieved from IBO website: https://web.archive.org/web/20130603195906/https://www.ibo.org/council/peterson/piper documents/piper_lecture.pdf

Pook, G. (2009). External examinations beyond national borders: The International Baccalaureate. In B. Vlaardingerbroek \& N. Taylor (Eds.), Secondary school external examination systems: Reliability, robustness and resilience (pp. 319-336). Amherst, NY: Cambria Press.

Reisigl, M., \& Wodak, R. (2001). Discourse and discrimination: Rhetorics of racism and antisemitism. London, UK: Routledge.

Resnik, J. (2012). The denationalization of education and the expansion of the International Baccalaureate. Comparative Education Review, 56(2), 248-269.

Richardson, J. E., \& Wodak, R. (2009). Recontextualising fascist ideologies of the past: Rightwing discourses on employment and nativism in Austria and the United Kingdom. Critical Discourse Studies, 6(4), 251-267.

Rowell, P. M. (1983). Planning for the implementation of the International Baccalaureate Program: A situational study (Unpublished doctoral dissertation). University of Alberta, Edmonton, AB.

Spahn, B. A. (2001). America and the International Baccalaureate-Implementing the International Baccalaureate in the United States: A study of three schools. Suffolk, UK: John Catt Educational Ltd.

Stubbs, M. (2001). Texts, corpora and problems of interpretation: A response to Widdowson. Applied Linguistics, 22(2), 149-172.

Tarc, P. (2009). Global dreams, enduring tensions: International Baccalaureate program in a changing world. New York: Peter Lang.

Tarc, P., \& Beatty, L. (2012). The emergence of the International Baccalaureate Diploma in Ontario: Diffusion, pilot study and prospective research. Canadian Journal of Education, $35(4), 341-375$.

Tarver, E. T. (2010). University admissions officers' perceptions of student performance within the International Baccalaureate Diploma Program (Unpublished $\mathrm{PhD}$ thesis). Louisiana State University.

Verneuille, J. T. (2011). The potential impacts of implementing the International Baccalaureate program in the Sag Harbor Union Free School district(Unpublished Master's thesis). State University of New York. 
Vogt, W. P. (2007). Quantitative research methods for professionals. Boston, MA: Pearson.

Walker, G. (2005). Looking back and looking forward: The next 30 years. Plenary Address to the IBNA Annual Regional Conference, Montreal, $9^{\text {th }}$ July. Retrieved from https://web.archive.org/web/20070930201614/http://www.ibo.org/dg/emeritus/speeches/d ocuments/ibna jul05.pdf

Weenink, D. (2008). Cosmopolitanism as a form of capital: Parents preparing their children for a globalizing world. Sociology, 42(6), 1089-1106.

Whitehead, K. (2005). Advertising advantage. The International Baccalaureate, social justice and the marketisation of schooling. Paper presented at the Australian Association for Research in Education Annual Conference, University of Western Sydney, Parramatta. Retrieved from http://www.aare.edu.au/data/publications/2005/whi05426.pdf

Wodak, R. (2001). The discourse-historical approach. In R. Wodak \& M. Meyer (Eds.), Methods of critical discourse analysis (pp. 63-94). London: Sage.

Wodak, R. (2007). Pragmatics and critical discourse analysis. Pragmatics \& Cognition, 15(1), 203-225. 



\section{Chapter 7}

Murderers, moonwalkers and markets: A corpus based critical discourse analysis of the International Baccalaureate (IB) in Canadian newspapers

This chapter presents the study on how the IB is discursively constructed in a 1.5

million word corpus of Canadian newspapers through collocation and concordance analysis.

A fully edited, peer-reviewed version of this article was first published by Critical

Approaches to Discourse Analysis across Disciplines (CADAAD) Journal, 2017, Volume 9, Issue 1, Page 1 to Page 26. 


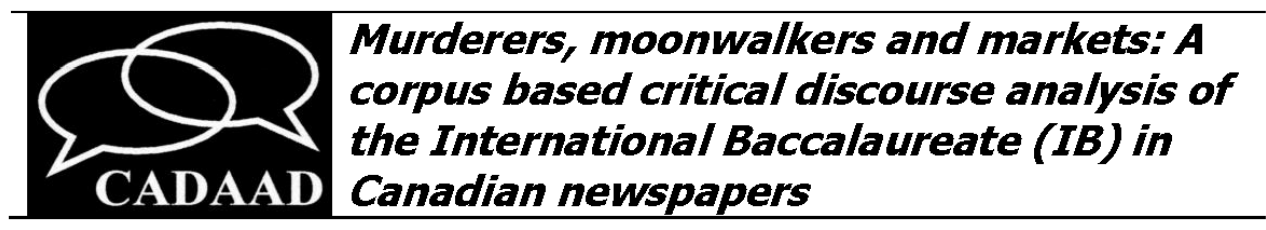

Copyright (C) 2017 Critical Approaches to Discourse Analysis across Disciplines www.cadaadjournal.com

Vol $9(1): 1-26$

\author{
SAIRA FITZGERALD \\ Carleton University \\ saira_fitzgerald@carleton.ca
}

\begin{abstract}
This paper examines the discursive construction of the International Baccalaureate (IB) in a 1.5 million word corpus of Canadian newspapers to see how different discourses not only reflect public perceptions but also shape them. The study combines corpus-driven and corpus-based methods together with critical discourse analysis to identify patterns of language that work to build up 'notions of typicality' (Hardt-Mautner 1995) in discourses surrounding the IB. Collocational and concordance analysis reveal a positive discourse prosody (Stubbs 2001) with underlying ideas of quality and morality. These values and attitudes, indicative of wider public opinion (majority discourse), have real world implications in terms of advantaging one group while disadvantaging another.
\end{abstract}

Key words: corpus, CDA, CDS, International Baccalaureate, IB, media, collocation

\title{
1. Introduction
}

Murderers, an astronaut, the real estate market - what connects these three very diverse topics? The answer is the International Baccalaureate (IB), a three-tier program of studies for students in kindergarten to grade $12(\mathrm{~K}-12)$, offered by the IB organization. ${ }^{1}$ In the first case, a 2004 news story that made headlines across Canada reported on the sentencing of two murderers. This story received wide coverage and shocked the nation because of the horrific nature of the crime which involved the bludgeoning of one of the killer's parents and disabled sister. Amidst all the gory details of the crime, the men, who were 19 years old at the time of the murders, were described as 'close friends and brilliant students in an international baccalaureate program'.

In the second case, a 1999 news story about Julie Payette, Canada's second woman in space and part of a seven-person crew going to the International Space Station, noted among her long list of achievements the 'International baccalaureate (1982)'. And in the third case, a recent trend was reported in a number of Canadian provinces of how real estate markets are 'heating up' and triggering 'bidding wars' in neighbourhoods where schools offer IB programs.

Each of the articles appears to assume that readers have some familiarity with, and therefore understand the passing reference to International Baccalaureate. Since little or no explanation is provided about what the IB is, 
these references appear to be accessing existing discourses surrounding the term, leaving the reader to draw inferences and conclusions based on associated values and assumptions. What might these discourses, values and assumptions be and how widespread are they?

The three very different semantic fields in which International Baccalaureate is mentioned in these articles, i.e., crime, space exploration, and real estate, suggest a phenomenon that is discursively constructed because it is not a fixed object confined to a single domain. Instead, International Baccalaureate appears to be flexible and to occur in a variety of contexts according to need (such as selling a house or listing a person's accomplishments). It also seems to indicate something different from a mere school curriculum. For example, substituting the words 'high school program' or 'primary school program' in any of the stories mentioned above would not have carried the same sort of weight. So although the IB is in fact a curriculum for students in kindergarten to grade 12, this aspect is backgrounded (van Leeuwen 1996) in the three news reports, in order to convey a different meaning.

With the important role that media play in both constructing and reflecting social reality (e.g., Baker 2006; Mautner 2008, 2009b), the aim of this study is to discover how International Baccalaureate is represented in the Canadian press, what values and attitudes appear to be associated with it, and what the implications of this representation might be in the wider social context. To address these questions, this study uses corpus linguistics combined with aspects of critical discourse analysis, referred to as 'a new 'hybrid' form of analysis' (Baker 2014: 213). This approach has become increasingly popular (Baker and Levon 2015; see also Baker and McEnery 2015) and is well suited for discovering overall linguistic trends, i.e., 'notions of typicality' (HardtMautner 1995) through large amounts of naturally occurring data, with a view to making explicit underlying assumptions that link lexical items to social practice and vice versa.

This paper is divided into the following sections. First, I situate the International Baccalaureate (IB) in the context of this research and explain why its representation might be considered 'problem-oriented' (Wodak and Meyer, 2016: 31). Second, I review relevant literature focussing on how corpus approaches to critical discourse analysis (CDA; also called critical discourse studies [CDS], see e.g., Wodak 2013: xxi) help identify trends and assumptions that work to construct groups in positive or negative ways. Third, I describe the data, the tools, and the analytical framework. Finally, I discuss the findings and offer some concluding remarks.

\section{Situating the International Baccalaureate (IB)}

The International Baccalaureate (IB) is a series of educational programs for students aged 3 to 19 offered in schools around the world. Originally created for a transient population in need of a portable and recognized curriculum, it has evolved to become an alternative to local curricula in countries such as Australia, the United States, the United Kingdom and Canada (e.g., Bagnall 1994, 2010; Bunnell 2011, 2012; Daly 2012; Paris 2003; Tarc \& Beatty 2012). For example, the number of IB schools in Canada has increased from 47 in 
1992 (Bagnall 1994) to 375 today (IBO 2017). However, with this move into publicly funded schools, issues of equity (i.e., only some have access) and the apparent debasing of the other curricula have started to emerge (e.g., W. Baker 2014; Doherty 2009; Resnik 2012; Tarc 2009; Whitehead 2005). The adoption of IB programs in publicly funded schools can be seen as problematic in terms of 'who benefits' - an important CDA/CDS question and even more so, who does not benefit in this situation (Baker et al. 2013b), i.e., students, teachers, and even schools that are excluded from enjoyment of extra resources and favourable treatment.

Although Canada ranks second highest in the world in terms of number of IB schools, research focussing on the impact of Canada's adoption of IB programs is relatively minimal. This paper is part of a larger study examining the discursive construction of the IB in the Canadian context, the aim of which is to discover the values and attitudes associated with the International Baccalaureate label, which appear to have become 'naturalized' (Baker 2010: 124) or taken for granted, as the three newspaper stories above seem to indicate. Suggestion of a hegemonic discourse surrounding the IB was found in the first stage of the study, which involved surveying admissions officers in Canadian universities about their views of the IB (Fitzgerald 2015, in press). This was seen as an important initial step in the research process (Baker 2005) and was based on similar surveys conducted in the United Kingdom (Jenkins 2003), Australia/New Zealand (Coates et al. 2007), and the United States (Daly 2012; Tarver 2010). What was notable about all of these was the uniformity of responses with respect to their positive views of the IB. In each case, participants rated the IB higher than their local curriculum, but also reported a lack of knowledge about what the program actually entailed. The consistent pattern of responses from so many different countries suggested the existence of a (positive) hegemonic IB discourse. As Stubbs (2001b: 215) argues, 'Repeated patterns show that evaluative meanings are not merely personal and idiosyncratic, but widely shared in a discourse community. A word, phrase or construction may trigger a cultural stereotype'.

To see whether a similarly positive view of the IB occurs outside the university context, the research was expanded to the public domain to see how the IB is represented, in what sorts of contexts it appears, and what types of linguistic patterns surround it, by looking at non-IB generated material as a way to identify wider societal trends. That is, the corpus used in this study is made up solely of articles produced by newspapers across Canada, and does not include any promotional and/or other material produced by the organization itself.

\section{Literature review}

Linking macro level social practice to micro level linguistic choices and vice versa is a key aspect of corpus based CDA/CDS research (e.g., Baker and McEnery 2005; Baker et al. 2013; Mautner 2008, 2009a). According to Mautner (2009b: 123), 'the way labels...are used reflects social attitudes, perspectives and categorizations. And the labels, in turn, shape the way in which social structures and relationships are perceived'. In this regard, to observe that a certain attitude or perspective is manifested linguistically, it is important to study not just the individual words or phrases themselves but 
also how they relate to or are embedded in the wider social, historical and political context, with each influencing and shaping the other. This dialectical relationship between a discursive event and the social structures framing it is a key tenet of this approach. Understanding how widespread or common such attitudes or perceptions might be, and how powerful or hegemonic their tendencies are, can be explored through corpus analysis, using large amounts of text and computer software tools to uncover patterns in the language. Corpus analysis makes it possible to uncover the semantic relations associated with particular words, phrases and expressions, and thereby determine the webs of meaning they convey. Discovering the particular types of 'semantic load' or 'semantic aura' (Mautner 2009b: 127-128) that words and phrases carry provides insight into the kind of ideological work they are doing, and their association with particular social issues and attitudes. A further benefit of the 'useful methodological synergy' (Baker et al. 2008) of corpus based CDA/CDS is that it helps guard against the potential shortcomings of each approach, such as inadvertently cherry-picking a few examples on the one hand, or focusing solely on decontextualized data on the other (e.g., Baker 2006; Mautner 2009b).

This approach was pioneered by Hardt-Mautner (1995) in her study of EC/EU discourse in the British press, where a clear mismatch between the qualitative (CDA) approach and the quantity of data to be analyzed required the use of corpus tools to aid the analysis. Later studies focussed on the discursive construction of various groups, such as refugees and asylum seekers in UN and newspaper texts (Baker and McEnery 2005; see also Baker et al. 2008; Gabrielatos and Baker 2008), gay men in different social contexts (Baker 2005), the elderly and the unemployed in large corpora of general English (Mautner 2007, 2009b), Muslims and Islam in the British press (Baker et al. 2013a, 2013b), and Trans people and foreign doctors in the British press (Baker 2014; Baker and McEnery 2014). In each case, recurring linguistic patterns were found that tended to embody values and attitudes towards different groups which were not always explicit or easily intuited. As O'Halloran and Coffin (2004: 279) put it, there is a certain 'feel' to something but we are unsure why.

Referred to as semantic or discourse prosody (Baker 2006; Louw 1993; Stubbs 2001), such attitudes and values are reflective of the response of a wider social community (Stubbs 2001), rather than a solely personal one. The repeated patterns of words and phrases contribute to the incremental or cumulative effect of discourse' (Baker 2006: 13) 'priming' (Hoey 2005) particular interpretations that gradually come to be viewed as common-sense ways of thinking or are taken for granted (Stubbs 1996). Using a large corpus allows us to observe how words behave in relation to their frequency and patterns of usage. Such recurring patterns often point to dominant discourses or habitual ways of talking about particular groups, which further work to reinforce stereotypes.

For example, in his study of bachelor and spinster, Baker (2006) noted that while both words refer to unmarried adults and could be viewed as semantic equivalents, each carries a very different discourse prosody as evidenced by the words that collocated (co-occurred) with them, making one appear in a more positive light than the other. Similarly, Mautner (2009b) analyzed 
collocations of the word unemployed as it occurred in a corpus of British newspapers, and found that it co-occurred with negative attributes such as desperate, disadvantaged, divorced, homeless. The important point here is that such associative meanings have less to do with simple description (e.g., a person who is unmarried or a person who does not have a job) and more to do with societal value judgments. Through a word's 'collocational profile' (Mautner 2007: 52), it is possible to gain insight into the typical kinds of values and attitudes associated with it. As these become entrenched and taken for granted through frequent repetition, a word can become primed so that even when it appears without the usual collocates, it still carries the meanings that have come to be associated with it, making such usage difficult to challenge. As Tognini-Bonelli (2001: 111) makes clear, 'words which are coselected do not maintain their independence'.

\section{Analytical Framework}

This study uses corpus tools to obtain a collocation profile of International Baccalaureate $(I B)$ as it occurs in a specialized corpus of Canadian newspapers. Collocates are also examined in a large corpus of general English to further aid interpretation (e.g., Baker 2013; Mautner 2007). The aim is to uncover the cumulative effects of language and gain a fuller understanding of how a picture is built up from word-level to more abstract evaluative attitudes or auras surrounding $I B .^{2}$ Three interrelated concepts are important for this purpose: (i) collocation; (ii) semantic preference; and (iii) discourse prosody. Although the distinction between some of these is not always clear-cut (Stubbs 2001), they are presented separately below for the purposes of discussion. Drawing on these concepts, the present study aims to discover which words tend to occur in close proximity to $I B$, and whether they contribute evaluative or descriptive meanings.

\subsection{Collocation}

Collocation refers to words that tend to occur near each other more often than we might expect if the words were in random order, such as innocent bystander (Baker et al. 2006). Understanding words in relation to the company they keep (Firth 1957: 6) is useful for discovering the kinds of attitudes or assumptions they embody, and how these attitudes imbue words with meaning' (Baker 2016: 140). Observing the behaviour of words in relation to their collocates also allows for unexpected or surprising findings about seemingly innocuous words (e.g., Stubbs 2001; Tognini-Bonelli 2004). What might appear at first glance to be a straightforward description could turn out to be more evaluative. In addition, as Hunston (2002: 119) argues, collocations can become 'fixed phrases that represent a packaging of information' and, as such, be more difficult to challenge or perhaps even notice as they get picked up and repeated, thereby contributing to what Baker (2006) calls the incremental effect of discourse.

\subsection{Semantic Preference}

Based on the idea that there are many ways to say the same thing, moving 
beyond individual words to semantically related groups allows for the identification of dominant discourses, i.e., what is typical in the wider society. Semantic preference is defined by Stubbs (2001: 65) as the relation not between individual words, but between a lemma or word-form and a set of semantically related words'. For example, Mautner (2007) found that the word elderly tended to co-occur with groups of words related to the semantic domain of disability, frailty and care, while Baker (2006: 87) found that the word refugee showed a semantic preference for quantification. The semantic categories associated with particular words help reveal how they are typically represented 'independent of speakers', thereby providing insight not only into the different layers of meaning, but also how a lexical item might function in the wider social context.

\subsection{Discourse Prosody}

According to Stubbs (2001: 65), discourse prosody is related to semantic preference but expresses speaker attitude and is evaluative. Unlike semantic prosody (Louw 1993; Sinclair 1991), Stubbs argues that discourse prosody not only maintains the relation to speakers, but also works at a more abstract level, having 'great lexical variability' (88). As such, meaning is built up through repeated and shared usage, having a cumulative positive or negative effect. Analysis of such trends and patterns makes it possible to identify societal value judgements associated with lexical items (Mautner 2007), giving them an evaluative aura of meaning which is 'an indication that something is good or bad' (Hunston 2004: 159). As such, discourse prosody contributes to meaning that may not be evident through intuition or a small selection of texts, but which can be detected through numerous examples made possible by a large corpus (Partington 2004).

\section{Method}

\subsection{The Corpus}

Articles for the specialized IB media corpus were obtained through two online news databases, Canada Newsstand Complete and LexisNexis Academic, using the search terms international AND baccalaureate, ib AND diploma OR student. These search terms were determined based on prior knowledge and encounters with the topic. All Canadian newspapers (national, regional, local, and community (paid or free)) available at the time of the search were included to ensure maximum representation of public attitudes and perceptions.

Selecting all the articles provided by the two databases avoided the possibility of selection bias, i.e., inadvertently focusing only on articles that suited my purposes. In addition, it also allowed for a greater unsolicited window into public opinion (Mautner 2008), as it included not just powerful elite sources, but letters and opinion pieces from parents, students and other members of the public. As such, the IB media corpus is varied, containing maximum coverage on the topic as available on the two news databases (McEnery and Hardie 2012; Seale 2003). It is also important to note that the IB media corpus contains articles that are produced and reproduced (constructed) by 
different segments of society rather than generated by the IB organization itself.

Once the data were cleaned by removing repeated or erroneous articles (e.g., section $1 \mathrm{~B}$ being misread as $\mathrm{IB}$ ) and deleting extraneous information such as author names, publication dates, etc., the final IB media corpus contained 2,326 articles from 1977 to 2016 and consisted of 1,521,796 words. Articles were not sorted by genre, i.e., editorial opinion, letters, features, etc. (see Baker et al. 2013b: 266), but grouped together according to newspaper since the focus of the study was to establish overall trends in terms of how $I B$ was talked about in general rather than how it occurred in specific contexts.

As Mautner (2009b: 133) states, it is important to verify interpretations against a larger reference corpus, particularly when using a small specialized corpus, to see what kind of 'collocational baggage' words carry in the 'wider universe of discourse'. The Corpus of Contemporary American English (COCA; Davis 2015), a corpus of 520 million words comprising texts from fiction, magazines, newspapers, academic and spoken genres from 1990-2015, was used as a reference corpus to compare words or patterns found in the IB media corpus to how the words behave in general English and the semantic preferences and discourse prosodies they exhibit. COCA was selected because it covers a time period closest to that of the IB media corpus and, due to close geographical proximity, also contains a similar variety of English (Baker 2013).

\subsection{Data and Analysis}

Different corpus tools yield different results and therefore, as Anthony (2013) argues, the tool is as important in the analysis as the corpus data. For this study, AntConc (Anthony 2014), a freeware corpus analysis toolkit, was used. AntConc provides a number of ways that corpus data can be sorted to make different patterns visible. It also allows collocations of search terms to be obtained through a statistical choice of Mutual Information (MI) or t-score. MI is a measure of collocational strength: the higher the number, the stronger the collocation (Baker 2006, 2016); t-score, on the other hand, measures certainty and therefore tends to highlight high frequency grammatical words (Mautner 2007). For this study, the MI statistic was chosen because it favours content words over grammatical ones, and also indicates the strength of relationships between words, i.e., the likelihood of them occurring next to each other rather than separately. This statistic also identifies rare or less frequent words as collocates, which was important because of the size and specialized nature of the corpus, where rare but strong collocations might reveal additional (minority) discourses (see Baker et al. 2013a: 262; Gabrielatos and Baker 2008: 11). An MI score of 3 or above was required, which has generally been accepted as evidence for collocation (e.g., Baker 2006; Hunston 2002; Mautner 2007) as well as a minimum joint frequency of 5 (Baker 2014; Mautner 2007). In addition, proper names and function words were excluded from the list.

Collocations provide a useful entry point into the data, highlighting the most salient lexical patterns. However, due to the specialized corpus, once collocations were identified, all occurrences of the word were examined to see 
how they behaved. This was done by manually scanning concordance lines, which can be sorted alphabetically to the left or right of the search term, making it easier to spot patterns. They also provide the immediate context (co-text) in which the search term appears, and can be expanded to reveal more text as required. Looking at all the occurrences of the word was considered important in order to ensure that no instances that related to $I B$ were overlooked, and also to see how the words behaved when they were not co-occurring with $I B$.

\subsection{Discovering Discourse Prosody through Collocations}

The node word chosen to obtain collocates was baccalaureate, 3 since a preliminary scan of concordance lines showed that, on occasion, this was the term used rather than international baccalaureate. The default span for collocates on AntConc is five words to the left and right of the search term or node. However, in the IB media corpus, the node baccalaureate occurs in varying phrasal structures that occupy most of this span, e.g., International Baccalaureate (IB) World School. Since international and other words such as program or diploma are more likely to be present within the 5-word span and reference to $I B$ is often presented in formulaic chunks, a $5 \mathrm{~L} / 5 \mathrm{R}$ span for collocates of baccalaureate was considered too narrow to identify words that frequently co-occur with International Baccalaureate [+phrase]. Therefore, to obtain a more representative set of collocates, the span was expanded to 10 words to the left and right of the node (see Baker 2006; Baker et al. 2013b; McEnery and Hardie 2012).

A list of the 100 strongest collocates (see Appendix 1) was obtained to gain insight into the dominant representation of IB in the corpus. To understand how collocates were used in context, concordance lines and, when necessary, full articles, were examined. Collocates that indexed similar concepts were grouped together according to semantic categories that emerged (see Appendix 2). Although the process of grouping and labelling is subjective (e.g., Marchi and Taylor 2009), it helps to draw out semantic preferences and related discourse prosodies. This article discusses the strongest 10 collocates, which are presented in Table 1.

\begin{tabular}{ll}
\hline Category & Collocations \\
Global outlook & international \\
Geographical location & geneva, swiss, switzerland \\
External oversight/regulation & examiner, authorized, candidacy, monitored \\
Names and types of curricula & programme \\
Attributes & rigorous \\
\hline
\end{tabular}

Table 1: Top 10 collocates for baccalaureate organized by category

Since the semantic category of geographical location was the most unexpected and therefore interesting, it is discussed first, while global outlook is deferred to the end of this section. 


\subsubsection{Geographical location: geneva, swiss, switzerland}

The occurrence of these three collocates in the top 10 indicates strong association with the node word. The IB is administered, based, created, established, founded, headquartered in Geneva, from where it reportedly oversees hundreds of schools around the world. Concordance lines of these three collocates reveal references to united nations, UNESCO, and non-profit educational foundation, as well as to children of diplomats and military personnel. All of this suggests that these three collocates realize a link between $I B$ and $\mathrm{UN}$ agencies. This link is further reinforced by frequent descriptions of the IB as created in the wake of the second world war and having a mission to create a more peaceful world.

\begin{tabular}{lll}
\hline $\begin{array}{l}\text { United Nations General Assembly } \\
\text { took a detour on the way to }\end{array}$ & Geneva & $\begin{array}{l}\text { and convened at McNally high } \\
\text { school }\end{array}$ \\
$\begin{array}{l}\text { The diploma was developed in the Geneva } \\
1960 \text { in }\end{array}$ & for children of United Nations \\
$\begin{array}{l}\text { Founded in the 1960's - C chartered Swiss } \\
\text { foundation under the }\end{array}$ & $\begin{array}{l}\text { Civil code with headquarters in } \\
\text { Geneva - Consultative status with } \\
\text { the United Nations } \\
\text { Education }\end{array}$ \\
\hline
\end{tabular}

Table 2: IB linked to UN

As can be seen in Table 2, through the collocates geneva and swiss, the IB is explicitly linked to the UN. Expanded concordance lines show that such references typically occur when relating IB genealogy, as the IB organization began in Geneva. Although it now also has offices in other parts of the world (Singapore, the US, the Hague), the connection to Switzerland remains strong, as indicated by the three collocates. The connection between the IB and UN agencies, based on their common geographical location, has been commented on by some researchers (e.g., Cambridge 2002) and, in fact, became so strong that this relationship had to be explicitly disavowed by the IB organization in response to vocal opposition to the organization's 'UN values' in the United States (IBO 2014).

The collocates switzerland and swiss both tend to occur in descriptions of the IB as a non-profit organization, as shown in Table 3:

\begin{tabular}{lll}
\hline $\begin{array}{l}\text { International Baccalaureate } \\
\text { Programme is a nonprofit } \\
\text { foundation, based in }\end{array}$ & Switzerland & $\begin{array}{l}\text { established 44 years ago. MYP } \\
\text { aligns }\end{array}$ \\
$\begin{array}{l}\text { Baccalaureate concept is a non- } \\
\text { profit international educational } \\
\text { foundation based in }\end{array}$ & Switzerland & $\begin{array}{l}\text { that has four programs for } \\
\text { children aged 3-19. }\end{array}$ \\
$\begin{array}{l}\text { IBO (International Baccalaureate } \\
\text { Program) is a non-profit }\end{array}$ & Swiss & $\begin{array}{l}\text { educational program } \\
\text { established in 1968. }\end{array}$ \\
\hline
\end{tabular}


Table 3: IB as non-profit organization

The repetition of non-profit together with switzerland and swiss when describing the IB seems to be accessing a discourse of aid or philanthropy, constructing it as an organization concerned with humanitarian values. This suggests that the IB organization has a charitable or benevolent aspect, motivated not by personal gain or profit but rather by a more virtuous principle or belief in a greater good.

A further aspect is revealed in the use of swiss to indicate high quality, as in the concordance lines shown in Table 4below:

\begin{tabular}{lll}
\hline $\begin{array}{l}\text { schools such as Edmonton's Jasper } \\
\text { Place, which he calls the }\end{array}$ & Swiss & $\begin{array}{l}\text { Watch of High Schools.' It ranks } \\
\text { among }\end{array}$ \\
$\begin{array}{l}\text { have held a constant value over time } \\
\text { like the }\end{array}$ & Swiss & $\begin{array}{l}\text { franc, whereas Ontario marks } \\
\text { have eroded }\end{array}$ \\
$\begin{array}{l}\text { world, including 30o in Canada. The Swiss } \\
\text { program is governed by a }\end{array}$ & $\begin{array}{l}\text {-based organization and is widely } \\
\text { regarded as one of the most } \\
\text { respected }\end{array}$ \\
$\begin{array}{l}\text { the International Baccalaureate } \\
\text { Middle Years system, a prestigious }\end{array}$ & $\begin{array}{l}\text { Srogram which emphasizes the } \\
\text { importance }\end{array}$ \\
\hline
\end{tabular}

Table 4: IB linked to quality

Although the references to Swiss watch and Swiss franc may not be understood by everyone, the context in which they occur provides the requisite guidance as to how the recipient should interpret them, which is clearly positive. The latter two concordance lines are less ambiguous in their use of evaluative attributes (most respected, prestigious) to associate quality with swiss. To see whether this notion of 'Swiss quality' also occurred outside the IB media corpus, a search in COCA was conducted and found a semantic preference for specific foods (cheese, chocolate), tools (army knife, watch), and finance (bank(s), account(s)), further reinforcing a discourse prosody of quality associated with swiss.

COCA was also searched to see how switzerland and geneva were used outside the IB media corpus. While switzerland collocates most strongly with geneva, followed by germany, france, lausanne, basel, showing a semantic preference for lexical items denoting different geographical locations, geneva collocates most strongly with convention(s) followed by words related to the activities of international organizations (talks, meetings, conference) and aspects of international law (rights, peace). Together, these suggest a discourse prosody of universality and global concerns, with a dimension of humanitarian values in terms of human rights and peaceful coexistence. The IB, by frequently being associated with geneva and switzerland, as well as being described as non-profit, thereby exhibiting a semantic preference for lexical items related to international concerns, also seems to acquire a humanitarian and philanthropic discourse prosody.

Thus, what might at first glance appear to be the provision of geographical 
information in a purely descriptive fashion upon closer examination seems to draw on a discourse prosody of humanitarian values that transcend a particular nation (UN, international, Geneva conventions, rights) and high quality of service based on universal values. In other words, by repeating swiss, geneva, switzerland, associated values such as human rights, quality, and neutrality could influence how $I B$ is viewed, indicative more of social attitudes than school curriculum (Mautner 2007).

5.3.2 External oversight/regulation: examiner, authorized, candidacy, monitored

These collocates were grouped together because they refer to regulatory aspects of the IB organization. The occurrence of four such collocates in the top 10 serves to construct $I B$ as an organization that not only operates according to a set of rules, but also has official roles for oversight or accountability. This may add to the notion of quality and stability suggested by the swiss group of collocates.

Of the 11 occurrences of examiner, seven refer to specific individuals who perform this function for the organization. The remaining five refer in general to an international IB examiner who evaluates the work produced by students enrolled in the IB program. Interestingly, the strongest collocates for examiner in COCA are medical, office, forensic, report about investigations into causes of death and autopsy reports. The idea of an international examiner' could thus suggest an impartial professional, skilled at sifting and evaluating, who will ultimately arrive at the truth of some matter in an objective way.

Concordance lines for the two collocates authorized and candidacy show that they refer to the process that schools must undergo before they are allowed to offer an IB program. The strongest collocate for authorized in COCA is congress, followed by use, speak, force, act, again suggesting official sanction or permission. Of the 11 concordance lines for candidacy, four show schools applying for candidacy status while five have either applied or been granted candidacy. Two schools are mentioned as considering whether or not to apply for candidacy. The repetition of candidacy status in contexts of schools celebrating upon obtaining this status (toasted their latest victory) or being referred to as winners (the first school to receive), suggests a positive discourse prosody associated with success and achievement or excellence (bringing to mind again the aspects of quality associated with swiss). A search in COCA shows that candidacy collocates most strongly with his, as in his presidential candidacy, followed by announced, presidential, perot, clinton, suggesting a semantic preference for words linked to elections. As such, candidacy may suggest notions of competition and fitness for purpose, i.e., even to be considered a candidate, certain requirements must be met, again reinforcing the discourse prosody of quality.

All occurrences for monitored in the IB media corpus refer to examinations, schools, program and standards which are monitored by an international organization, the foundation or the IB. Adverbs that occur with monitored are internationally, carefully, closely, suggesting that these different aspects of the IB, whether concrete (such as examinations and schools) or more abstract (such as standards) are subject to scrutiny to ensure that quality is 
maintained. Similar collocates for monitored are found in COCA, the strongest being closely, followed by being, carefully, progress, continuously. This suggests a semantic preference for words related to care and precision, perhaps for reasons of accountability. This further contributes to the construction of $I B$ as having quality assurance in a way that is set against the 'falling standards' prosody of mainstream education discourse (Stubbs 1996: 194).

\subsubsection{Names and types of curricula: programme}

Of the 165 instances of programme, almost all occur exclusively as part of the name of an IB curriculum (diploma programme, middle years programme, primary years programme) or as a general reference to ib programme, international baccalaureate programme. Ten instances which are not about the IB refer to musical performances (8) and sports in education (2). The word program occurs much more frequently in the corpus (2156) but has a less exclusive relationship with $I B$ and appears lower down the list of collocates (\#21). One obvious explanation for this difference has to do with American vs. British spellings, programme being the British variant of the American program, both of which are used in Canadian English. This type of usage can be seen in the following concordance line:

$\begin{aligned} & \text { his call to open an International programme, } \\ & \text { Baccalaureate }\end{aligned}$
$\begin{aligned} & \text { a program geared toward the } \\ & \text { school }\end{aligned}$

In this example, both spellings are used, one specifically connected to $I B$ and the other to describe it in a more general manner. Interestingly, while the words differ in spelling but seem to have the same meaning (as indicated in dictionaries and through a Google search), the two words exhibit rather different semantic preferences in COCA (which, as a corpus of American English, is expected to exhibit a linguistic distinction between the two spellings in a similar way to the IB media corpus). The strongest collocates for programme in COCA are UN organizations (nations, united, environment, development, food), followed by education and health (which also includes reference to the World Health Organization). On the other hand, program collocates most strongly with nuclear, weapons followed by training, designed, welcome, pilot suggesting different types of social concerns from high stakes (nuclear, weapons, space) to more specialized or specific events (designed, training, welcome, pilot). So in COCA, programme exhibits a semantic preference for UN-related words, whereas program has a wider range. In terms of $I B$ program/programme then, a discourse prosody relating to events or activities of social importance seems to be suggested, as well as a further (implied) connection to UN organizations.

\subsubsection{Attributes: rigorous}

Of the 201 occurrences of rigorous in the IB media corpus, 177 refer to $I B$, most frequently with the word academic (26) plus challenge, curriculum, program, studies. Other words include demanding, highly esteemed, intellectually challenging, more work, one of the most interesting programs, rich high school experience, pressure. The remaining 24 refer to schools, training, teaching and standards. The frequency of rigorous in the vicinity of $I B$ was noted by Doherty (2009: 12-13) in her study of IB discourse in 
Australia, where she argues that 'if the IB is seen to 'own' the qualities of 'academic rigour', 'challenge', 'well-roundedness', such claims create and promote a perception of their absence in other curricula'. In the IB media corpus, the appearance of rigorous in the top 10 collocates confirms the strong bond between the two. Furthermore, concordance lines for rigorous also reveal comparisons with other curricula, as shown in Table 5. In this case, rather than implying or alluding, $I B$ is explicitly constructed as being more rigorous than the regular curriculum.

\begin{tabular}{|c|c|c|}
\hline 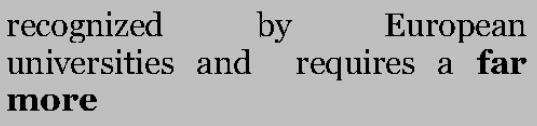 & rigorous & $\begin{array}{l}\text { academic preparation than the } \\
\text { standard U.S. high school } \\
\text { diploma }\end{array}$ \\
\hline $\begin{array}{l}\text { internationally recognized } \\
\text { diplomas are "much more }\end{array}$ & rigorous & $\begin{array}{l}\text { than Alberta diploma } \\
\text { curriculums, " says }\end{array}$ \\
\hline $\begin{array}{l}\text { also offers the International } \\
\text { Baccalaureate, a }\end{array}$ & rigorous & $\begin{array}{l}\text { program that expects more of } \\
\text { students than the usual OAC } \\
\text { demands- }\end{array}$ \\
\hline $\begin{array}{l}\text { took the international } \\
\text { baccalaureate program, which is } \\
\text { more }\end{array}$ & rigorous & than the regular curriculum \\
\hline
\end{tabular}

Table 5: IB as more rigorous than other curricula

Further examination in COCA found that the strongest collocate for rigorous is standards, followed by training, research, testing, process, program, and further down, curriculum and academic. This suggests a semantic preference for words relating to strict standards in the education and training domain. Thus, although dictionary and Google definitions of rigorous seem to carry a negative discourse prosody due to synonyms such as strict, harsh, severe (see also Partington 2004: 150), in the context of education and curriculum it seems to be a positive and desirable quality, something that sets it apart from the rest. Therefore, repeated references to $I B$ as rigorous suggest that it has the kind of quality that is lacking in other (regular) curricula.

\subsubsection{Global outlook: international}

Unsurprisingly, international collocates strongly with baccalaureate and is the first lexical item in the top 10. However, more than a quarter of the occurrences (1178) in the IB media corpus occur outside the collocational threshold. Concordance lines show that the context of this collocate is diverse and touches on a variety of topics that concern society, from sports (sport and recreation, olympic committee) to education (academic program, achievement tests, assessments, assignments) to humanitarian or diplomatic concerns (amnesty, agencies, aid). Other contexts appear to differentiate groups, e.g., international and canadian, international and domestic, international and local. These constructions work to present a binary opposition (Baker 2010), which might suggest opposing views, one being outward and global, the other inward and local. Furthermore, capacities or abilities are linked to the term, e.g., international and intercultural 
understanding, international awareness, suggesting that such pluralistic attitudes are more likely to be found in things international than local or national.

There are also references to organizations other than the IB (amnesty international, international monetary fund, international space station, international development agency). As international in the name conveys, each of these is concerned (ostensibly) with issues beyond those of a single country. Similarly, international baccalaureate may also carry an aura or discourse prosody of an organization that has an outward, global concern rather than a parochial and narrow one, by virtue of its name.

In COCA, the strongest collocate for international is community, followed by law, airport, trade, relations. Other collocates include development, organizations, aid, and also baccalaureate. It would appear, then, that international tends to co-occur with, and thus has a semantic preference for, words denoting travel, regulation, and global concerns, suggesting a discourse prosody of universality and governance which impacts everyone around the world (the international community). As a context for international baccalaureate, this may lend it a significance that goes beyond just a curriculum for students aged 3 to 19.

\subsubsection{Summary of findings}

In summary, the 10 strongest collocates for baccalaureate point to the representation of an organization motivated by universal humanitarian concerns, adhering to strict standards that assure a high level of quality for its programs. The dominant discourse prosody seems to be positive, embodying values and attitudes that work to elevate the importance and role of $I B$ beyond that of one curriculum among others. In other words, $I B$ seems to attract lexical items that have more to do with particular social values than to curriculum (e.g., Baker 2006; Mautner 2007). To see what kinds of words might be expected in relation to curriculum in general English, a search was conducted in COCA. The strongest collocate was school, followed by education, development, students, core, instruction. We can see, then, how the collocational profile for baccalaureate constructs a quite different picture.

\section{Discussion}

The aim of this study was to discover how International Baccalaureate (IB) is represented in a corpus of Canadian newspapers in order to gain insight into how the Canadian public in diverse roles (as evidenced by the array of contexts and types of articles) views the IB, i.e., what values and attitudes are typically associated with the label, and the implications this representation might have in terms of its impact on the wider society. By using $I B$ as a label, traits and qualities get carried over as part of the name and, as such, are not always mentioned explicitly but draw on the label and discourse prosody to bring them to the fore. Hoey (2005: 13) argues that 'every word is primed for use in discourse as a result of the cumulative effects of an individual's encounters with the word'. As such, if we repeatedly encounter words having positive or negative prosodies, we may be primed to expect a positive or negative meaning, and at the same time, reproduce and reinforce the prosody. 
As Stubbs (1996: 92) points out,

...if particular lexical and grammatical choices are regularly made, and if people and things are repeatedly talked about in certain ways, then it is plausible that this will affect how they are thought about.

Although Partington (2015: 241) reminds us that 'newspapers are usually critical of their society' and thus 'most social issues and groups will be spoken about more often in negative contexts than in positive ones', this is not the case for $I B$ and the way it is talked about in this media corpus, which seems predominantly positive.

Through collocation analysis, it is possible to tease apart 'fixed phrases' (Hunston 2002) that contribute to the packaging of $I B$. As has been shown, there is a discourse prosody of global importance or prestige associated with the word international that may not be thought about consciously but, through repetition and reification, becomes taken for granted as part of the meaning of $I B$. Phrases such as worldwide, around the world, all over the world, across the world, internationally recognized, globally recognized are repeated in descriptions of the IB, emphasizing the idea that students have some sort of global access instead of being confined to their local institution or home country. The juxtaposition suggests an implicit 'international good, local bad' dichotomy. Presenting $I B$ as recognizable no matter where one goes also enacts the 'international passport to education' (Blackburn 1991) idea that was central to its creation, since it was designed with itinerant lifestyles of the diplomatic world in mind. Again, there is an implied comparison, in which one is outward-looking and global whereas the other is insular and parochial.

A further aspect to the notion of universality and global importance is offered by Bunnell (2011: 67), who says that, for the IB, "international' means free of government and national identity'. Doherty (2009: 78) notes that this carries with it a 'moral discourse of internationalism' that emphasizes cooperation and unity across political and racial or ethnic boundaries as opposed to focusing solely on national or self-interest. This ideology of internationalism underpins the IB and formed a key part in its creation, which is reflected in the IB organization's mission statement (IBO 2017).

Other fixed phrases contributing to the packaging of $I B$ information found in the collocation analysis are the repeated references to geneva, switzerland or swiss-based. Ostensibly mentioned in relation to the IB's history, the societal value judgements associated with these words become visible through their semantic preferences and discourse prosodies. What is interesting about the frequent repetition to Swiss-related terms is the absence of reference to other countries that played a key role in the development of the IB curriculum (the US, France, Germany, the UK). In addition, what also tends to get masked or obscured is that the highest number of IB schools in the world are in the US and Canada. This 'hugely disproportionate' (Bunnell 2011: 69) North American presence gets hidden in the emphasis on 'worldwide' and 'international'.

The absence of other countries and the repeated link to Switzerland may serve to emphasize the notion that $I B$ does not favour any individual country but works for all equally. In her analysis of IB organizational discourse, Hahn 
(2003: 102) found that the organization plays up its neutral and nongovernmental aspect in order to convey the image of a UN-type organization with a firmly humanitarian and non-profit charitable mission, rather than that of a business engaged in education. In addition, with offices around the world, it actively promotes its international image, i.e., it transcends the nation (Hahn 2003) and is therefore ostensibly free of national bias. In this construction, what gets backgrounded is that this is in reference to a curriculum that was developed more for pragmatic than idealistic reasons (i.e., admission to universities rather than world peace). In most descriptions of IB history and the creation of the curriculum, emphasis is typically placed on the idealistic vision of the founders (Cambridge 2002; Hahn 2003).

References to $I B$ authorization also appear as fixed phrases with little explanation, providing another example of packaging information. A school can call itself $I B$ World School only when it is certified by the IB organization. This process takes several years and requires the school to 'measure up' to standards stipulated by the organization. Being successful at gaining this authorization gives a school the status associated with being named an $I B$ World School and becoming part of the 'international community' of such schools. Being vetted and deemed suitable by the IB organization, described as having strict standards that are respected and applied around the world, works to elevate the status of the school. This becomes an important factor in situations where schools may be facing potential closure due to declining enrolment and reduced funding.

Returning to the question of who does not benefit (Baker et al. 2013b) as a result of this positive representation, it would appear that these are the ones who are not part of the IB community. The non-IB students, teachers and schools are disadvantaged through the construction of $I B$, whose dominant positive discourse prosody seems to be bound up with the construction of a negative other. Such a construction, through repetition, becomes normalized and therefore more difficult to challenge. However, there are signs of an emerging 'resistant discourse' (Baker 2006: 14). For example, a presentation at the 2016 IB Conference of the Americas noted a 'sense of resentment that often [provincial curriculum] requirements are less onerous' (IBO 2016).

\section{Conclusion}

This paper has examined the discursive construction of $I B$ in the Canadian press to understand how different discourses not only reflect but also shape public perceptions. Through collocation analysis, patterns of language use were identified and analyzed in terms of their semantic preference and discourse prosody. Results suggest that the positive aura surrounding $I B$ is actively co-constructed by different segments of society represented in the IB media corpus. As such, they help to shed light on how this representation contributes to the 'production, elaboration and circulation' (Baker and Levon 2016: 111) of discourses surrounding $I B$. The similarity of positive views regarding $I B$ in very different contexts may also point to the occurrence of lexical priming.

Qualities that are routinely associated with the IB label simultaneously 
construct a group that lacks those qualities and as a result are placed at a disadvantage. In the context of publicly funded education (ostensibly promoting equity), this gets manifested in an imbalance of resource allocation, overcrowded classrooms, and additional burdens placed on those not part of the $I B$ world (e.g., Baluja and Hammer 2012). While care should be taken to not generalize findings beyond the corpus (Baker 2013), results do cohere with other studies that not only show a similar positive view, but also list the same catalogue of values and assumptions.

Notions of quality and morality associated with $I B$ may help explain why an article about an astronaut's achievements would refer to her having once been an IB student. The article about the murderers referred to as 'brilliant' and students in the 'highly respected IB program', seems to suggest that they once had great potential but sadly did not live up to it. The expansion of $I B$ value into the real estate market shows how influential public perceptions of the IB are, having real-world economic impact that goes well beyond the domain of a $\mathrm{K}-12$ curriculum.

\section{Notes}

1 Formerly called the IBO, both the organization and programs now generally get referred to by the single title International Baccalaureate (IB).

2 For simplicity, the italicized acronym $I B$ is used to refer to the node word baccalaureate.

3 It is important to note that in this specialized corpus, all instances of baccalaureate refer to the International Baccalaureate. However, this would not be the case in other corpora where the word is associated with different types of qualifications.

\section{References}

Anthony, L. (2013). A critical look at software tools in corpus linguistics. Linguistic Research $30(2): 141-161$.

Anthony, L. (2014). AntConc (Version 3.4.3) [Computer Software]. Tokyo, Japan: Waseda University. Available from http://www.laurenceanthony.net/

Bagnall, N. F. (1994). The International Baccalaureate in Australia and Canada: 1980-1993 (Unpublished doctoral dissertation). University of Melbourne.

Bagnall, N. F. (2010). Education without Borders: Forty years of the International Baccalaureate, 1970-2010. Saarbrucken: VDM Verlag Dr Muller.

Baker, P. (2005). Public Discourses of Gay Men. London: Routledge.

Baker, P. (2006). Using Corpora in Discourse Analysis. London, UK: Continuum.

Baker, P. (2010). Sociolinguistics and Corpus Linguistics. Edinburgh: Edinburgh University Press.

Baker, P. (2013). From gay language to normative discourse: A diachronic corpus analysis of Lavender Linguistics conference abstracts 1994-2012. Journal of Language and Sexuality 2(2): 179-205.

Baker, P. (2014). 'Bad wigs and screaming mimis': Using corpus-assisted techniques to carry out critical discourse analysis of the representation of Trans people in the British press. In C. Hart and P. Cap (eds.), Contemporary Critical Discourse Studies. London, UK: Bloomsbury. pp. 211-235. 
Baker, P. (2015). Does Britain need any more foreign doctors? Inter-analyst consistency and corpus-assisted (critical) discourse analysis. In N. Groom, M. Charles, and S. John (eds.), Corpora, Grammar and Discourse: In Honour of Susan Hunston. Amsterdam: John Benjamins. pp. 283-300.

Baker, P. (2016). The shapes of collocation. International Journal of Corpus Linguistics 21(2): 139-164.

Baker, P., Gabrielatos, C., KhosraviNik, M., Krzyżanowski, M., McEnery, T., and R. Wodak (2008). A useful methodological synergy? Combining critical discourse analysis and corpus linguistics to examine discourses of refugees and asylum seekers in the UK press. Discourse \& Society 19(3): 273-306.

Baker, P., Gabrielatos, C., and T. McEnery (2013a). Sketching Muslims: A corpus driven analysis of representations around the word "Muslim" in the British press 1998-2009. Applied Linguistics 34(3): 255-278.

Baker, P., Gabrielatos, C., and T. McEnery (2013b). Discourse Analysis and Media Attitudes: The Representation of Islam in the British Press. New York: Cambridge University Press.

Baker, P., Hardie, A., and T. McEnery (2006). A Glossary of Corpus Linguistics. Edinburgh University Press.

Baker, P., and E. Levon (2015). Picking the right cherries? A comparison of corpus-based and qualitative analyses of news articles about masculinity. Discourse \& Communication 9(2) 1-16.

Baker, P., and E. Levon (2016). 'That's what I call a man': Representations of racialised and classed masculinities in the UK print media. Gender and Language 10(1): 106-139.

Baker, P., and T. McEnery (2005). A corpus-based approach to discourses of refugees and asylum seekers in UN and newspaper texts. Journal of Language and Politics 4(2): 197226.

Baker, P., and T. McEnery (2014). 'Find the doctors of death': Press representation of foreign doctors working in the NHS, a corpus-based approach. In A. Jaworski and N. Coupland (eds.), The Discourse Reader ( ${ }^{\text {rd }}$ edn.). New York, NY: Routledge. pp. 465-48o.

Baker, P., and T. McEnery (eds.) (2015). Corpora and Discourse Studies: Integrating Discourse and Corpora. New York, NY: Palgrave, Macmillan.

Baker, W. (2014). 'Curricular choice' in Ontario public secondary schools: Exploring the policy and practice of the International Baccalaureate Diploma Programme (Unpublished master's thesis). The University of Western Ontario.

Baluja, T., and K. Hammer (2012, September 6). From \$3,ooo to zero, fees vary wildly for prestigious high-school program. The Globe and Mail. Retrieved from http://www.theglobeandmail.com/news/national/education/from-3ooo-to-zero-feesvary-wildly-for-prestigious-high-school-program/article425540o/

Blackburn, R. (1991). The International Baccalaureate: A curriculum at upper secondary level and a university entrance examination. In P. Jonietz and D. Harris (eds.), World Yearbook of Education 1991: International Schools and International Education. London: Kogan Page. pp. 6-14.

Bunnell, T. (2011). The International Baccalaureate in the United States: From Relative inactivity to imbalance. The Educational Forum 75: 66-79.

Bunnell, T. (2012). Global Education under Attack: International Baccalaureate in America. Frankfurt: Peter Lang.

Cambridge, J. (2002). Global product branding and international education. Journal of Research in International Education 1(2): 227-243.

Coates, H., Rosicka, C., and M. MacMahon-Ball (2007). Perceptions of the International Baccalaureate DiplomaProgramme among Australian and New Zealand Universities. Retrieved from http://www.ibo.org/en/about-the-ib/research/programme-impactresearch/diploma-studies/ 
Daly, K. (2012). An exploration of Virginia law on recognition, university officials, and perceptions of the International Baccalaureate Diploma Programme (Unpublished PhD thesis). George Mason University, USA.

Davis, M. (2015). The Corpus of Contemporary American English (COCA): 520 million words, 1990-2015. Available at http://corpus.byu.edu/coca/

Doherty, C. (2009). The appeal of the International Baccalaureate in Australia's educational market: A curriculum of choice for mobile futures. Discourse: Studies in the Cultural Politics of Education 30(1): 73-89.

Firth, J. R. (1957). Papers in Linguistics 1934-1951. Oxford: Oxford University Press.

Fitzgerald, S. (2015). Perceptions of the International Baccalaureate (IB) in Ontario universities. Canadian Journal of Education 38(3): 1-34.

Fitzgerald, S. (in press). Perceptions of the International Baccalaureate (IB) in Canadian universities. Canadian Journal of Higher Education.

Gabrielatos, C., and P. Baker (2008). Fleeing, sneaking, flooding: A corpus analysis of discursive constructions of refugees and asylum seekers in the UK Press, 1996-2005. Journal of English Linguistics 36(1): 5-38.

Hahn, A. M. (2003). The intersection of language, power and international education: A critical discourse analysis of the International Baccalaureate Organization (Unpublished doctoral dissertation). Columbia University.

Hardt-Mautner, G. (1995). 'Only connect.' Critical discourse analysis and corpus linguistics. Retrieved from http:/ucrel.lancs.ac.uk/papers/techpaper/vol6.pdf

Hoey, M. (2005). Lexical Priming: A New Theory of Words and Language. London: Routledge.

Hunston, S. (2002). Corpora in Applied Linguistics. Cambridge: Cambridge University Press.

Hunston, S. (2004). Counting the uncountable: Problem of identifying evaluation in a text and in a corpus. In A. Partington, J. Morley and L. Haarman (eds.), Corpora and Discourse. Bern: Peter Lang. pp. 157-188.

International Baccalaureate Organization. (2014). Myth and Facts about the International Baccalaureate. Retrieved from http://www.midwestibschools.org/Countering_IB_Myths_in_Your_School_Community _2014.pdf

International Baccalaureate Organization. (2016). Juggling the IB and OSSD. Retrieved from http://www.ibo.org/about-the-ib/the-ib-by-region/ib-americas/americas-regionalconference/2016-americas-conference/

International Baccalaureate Organization. (2017). Mission. Retrieved from http://www.ibo.org/about-the-ib/mission/

Jenkins, C. (2003). Perceptions of the IB Diploma Programme. Retrieved from http://www.ibo.org/en/about-the-ib/research/programme-impact-research/diplomastudies/

KhosraviNik, M. (2010). The representation of refugees, asylum seekers and immigrants in British newspapers: A critical discourse analysis. Journal of Language and Politics 9(1): 128.

Louw, B. (1993). Irony in the text or insincerity in the writer? The diagnostic potential of semantic prosodies. In M. Baker, G. Francis and E. Tognini-Bonelli (eds.), Text and Technology: In Honour of John Sinclair. Amsterdam: John Benjamns. pp. 157-176.

Marchi, A., and C. Taylor (2009). If on a winter's night two researchers...A challenge to assumptions of soundness of interpretation. Critical Approaches to Discourse Analysis across Disciplines 3(1): 1-20.

Mautner, G. (2007). Mining large corpora for social information: The case of elderly. Language in Society 36: 51-72. 
Mautner, G. (2008). Analyzing newspapers, magazines and other print media. In R. Wodak and M. Krzyżanowski (eds.), Qualitative Discourse Analysis in the Social Sciences. New York, NY: Palgrave Macmillan. pp. 30-53.

Mautner, G. (2009a). Corpora and critical discourse analysis. In P. Baker (ed.), Contemporary Corpus Linguistics. London: Continuum. pp. 32-46.

Mautner, G. (2009b). Checks and balances: How corpus linguistics can contribute to CDA. In R. Wodak and M. Meyer (eds.), Methods of Critical Discourse Analysis ( $2^{\text {nd }}$ edn.). London, UK: Sage. pp. 122-143.

McEnery, T., and A. Hardie (2012). Corpus Linguistics. Cambridge: Cambridge University Press.

O'Halloran, K., and C. Coffin (2004). Checking overinterpretation and underinterpretation: Help from corpora in critical linguistics. In C. Coffin, A. Hewings and K. O'Halloran (eds.), Applying English Grammar: Functional and Corpus Approaches. London, UK: Hodder Arnold. pp. 275-297.

Paris, P. G. (2003). The International Baccalaureate: A Case Study on why students choose to do the IB. International Education Journal 4(3): 232-243.

Partington, A. (2004). 'Utterly content in each other's company': Semantic prosody and semantic preference. International Journal of Corpus Linguistics 9(1): 131-156.

Partington, A. (2015). Corpus-assisted comparative case studies of representations of the Arab world. In P. Baker and T. McEnery (eds.), Corpora and Discourse Studies: Integrating Discourse and Corpora. New York, NY: Palgrave, Macmillan. pp. 220-243.

Resnik, J. (2012). The denationalization of education and the expansion of the International Baccalaureate. Comparative Education Review 56(2): 248-269.

Seal, C. (2003). Methodology versus scholarship? Overcoming the divide in analysing identity narratives of people with cancer. Journal of Language and Politics 2(2): 289-309.

Sinclair, J. (1991). Corpus, Concordance, Collocation. Oxford: Oxford University Press.

Stubbs, M. (1996). Text and Corpus Analysis: Computer-Assisted Studies of Language and Culture. Oxford: Blackwell.

Stubbs, M. (2001). Words and Phrases: Corpus Studies of Lexical Semantics. Oxford: Blackwell.

Tarc, P. (2007). What is the "international" of the International Baccalaureate? Towards a periodization of IB in the world (Unpublished PhD thesis). York University, Toronto.

Tarc, P. (2009). Global Dreams, Enduring Tensions: Intermational Baccalaureate Program in a Changing World. New York: Peter Lang.

Tarc, P., and L. Beatty (2012). The emergence of the International Baccalaureate Diploma in Ontario: Diffusion, pilot study and prospective research. Canadian Journal of Education 35(4): 341-375.

Tarver, E. T. (2010). University admissions officers' perceptions of student performance within the International Baccalaureate Diploma Program (Unpublished PhD thesis). Louisiana State University.

Tognini-Bonelli, E. (2004). Working with corpora: Issues and insights. In C. Coffin, A. Hewings and K. O'Halloran (eds.), Applying English Grammar: Functional and Corpus Approaches. London, UK: Hodder Arnold. pp. 11-24.

van Leeuwen, T. (1996). The representation of social actors. In C. R. Caldas-Coulthard and M. Coulthard (eds.), Texts and Practices: Readings in Critical Discourse Analysis. New York, NY: Routledge. pp. 32-70.

Whitehead, K. (2005). Advertising advantage. The International Baccalaureate, social justice and the marketisation of schooling. Paper presented at the Australian Association for Research in Education Annual Conference, University of Western Sydney, Parramatta. Retrieved from http://www.aare.edu.au/o5pap/whio5426.pdf 
Wodak, R. (ed.) (2013). Critical Discourse Analysis, Volume 1: Concepts, History, Theory. Los Angeles, CA: Sage.

Wodak, R., and M. Meyer (eds.) (2016). Methods of Critical Discourse Studies ( $3^{\text {rd }}$ edn.). Los Angeles, CA: Sage. 


\section{Appendix}

Top 100 collocates for baccalaureate ranked by MI score

\begin{tabular}{|c|c|c|c|c|}
\hline No. & Collocate & Joint frequency & Raw frequency & MI score \\
\hline 1 & international & 3039 & 4217 & 8.51157 \\
\hline 2 & examiner & 7 & 11 & 8.20659 \\
\hline 3 & geneva & 32 & 72 & 7.81427 \\
\hline 4 & authorized & 11 & 27 & 7.68874 \\
\hline 5 & candidacy & 6 & 11 & $7 \cdot 56916$ \\
\hline 6 & programme & 61 & 165 & $7 \cdot 54861$ \\
\hline 7 & swiss & 6 & 17 & $7 \cdot 48169$ \\
\hline 8 & rigorous & 66 & 201 & $7 \cdot 37754$ \\
\hline 9 & switzerland & 27 & 85 & $7 \cdot 32969$ \\
\hline 10 & monitored & 6 & 10 & $7 \cdot 32123$ \\
\hline 11 & placement & 88 & 281 & $7 \cdot 30920$ \\
\hline 12 & accredited & 21 & 68 & 7.28905 \\
\hline 13 & introducing & 15 & 50 & 7.24723 \\
\hline 14 & demanding & 39 & 132 & 7.22520 \\
\hline 15 & enriched & 46 & 157 & 7.21314 \\
\hline 16 & pyp & 12 & 41 & 7.21160 \\
\hline 17 & honors & 10 & 35 & 7.17684 \\
\hline 18 & advanced & 129 & 459 & 7.15307 \\
\hline 19 & organization & 95 & 339 & 7.14891 \\
\hline 20 & certification & 14 & $5^{\circ}$ & 7.14769 \\
\hline 21 & program & 2156 & 7831 & 7.12335 \\
\hline 22 & introduction & 12 & 44 & 7.10973 \\
\hline 23 & partial & 10 & 37 & 7.09667 \\
\hline
\end{tabular}




\begin{tabular}{|c|c|c|c|c|}
\hline 24 & diploma & 225 & 837 & 7.08889 \\
\hline 25 & accreditation & 16 & 60 & 7.07730 \\
\hline 26 & respected & 14 & 53 & 7.06363 \\
\hline 27 & enrolled & 92 & 350 & 7.05655 \\
\hline 28 & academies & 20 & 78 & 7.02072 \\
\hline 29 & renowned & 14 & 55 & 7.01019 \\
\hline 30 & prestigious & 61 & 244 & 6.98419 \\
\hline 31 & academically & 56 & 230 & 6.94606 \\
\hline 32 & montessori & 33 & 136 & 6.94113 \\
\hline 33 & primary & 62 & 257 & 6.93277 \\
\hline 34 & designation & 9 & 39 & 6.86872 \\
\hline 35 & challenging & 59 & 259 & 6.85003 \\
\hline 36 & accelerated & 10 & 44 & 6.84669 \\
\hline 37 & feasibility & 5 & 23 & 6.78256 \\
\hline 38 & co-ordinator & 38 & 175 & 6.78091 \\
\hline 39 & charging & 8 & 37 & 6.77474 \\
\hline 40 & ibo & 14 & 65 & 6.76918 \\
\hline 41 & equivalent & 18 & 85 & 6.74473 \\
\hline 42 & examination & 8 & 38 & 6.73627 \\
\hline 43 & examinations & 9 & 45 & 6.66227 \\
\hline 44 & pre & 54 & 274 & 6.64105 \\
\hline 45 & authorization & 6 & 31 & 6.61496 \\
\hline 46 & immersion & 95 & 503 & 6.57964 \\
\hline 47 & leads & 11 & 59 & 6.56098 \\
\hline 48 & instrumental & 5 & 27 & 6.55123 \\
\hline 49 & intensive & 12 & 65 & 6.54679 \\
\hline 50 & implement & 9 & 49 & 6.53941 \\
\hline
\end{tabular}




\begin{tabular}{|c|c|c|c|c|}
\hline 51 & approved & 27 & 149 & 6.51991 \\
\hline 52 & coordinator & 9 & 50 & 6.51026 \\
\hline 53 & prepares & 16 & 89 & 6.50846 \\
\hline 54 & popularity & 7 & 39 & 6.50615 \\
\hline 55 & regarded & 5 & 28 & 6.49877 \\
\hline $5^{6}$ & participant & 5 & 28 & 6.49877 \\
\hline 57 & offer & 151 & 852 & 6.48789 \\
\hline 58 & globally & 9 & 51 & 6.48169 \\
\hline 59 & honours & 27 & 155 & 6.46296 \\
\hline 60 & offers & 91 & 523 & 6.46132 \\
\hline 61 & opt & 5 & 29 & 6.44814 \\
\hline 62 & enhanced & 14 & 82 & 6.43400 \\
\hline 63 & certificate & 16 & 94 & 6.42961 \\
\hline 64 & graduated & 34 & 201 & 6.42061 \\
\hline 65 & offering & 60 & 356 & 6.41535 \\
\hline 66 & internationally & 26 & 155 & 6.40851 \\
\hline 67 & implementing & 7 & 42 & 6.39923 \\
\hline 68 & excelled & 5 & 30 & 6.39923 \\
\hline 69 & earning & 10 & 60 & 6.39923 \\
\hline 70 & status & 22 & 133 & 6.38834 \\
\hline 71 & specialized & 27 & 165 & 6.37276 \\
\hline 72 & expansion & 13 & 80 & 6.36271 \\
\hline 73 & boasts & 5 & 31 & 6.35193 \\
\hline 74 & diplomas & 8 & $5^{\circ}$ & 6.34034 \\
\hline 75 & bid & 6 & 38 & 6.32123 \\
\hline 76 & introduce & 7 & 45 & 6.29970 \\
\hline 77 & certified & 9 & 59 & 6.27148 \\
\hline
\end{tabular}




\begin{tabular}{|c|c|c|c|c|}
\hline 78 & load & 14 & 92 & 6.26799 \\
\hline 79 & administered & 5 & 33 & 6.26173 \\
\hline 80 & bound & 10 & 67 & 6.24003 \\
\hline 81 & programs & 335 & 2247 & 6.23843 \\
\hline 82 & maintains & 7 & 47 & 6.23696 \\
\hline 83 & middle & 69 & 468 & 6.22235 \\
\hline 84 & brilliant & 5 & 34 & 6.21866 \\
\hline 85 & prep & 8 & 55 & 6.20283 \\
\hline 86 & candidate & 20 & 138 & 6.19760 \\
\hline 87 & expand & 18 & 125 & 6.18833 \\
\hline 88 & draws & 6 & 42 & 6.17684 \\
\hline 89 & profit & 22 & 155 & 6.16750 \\
\hline 90 & introduced & 18 & 128 & 6.15412 \\
\hline 91 & moves & 6 & 43 & 6.14289 \\
\hline 92 & completing & 12 & 86 & 6.14289 \\
\hline 93 & geared & 5 & 36 & 6.13620 \\
\hline 94 & secondary & 245 & 1784 & 6.11993 \\
\hline 95 & offered & 92 & 679 & 6.10049 \\
\hline 96 & applying & 12 & 90 & 6.07730 \\
\hline 97 & $\mathrm{ib}$ & 455 & 3422 & 6.07329 \\
\hline 98 & recognized & 47 & 355 & 6.06711 \\
\hline 99 & maintaining & 9 & 68 & 6.06666 \\
\hline 100 & establish & 7 & 53 & 6.06363 \\
\hline
\end{tabular}




\section{Appendix 2}

Top 100 collocates for baccalaureate organized by category

\begin{tabular}{|c|c|}
\hline Category & Collocations (top 10 in bold) \\
\hline Global outlook & international, globally, internationally \\
\hline Geographical location & geneva, swiss, switzerland \\
\hline $\begin{array}{l}\text { External } \\
\text { oversight/regulation }\end{array}$ & $\begin{array}{l}\text { examiner, authorized, candidacy, monitored, } \\
\text { accredited, certification, accreditation, designation, } \\
\text { feasibility, charging, examination, examinations, } \\
\text { authorization, approved, offer, offers, offering, status, } \\
\text { expansion, bid, certified, administered, candidate, expand, } \\
\text { offered, applying }\end{array}$ \\
\hline $\begin{array}{l}\text { Names and types of } \\
\text { curricula }\end{array}$ & $\begin{array}{l}\text { programme, placement, pyp, program, partial, diploma, } \\
\text { montessori, primary, pre, immersion, certificate, } \\
\text { specialized, diplomas, programs, middle, prep, secondary }\end{array}$ \\
\hline Attributes & $\begin{array}{l}\text { rigorous, demanding, enriched, honors, advanced, } \\
\text { respected, renowned, prestigious, academically, } \\
\text { challenging, accelerated, equivalent, leads, instrumental, } \\
\text { intensive, prepares, popularity, regarded, honours, } \\
\text { enhanced, excelled, boasts, load, brilliant, draws, geared, } \\
\text { recognized }\end{array}$ \\
\hline Institutional & $\begin{array}{l}\text { introducing, organization, introduction, academies, ibo, } \\
\text { implement, implementing, introduce, profit, introduced, } \\
\text { moves, ib, establish }\end{array}$ \\
\hline People & $\begin{array}{l}\text { enrolled, co-ordinator, coordinator, participant, opt, } \\
\text { graduated, earning, bound, maintains, completing, } \\
\text { maintaining }\end{array}$ \\
\hline
\end{tabular}




\section{Chapter 8}

When you're in with the in-crowd: The discursive construction of the International Baccalaureate (IB) in a corpus of Canadian newspapers

This chapter presents the study examining discursive strategies employed in the construction of an IB in-group and a non-IB out-group. Manuscript currently under peerreview. 


\title{
When you're in with the in-crowd: The discursive construction of the International Baccalaureate (IB) in a corpus of Canadian newspapers
}

\begin{abstract}
This paper examines the discursive construction of the International Baccalaureate (IB) in a 1.5 million word corpus of Canadian newspapers. Combining corpus analysis with the Discourse Historical branch of Critical Discourse Analysis, the study aims to identify discursive strategies employed in the construction of an IB in-group and a non-IB out-group, and suggests they are similar to those evident in discourses of discrimination that marginalize or exclude the out-group (Baker et al., 2013a; KhosraviNik, 2010; Reisigl $\&$ Wodak, 2001). While discourses of discrimination tend to be directed at minority groups, in this case, the minority group is the in-group, exhibiting uniformly positive qualities. As a result, a 'dichotomous world of insiders and outsiders' (Reisigl \& Wodak, 2001: 105) is created, privileging one and disadvantaging the other.
\end{abstract}

Key words: corpus, DHA, International Baccalaureate (IB), in-group/out-group

\section{Introduction}

The International Baccalaureate (IB) is a series of educational programs for students aged 3 to 19 offered in schools around the world. Originally created for a transient population in need of a portable and recognized curriculum, it has evolved to become an alternative to local curricula in countries such as Australia, the United States, the United Kingdom and Canada (e.g., Bagnall, 1994; Bunnell, 2011a, 2011b, 2012; Daly, 2012; Paris, 2003; Tarc \& Beatty, 2012). However, with this move into publicly funded schools, issues of equity (i.e., only some have access) and the apparent debasing of the other curricula have started to emerge (e.g., W. Baker, 2014; Doherty, 2009; Resnik, 2012; Tarc, 2009; Whitehead, 2005).

This paper is part of a larger study examining the discursive construction of the IB in the Canadian context, an important aim of which is to make transparent how values and attitudes associated with the IB label lead to the construction of a 'dichotomous world of insiders and outsiders' (Reisigl \& Wodak, 2001: 105), privileging one group while disadvantaging the other. Such a 'discourse of difference' (Wodak, 1996: 113; see also KhosraviNik, 2010) distinguishes between an in-group and an out-group based on specific traits attributed to one group, in this case, positive traits attributed to IB students, curricula and schools. This positive view of the IB was found in studies surveying the perceptions of university personnel conducted in the United Kingdom (Jenkins, 2003), Australia/New Zealand (Coates et al., 2007), the United States (Daly, 2012; Tarver, 2010) and Canada (Author, 2015, in press). In each case, uniform qualities and values associated with the IB label were found (e.g., better preparation for university, rigorous curriculum, smart students, etc.).

This similarity of responses suggests Baker's (2006) notion of the incremental effect of discourse, i.e., a 'steady drip-drip effect' (Baker, 2010: 313) in which patterns of language repeated often enough gradually become normalized or taken for granted. For example, the survey results showed a consistent pattern in which the positive view of the IB was accompanied by a corresponding negative view of the local (state or provincial) curriculum. In other words, when asked to compare the IB with their local curriculum, 
respondents rated the IB higher, even though knowledge about the specific nature of the IB was superficial or lacking. This consistent pattern suggests that a hegemonic discourse surrounding the IB exists, one that seems to have become naturalized through repetition (Baker, 2010), resulting in a stereotyped image.

Such consistently positive views of the IB and negative views of the local curriculum seem to indicate the enactment of an in-group/out-group construction similar to those found in discourses of discrimination, where out-groups (usually the minority) are described in negative or derogatory terms, while in-groups (usually the majority) are presented in a positive light. Such cases often involve 'difference-levelling sameness and homogeneity' (Reisigl \& Wodak, 2001: 56) whereby diverse groups of people are constructed as a uniform whole embodying particular characteristics that contribute to stereotypes. Doherty's (2009: 12) study of newspaper articles in the Australian context demonstrated that the language used to describe the IB was entirely positive without any hint of critique, which 'casts a shadow on others' by implying that the qualities found in the IB were absent in other curricula.

The primary aim of this study is to discover how the IB is represented in the Canadian public domain as found in the country's newspapers, and how such representation contributes to the 'production, elaboration and circulation' (Baker \& Levon, 2016: 111) of a dominant or hegemonic view of the IB. The overarching research questions guiding this study are: (i) How is the IB represented in a large corpus of Canadian newspapers? (ii) What are the implications of this representation, whether positive, negative or neutral? To address these questions, this study combines corpus linguistics (CL) with aspects of the discourse historical approach (DHA) branch of critical discourse analysis (CDA) to identify systematic repetitive linguistic patterns that are then examined in more detail.

The paper is divided into the following sections. First, I provide a brief history of the IB. Second, I review relevant literature on corpus based CDA/DHA studies that examine minority and insider-outsider group constructions. Third, I describe the analytical framework and the tools and data employed in the study. Fourth, I discuss the findings and analysis, and offer some concluding remarks.

\section{A brief history of the IB}

The International Baccalaureate (IB) was officially launched in 1968 as a two-year high school diploma aimed at 'internationally mobile students preparing for university'. ${ }^{1}$ It arose from a concern of parents frequently required to change their country of residence as a result of diplomatic or other international work, whose children therefore had to move schools and change curricula. This resulted in fragmented and disparate credentials that made it difficult for such students to gain admission into universities of their choice. These 'global nomads' (Langford, 1998) were considered to be 'disadvantaged by having to live and study abroad' (Bagnall, 1994: 5), since they were often living in parts of the non-western world, where it was assumed that the local education was either inferior or inaccessible because of language barriers (Hayden, 1998). It became clear to teachers, parents, and 'a number of highly placed international civil servants grouped in Geneva' 
(Hill, 2002: 20) that what was needed was an 'internationally acceptable school-leaving credential whose standards reflected the highest common factor in all subjects required by admissions policies of universities in different countries' (Fox, 1998: 65).

The resulting IB diploma curriculum was a synthesis of French, British, German and American concepts felt to achieve a balance between national and international perspectives, and combining an emphasis on both depth and breadth of knowledge on the one hand, and theoretical and practical learning on the other. In addition to its hybrid character, an important way in which the IB diploma program differed from other curricula was through 'the inclusion of three special requirements: a common course in the Theory of Knowledge (TOK), an independent Extended Essay, and participation in creative and social service activities', requirements that 'give the IB Diploma Programme its character as a total, integrated curriculum' (Fox, 1998: 68-9). By providing students with opportunities for reflection, critical thinking, research, and community service, the IB diploma program aimed at educating 'the whole person' (Fox, 1998: 68).

According to Hayden \& Thompson (2011: 18), after "some 30 years as an only child, the DP [diploma program] was joined by two new siblings: the IB Middle Years Programme (MYP) in 1994 and the IB Primary Years Programme (PYP) in 1997'. With the addition of new programs and the resulting increase in acronyms, the IB organization issued an information guide that included an 'English to IBese dictionary: To help you communicate with the locals' (IBO, 2007). The need for such a document points to possible confusion engendered by the profusion of abbreviated forms for different programs and the many regional offices and associations. Currently, the IB organization offers four programs, each with a specific name and age group attached. There are also numerous options available to students in terms of degree of involvement. For example, students in the last two years of high school may choose to enrol in a single IB course (sometimes referred to as 'partial IB'), while others may opt for the full two-year IB diploma.

\section{Review of the literature}

The issue of how vulnerable or minority groups are constructed in society is frequently examined in corpus based CDA/DHA studies, a combined approach that has become increasingly popular (Baker \& Levon, 2015; see also Baker \& McEnery, 2015) and is based on the key assumption that language and the social are dialectically linked. Using large amounts of naturally occurring linguistic data, patterns of typicality are systematically identified to make explicit how certain groups come to be associated with particular qualities through repetition, resulting in a stereotyped image that embodies positive or negative qualities. The 'useful methodological synergy' of CL and CDA/DHA (Baker et al., 2008) helps guard against the potential shortcomings of either approach, such as inadvertently cherry-picking a few examples on the one hand, or focusing solely on decontextualized data on the other (e.g., Baker, 2006; Mautner, 2009b).

A number of studies have focused on identifying linguistic patterns surrounding groups such as refugees and asylum seekers in UN and newspaper texts (Baker \& McEnery, 2005), the elderly and the unemployed in large corpora of general English (Mautner, 
2007, 2009b), Muslims and Islam in the British press (Baker et al., 2013a, 2013b), and Trans people and foreign doctors in the British press (Baker, 2014; Baker \& McEnery, 2014). In each case, recurring patterns were found that tended to embody values and attitudes towards different groups which were not always explicit or easily intuited. Through frequent repetition, labels used to refer to a group (e.g., the unemployed) evoked qualities or behaviour that had become associated with the name (e.g., desperate, divorced, demoralized). Such recurring patterns often point to dominant discourses or habitual ways of talking about particular groups, thereby reinforcing stereotypes and 'an aura of common sense, [which has] come to seem natural and comprehensive rather than partial and selective' (Stubbs, 1996: 194). In this way, in-group (positive self) and outgroup (negative other) dichotomies are constructed and reproduced through daily interaction and everyday discourse.

\section{Analytical framework: in-group/out-group}

This study draws on the discourse historical approach (DHA) branch of CDA to examine how discursive strategies (i.e., systematic ways of using language) are used to construct in-groups and out-groups, leading to social exclusion or discrimination. As noted by Wodak and her colleagues, while discourses of difference and discrimination may vary in terms of the specific group in question, the discursive strategies and linguistic realizations tend to be very similar (KhosraviNik, 2010; Reisigl \& Wodak, 2001), with construction of the 'other' generally taking the form of a 'they' group with negative qualities and a 'we' group embodying positive ones. The term 'strategy' refers to varying degrees of intentionality, from automatic to conscious depending on the context and purpose (see de Cillia et al., 1999). Furthermore, the DHA also assumes that the discursive construction of a particular group does not occur in a unidirectional top-down way (Reisigl \& Wodak, 2001: 24), but rather is co-constructed by different segments of society (official, public, semi-private) through interaction in different domains, with each segment shaping and being shaped by others in a dialectical relationship (de Cillia et al., 1999; Reisigl \& Wodak, 2001). In other words, the stereotyped image is perpetuated and reproduced through multiple levels of interaction (e.g., political, economic, legal), not necessarily intentionally but as social practice.

In order to discover how a particular group is represented in the wider social context, the DHA focuses on five types of discursive strategies used in the construction of in-groups and out-groups: i) nomination/referential (how are groups named?); ii) predication (what qualities are ascribed to them?); iii) argumentation (how are these claims justified?); iv) perspectivization (from what point of view are these claims made?); and v)

intensification/mitigation (are these overt or implied?). Furthermore, linking micro level linguistic choices and macro level social practice is fundamental (e.g., Mautner, 2009a; Reisigl, 2008). For this purpose, the DHA offers the heuristic of a four-level, micro to macro level model of context. These levels are not independent but integrated and recursive, and can be drawn on as a whole in the analysis (e.g., Engström \& Paradis, 2015).

Drawing on the work of Stuart Hall (1989), Wodak (1996: 116) states that discourses of difference are based on the premise that a discourse may be considered discriminatory if 
it 'serves to establish social, political and economic practices that preclude certain groups from material and symbolic resources'. Such discourses involve two primary aspects: i) group definition and construction; and ii) normative evaluations about the group. In the present study, the most salient strategies in the DHA analytical framework in terms of ingroup and out-group construction are nomination (denoting membership categorization) and predication (attribution of negative or positive traits, implicit or explicit). Studies exploring such discourses of difference and discrimination have tended to focus on those in which minority or vulnerable groups are out-groups (e.g., refugees), while the majority is the in-group (e.g., the British). In contrast, the present study looks at a situation in which the minority is constructed as the in-group while the majority emerges as the outgroup.

Use of a large corpus allows a view into the values and attitudes held by a particular society or social group, and the identification of dominant discourses and ideologies that may not be evident in close qualitative analysis of a few samples alone, as well as the possibility of detecting other minority or resistant discourses. The media corpus in this study is used to provide insight into how the Canadian public (in diverse roles as evidenced by the array of contexts and types of articles) views the IB, and the implications this might have in terms of impact on the wider society. The relationship between newspaper and reader is understood as complex and dialectical, with each responding to and shaping the other, i.e., 'meaning is created from interaction between a text and its readers' (Baker et al., 2013a: 6) and, through this interaction, further contributing to the entrenchment of dominant discourses. Through corpus analysis and the DHA, it is possible to see how meaning is co-constructed through "top-down procedures of hegemonic public opinion-making and the bottom-up processes of...moods, anxieties and swings of specific groups' (de Cillia et al., 1999: 153).

\section{Method}

Articles for the specialized IB media corpus were obtained through two online news databases, Canada Newsstand Complete and LexisNexis Academic, using the search terms international AND baccalaureate, ib AND diploma OR student. These search terms were determined based on prior knowledge and encounters with the topic. All Canadian newspapers (national, regional, local and community (paid or free)) were included to ensure maximum representation of public attitudes and perceptions. As well, all articles were selected to avoid the possibility of selection bias, i.e., inadvertently focusing only on articles that suited my purposes. In this way, a greater 'unsolicited' (Mautner, 2008) window into public opinion was made possible, as it included not just powerful elite sources but letters and opinion pieces from parents, students and other members of the public, which 'allows one to observe the local co-construction of meaning' (de Cillia et al., 1999: 152). As such, the IB media corpus is varied, containing maximum coverage on the topic as available on the two news databases (McEnery \& Hardie, 2012). It is also important to note that the IB media corpus contains linguistic data produced and reproduced by different segments of society rather than generated by the IB organization itself. 
Once the data were cleaned by removing repeated or erroneous articles (e.g., section 1B being misread as IB) and deleting extraneous information such as author names, publication dates, etc., the final IB media corpus contained 2,326 articles from 1977 to 2016 and consisted of 1,521,796 words. Articles were not sorted by genre, i.e., editorial opinion, letters, features, etc., but grouped together according to newspaper since the focus of the study was to establish overall trends in terms of how the IB was talked about in general rather than how it occurred in specific contexts, with the different voices potentially representing the 'invisible majority' (Baker et al., 2013a: 12).

Following Baker et al. (2013a), this study uses Sketch Engine (Kilgariff et al., 2014), an online software tool that allows a corpus to be uploaded, grammatically tagged and analyzed for salient patterns. The analysis was conducted in two stages: i) a 'broad brush' (Baker et al., 2013b: 257) quantitative approach to the corpus as a whole using word sketch and ii) a detailed qualitative analysis of a downsampled selection of random concordance lines (Gabrielatos \& Baker, 2008).

The first stage of the analysis involved obtaining a word sketch of the search term baccalaureate $(\mathrm{ib}),{ }^{2}$ the node word chosen based on preliminary examination of the data. A word sketch is a one-page summary of a word's grammatical and collocational behaviour (Kilgarriff et al., 2004). It groups collocates according to different grammatical patterns 'which occur much more often than expected' (Culpepper, 2009: 82). By presenting a summary of the grammatical behaviour of a word, a word sketch not only provides dominant patterns of a word instantly and thereby saves time, but also adds another level of triangulation and bias-check by directing the researcher to account for patterns that might have been overlooked in the more traditional list form of collocates. As part of this first stage, 'thinned' (Baker et al., 2006: 158) samples of concordance lines for the top three collocates were examined. A concordance, often referred to as key word in context (KWIC), is a list of all the occurrences of a search term (node) in a corpus presented with a few words to the left and right, and can be sorted alphabetically, making it possible for the researcher to identify patterns. Once a pattern has been identified, detailed analysis of the line in its larger context can follow.

Through concordance analysis, it is possible to identify the kinds of discursive strategies used in the construction of in-groups and out-groups, such as nomination and predication (Baker, 2010; Reisigl \& Wodak, 2001). Therefore, the second stage involved more indepth analysis of a downsampled selection from the corpus (see e.g., Gabrielatos \& Baker, 2008). This more qualitative part of the analysis used concordance lines with expanded co-text that provided additional contextual information as well as opportunities to identify meanings that are implied rather than stated explicitly. Nomination strategies are first identified and analyzed quantitatively based on frequency using word sketch and a thinned sample of concordance lines for each of the top three collocates (program, student, school), while predication strategies are analyzed qualitatively for the node word baccalaureate( $(i b)$ using a downsampled random selection of 100 concordance lines with expanded co-text (e.g., Baker et al, 2013b).

\section{Analysis}




\section{Group membership (nomination)}

The word sketch for baccalaureate(ib) showed that it appears most frequently in its adjectival form, modifying other nouns (4782 [75\%]). In order to get a clearer understanding of the types of nouns being modified, i.e., the class of words for which the node word shows a semantic preference (Stubbs, 2001), they were grouped together into four broad categories based on similarity (see Table 1):

Table 1: Most frequent noun collocates modified by baccalaureate( $i b)$

\begin{tabular}{|c|c|}
\hline Category & Collocates \\
\hline Curriculum & $\begin{array}{l}\text { program }(2731) \text {, diploma }(162), \text { course }(105) \text {, class }(71) \text {, exam }(70) \text {, } \\
\text { curriculum }(65) \text { study }(18) \text {, certificate }(14) \text { credit }(11) \text { degree }(9)\end{array}$ \\
\hline People & student (405), co-ordinator (59), graduate (37), teacher (27), candidate (9) \\
\hline Institution & school (229), organization (89) \\
\hline Regulation & status (17), designation (13), certification (9) \\
\hline
\end{tabular}

As Table 1 shows, baccalaureate( $(b)$ primarily modifies lexical items related to curriculum (e.g., international baccalaureate (ib) program), people (e.g., international baccalaureate (ib) student), institution (e.g., international baccalaureate (ib) school) and regulation (e.g., international baccalaureate (ib) status). Nomination strategies (i.e., how groups are named) can thus be easily identified, in which group membership is achieved by labelling diverse elements $I B,{ }^{3}$ thereby expanding membership categorization beyond that of a particular curriculum. What is interesting is that the search term baccalaureate( $(\mathrm{b}$ ) co-occurs most frequently with words from a variety of semantic fields, extending from specific curriculum-related words (e.g., subject areas such as math and science) to other areas, suggesting a differentiating function between things $I B$ and an implied non- $I B$. For example, the appearance of $I B$ student or $I B$ curriculum implies the existence of a non IB student or non IB curriculum as its binary opposite (Baker, 2010). The word sketch collocational profile for baccalaureate(ib) thus provides a first glimpse of how diverse elements (curriculum, people, institution, regulation) are collectivized under the $I B$ label, an initial indication of the formation of a particular group (Mautner, 2007: 59).

In addition to providing a node word's grammatical behaviour, a word sketch also identifies the 'longest commonest match', ${ }^{4}$ defined as the most common realization of the collocational pair, i.e., the types of phrases found to be most typical of a node. In this case, the most typical occurrence of the node in the IB media corpus is the international baccalaureate (ib) program, which seems to imply a single entity due to the definite article the. Thus, even though there are a range of different IB programs available, the most common nomination strategy is that of collectivization (KhosraviNik, 2010; Reisigl \& Wodak, 2001), i.e., construction of a single homogeneous group through which important differences of each program are excluded, backgrounded or obscured.

For the purposes of further concordance analysis of word sketch results, a 'thinned' (Baker et al., 2006: 158) random sample of 100 concordance lines was obtained for program (the most frequent noun collocate), to examine how nomination strategies were being employed. Of these, two referred to primary years program, one to middle years 
program, and six to diploma program. The remainder (91) made no reference to any particular program, and referred to $I B$ as a single entity (see concordance 1).

Concordance 1: Collectivization

\begin{tabular}{|l|l|l|}
\hline $\begin{array}{l}\text { initially applied to host the } \\
\text { international }\end{array}$ & baccalaureate & $\begin{array}{l}\text { program in early 2005. One } \\
\text { school in }\end{array}$ \\
\hline $\begin{array}{l}\text { Co in 1951, which runs the } \\
\text { International }\end{array}$ & baccalaureate & $\begin{array}{l}\text { program offered around the } \\
\text { world. In }\end{array}$ \\
\hline $\begin{array}{l}\text { globalized, rapidly changing } \\
\text { world. The }\end{array}$ & IB & $\begin{array}{l}\text { program gives students the } \\
\text { skills the }\end{array}$ \\
\hline $\begin{array}{l}\text { the board with the idea of } \\
\text { bringing the }\end{array}$ & $\begin{array}{l}\text { program to the area. "I've } \\
\text { always enc }\end{array}$ \\
\hline
\end{tabular}

In addition, expanded concordance lines reveal that even in those instances where specific programs are mentioned by name, the description that follows tends to be that of the two-year diploma program, as can be seen in the following excerpt:

(1) The...District School Board is conducting a parent survey to determine interest in an International Baccalaureate (IB) program for students in primary grades. The IB

program is a demanding pre-university course of study designed for highly motivated students... The program is supposed to challenge students beyond traditional secondary school curriculum and experiences. Students who successfully complete the course could find access to universities all over the world.

This type of conflation is evident in numerous examples where the international baccalaureate (ib) program tends to be described according to diploma program requirements. The collectivized reference masks specific program characteristics, leading to 'confusion, conflation, inconsistency' (Baker et al, 2008: 284) through 'misuse of terminology' (Gabrielatos \& Baker, 2008: 26) and the selective presentation of information.

Conflation is further evident in the terms commonly used to modify baccalaureate(ib) identified in the word sketch. While international is the most frequent, as would be expected, the other common modifiers (partial, full, two-year) seem to indicate a level of scale or degree that suggests a different picture from the single unified entity discussed above. That is, reference to a full or partial program seems to imply that both are part of the two-year diploma program, regardless of how many components are undertaken (see concordance 2).

Concordance 2: Expanded group membership

\begin{tabular}{|l|l|l|}
\hline $\begin{array}{l}\text { areas of study. Or they can } \\
\text { take a partial }\end{array}$ & IB & $\begin{array}{l}-- \text { the most popular option } \\
-- \text { studying }\end{array}$ \\
\hline $\begin{array}{l}\text { to take full IB, there is } \\
\text { always partial }\end{array}$ & IB & $\begin{array}{l}\text { to fall back on, allowing } \\
\text { you to still }\end{array}$ \\
\hline $\begin{array}{l}\text { stayed in IB. Since I } \\
\text { dropped out of full }\end{array}$ & IB & $\begin{array}{l}\text { and joined partial, I have } \\
\text { been much }\end{array}$ \\
\hline $\begin{array}{l}\text { two-year , pre-university } \\
\text { International }\end{array}$ & Baccalaureate & $\begin{array}{l}\text { (IB) program. Operated by } \\
\text { the International }\end{array}$ \\
\hline
\end{tabular}


This type of 'relational identification' (Reisigl \& Wodak, 2001: 53) expands group membership, masking the fact that it includes those who may be just sampling rather than committing to the prescribed series of program elements. It is important to keep in mind that the diploma program was created with very specific criteria in mind, taking into account breadth (six disciplinary fields) with a central core focussed on reflection and critical thinking, research and writing, and community service. To earn the diploma, students are required to complete all components. Opting out of any aspect means that it is no longer the 'diploma program' but simply a course from a range of possible options. Referring to it as partial gives the impression that students are still engaged in the diploma program, and suggests that even those who might technically not belong to this group are included, thereby enjoying the associated predicative attributes. This adds additional confusion and conflation as easier generalizing terms are used in preference to clumsy and complicated specific ones. Such phrases can become fixed and entrenched, making them more difficult to challenge or even notice (Baker, 2010).

To further examine nomination strategies for the second most frequent noun collocate student, another random sample of 100 concordance lines was obtained. Of these, only three specified the program in which students were enrolled (e.g., ib diploma students). The remainder all used the generalizing term international baccalaureate (ib) student, of which 32 referred to specific individuals and 65 to IB students in general. This type of collectivization 'can be defined as linguistic processes through which groups of people are systematically referred to and constructed as one unanimous group with all sharing similar characteristics' (KhosraviNik, 2010: 13), which perpetuates the assumption that all are the same.

A random sample of 100 concordance lines was also obtained for the third most frequent noun collocate school. Of these, 26 referred to international baccalaureate (ib) world school and six to specific types (primary, middle, diploma). The remaining 68 referred to IB schools in general, again demonstrating the collectivization process involved in membership categorization. The important point here is that in a corpus of 108 Canadian newspapers, the dominant nomination strategy appears to serve a collectivizing function, signalling group membership.

\section{Positive in-group/negative out-group (predication)}

Having found through the word sketch analysis that baccalaureate(ib) is most frequently used as a label to collectivize diverse elements into a single group, the next step was to identify the values and attributes associated with the group through predication strategies (Engstrom \& Paradis, 2015; Reisigl \& Wodak, 2001). Therefore, the analysis turns to a more qualitative examination of baccalaureate ( $i b)$, for which a separate random sample of 100 concordance lines was obtained. The purpose of obtaining a random sample was to further guard against inadvertently 'cherry picking' particular examples to suit my purposes (e.g., Baker et al., 2013a; Gabrielatos \& Baker, 2008). The detailed analysis focuses on how the top three noun collocates program, student, and school work together to construct $I B$ as the in-group, with the emergence of non- $I B$ as the out-group. 
According to Reisigl \& Wodak (2001), predicational strategies are employed to ascribe positive or negative characteristics and traits to groups, thereby creating a dichotomous world of insiders and outsiders, 'us' and 'them'. Predicational strategies are used in combination with nomination (referential) strategies, which often overlap and cannot be neatly separated, i.e., the name itself may connote values and attitudes that have become associated with it and therefore no longer need to be made explicit. In the case of $I B$, as discussed above, nomination involves a variety of categories being modified, such as curriculum, people and institutions. Through predicational strategies, it is possible to identify the kinds of values that become associated with these nominated groups. Predications are not always overt or explicit but can be implied or alluded to, leaving the audience to draw conclusions based on assumptions of shared background knowledge.

The International Baccalaureate (IB) program

Three main predicational patterns used to construct the international baccalaureate (ib) program were found in this random sample: i) recognized internationally; ii) more challenging than other (regular, traditional or local) curricula; iii) equivalent to university (or post-secondary) level study.

i) Recognized internationally

There were 34 occurrences of $I B$ as something known all over the world. Phrases such as worldwide recognition, around the world, all over the world, across the world, internationally recognized, globally recognized are repeated in descriptions of the international baccalaureate (ib) program. Related phrases are allows students to study anywhere, provides students access to universities all over the world. By repeatedly referring to $I B$ in relation to the world, a dual effect is achieved. On the one hand, it is presented as something recognizable no matter where one goes, thereby enacting the 'international passport to education' (Blackburn, 1991) idea that was central to its creation, and also suggesting that there are large numbers of students and schools in different parts of the world forming the IB group. On the other hand, by continually referring to its recognition around the world, there is an implication that other (local) curricula may not be so recognized and therefore not able to provide the type of global mobility necessary in today's interconnected world. Such a view was found in an expanded concordance line, in a statement by a parent who said, 'If my child wants to apply to a well-known university like Princeton, they know what IB is -- they don't know what OAC [Ontario Academic Credit] is'.

ii) More challenging

There were 39 references to various qualities of IB programs (such as challenging, rigorous, demanding, prestigious, high-quality). Through the repeated use of such evaluative attributes, a binary opposite seems to be suggested. This can be implicit, as in the following excerpts:

(2) As a former student enrolled in the International Baccalaureate program, I was disappointed and angered to read of the proposed cuts by the Alberta government...How will we be able to compete in an increasingly international economy if our education system is not up to par? 
(3) the International Baccalaureate program requires a depth of research and learning that puts its grads among an elite group who achieve a worldwide standard of excellence.

Comparisons are also stated explicitly, as in the following excerpts:

(4) IB graduates are recognized by universities all over the world as having received a

higher standard of education.

(5) The IB program is much better than the regular program.

In these descriptions, the provincial curriculum is presented as inferior, suggesting that local curricula are unable to provide the same level of quality as IB programs, thus contributing to the positive in-group/negative out-group construction. The use of vague generalizations masks the diversity that exists not only among IB programs, but also among Canadian provincial curricula. Such statements seem to exhibit the same kinds of nomination and predicational strategies usually employed in 'anti-foreigner' constructs (KhosraviNik, 2010: 5) where a 'functionally determined outgroup' is formed. This type of dichotomous construction tends to precede the privileging of one group and the exclusion and disadvantaging of the other.

iii) Equivalent to university

There were 61 occurrences of $I B$ in relation to university (e.g., preferred admission, advantage, preparation, scholarship, exemption, transfer credit, advanced standing).

Linking IB to university through such attributes contributes to the image of a high quality program in a way that is absent in descriptions of provincial curricula, even though these also prepare students for university study. The emphasis on transfer credits or exemptions awarded by universities for IB courses works to elevate these courses by placing them on the same level as universities, thereby suggesting that those engaged in IB study are already doing university-level work and therefore are more prepared and likely to succeed than students in other curricula. However, what gets backgrounded or masked in these generalizing descriptions is that the types of attributes associated with postsecondary study are based on the requirements of the two-year diploma program and its different components, which was designed specifically for university admission. None of the descriptions of $I B$ in the random sample provided details on what the primary or middle years programs entail, instead presenting a simplified (reified) picture of a single curriculum associated with attributes that originally came about in connection to the diploma program.

The link to universities is further reinforced through the use of the relational prefix pre, as can be seen in concordance 3 below:

Concordance 3: Linking to university

\begin{tabular}{|l|l|l|}
\hline $\begin{array}{l}\text { year. The IB program is a } \\
\text { demanding }\end{array}$ & $\begin{array}{l}\text { pre- } \\
\text { university }\end{array}$ & $\begin{array}{l}\text { course of study designed } \\
\text { for highly }\end{array}$ \\
\hline $\begin{array}{l}\text { Baccalaureate (IB) program, a } \\
\text { demanding }\end{array}$ & $\begin{array}{l}\text { pre- } \\
\text { university }\end{array}$ & $\begin{array}{l}\text { course of study designed } \\
\text { for highly }\end{array}$ \\
\hline $\begin{array}{l}\text { IB program is a rigorous two } \\
\text { year }\end{array}$ & $\begin{array}{l}\text { pre- } \\
\text { university }\end{array}$ & $\begin{array}{l}\text { program consisting of } \\
\text { courses of st }\end{array}$ \\
\hline
\end{tabular}


Through this repeated construction linking $I B$ to university, a seamless path between the two tends to get established, suggesting that one offers preparation and training which naturally culminates in the other. This might also suggest that such a direct pathway to university studies is unavailable in other curricula.

International Baccalaureate (IB) students

The main predicational pattern used to construct international baccalaureate (ib) students found in the random sample was i) highly motivated and like to learn. There were 24 occurrences of $I B$ students described as having particular traits, e.g., highly motivated, excited about learning, see the value of education, very motivated, really enthused, academically motivated, mature, highly academic, smart and driven, have a real passion for learning, are better prepared. Concordance lines expanded for additional context show that universities appear to recognize these qualities and even modify their recruitment and application processes to accommodate or privilege $I B$ students, who are seen as different from other students. One such concordance line shows that a leading university in British Columbia introduced a separate application for $I B$ students because 'the university wants those motivated students on its campus', which suggests that non-IB students may not be so motivated. The implied comparison suggests that $I B$ students are different from other students coming from Canadian provincial curricula, thereby helping to construct a positive in-group and a negative out-group.

This binary construction is further evident in statements referring to IB students as a homogeneous group (all ib students, as ib students) or in the singular as a type (as an ib student, being an ib student), again reinforcing the idea of shared characteristics, a key feature of stereotypes and discriminatory discourses. While $I B$ students are constructed as the in-group with positive attributes, the out-group is constructed in the form of a binary opposite, non-IB students (see concordance 4):

Concordance 4: Non-IB students as out-group

\begin{tabular}{|l|l|l|}
\hline $\begin{array}{l}\text { gives an IB student the } \\
\text { comparative advantage over a }\end{array}$ & $\begin{array}{l}\text { non-IB } \\
\text { student }\end{array}$ & $\begin{array}{l}\text { who must learn the material } \\
\text { for the first time }\end{array}$ \\
\hline $\begin{array}{l}\text { same movement toward } \\
\text { mediocrity." Even }\end{array}$ & $\begin{array}{l}\text { non-IB } \\
\text { students }\end{array}$ & $\begin{array}{l}\text { vaunt IB as a mark of } \\
\text { Greyhound superiority }\end{array}$ \\
\hline $\begin{array}{l}\text { not entirely surprising that } \\
\text { Colonel By (which also has }\end{array}$ & $\begin{array}{l}\text { non-IB } \\
\text { students }\end{array}$ & $\begin{array}{l}\text { ) is consistently ranked the } \\
\text { top }\end{array}$ \\
\hline $\begin{array}{l}\text { programs like IB are elitist, } \\
\text { they seem to help }\end{array}$ & $\begin{array}{l}\text { non-IB } \\
\text { students }\end{array}$ & stay on a positive slope. \\
\hline $\begin{array}{l}\text { clubs. That helps them mix } \\
\text { with the school's }\end{array}$ & $\begin{array}{l}\text { non-IB } \\
\text { students }\end{array}$ & $\begin{array}{l}\text { "They need to be good time } \\
\text { managers }\end{array}$ \\
\hline
\end{tabular}

There seems to be a suggestion that $I B$ students are beneficial for an institution not only because they appear to be smarter and more motivated, but also because they appear to wield a positive influence on non-IB students (who recognize the superiority of IB) by helping 'them stay on a positive slope' and also by socializing with them through school clubs. While the us/them construction is much more explicit in this type of usage, it is not that frequent in the corpus, occurring only eight times (non-IB students, non-IB courses, 
non-IB grads). Therefore, the dominant predicational strategy attributing positive and negative values seems to be achieved through implicature (e.g., Wodak, 2008).

International Baccalaureate (IB) schools

Two main predicational patterns used to construct international baccalaureate (ib) schools were found in the random sample: i) meet high IB standards; ii) part of a worldwide community.

i) Meet high IB standards

There were 11 references to the application and accreditation process a school must undergo before it can offer an IB program. Not just students gain status by joining the ingroup; schools are also seen to be better, as in the following excerpt:

(6) The International Baccalaureate is recognized as one of the world's most respected pre-university diploma programs. "I think it's a real honour to be recognized now as a school that's capable of offering the IB program," said CEC vice-principal...

Being vetted and deemed suitable by the IB organization, which is described as having strict standards that are respected and applied around the world, works to elevate the status of the school and places it in the wider context of in-group membership.

The various stages from application to authorization also earn the school in-group membership. A school can be accepted or accredited but also be working toward becoming, which gives little indication as to what stage the school is at in terms of the application process or what exactly it is doing to achieve such status. As with the relational identification strategies used to expand the notion of $I B$ student and $I B$ program through the use of prefixes (e.g., pre) and modifiers (e.g., partial, potential), a school's status may also be elevated in becoming relationally identified with the in-group during various stages of the authorization process, such as being designated an $I B$ Candidate School (meaning that a school has submitted an application and been granted 'candidate status') or by being described as seeking or pursuing authorization in order to achieve IB certification. In some cases, even considering the possibility (bid to become part of) or expressing intention (directors made the decision...work towards being an) suggests a change in the way a school might be regarded.

ii) Part of a worldwide community

There were 13 references to the growing numbers of $I B$ schools around the world. A school can call itself IB World School only when it is certified by the IB organization. Once this designation or status is achieved, it joins the wider collective of such schools around the world. As with collectivized references to $I B$ students, IB World Schools are also referred to in a generalizing and essentializing manner (as an IB world school, all IB world schools) and constructed as a worldwide community of schools sharing a common philosophy and purpose, informed by the IB mission statement. ${ }^{5}$ Becoming an IB World School seems to indicate that a school has not only joined a worldwide community but also has been judged worthy of this membership. Descriptions of these schools often advert to their exclusive nature, such as first in the area or the only school to achieve this 
designation. Numbers are frequently used to indicate strength of membership around the world or within the country or province, as can be seen in concordance 6 below.

Concordance 6: Number of IB schools

\begin{tabular}{|c|c|c|}
\hline $\begin{array}{l}\text { ment. Founded in } 1968 \text {, the } \\
\text { International }\end{array}$ & Baccalaureate & $\begin{array}{l}\text { currently works with } \mathbf{3 , 9 6 4} \\
\text { schools in } \mathbf{1 4 7} \text { countries } \\
\text { to develop and offer }\end{array}$ \\
\hline $\begin{array}{l}\text { lament the province's low } \\
\text { standards in education. } \\
\text { Since the } 1960 \text { s the } \\
\text { International }\end{array}$ & Baccalaureate & $\begin{array}{l}\text { has sprung up in more than } \\
\mathbf{5 0 0} \text { schools in } \mathbf{7 3} \\
\text { countries around the } \\
\text { world, }\end{array}$ \\
\hline $\begin{array}{l}\text { that original mandate. Canada } \\
\text { now has } \mathbf{3 4 8}\end{array}$ & $\mathrm{IB}$ & $\begin{array}{l}\text { schools, the second } \\
\text { highest number after }\end{array}$ \\
\hline $\begin{array}{l}\text { students aged } 3 \text { to } 19- \\
\text { taught at almost } \mathbf{3 , 5 0 0}\end{array}$ & IB & $\begin{array}{l}\text { World schools in } \mathbf{1 4 3} \\
\text { countries around the }\end{array}$ \\
\hline
\end{tabular}

This type of quantification tends to follow a similar pattern, referring to schools, countries, and students. The use of numbers as a predicational strategy might suggest the idea that it must be good because so many people around the world are using it and everyone cannot be wrong, which, according to Wodak (1996: 116), forms an important part of 'we' (or in-group) discourse. Even though the IB organization itself states that there is no 'typical' IB school and that each school is different (IBO, 2014), constructing $I B$ World Schools as a homogenous and worldwide group helps to reify and solidify the image of a single entity, allowing predicational attributes to be associated with all IB schools, giving the impression that they are all the same.

\section{Discussion and concluding remarks}

This article examines how the International Baccalaureate (IB) is represented in a corpus of Canadian newspapers and the implications this representation might have, whether positive, negative, or neutral. Focusing on the discursive strategies of nomination (how are groups named?) and predication (what qualities are ascribed to them?) as revealed through corpus analysis, it becomes possible to make explicit the ways that a discriminatory discourse of difference is being constructed through everyday interaction (e.g., politics, sports, letters and opinions). According to Reisigl \& Wodak (2001), a fundamental aspect of discriminatory discourses is the construction of the 'other' and the subsequent assignment of values, whether negative or positive, implicit or explicit. These elements were found to be present in discourses surrounding the IB.

Through the discursive strategy of nomination, $I B$ signals group membership consisting of diverse elements (e.g., curricula, students, schools) which have associated predicational 'traits, characteristics, qualities, and features' (Reisigl \& Wodak, 2001: 44) that are not always mentioned explicitly, but draw on the IB label as a 'shortcut' (Baker et al., 2013b: 264) to imply or allude to them. The qualities associated with the IB were found to be positive, suggesting that perceptions of the wider Canadian public cohere with those found in the studies of university personnel, indicating a consistently positive view across domains. The corpus analysis revealed that despite the multiple perspectives comprised by the data, $I B$ is a primarily uncontested positive expression which includes some and excludes others. 
The construction of a positive stereotype is problematic in that it privileges its members while denying or excluding non-members from the same (Baker \& Potts, 2013). This paper argues that the repeated view of $I B$ as 'better' constructs a notion of 'other' in the form of non-IB by using some of the same types of discursive strategies usually found in discourses of discrimination to exclude and disadvantage those in the out-group. Qualities that are routinely associated with the IB label simultaneously construct a group that lacks those qualities and, as a result, is placed at a disadvantage in the context of publicly funded education, whose aim, ostensibly, is to be equitable. This results in an imbalance of resources, with larger burdens placed on those who are non-IB (e.g., W. Baker, 2014). Such exclusion exhibits elements of a discriminatory construct where a particular group is placed at a disadvantage as a result of a binary in-group/out-group construction. An interesting aspect revealed in this study is an inversion of the usual pattern of discrimination, where the out-group tends to be the minority. In this case, it is the (IB) minority that is the in-group, with the disadvantaged out-group being the (non-IB) majority. This binary distinction is not due to a single powerful source but one that is coconstructed throughout society.

By highlighting how groups may be excluded or disadvantaged through in-group/outgroup construction, this paper hopes to problematize the seemingly uncritical acceptance and adoption of IB programs in Canadian public schools, where scarce funds may be used to benefit a select few instead of being applied to the improvement of the whole school. As discussed above, discourses surrounding $I B$ are co-constructed by different segments of society, in the way they contribute to the existing image through nomination and predication strategies. In the construction of $I B$ and non- $I B$, those outside the group, such as students, teachers, schools, and even school boards, become seen as inferior. The encroachment of the IB into publicly funded schools highlights the embedded inequality in its ontology and should make it a candidate for public scrutiny and debate. Instead, there appears to be uncritical acceptance and support for this relatively unknown entity (as evidenced in the survey responses of university personnel). Such support and acceptance can be seen in the statements of representatives from leading Canadian universities who routinely state that their institutions privilege and actively seek out $I B$ students because they are better prepared, and therefore more likely to succeed at postsecondary studies than their non- $I B$ counterparts (Arida, 2016; Loat, 2007; Piper, 2006). Canada has the second-highest number of IB schools in the world (next to the US) and this growth seems to have occurred without much critical analysis or public scrutiny. To paraphrase Panisch (2001), this seems odd given that one of the key attractions for the program is purported to be 'critical thinking'.

\footnotetext{
Notes

${ }^{1}$ https://web.archive.org/web/20141108234603/https://www.ibo.org/history/

${ }^{2}$ In this specialized corpus, all instances of baccalaureate refer to the International Baccalaureate, which would not be the case in other corpora where the word is associated with different types of qualifications.

${ }^{3}$ For simplicity, the italicized acronym $I B$ is used to refer to the node word baccalaureate (ib).

${ }_{5}^{4}$ Kilgarriff (n.d.). https://www. sketchengine.co.uk/user-guide/glossary/?letter=L

${ }^{5} \mathrm{http}: / /$ www.ibo.org/about-the-ib/mission/
} 


\section{References}

Author. (2015)

Author. (in press).

Arida, A. (2016). Understanding the IB diploma for undergraduate admissions and firstyear performance. Paper presented at the 2016 ARUCC [Association of Registrars of the Universities and Colleges of Canada] conference, Vancouver, BC. Retrieved from http://www.arucc.ca/uploads/ARUCC-2016/D6.pdf

Bagnall, N. F. (1994). The International Baccalaureate in Australia and Canada: 19801993 (Unpublished doctoral dissertation). University of Melbourne.

Baker, P. (2006). Using corpora in discourse analysis. London, UK: Continuum.

Baker, P. (2010). Sociolinguistics and corpus linguistics. Edinburgh: Edinburgh University Press.

Baker, P. (2014). 'Bad wigs and screaming mimis': Using corpus-assisted techniques to carry out critical discourse analysis of the representation of Trans people in the British press. In C. Hart \& P. Cap (Eds.), Contemporary critical discourse studies (pp. 211-235). London, UK: Bloomsbury.

Baker, P., Gabrielatos, C., KhosraviNik, M., Krzyżanowski, M., McEnery, T., \& Wodak, R. (2008). A useful methodological synergy? Combining critical discourse analysis and corpus linguistics to examine discourses of refugees and asylum seekers in the UK press. Discourse \& Society, 19(3), 273-306.

Baker, P., Gabrielatos, C., \& McEnery, T. (2013a). Discourse analysis and media attitudes: The representation of Islam in the British press. New York: Cambridge University Press.

Baker, P., Gabrielatos, C., \& McEnery, T. (2013b). Sketching Muslims: A corpus driven analysis of representations around the word 'Muslim' in the British press 19982009. Applied Linguistics, 34(3), 255-278.

Baker, P., Hardie, A., \& McEnery, T. (2006). A glossary of corpus linguistics. Edinburgh University Press.

Baker, P., \& Levon, E. (2016). 'That's what I call a man': Representations of racialised and classed masculinities in the UK print media. Gender and Language, 10(1), 106-139. 
Baker, P., \& McEnery, T. (2005). A corpus-based approach to discourses of refugees and asylum seekers in UN and newspaper texts. Journal of Language and Politics, $4(2), 197-226$.

Baker, P., \& McEnery, T. (2014). 'Find the doctors of death': Press representation of foreign doctors working in the NHS, a corpus-based approach. In A. Jaworski \& N. Coupland (Eds.), The discourse reader ( $3^{\text {rd }}$ ed.) (pp. 465-480). New York, NY: Routledge.

Baker, P., \& McEnery, T. (Eds.). (2015). Corpora and discourse studies: Integrating discourse and corpora. London, UK: Palgrave Macmillan.

Baker, P., \& Potts, A. (2013). 'Why do white people have thin lips?': Google and the perpetuation of stereotypes via auto-complete search forms. Critical Discourse Studies, 10(2), 187-204.

Baker, W. (2014). 'Curricular choice' in Ontario public secondary schools: Exploring the policy and practice of the International Baccalaureate Diploma Programme (Unpublished master's thesis). The University of Western Ontario.

Bartlett, K. (1998). International curricula: More or less important at the primary level? In M. C. Hayden \& J. J. Thompson (Eds.), International Education: Principles and Practice (pp. 77-91). London, UK: Kogan Page.

Bunnell, T. (2011a). The growth of the International Baccalaureate ${ }^{\circledR}$ Diploma Program: Concerns about the consistency and reliability of the assessments. The Educational Forum, 75, 174-187.

Bunnell, T. (2011b). The International Baccalaureate in the United States: From Relative inactivity to imbalance. The Educational Forum, 75, 66-79.

Bunnell, T. (2012). Global education under attack: International Baccalaureate in America. Frankfurt: Peter Lang.

Coates, H., Rosicka, C., \& MacMahon-Ball, M. (2007). Perceptions of the International Baccalaureate DiplomaProgramme among Australian and New Zealand Universities. Retrieved from http://www.ibo.org/en/about-theib/research/programme-impact-research/diploma-studies/

Culpepper, J. (2009). The metalanguage of IMPOLITENESS: Using sketch engine to explore the Oxford English Corpus. In P. Baker (Ed.), Contemporary corpus linguistics (pp. 47-63). London: Continuum.

Daly, K. (2012). An exploration of Virginia law on recognition, university officials, and perceptions of the International Baccalaureate Diploma Programme (Unpublished PhD thesis). George Mason University, USA. 
de Cillia, R., Reisigl, M., \& Wodak, R. (1999). The discursive construction of national identities. Discourse \& Society, 10(2), 149-173.

Doherty, C. (2009). The appeal of the International Baccalaureate in Australia's educational market: A curriculum of choice for mobile futures. Discourse: Studies in the Cultural Politics of Education, 30(1), 73-89.

Engström, R., \& Paradis, C. (2015). The in-group and out-groups of the British National Party and the UK Independence Party: A corpus-based discourse-historical analysis. Journal of Language and Politics, 14(4), 501-527.

Fox, E. (1998). The emergence of the International Baccalaureate as an impetus for curricular reform. In M. C. Hayden \& J. J. Thompson (Eds.), International Education: Principles and Practice (pp. 65-76). London, UK: Kogan Page.

Gabrielatos, C., \& Baker, P. (2008). Fleeing, sneaking, flooding: A corpus analysis of discursive constructions of refugees and asylum seekers in the UK Press, 19962005. Journal of English Linguistics, 36(1), 5-38.

Hayden, M. (1998). International education in practice. In M. Hayden \& J Thompson (Eds.), International education: Principles and practice (pp. 1-8). London: Kogan Page.

Hayden, M., \& Thompson, J. (Eds.). 2011. Taking the MYP forward. Woodbridge: John Catt Educational.

Hill, I. (2002). The history of international education: An International Baccalaureate perspective. In M. Hayden, J. Thompson, \& G. Walker (Eds.), International education in practice: Dimensions for national \& international schools (pp. 1829). London: Kogan Page.

International Baccalaureate Organization. (2007). 21 Things you should know about the $I B$. Retrieved from https://web.archive.org/web/20120320064741/http://www.ibo.org/facts/21things/ documents/21thingsyoushouldknowabouttheIBMarch08.pdf

Jenkins, C. (2003). Perceptions of the IB Diploma Programme. Retrieved from http:/www.ibo.org/en/about-the-ib/research/programme-impactresearch/diploma-studies/

Kilgarriff, A., Baisa, V., Bušta, J., Jakubíček, M., Kovář, V., Michelfeit, J., ... Suchomel, V. (2014). The sketch engine: Ten years on. Lexicography, 1, 7-36.

Kilgarriff, A., Rychly, P., Smrz, P., \& Tugwell, D. (2004). The sketch engine. Proceedings of EURALEX 2004 (pp. 105-116). Lorient, France.

KhosraviNik, M. (2010). The representation of refugees, asylum seekers and immigrants in British newspapers: A critical discourse analysis. Journal of Language and Politics, 9(1), 1-28. 
Langford, M. (1998). Global nomads, third culture kids and international schools. In M. C. Hayden \& J. J. Thompson (Eds.), International Education: Principles and Practice (pp. 28-43). London, UK: Kogan Page.

Loat, W. (2007). Bridging the gap: The IB program as university preparation. AACRAOSEM Newsletter. American Association of Collegiate Registrars and Admissions Officers. Retrieved from http://www4.aacrao.org/semsource/sem/ index6861.html?fa $=$ print \&id $=3697$

Mautner, G. (2007). Mining large corpora for social information: The case of elderly. Language in Society, 36, 51-72.

Mautner, G. (2008). Analyzing newspapers, magazines and other print media. In R. Wodak \& M. Krzyżanowski (Eds.), Qualitative discourse analysis in the social sciences (pp. 30-53). New York, NY: Palgrave Macmillan.

Mautner, G. (2009a). Corpora and critical discourse analysis. In P. Baker (Ed.), Contemporary corpus linguistics (pp. 32-46). London: Continuum.

Mautner, G. (2009b). Checks and balances: How corpus linguistics can contribute to CDA. In R. Wodak \& M. Meyer (Eds.), Methods of critical discourse analysis $\left(2^{\text {nd }}\right.$ ed.) (pp. 122-143). London, UK: Sage.

McEnery, T., \& Hardie, A. (2012). Corpus linguistics. Cambridge: Cambridge University Press.

Panich, C. (2001). A study of the university performance of students with International Baccalaureate high school experience (Unpublished $\mathrm{PhD}$ thesis). Duquesne University, Pittsburgh, PA.

Paris, P. G. (2003). The International Baccalaureate: A Case Study on why students choose to do the IB. International Education Journal, 4(3), 232-243.

Piper, M. (2006). Universities and the IBO: Your mission is our mission. Peterson Lectures. International Baccalaureate Organization. Retrieved from https://web.archive.org/web/20130603195906/https:/www.ibo.org/council/peters on/piper/documents/piper lecture.pdf

Reisigl, M. (2008). Analyzing political rhetoric. In R. Wodak \& M. Krzyżanowski (Eds.), Qualitative discourse analysis in the social sciences (pp. 96-120). New York, NY: Palgrave Macmillan.

Reisigl, M., \& Wodak, R. (2001). Discourse and discrimination: Rhetorics of racism and antisemitism. London, UK: Routledge.

Renaud, G. (1991). The International Schools Association (ISA): Historical and philosophical background. In P. Jonietz \& D. Harris (Eds.), World yearbook of education 1991: International schools and international education (pp. 6-14). London: Kogan Page. 
Resnik, J. (2012). The denationalization of education and the expansion of the International Baccalaureate. Comparative Education Review, 56(2), 248-269.

Stubbs, M. (1996). Text and corpus analysis: Computer-assisted studies of language and culture. Oxford: Blackwell.

Stubbs, M. (2001). Words and phrases: Corpus studies of lexical semantics. Oxford: Blackwell.

Tarc, P. (2009). Global dreams, enduring tensions: International Baccalaureate program in a changing world. New York: Peter Lang.

Tarc, P., \& Beatty, L. (2012). The emergence of the International Baccalaureate Diploma in Ontario: Diffusion, pilot study and prospective research. Canadian Journal of Education, 35(4), 341-375.

Tarver, E. T. (2010). University admissions officers' perceptions of student performance within the International Baccalaureate Diploma Program (Unpublished PhD thesis). Louisiana State University.

van Dijk, T. (2001). Multidisciplinary CDA: A plea for diversity. In R. Wodak \& M. Meyer (Eds.), Methods of critical discourse analysis (pp. 95-120). London: Sage.

Whitehead, K. (2005). Advertising advantage. The International Baccalaureate, social justice and the marketisation of schooling. Paper presented at the Australian Association for Research in Education Annual Conference, University of Western Sydney, Parramatta. Retrieved from

http:/www.aare.edu.au/data/publications/2005/whi05426.pdf

Wodak, R. (1996). The genesis of racist discourse in Austria since 1989. In C. R. CaldasCoulthard \& M. Coulthard (Eds.), Texts and practices: Readings in critical discourse analysis (pp. 107-128). New York, NY: Routledge.

Wodak, R. (2008). 'Us' and 'them': Inclusion and exclusion - discrimination via discourse. In G. Delanty, R. Wodak, \& P. Jones (Eds.), Identity, belonging and migration (pp. 54-77). Liverpool University Press.

Wodak, R., \& Matouschek, B. (1993). 'We are dealing with people whose origins one can clearly tell just by looking': critical discourse analysis and the study of neoracism in contemporary Austria. Discourse \& Society, 4(2), 225-248. 


\section{Chapter 9}

\section{Conclusion}

This chapter summarizes the research presented in this dissertation and reviews the key findings reported in the four journal articles. It concludes with the study's contributions, limitations, and directions for further research.

The overall aim of this research study was to gain insight into how the IB is perceived and represented in Canada and the implications this might have for the wider society (e.g., publicly funded education or real estate markets). For this reason, two populations were targetted, namely university admissions personnel (online survey and semistructured interviews) and the general public (corpus of Canadian newspapers as a window into public opinion). The dialectical relationship between a discursive phenomenon and the social structures framing it was discussed in Chapter 2, whereas the importance of university admission to the IB was discussed in detail in Chapter 3. From these contexts, obtaining views from university admissions personnel and the general public was seen as key to gaining a better understanding of the IB in Canada.

I began the dissertation by making explicit my position as a researcher on this topic and how I came to be interested in the IB as a discursive phenomenon. Through my experience of the IB in multiple contexts, I became aware that although there was a prevalently positive view of the IB, this view also seemed to be accompanied by a lack of specific knowledge about it. Also noticeable was the uniformity in these different contexts of the language used to describe the IB, e.g., "it is a very rigorous and challenging program" and "IB students are very smart". Another point of interest was that these trends were repeated across countries with very different education systems, such as Australia, New 
Zealand, the UK, the US, and Canada, where there appeared to be general agreement that the IB was better than the local education system. In addition, there seemed to be a number of values and assumptions that were routinely associated with the IB name (e.g., tolerance and respect of others, hardworking, caring, etc.). Such descriptions seemed to suggest that only the IB engenders these qualities, while other curricula do not. Thus, descriptions of the IB seemed to be more about societal value judgements than school programs, suggesting that this was a discursive phenomenon.

In investigating this phenomenon, it was important to use systematic analysis to move beyond anecdotes and impressions, and also guard against my own (potential) bias. Therefore, a corpus-based CDA/DHA approach was used in this study to facilitate multiple methods and sources of data to aid triangulation. Chapter 2 discussed the theoretical and methodological details of this approach, for which I created a specialized corpus consisting of all Canadian newspapers and articles on the IB available from two online databases.

Chapter 3 presented a critical review of the literature on the IB based on one of the key principles of the DHA, which is to examine multiple genres from multiple public spaces to uncover distortions and inaccuracies as well as to integrate a wide view of the historical context in which a phenomenon is embedded. As discussed in that chapter, much of the information about the IB tends to be produced by the organization itself or its practitioners, and thus a comprehensive review from a variety of sources was necessary. This brought to light a number of key points pertaining to the historical development and presentation of the IB in much of the literature, such as the shift in emphasis that seems to have occurred in accounts of the history of the IB, from a pragmatic (i.e., university admission) to an idealistic (i.e., world peace) endeavour. This shift became evident through the historical sources and 
sheds light on how some of the values and attitudes associated with the IB may be constructed. Another key point that came to light was the conflation that happens as a result of different IB programs being lumped together under one general label, or by obfuscating differences through lengthy descriptions of the DP when discussing the other programs. This conflation appeared to be widespread and systematic, thereby making it necessary to exercise caution when reading IB-related material.

Chapter 4 provided additional information on the methods used in the study that, due to space constraints, was not included in the four articles that constitute the research findings. In particular, I provided details on the process of obtaining REB clearances from universities across the country needed to recruit participants for the first part of the study. The length and complexity of this process explains why the sample size of the study is relatively small compared to similar studies conducted in Australia/NZ and the UK.

\section{Summary of findings from journal articles (Chapters 5-8)}

Chapter 5 presents the study of university perceptions in Ontario, followed by a similar study Canada-wide in Chapter 6. These two studies, which formed the first part of the research, used an online survey and semi-structured interviews to obtain data. Chapter 7 moved from the university context to general public opinion as found in a specialized corpus of Canadian newspapers. Key concepts in this study were collocation, semantic preference and discourse prosody, used as a way to tease apart values and attitudes that appear to be associated with the IB label. Chapter 8 continued this line of enquiry, using the same corpus but a different corpus tool, which provided a way to identify discursive strategies. Each article not only reflects a different stage of the research design but also delineates the 
development of more specific research questions based on the results that were obtained at each stage.

The results reported in the first article confirmed the highly positive view of the IB in relation to other curricula, but also indicated that underlying this was a superficial understanding of the IB, i.e., the certainty about the IB diminished as questions became more specific. The positive skew of the survey questions was retained to remain as close as possible to earlier surveys done in the UK and Australia/NZ. Although this skew had initially been seen as a limitation, it proved to be a surprising and key source of information because it revealed that, while respondents unanimously agreed on the superiority of the IB, when asked to identify specific ways in which the curriculum was better, they were unable to respond. This aspect of the survey was questioned by the Carleton REB, by a respondent when the survey was field tested, and also by one of the survey participants. As it turned out, these more specific questions became central to the analysis and also showed similarity with the earlier surveys, i.e., the same pattern of response.

At this initial stage of the research, a connection was seen with the IB organization's efforts to form this positive perception through publications and workshops designed to "assist" university personnel in understanding the IB curriculum. As the first article argues, the similarity of response could be attributed to the IB organization itself using Berger and Luckmann's (1966) concept of institutionalization, which helps to explain why everyone seemed to be "telling the same story", and through intertextual links and the dialectical nature of the IB organization's communication strategy with university admissions personnel. 
The second article expanded on this study to include all Canadian provinces, to determine what perceptions were held across the country. While a similar pattern was discovered, i.e., the IB was viewed as better than all other curricula even though knowledge about the program was lacking, another element was found in this study through the openended comments, which revealed references to "IB student" as a homogeneous group having particular qualities. This seemed to point to $I B$ as a value-laden term associated with particular qualities. It also suggested a binary opposite, i.e., a "non-IB student" who would lack these qualities.

One finding from the studies in the first part was that the primary source of IB information appeared to be the IB organization itself. Therefore, looking at how the IB was represented in sources other than those of the organization became important, to discover how people talked about the IB in general, i.e., how the IB is perceived and constructed in Canada. One way to do this was by looking at how the IB is represented in newspapers across the country. Although newspapers may not contain all opinions on a given topic (Karim, 2008), their place in the public sphere makes them an important source of the most prominent expressions in a given society. Furthermore, the unsolicited nature of the data (Mautner, 2008) provided an important contrast to the elicited responses of the survey and semi-structured interviews in the first part of the study.

The third article thus moved outside the confines of university admission to the wider society as more research into the IB showed that (a) positive perceptions extended beyond universities to the general population and (b) programs tended not to be differentiated but referred to simply as IB. Through corpus data and collocation analysis, fixed phrases associated with $I B$ as a label were teased apart to discover underlying values 
and attitudes that have come to be taken for granted. What this study revealed was that $I B$ seemed to be more about social attitudes than about a curriculum. It also pointed to one group of students, teachers and schools being privileged at the expense of another, thereby addressing the important CDA question of "who benefits" (Baker et al., 2013a). However, based on the historical context and the financial difficulties the IB organization experienced in its early years discussed in Chapter 3, it could be argued that it is also the organization itself "who benefits", as the increase in the number of schools results in greater membership and associated fees.

The fourth article investigated the way these different groups were discursively constructed by analyzing a smaller random sample from the IB media corpus in more detail. A word sketch made it possible to see the construction of an $I B$ in-group and a non-IB outgroup. What also became evident in this study was the great deal of conflation that occurs with IB programs. By lumping all the programs together under a single IB label, qualities tied to the original DP get applied to the other programs. Importantly, this study found that the discursive strategies used to construct the in-group and out-group were similar to those evident in discourses of discrimination and difference. Present across domains, this view was found to be a predominantly uncontested positive expression that included some but excluded others. Although such binaries are seldom clear-cut in practice, the results of the study suggest that such a division might exist and, in the context of publicly funded education, be deserving of scrutiny. 


\section{Contributions, limitations and directions for further research}

The research reported in this dissertation contributes to the growing body of work in the area of corpus-based (critical) discourse analysis and demonstrates how this "useful methodological synergy" (Baker et al., 2008) can be harnessed to gain insight into discourse as social practice. As the articles show, concepts from this combined approach allowed recurring patterns of language use to be identified, which pointed to the existence of a dominant (hegemonic) discourse across different social domains. Furthermore, values and attitudes that are taken for granted as a result of habitual ways of referring to groups can be made more explicit, thereby making it possible to challenge entrenched (possibly discriminatory) views. Examining the IB as a discursive phenomenon reveals how social practice in terms of daily interaction reproduces dominant discourses that benefit some and disadvantage others (e.g., the rising prices in real estate markets or preferential treatment offered to particular groups).

A key limitation of this study is that it examines the discursive construction of the IB in English Canada (universities and newspapers). While the province of Quebec is represented in the data, it is restricted to English-medium universities and newspapers. Quebec has the highest number of IB schools in Canada (147 to Ontario's 103) and thus should be examined more fully. Also not included in this study are the three Canadian territories (Nunavut, Yukon and Northwest Territories); however, the population of these is small compared to the provinces.

A further limitation was the small number of participants for the survey compared to similar studies conducted in the UK and Australia/NZ. However, unlike the previous 
studies, the fact that all participants had contact with IB-educated applicants helped mitigate this limitation.

In terms of the specialized IB corpus, only those newspapers that were available on the two databases at the time of the search were included. As such, the corpus does not include all of the newspapers available in Canada. In addition, some of the provinces (i.e., BC and Ontario) are over-represented while others, such as PEI and Newfoundland, have only a few articles (see Figure 4.2). So although the study reports on perceptions in Canada, this perception may be more concentrated in specific regions rather than equally spread across the country (Vessey, 2016).

One of the study's limitations is also its contribution: it examines the IB in Canada as a whole, thereby giving a broad picture but eliding provincial differences, which would be important for understanding the role of the IB in different provincial contexts. As discussed in Chapter 3, research on the IB in Canada is relatively minimal, and mostly restricted to particular provinces or schools. This study hopes to contribute an updated baseline of information since the last Canada-wide study by Bagnall (1994). It also moves beyond anecdote by providing empirical evidence of the dominant positive view of the IB in Canada.

In terms of further research, then, an important avenue would be to compare the different provinces as to perceptions of the IB, to understand how it is discursively constructed in each. This could be done through a keyword analysis (see Chapter 2) comparing the different provincial subcorpora to the whole corpus. Keywords are an important part of corpus linguistic research, helping to identify the "aboutness" of a corpus, and how it compares to other types of corpora, but did not form part of the research reported in this dissertation because the focus was on how the IB was perceived in Canada 
as a whole rather than in each province. However, preliminary analyses using keywords have been conducted, which revealed different preoccupations surrounding the IB in each province and different roles the IB plays in furthering particular agendas. For example, keywords for BC seemed to cluster around school closures and IB accreditation, whereas for Nova Scotia they seemed to concern budgets and costs. Further research is needed to understand how and why the IB is adopted in each province and the implications this has in terms of the provincial curriculum. This inter-provincial focus could also usefully be supported by examination of parliamentary debates as recorded in Hansard transcripts (e.g., Baker, 2006). Since education in Canada is a provincial responsibility, introduction of IB programs into publicly-funded schools requires some type of agreement or permission from provincial ministries of education. Parliamentary debates could provide a valuable source for discovering the kinds of issues that arise, as well as the language surrounding the IB and how it is presented.

Another avenue of research would be to examine how perceptions of the IB have changed from the time it was first introduced (1974 in BC) to the present, to look for changes in language used to talk about the IB and to trace the emergence of the $I B$ stereotype. Descriptions from the corpus data could also be compared to archival information contained in other domains, such as university calendars (prospectuses). A preliminary examination of these calendars showed that information about the IB initially tended to be brief, consisting of a single line, and later changed to much lengthier descriptions. This shift seems to have occurred around the same time across universities, possibly indicating an increased interest in the program. It also seems to have occurred during the same period that COCA and CNC show a spike in IB reporting, and coincides 
with the time that the IB North America office was running its workshops. Such triangulation may help point to further reasons for the uniformity of perceptions found in the present study.

In summary, this research presents two key findings: (1) there exists a dominant (hegemonic) discourse surrounding IB in Canada, and (2) it bears a striking resemblance to discourses of discrimination and difference. The continuous praise that is heaped upon the IB tends to create a negative view of things non-IB (programs, students, schools). Since one is "better", there is an implied comparison at work that seems to go unnoticed. As a result, a stereotyped image gets perpetuated through repetition that eventually becomes common sense knowledge which is taken for granted and more assumed than stated explicitly. In the context of Canada's publicly funded education system, where the IB has grown increasingly popular, such a view is problematic as it advantages a select few (e.g., by preferred admission into universities) while disadvantaging the rest (e.g., imbalance of resources), thereby creating a context of insiders and outsiders or, as was the case in Tanzania, blackboard/whiteboard. 


\section{References}

Abrioux, M., \& Rutherford, J. (2013). Introducing the IB Diploma Programme. New York, NY: Cambridge University Press.

Ädel, A. (2010). How to use corpus linguistics in the study of political discourse. In A. O’Keeffe \& M. McCarthy (Eds.), The Routledge handbook of corpus linguistics (pp. 591 604). New York, NY: Routledge.

Ädel, A., \& Reppen, R. (2008). Corpora and discourse: The challenges of different settings. Amsterdam: John Benjamins.

Angermuller, J., Maingueneau, D., \& Wodak, R. (Eds.). (2014). The discourse studies reader: Main currents in theory and analysis. Amsterdam: John Benjamins

Anthony, L. (2013). A critical look at software tools in corpus linguistics. Linguistic Research, $30(2), 141-161$.

Anthony, L. (2014). AntConc (Version 3.4.3) [Computer Software]. Tokyo, Japan: Waseda University. Available from http://www.laurenceanthony.net/

Association of Registrars of the Universities and Colleges of Canada (ARUCC). (2014). Executive profiles. Retrieved from https://www.arucc.ca/uploads/PDF/Executive_Profiles_2014_2016.pdf

Bagnall, N. F. (1994). The International Baccalaureate in Australia and Canada: 1980-1993 (Unpublished doctoral dissertation). University of Melbourne.

Bagnall, N. F. (2010). Education without borders: Forty years of the International Baccalaureate, 19702010. Saarbrucken: VDM Verlag Dr Muller.

Baker, P. (2004). Querying keywords: Questions of difference, frequency and sense in keywords analysis. Journal of English Linguistics, 32(4), 346-359. 
Baker, P. (2005). Public discourses of gay men. London: Routledge.

Baker, P. (2006). Using corpora in discourse analysis. London, UK: Continuum.

Baker, P. (2009). (Ed.). Contemporary corpus linguistics. London, UK: Continuum.

Baker, P. (2010a). Representations of Islam in British broadsheet and tabloid newspapers 1999-2005. Journal of Language and Politics, 9(2), 310-338.

Baker, P. (2010b). Sociolinguistics and corpus linguistics. Edinburgh: Edinburgh University Press.

Baker, P. (2011). Social involvement in corpus studies. In V. Viana, S. Zyngier, \& G.

Barnbrook (Eds.), Perspectives on corpus linguistics (pp. 17-27). Amsterdam: John Benjamins.

Baker, P. (2012). Acceptable bias? Using corpus linguistics methods with critical discourse analysis. Critical Discourse Studies, 9(3), 247-256.

Baker, P. (2013). From gay language to normative discourse: A diachronic corpus analysis of Lavender Linguistics conference abstracts 1994-2012. Journal of Language and Sexuality, 2(2), 179-205.

Baker, P. (2014). "Bad wigs and screaming mimis": Using corpus-assisted techniques to carry out critical discourse analysis of the representation of Trans people in the British press. In C. Hart \& P. Cap (Eds.), Contemporary critical discourse studies (pp. 211-235). London, UK: Bloomsbury.

Baker, P. (2015). Does Britain need any more foreign doctors? Inter-analyst consistency and corpus-assisted (critical) discourse analysis. In N. Groom, M. Charles, \& S. John (Eds.), Corpora, grammar and discourse: In honour of Susan Hunston (pp. 283-300). Amsterdam: John Benjamins. 
Baker, P. (2016). The shapes of collocation. International Journal of Corpus Linguistics, 21(2), $139-164$.

Baker, P., \& Egbert, J. (Eds.). (2016). Triangulating methodological approaches in corpus-linguistic research. New York, NY: Routledge.

Baker, P., Gabrielatos, C., KhosraviNik, M., Krzyżanowski, M., McEnery, T., \& Wodak, R. (2008). A useful methodological synergy? Combining critical discourse analysis and corpus linguistics to examine discourses of refugees and asylum seekers in the UK press. Discourse \& Society, 19(3), 273-306.

Baker, P., Gabrielatos, C., \& McEnery, T. (2013a). Discourse analysis and media attitudes: The representation of Islam in the British press. New York: Cambridge University Press.

Baker, P., Gabrielatos, C., \& McEnery, T. (2013b). Sketching Muslims: A corpus driven analysis of representations around the word "Muslim" in the British press 19982009. Applied Linguistics, 34(3), 255-278.

Baker, P., Hardie, A., \& McEnery, T. (2006). A glossary of corpus linguistics. Edinburgh University Press.

Baker, P., \& Levon, E. (2015). Picking the right cherries? A comparison of corpus-based and qualitative analyses of news articles about masculinity. Discourse \& Communication, $9(2), 1-16$.

Baker, P., \& Levon, E. (2016). “That's what I call a man”: Representations of racialised and classed masculinities in the UK print media. Gender and Language, 10(1), 106-139.

Baker, P., \& McEnery, T. (2005). A corpus-based approach to discourses of refugees and asylum seekers in UN and newspaper texts. Journal of Language and Politics, 4(2), $197-$ 226. 
Baker, P., \& McEnery, T. (2014). "Find the doctors of death": Press representation of foreign doctors working in the NHS, a corpus-based approach. In A. Jaworski \& N. Coupland (Eds.), The discourse reader ( $3^{\text {rd }}$ ed.) (pp. 465-480). New York, NY: Routledge.

Baker, P., \& McEnery, T. (Eds.). (2015). Corpora and discourse studies: Integrating discourse and corpora. London, UK: Palgrave Macmillan.

Baker, P., \& Potts, A. (2013). "Why do white people have thin lips?”: Google and the perpetuation of stereotypes via auto-complete search forms. Critical Discourse Studies, 10(2), 187-204.

Baker, W. (2014). "Curricular choice" in Ontario public secondary schools: Exploring the policy and practice of the International Baccalaureate Diploma Programme (Unpublished master's thesis). The University of Western Ontario.

Baluja, T., \& Hammer, K. (2012, September 6). From \$3,000 to zero, fees vary wildly for prestigious high-school program. The Globe and Mail. Retrieved from http://www.theglobeandmail.com/news/national/education/from-3000-to-zerofees-vary-wildly-for-prestigious-high-school-program/article4255400/

Barnes, D. (1998). And then there were three...IB programmes, that is... International Schools Journal, XVIII(1), 44-49.

Barnes, R. (2004). Perceptions of the International Baccalaureate Programme. IB Research Notes, 4(1), 2-4.

Bartlett, K. (1998). International curricula: More or less important at the primary level? In M. C. Hayden \& J. J. Thompson (Eds.), International Education: Principles and Practice (pp. 77-91). London, UK: Kogan Page. 
Batey-Stepancic, A. (2006). The International Baccalaureate Organization: Characteristics and practices that lead to improved school climate and student achievement (Unpublished doctoral dissertation). Roosevelt University.

Bent, M. M. (2009). A peaceful partnership? A case study of three IB English A1 teachers' conceptions of peace education at an IB World School in Peru (Unpublished master's thesis). OISE, University of Toronto.

Berkey, T. B. (1994). The contributions of curriculum adaptability, adequate resources and broad support to the success of International Baccalaureate programmes in North America (Unpublished doctoral dissertation). University of Akron, Ohio.

Berger, P. L., \& Luckmann, T. (1966). The social construction of reality: A treatise in the sociology of knowledge. New York, NY: Penguin Books.

Biber, D., \& Conrad, S. (2001). Quantitative corpus-based research: Much more than bean counting. TESOL Quarterly, 35(2), 331-336.

Biber, D., \& Reppen, R. (Eds.). (2015). The Cambridge handbook of English corpus linguistics. Cambridge, UK: Cambridge University Press.

Blackburn, R. (1991). The International Baccalaureate: A curriculum at upper secondary level and a university entrance examination. In P. Jonietz \& D. Harris (Eds.), World yearbook of education 1991: International schools and international education (pp. 6-14). London: Kogan Page.

Blommaert, J. (2005). Discourse: A critical introduction. Cambridge, UK: Cambridge University Press. 
Bunnell, T. (2007). The international education industry: An introductory framework for conceptualizing the potential scale of an "alliance". Journal of Research in International Education, 6(3), 349-367.

Bunnell, T. (2008a). The global growth of the International Baccalaureate Diploma Programme over the first 40 years: A critical assessment. Comparative Education, 44(4), 409-424.

Bunnell, T. (2008b). The International Baccalaureate in England and Wales: the alternative paths for the future. The Curriculum Journal, 19(3), 151-160.

Bunnell, T. (2009). The International Baccalaureate in the United States and the emerging 'culture war'. Discourse: Studies in the cultural politics of education, 30(1), 61-72.

Bunnell, T. (2010). The International Baccalaureate and a framework for class consciousness: The potential outcomes of a 'class-for-itself. Discourse: Studies in the Cultural Politics of Education, 31(3), 351-362.

Bunnell, T. (2011a). The growth of the International Baccalaureate ${ }^{\circledR}$ Diploma Program: Concerns about the consistency and reliability of the assessments. The Educational Forum, 75, 174-187.

Bunnell, T. (2011b). The International Baccalaureate in the United States: From Relative inactivity to imbalance. The Educational Forum, 75, 66-79.

Bunnell, T. (2011c). The International Baccalaureate Middle Years Programme after 30 years: A critical inquiry. Journal of Research in International Education, 10, 261-274.

Bunnell, T. (2011d). The International Baccalaureate: Its growth and complexity of challenges. In R. Bates (Ed.), Schooling internationally: Globalisation, internationalisation and the future for international schools (pp. 165-181). New York, NY: Routledge. 
Bunnell, T. (2012). Global education under attack: International Baccalaureate in America. Frankfurt: Peter Lang.

Bunnell, T. (2013). The International Baccalaureate and the role of the "pioneer" international schools. In R. Pearce (Ed.), International education and schools: Moving beyond the first 40 years (pp. 167-182). London, UK: Bloomsbury Academic.

Bunnell, T. (2014). The International Baccalaureate and its "Second Era" of ambitious rhetoric: Wider access and greater impact. In D. P. Hobson \& I. Silova (Eds.), Globalizing minds: Rhetoric and realities in international schools (pp. 137-157). Charlotte, NC: Information Age Publishing, Inc.

Bunnell, T. (2015). The rise and decline of the International Baccalaureate Diploma Program in the United Kingdom. Oxford Review of Education, 41(3), 387-403.

Bunnell, T. (2016). The dearth of International Baccalaureate schools across Africa. Africa Education Review, 13 (2), pp. 181-195.

Burr, V. (1995). An introduction to social constructionism. London: Routledge.

Byrd, S., Ellington, L., Gross, P., Jago, C., \& Stern, S. (2007). Advanced Placement and International Baccalaureate: Do they deserve gold star status? Washington, DC: Thomas B. Fordham Institute. Retrieved from http://edex.s3-us-west2.amazonaws.com/publication/pdfs/APIB $920 . p d f$

Caliskan, A., Bryson, J. J., \& Narayanan, A. (2017). Semantics derived automatically from language corpora contain human-like biases. Science, 356, 183-186.

Cambridge, J. (2002). Response to Judy Hinrichs article. IB Research Notes, 2(1), 11. International Baccalaureate Organization. Retrieved from 
https://web.archive.org/web/20110105235113/http://www.ibo.org/programmes/r esearch/publications/documents/notesfebruary02.pdf

Cambridge, J. (2008). A review of research relating to the IB Diploma Programme. International Baccalaureate Organization (IBO). Retrieved from http://www.ibo.org/globalassets/publications/ib-research/dpresearchreview-1.pdf

Cambridge, J., \& Thompson, J. (2004). Internationalism and globalization as contexts for international education. Compare, 34(2), 161-175.

Caspary, K. (2011). Research brief: Postsecondary enrollment patterns of IB Certificate and Diploma candidates from U.S. High Schools. Center for Educational Policy SRI International. Retrieved from http://www.ibo.org/contentassets/d1c0accb5b804676ae9e782b78c8bc1c/ibsuppdo mesticresearchbrief2011-04-06.pdf

Caspary, K., \& Bland, J. (2011). Research brief: First college courses taken by Florida IB students. Center for Educational Policy SRI International. Retrieved from http://www.ibo.org/contentassets/d1c0accb5b804676ae9e782b78c8bc1c/flcoursesr esearchbrief2011-04-06.pdf

Chapman, M. (2011). Evolving the middle years curriculum in practice. In M. Hayden \& J. Thompson (Eds.), Taking the MYP forward (pp. 193-202). Woodbridge: John Catt Educational.

Chichekian, T. (2011). The articulation of inquiry in research about teaching and learning in the International Baccalaureate (Unpublished MA thesis). McGill University.

Clarke, I., Kwon, W., \& Wodak, R. (2012). A context-sensitive approach to analysing talk in strategy meetings. British Journal of Management, 23, 455-473. 
Clissold, K. (2012). Considering school-level policy decisions: A study of the values underpinning the pursuit of the International Baccalaureate programs (Unpublished doctoral dissertation). University Of Hawai'I at Mānoa.

Coates, H., Rosicka, C., \& MacMahon-Ball, M. (2007). Perceptions of the International Baccalaureate DiplomaProgramme among Australian and New Zealand Universities. Retrieved from http://www.ibo.org/en/about-the-ib/research/programme-impactresearch/diploma-studies/

Coffin, C., Hewings, A., \& O’Halloran, K. (Eds.). (2004). Applying English grammar: Functional and corpus approaches. London,UK: Hodder Arnold.

Connell, J. (2010). Expanding our horizons: An exploration of the implementation of the International Baccalaureate Programme in Prince Edward Island (Unpublished master's thesis). University of Prince Edward Island.

Conner, J. O. (2007). Student engagement during the senior year: Experiences with the International Baccalaureate Diploma Program's extended essay (Unpublished doctoral dissertation). Stanford University.

Conner, J. O. (2008). From International Schools to Inner-City Schools: The First Principles of the International Baccalaureate Diploma Program. Teachers College Record, 110(2), $322-351$.

Creswell, J. W., \& Plano Clark, V. L. (2007). Designing and conducting mixed methods research. London, UK: Sage.

Creswell, J. W., \& Plano Clark, V. L. (2011). Designing and conducting mixed methods research (2 ${ }^{\text {nd }}$ ed.). London, UK: Sage. 
Crouch, M. E. (1979). An analysis of selected elements of the International Baccalaureate (Unpublished doctoral dissertation), Washington State University.

Daly, K. (2012). An exploration of Virginia law on recognition, university officials, and perceptions of the International Baccalaureate Diploma Programme (Unpublished doctoral dissertation). George Mason University, USA.

Davis, M. (2015). The Corpus of Contemporary American English (COCA): 520 million words, 19902015. Available at http://corpus.byu.edu/coca/

de Cillia, R., Reisigl, M., \& Wodak, R. (1999). The discursive construction of national identities. Discourse \& Society, 10(2), 149-173.

DiGiorgio, C. (2010). Choices of students, parents, and teachers and their effects on schools and communities: A case study of a new enriched high school program. Journal of School Choice, 4(3), 278-292.

Doherty, C. (2009). The appeal of the International Baccalaureate in Australia's educational market: A curriculum of choice for mobile futures. Discourse: Studies in the Cultural Politics of Education, 30(1), 73-89.

Doherty, C. (2013). Making a point of difference: The glocalised ecology of the International Baccalaureate Diploma in Australian schools. Globalisation, Societies and Education, 11(3), 379-397.

Doherty, C., Luke, A., Shield, P., \& Hincksman, C. (2012). Choosing your niche: The social ecology of the International Baccalaureate Diploma in Australia. International Studies in Sociology of Education, 22(4), 311-332. 
Doherty, C., \& Shield, P. (2012). Teachers' work in curricular markets: Conditions of design and relations between the International Baccalaureate Diploma and the local curriculum. Curriculum Inquiry, 42(3), 414-441.

Drake, B. (2004). International education and IB programmes: Worldwide expansion and potential cultural dissonance. Journal of Research in International Education, 3(2):189-205.

Drone, J. (1988). Kenya education and the international baccalaureate: An interdisciplinary curriculum unit expanding the "study of man" options - bistory and geography (Unpublished doctoral dissertation). Columbia University Teachers College.

Duarte, G. (2012). The International Baccalaureate Diploma Program's impacting high school culture and climate (Unpublished doctoral dissertation). California State University.

Duncan, P. (2012). The discursive protection of national interests. Journal of language and politics, $11(3), 357-381$.

Durrant, P., \& Doherty, A. (2010). Are high-frequency collocations psychologically real? Investigating the thesis of collocational priming. Corpus Linguistics and Linguistic Theory, $6(2), 125-155$.

Elliot, J. (2014). The business of schooling: Marketing in Canadian independent schools (Unpublished doctoral dissertation). Ontario Institute for Studies in Education, University of Toronto.

Engström, R., \& Paradis, C. (2015). The in-group and out-groups of the British National Party and the UK Independence Party: A corpus-based discourse-historical analysis. Journal of Language and Politics, 14(4), 501-527.

Esteva, G. (1995). Development. In W. Sachs (Ed.), The development dictionary: A guide to knowledge as power (pp. 6-25). London, UK: Zed Books. 
Fairclough, N. (1989). Language and power. London, UK: Longman.

Fairclough, N. (1995). Media discourse. London, UK: E. Arnold.

Fairclough, N., \& Wodak, R. (1997). Critical discourse analysis. In T. A. van Dijk (Ed.), Discourse as social interaction (pp. 258-284). London, UK: Sage.

Flowerdew, L. (2012). Corpus-based discourse analysis. In J. P. Gee \& M. Handford (Eds.), The Routledge handbook of discourse analysis (pp. 174-187). New York, NY: Routledge.

Fox, E. (1985). International schools and the International Baccalaureate. Harvard Educational Review, 55(1), 53-68.

Fox, E. (1998). The emergence of the International Baccalaureate as an impetus for curricular reform. In M. C. Hayden \& J. J. Thompson (Eds.), International Education: Principles and Practice (pp. 65-76). London, UK: Kogan Page.

Frank-Gemmill, G. (2013). The IB Diploma and UK university degree qualifications. Journal of Research in International Education, 12(1), 49-65.

Frankenberg-Garcia, A., Flowerdew, L., \& Aston, G. (Eds.). (2011). New trends in corpora and language learning. New York, NY: Continuum.

Freake, R., Gentil, G., \& Sheyholislami, J. (2011). A bilingual corpus-assisted discourse study of the construction of nationhood and belonging in Quebec. Discourse \& Society, $22(1), 21-47$.

Gabrielatos, C., \& Baker, P. (2008). Fleeing, sneaking, flooding: A corpus analysis of discursive constructions of refugees and asylum seekers in the UK Press, 1996-2005. Journal of English Linguistics, 36(1), 5-38. 
Gabrielatos, C., \& Duguid, A. (2015). Corpus linguistics and CDA: Revisiting the notion of synergy. Retrieved from https:/ / repository.edgehill.ac.uk/6380/1/CLS9.Gabrielatos\&Duguid.pdf

Germond, B., McEnery, T., \& Marchi, A. (2016). The EU's comprehensive approach as the dominant discourse: A corpus-linguistics analysis of the EU's counter-piracy narrative. European Foreign Affairs Review, 21(1), 135-154.

Gilliam, L. H. (1997). The impact of the International Baccalaureate program on school change (Unpublished doctoral dissertation). Virginia Commonwealth University. Green, F., \& Vignoles, A. (2012). An empirical method for deriving grade equivalence for university entrance qualifications: An application to A levels and the International Baccalaureate. Oxford Review of Education, 38(4), 473-491.

Grexa, T. (1988). A case for the International Baccalaureate. The Journal of College Admissions, 121, 2-6.

Hahn, A. M. (2003). The intersection of language, power and international education: A critical discourse analysis of the International Baccalaureate Organization (Unpublished doctoral dissertation). Teachers College, Columbia University.

Halic, O. (2013). Postsecondary educational attainment of IB diploma candidates from US high schools. International Baccalaureate Organization. Retrieved from Halic, O. (2013). Retrieved from http://www.ibo.org/globalassets/publications/ibresearch/dp/nscpostsecondaryfullreportfinal.pdf

Hara, K. (2011). Educational change beyond borders: International Baccalaureate in New Zealand (Unpublished doctoral dissertation). Auckland University of Technology. 
Hardie, A., \& McEnery, T. (2010). On two traditions in corpus linguistics, and what they have in common. International Journal of Corpus Linguistics, 15(3), 384-394.

Hardt-Mautner, G. (1995). 'Only connect.' Critical discourse analysis and corpus linguistics. Retrieved from http://ucrel.lancs.ac.uk/papers/techpaper/vol6.pdf

Hart, C., \& Cap, P. (Eds.). (2014). Contemporary critical discourse studies. London, UK: Bloomsbury.

Hayden, M. (1998). International education in practice. In M. Hayden \& J Thompson (Eds.), International education: Principles and practice (pp. 1-8). London: Kogan Page.

Hayden, M., \& Thompson, J. (Eds.). 2011. Taking the MYP forward. Woodbridge: John Catt Educational.

Hanover Research. (2010). Current trends in International Baccalaureate programs. Retrieved from Hanover Research website: http://www.ibsom.org/uploads/9/0/6/3/9063770/current_trends_in_international_b accalaureate_programs_-_membership.pdf

Hayden, M. C., \& Wong, C. S. D. (1997). The International Baccalaureate: International education and cultural preservation. Educational Studies, 23(3), 349-361.

Hayot, P. T. (1984). The International Baccalaureate: A study of the evolution of International Baccalaureate education in France since 1976 (Unpublished doctoral dissertation). University of Michigan.

Higher Education Statistics Agency (HESA). (2011). International Baccalaureate students studying at UK higher education institutions: How do they fare? Retrieved from http://www.ibo.org/contentassets/d74675437b4f4ab38312702599a432f1/hesaukpo $\underline{\text { stsec final report.pdf }}$ 
Higher Education Statistics Agency (HESA). (2016). International Baccalaureate students studying at UK higher education institutions: How do they perform in comparison with A Level students? Retrieved from http://ibo.org/contentassets/d74675437b4f4ab38312702599a432f1/hesa_final_rep ort.pdf

Hill, I. (2001). Early stirrings: The beginnings of the international education movement. International Schools Journal, 20(2), 11-22.

Hill, I. (2002). The history of international education: An International Baccalaureate perspective. In M. Hayden, J. Thompson, \& G. Walker (Eds.), International education in practice: Dimensions for national \& international schools (pp. 18-29). London: Kogan Page.

Hill, I. (2010). The International Schools Journal compendium: The International Baccalaureate pioneering in education. Woodbridge, UK: John Catt.

Hill, I., \& Hayden, M. (2010). The International Baccalaureate: Pioneering in education. Woodbridge, UK: John Catt Educational Limited.

Hill, I., \& Saxton, S. (2014). The International Baccalaureate (IB) Programme: An international gateway to higher education and beyond. Higher Learning Research Communications, 4(3), 42-52.

Hill, J. (2013). College success factors for international students studying in the United States of America after completing an International Baccalaureate high school program (Unpublished doctoral dissertation). Northwest Nazarene University, USA.

Hinrichs, J. (2002). The effect of the International Baccalaureate Diploma Programme on international understanding. IB Research Notes, 2(1), 3-9. Retrieved from 
https://web.archive.org/web/20110105235113/http://www.ibo.org/programmes/r esearch/publications/documents/notesfebruary02.pdf

Hinrichs, J. (2003). A comparison of levels of international understanding among students of the International Baccalaureate Diploma and Advanced Placement programs in the USA. Journal of Research in International Education, 3(2), 331-348.

Hoey, M. (2005). Lexical priming: A new theory of words and language. London: Routledge.

Hunston, S. (2002). Corpora in applied linguistics. Cambridge, UK: Cambridge University Press.

Hunston, S. (2004). Counting the uncountable: Problem of identifying evaluation in a text and in a corpus. In A. Partington, J. Morley, \& L. Haarman (Eds.), Corpora and discourse (pp. 157-188). Bern: Peter Lang.

Hunston, S. (2007). Semantic prosody revisited. International Journal of Corpus Linguistics, 12(2), $249-268$.

Hunt, S. (2015). Representations of gender and agency in the Harry Potter series. In P. Baker \& T. McEnery (Eds.), Corpora and discourse: Integrating discourse and corpora (pp. 266-284). London, UK: Palgrave Macmillan.

International Baccalaureate Organization. (2003). 2003 Canadian survey of bigh school seniors participating in the International Baccalaureate Program. Retrieved from https://web.archive.org/web/20130704093644/https://www.ibo.org/ibna/research Ldocuments/2003StudentSurvey.Canada.pdf

International Baccalaureate Organization. (2006). Publications. Retrieved from https://web.archive.org/web/20060202051346/http://www.ibo.org:80/programme s/research/publications/index.cfm\#jrie 
International Baccalaureate Organization. (2007a). International Baccalaureate: 21 things you should know about the IB. Retrieved from https://web.archive.org/web/20120320064741/http://www.ibo.org/facts/21things /documents/21thingsyoushouldknowabouttheIBMarch08.pdf

International Baccalaureate Organization. (2007b). The IB Diploma Programme: A guide for universities and colleges. Retrieved from https://web.archive.org/web/20130117051410/https://www.ibo.org/communicati ons/publications/documents/e_uni_recognition_brochure_07.PDF

International Baccalaureate Organization. (2010a). IB Diploma Programme: A strong predictor of success in university. Recent research on the performance of students in the IB Diploma Programme. Retrieved from http://www.ohioib.org/StudentPerfBrochure1 9.pdf

International Baccalaureate Organization. (2010b). Preparation for university success. Retrieved from http://dmpsib.wikispaces.com/file/view/Preparation+for+University+Success.pdf International Baccalaureate Organization. (2011). Research on the International Baccalaureate 2010. Retrieved from http://www.ibo.org/globalassets/publications/ibresearch/2010references ext final-1.pdf

International Baccalaureate Organization. (2014a). IB: Myths vs. facts. Retrieved from https://www.ibo.org/ibna/actionkits/documents/Myths Facts 001.pdf International Baccalaureate Organization. (2014b). Myth and facts about the International Baccalaureate. Retrieved from http://www.midwestibschools.org/Countering IB Myths in Your School Comm unity 2014.pdf 
International Baccalaureate Organization. (2014c). The IB Diploma Programme: A guide for universities. Retrieved from http://cacti.acs.bg/pr/DPGuideforUniversities13Mar14_web.pdf International Baccalaureate Organization. (2014d). Four programmes at a glance. Retrieved from https://web.archive.org/web/*/http://www.ibo.org/programmes/index.cfm International Baccalaureate Organization. (2014e). History of the International Baccalaureate. Retrieved from https://web.archive.org/web/20141108234603/https://www.ibo.org/history/ International Baccalaureate Organization. (2014f). Resources for universities and applicants in the US and Canada: IB Americas College \& University Task Force (CURT). Retrieved from https://web.archive.org/web/20140713213328/http://ibo.org/informationfor/univer sitiesandgovernments/universities/curt/

International Baccalaureate Organization. (2015a). The IB: An historical perspective. Retrieved from http://www.ibo.org/globalassets/digital-tookit/presentations/1503presentation-historyoftheib-en.pdf International Baccalaureate Organization. (2015b). University admissions officers suggest $\mathrm{DP}$ as best preparation for workplace and university. Retrieved from http://www.ibo.org/en/news/news-about-the-ib/university-admissions-officerssuggest-dp-as-best-preparation-for-workplace-and-university/ International Baccalaureate Organization. (2016a). Guide to the International Baccalaureate Diploma Programme. Retrieved from 
http://www.ibo.org/globalassets/publications/recognition/dp-guide-foruniversities-en-2016.pdf

International Baccalaureate Organization. (2016b). University admissions officers favour DP over A

Levels. Retrieved from http://www.ibo.org/news/news-about-the-ib/universityadmissions-officers-favour-dp-over-a-levels/

International Baccalaureate Organization. (2016c). The Higher Education Statistics Agency 2016 report. Retrieved from http://ibo.org/uk/students-parents/the-higher-educationstatistics-agency-2016-report-key-findings/

International Baccalaureate Organization. (2016d). Approaching 40 years of the IB in Africa. Retrieved from http://www.ibo.org/news/news-about-the-ib/approaching-40years-of-the-ib-in-africa/

International Baccalaureate Organization. (2017a). About the IB. Retrieved from http://www.ibo.org/about-the-ib/

International Baccalaureate Organization. (2017b). Benefits of the IB. Retrieved from http://www.ibo.org/benefits/

International Baccalaureate Organization. (2017c). Facts and figures. Retrieved from http://www.ibo.org/about-the-ib/facts-and-figures/

International Baccalaureate Organization. (2017d). How to become an IB World School. Retrieved from http://www.ibo.org/become-an-ib-school/how-to-become-an-ib-school

International Baccalaureate Organization. (2017e). Programmes. Retrieved from http://www.ibo.org/en/programmes/

International Baccalaureate Organization. (2017f). Mission. Retrieved from http://www.ibo.org/about-the-ib/mission/ 
International Baccalaureate Organization. (2017g). The IB by country. Retrieved from http://www.ibo.org/about-the-ib/the-ib-by-country/

International Baccalaureate Organization. (2017h). Benefits for schools. Retrieved from http://www.ibo.org/benefits/benefits-for-schools/

International Baccalaureate Organization. (2017i). Research resources. Retrieved from http://www.ibo.org/research/research-resources/

James, K. (2005). International education: The concept, and its relationship to intercultural education. Journal of Research in International Education, 4(3), 313-332.

Jenkins, C. (2003). Perceptions of the IB Diploma Programme. Retrieved from http://www.ibo.org/en/about-the-ib/research/programme-impactresearch/diploma-studies/

Johnson, S., Culpeper, J., \& Suhr, S. (2003). From “politically correct councillors” to "Blairite nonsense": Discourses of "political correctness" in three British newspapers. Discourse \& Society, 14(1), 29-47.

Jonietz, P. L. (1991). A philosophy of international education: An interview with Robert Blackburn, Deputy Director of the International Baccalaureate Office, London, 25/9/89. In P. L. Jonietz \& D. Harris (Eds.), World yearbook of education 1991: International schools and international education (pp. 217-223). London, UK: Kogan Page.

Karim, K. H. (2008). Press, public sphere, and pluralism: Multiculturalism debates in Canadian English-language newspapers. Canadian Ethnic Studies, 40(1), 57-78.

KhosraviNik, M. (2009). The representation of refugees, asylum seekers and immigrants in British newspapers during the Balkan conflict (1999) and the British general election (2005). Discourse \& Society, 20(4), 477-498. 
KhosraviNik, M. (2010). The representation of refugees, asylum seekers and immigrants in British newspapers: A critical discourse analysis. Journal of Language and Politics, 9(1), 1 28.

KhosraviNik, M., Krzyzanowski, M., \& Wodak, R. (2012). Dynamics of representation in discourse: Immigrants in the British press. In M. Messer, R. Schröder \& R. Wodak (Eds.), Migrations: Interdisciplinary Perspectives (pp. 283-295). Vienna: Springer-Verlag.

Kilgarriff, A. (2005). Language is never, ever, ever, random. Corpus Linguistics and Linguistic Theory, 1(2), 263-275.

Kilgarriff, A. (2012). Getting to know your corpus. International conference on Text, Speech and Dialogue. Retrieved from https://www.sketchengine.co.uk/wpcontent/uploads/2015/07/Getting_to_know_2012.pdf

Kilgarriff, A. (2015). SketchEngine [Computer Software]. Available from http://www.sketchengine.co.uk/

Kilgarriff, A., Baisa, V., Bušta, J., Jakubíček, M., Kovář, V., Michelfeit, J., ... Suchomel, V. (2014). The sketch engine: Ten years on. Lexicography, 1, 7-36.

Kilgarriff, A., Rychly, P., Smrz, P., \& Tugwell, D. (2004). The sketch engine. Proceedings of EURALEX 2004 (pp. 105-116). Lorient, France.

Koller, V., \& Mautner, G. (2004). Computer applications in critical discourse analysis. In C. Coffin, A. Hewings \& K. O’Halloran (Eds.), Applying English grammar: Functional and corpus approaches (pp. 216-228). London, UK: Hodder Arnold.

Krishnamurthy, R. (1996). Ethnic, racial and tribal: The language of racism? In C. R. CaldasCoulthard \& M. Coulthard (Eds.), Texts and practices (pp. 129-149). London, UK: Routledge. 
Kroll, J. R. (1984). The evolution of the International Baccalaureate Program, 1964-1984

(Unpublished doctoral dissertation). University of Wisconsin-Milwaukee.

Krzyżanowski, M. (2005). 'European identity wanted!’: On discursive and communicative dimensions of the European Convention. In R. Wodak \& P. Chilton (Eds.), A new agenda in (critical) discourse analysis: Theory, methodology and interdisciplinarity (pp. 137-163). Philadelphia, PA: John Benjamins.

Krzyżanowski, M., \& Forchtner, B. (2016). Theories and concepts in critical discourse studies: Facing challenges, moving beyond foundations. Discourse \& Society, 27(3), 253-261.

Kuhn, T. S. (1962). The structure of scientific revolutions ( $2^{\text {nd }}$ ed.). Chicago: The University of Chicago Press.

Kwon, W., Clarke, I., \& Wodak, R. (2014). Micro-level discursive strategies for constructing shared views around strategic issues in team meetings. Journal of Management Studies, 51(2), 265-290.

Kyburg, R. M., Hertberg-Davis, H., \& Callahan, C. M. (2007). Advanced Placement and International Baccalaureate programs: Optimal learning environments for talented minorities? Journal of Advanced Academics, 18(2), 172-215.

Langford, M. (1998). Global nomads, third culture kids and international schools. In M. C. Hayden \& J. J. Thompson (Eds.), International Education: Principles and Practice (pp. 2843). London, UK: Kogan Page.

Leach, R. (1969). International schools and their role in the field of international education. Oxford: Pergamon Press. 
Lee, D. Y. W. (2008). Corpora and discourse analysis: New ways of doing old things. In V. K. Bhatia, J. Flowerdew, \& R. H. Jones (Eds.), Advances in discourse studies (pp. 86-99). New York, NY: Routledge.

Leslie, B. (2017, January 26). Saving high school goes beyond dollars and cents. Ottawa South News. Retrieved from https://issuu.com/emcsouth/docs/ottawasouthmanoticknews012617

Loat, W. (2007). Bridging the gap: The IB program as university preparation. AACRAOSEM Newsletter. American Association of Collegiate Registrars and Admissions Officers. Retrieved from https://web.archive.org/web/20141101175801/http://www4.aacrao.org:80/semso urce $/$ sem $/$ index6861.html?fa $=$ print\&id $=3697$

Louw, B. (1993). Irony in the text or insincerity in the writer?: The diagnostic potential of semantic prosodies. In M. Baker, G. Francis, \& E. Tognini-Bonelli (Eds.), Text and technology: In honour of John Sinclair (pp. 157-176). Amsterdam: John Benjamins.

Mahlberg, M. (2009). Patterns in news stories: A corpus approach to teaching discourse analysis. In L. Lombardo (Ed.), Using corpora to learn about language and discourse (pp. 99132). Bern, Switzerland: Peter Lang.

Marchi, A., \& Taylor, C. (2009). If on a winter's night two researchers...A challenge to assumptions of soundness of interpretation. Critical Approaches to Discourse Analysis across Disciplines, 3(1), 1-20.

Mathews, J., \& Hill, I. (2005). Supertest: How the International Baccalaureate can strengthen our schools. Chicago: Open Court. 
Matthews, M. (1989). The Scale of International Education. International Schools Journal, 17, 717.

May, H., Rodriguez, A., Sirinides, P. M., Perna, L. W., Yee, A., \& Ransom, T. (2013). Apples and oranges: Comparing the backgrounds and academic trajectories of International Baccalaureate (IB) students to a matched comparison group. Center for Research in Education \& Social Policy. Retrieved from http:/ / repository.upenn.edu/cgi/viewcontent.cgi?article $=1006 \&$ context $=$ cpre resea $\underline{\text { rchreports }}$

Mayer, A. P. (2006). Intermpting social reproduction: The implementation of an International Baccalaureate Diploma program in an urban high school (Unpublished doctoral dissertation). University of California.

Mayer, M. (1968). Diploma: International schools and university entrance. New York, NY: The Twentieth Century Fund.

Mautner, G. (2005). The entrepreneurial university: A discursive profile of a higher education buzzword. Critical Discourse Studies, 2(2), 95-120.

Mautner, G. (2007). Mining large corpora for social information: The case of elderly. Language in Society, 36, 51-72.

Mautner, G. (2008). Analyzing newspapers, magazines and other print media. In R. Wodak \& M. Krzyżanowski (Eds.), Qualitative discourse analysis in the social sciences (pp. 30-53). New York, NY: Palgrave Macmillan.

Mautner, G. (2009a). Corpora and critical discourse analysis. In P. Baker (Ed.), Contemporary corpus linguistics (pp. 32-46). London: Continuum. 
Mautner, G. (2009b). Checks and balances: How corpus linguistics can contribute to CDA. In R. Wodak \& M. Meyer (Eds.), Methods of critical discourse analysis (2 ${ }^{\text {nd }}$ ed.) (pp. 122143). London, UK: Sage.

McEnery, T. (2006). Swearing in English: Bad language, purity and power from 1586 to the present. London, UK: Routledge.

McEnery, T., \& Gabrielatos, C. (2006). English corpus linguistics. In B. Aarts \& A. McMahon (Eds.), The handbook of English linguistics (pp. 33-71). Malden, MA: Blackwell.

McEnery, T., \& Hardie, A. (2012). Corpus linguistics. Cambridge: Cambridge University Press. McEnery, T., McGlashan, M., \& Love, R. (2015). Press and social media reaction to ideologically inspired murder: The case of Lee Rigby. Discourse \& Communication, 9(2), 237-259.

McEnery, T., \& Wilson, A. (2001). Corpus linguistics: An Introduction (2 ${ }^{\text {nd }}$ ed.). Edinburgh: Edinburgh University Press.

McEnery, T., Xiao, R., \& Tono, Y. (2006). Corpus-based language studies: An advanced resource book. London, UK: Routledge.

Meadows, P. L. (2017). International education for all: The implementation of an International Baccalaureate program into a rural high school (Unpublished doctoral dissertation). Capella University, USA.

Mills, S. (2004). Discourse. London, UK: Routledge.

Nicol, H. Gilbert. (1982). The International Baccalaureate in Canada and the United States. The International Schools Journal, 3, 29-33. 
O'Connor, R. P. (2011). Raising all boats? An examination of claims that the International Baccalaureate diploma program is good for all (Unpublished doctoral dissertation). University of Iowa.

O’Halloran, K., \& Coffin, C. (2004). Checking overinterpretation and underinterpretation: Help from corpora in critical linguistics. In C. Coffin, A. Hewings \& K. O’Halloran (Eds.), Applying English grammar: Functional and corpus approaches (pp. 275-297). London, UK: Hodder Arnold.

Oberhuber, F. (2005). Deliberation or 'mainstreaming'?: Empirically researching the European Convention. In R. Wodak \& P. Chilton (Eds.), A new agenda in (critical) discourse analysis: Theory, methodology and interdisciplinarity (pp. 165-187). Philadelphia, PA: John Benjamins.

O’Keeffe, A., \& McCarthy, M. (Eds.). (2010). The Routledge handbook of corpus linguistics. New York, NY: Routledge.

Orpin, D. (2005). Corpus linguistics and critical discourse analysis: Examining the ideology of sleaze. International Journal of Corpus Linguistics, 10(1), 37-61.

Panich, C. (2001). A study of the university performance of students with International Baccalaureate high school experience (Unpublished $\mathrm{PhD}$ thesis). Duquesne University, Pittsburgh, PA.

Paris, P. G. (2003). The International Baccalaureate: A case study on why students choose to do the IB. International Education Journal, 4(3), 232-243.

Parker, J. M. (2000). An examination of the self-reported effects of the International Baccalaureate program on non-International Baccalaureate students (Unpublished doctoral dissertation). South Carolina State University. 
Parker, N. E. (1996). Identifying and evaluating factors based on students' perceptions affecting students' success (Unpublished doctoral dissertation). University of Minnesota.

Parker, W. C. (2008). International Education - What's in a Name? Phi Delta Kappan, 90(3): 196-202.

Parker, W. C. (2011). "International education” in US public schools. Globalisation, Societies and Education, 9(3), 487-501.

Partington, A. (2003). The linguistics of political argument: The spin-doctor and the wolf-pack at the White House. London: Routledge.

Partington, A. (2004). "Utterly content in each other's company": Semantic prosody and semantic preference. International Journal of Corpus Linguistics, 9(1), 131-156.

Partington, A. (2014). Mind the gaps: The role of corpus linguistics in researching absences. International Journal of Corpus Linguistics, 19(1), 118-146.

Partington, A., Duguid, A., \& Taylor, C. (2013). Patterns and meanings in discourse: Theory and practice in corpus-assisted discourse studies (CADS). Amsterdam: John Benjamins.

Pascoe, M. B. (2016). Effective practices to address implementation challenges in IB diploma programmes in Michigan schools (Unpublished doctoral dissertation). Western Michigan University.

Perna, L. W., May, H., Yee, A., Ransom, T., Rodriguez, A., \& Fester, R. (2011). The potential role of the International Baccalaureate (IB) Diploma Programme in improving academic preparation for college for all students. Paper presented at the Annual Meeting of the Association for the Study of Higher Education, Charlotte, North Carolina. Retrieved from http://www.cpre.org/sites/default/files/meetingpaper/1372 ashe2011ibpaper1232011.pdf 
Peterson, A. D. C. (1972). The International Baccalaureate: An experiment in international education. London, UK: George G. Harrap \& Co. Ltd.

Peterson, A. D. C. (1987). Schools across frontiers: The story of the International Baccalaureate and the United World Colleges. La Salle, IL: Open Court.

Piper, A. (2000). Some have credit cards and others have giro cheques: "Individuals" and “people” as lifelong learners in late modernity. Discourse \& Society, 11(3), 515-542.

Postlethwaite, T. N. (1970). Book reviews. International Review of Education, 16(4), 504-506.

Potts, A. (2015). Filtering the flood: Semantic tagging as a method of identifying salient discourse topics in a large corpus of Hurricane Katrina reportage. In P. Baker \& T. McEnery (Eds.), Corpora and discourse studies: Integrating discourse and corpora (pp. 285304). London, UK: Palgrave MacMillan.

Powell, K. E. (2002). The International Baccalaureate Middle Years Programme: A model of program implementation and school reform (Unpublished doctoral dissertation). University of Pittsburgh.

Prentice, S. (2010). Using automated semantic tagging in critical discourse analysis: A case study on Scottish independence from a Scottish nationalist perspective. Discourse \& Society, 21(4), 405-437.

Regina Board of Education. (2016). International Baccalaureate program review and implementation plan. Retrieved from http://www.rbe.sk.ca/sites/default/files/boarddocs/international baccalaureate pr ogram review.pdf 
Reisigl, M. (2008). Analyzing political rhetoric. In R. Wodak \& M. Krzyżanowski (Eds.), Qualitative discourse analysis in the social sciences (pp. 96-120). New York, NY: Palgrave Macmillan.

Reisigl, M., \& Wodak, R. (2001). Discourse and discrimination: Rhetorics of racism and antisemitism. London, UK: Routledge.

Reisigl, M., \& Wodak, R. (2009). The Discourse-Historical Approach (DHA). In R. Wodak \& M. Meyer (Eds.), Methods of critical discourse analysis (2 ${ }^{\text {nd }}$ ed., pp. 87-121). London: Sage.

Remillard, J. R. (1978). Knowledge and social control in a multinational context: An analysis of the development, content and potential of the International Baccalaureate (Unpublished doctoral dissertation). State University of New York, Buffalo.

Renaud, G. (1974). Experimental period of the International Baccalaureate: Objectives and results. Paris: UNESCO.

Resnik, J. (2009). Multicultural education - good for business but not for the state? The IB curriculum and global capitalism. British Journal of Educational Studies, 57(3), 217-244.

Resnik, J. (2012). The denationalization of education and the expansion of the International Baccalaureate. Comparative Education Review, 56(2), 248-269.

Rhodes, T. (2007). Accelerated learning for what? Association of American Colleges and Universities. Retrieved from https://www.aacu.org/peerreview/prwi07/documents/ PRWI07_Rhodes.pdf

Richards, N. (1998). The emperor's new clothes? The issue of staffing in international schools. In M. C. Hayden \& J. J. Thompson (Eds.), International Education: Principles and Practice (pp. 65-76). London, UK: Kogan Page. 
Richardson, J. E., \& Wodak, R. (2009). Recontextualising fascist ideologies of the past: Right-wing discourses on employment and nativism in Austria and the United Kingdom. Critical Discourse Studies, 6(4), 251-267.

Rodway, J. D. A. (2008). Making sense of international mindedness in the International Baccalaureate Diploma Program (Unpublished master's thesis). OISE, University of Toronto.

Rogers, R., Malancharuvil-Berkes, E., Mosley, M., Hui, D., \& O’Garro Joseph, G. (2005). Critical discourse analysis in education: A review of the literature. Review of Educational Research, 75(3), 365-416.

Rowell, P. M. (1983). Planning for the implementation of the International Baccalaureate Program: A situational study (Unpublished doctoral dissertation). University of Alberta, Edmonton, $\mathrm{AB}$.

Salahshour, N. (2016). Liquid metaphors as positive evaluations: A corpus-assisted discourse analysis of the representation of migrants in a daily New Zealand newspaper. Discourse, Context and Media, 13, 73-81.

Salama, A. H. Y. (2011). Ideological collocation and the recontexualizaton of Wahhabi-Saudi Islam post-9/11: A synergy of corpus linguistics and critical discourse analysis. Discourse \& Society, 22(3), 315-342.

Salomon, M. B. (1981). Curriculum development for internationalism: The International Baccalaureate revisited (Unpublished doctoral dissertation). University of Massachusetts.

Samore, D. C. M. (1992). Admissions criteria as predictors of success in the International Baccalaureate (Unpublished doctoral dissertation). Florida Atlantic University.

Schiffrin, D., Tannen, D., \& Hamilton, H. E. (Eds.). (2001). The handbook of discourse analysis. Malden, MA: Blackwell. 
Scott, M. (1997). PC analysis of key words - and key key words. System, 25(2), 233-245.

Scott, M. (2017). WordSmith Tools version 7, Stroud: Lexical Analysis Software.

Sills, R. A. (1996). The International Baccalaureate: Teacher response to a centralized curriculum (Unpublished doctoral dissertation). Harvard University.

Sjorgen, C., \& Vermey, E. G. (1986). The International Baccalaureate: Views from selected American universities. International Quarterly, 26-28. Retrieved from http://internationalcounselor.org/College\%20program/ib_and_college_admissions. htm\#research

Sinclair, J. (1991). Corpus, concordance, collocation. Oxford, UK: Oxford University Press.

Sinclair, J. (2004). Developing linguistic corpora: A guide to good practice. AHDS Literature, Languages and Linguistics, University of Oxford, UK. Retrieved from ota.ox.ac.uk/documents/creating/dlc/chapter1.htm

Smith, D. N. A. (2010). A corpus-driven discourse analysis of transcripts of Hugo Chavez's television programme "Alo Presidente" (Unpublished doctoral dissertation). University of Birmingham.

Spahn, B. A. (2001). America and the International Baccalaureate-Implementing the International Baccalaureate in the United States: A study of three schools. Suffolk, UK: John Catt Educational Ltd.

Starr, L. J. (2012). A critique of the International Baccalaureate Learner Profile as a curricular document: Context, hegemony, hermeneutics and the four Rs. University of Victoria, Department of curriculum and instruction. Retrieved from http://theyonseijournal.com/wp-content/uploads/2012/08/pear-2-starr_1.pdf 
Stobie, T. D. (2005). A consideration of the extent to which the Middle Years Programme and Diploma Programme of the International Baccalaureate Organization provide a coherent and consistent educational continuum (Unpublished doctoral dissertation). University of Bath, UK.

Stubbs, M. (1993). British traditions in text analysis: From Firth to Sinclair. In M. Baker, G. Francis, \& E. Tognini-Bonelli (Eds.), Text and technology: In honour of Jobn Sinclair (pp. 1-33). Amsterdam: John Benjamins.

Stubbs, M. (1994). Grammar, text, and ideology: Computer-assisted methods in the linguistics of representation. Applied Linguistics, 15(2), 201-223.

Stubbs, M. (1995). Collocations and semantic profiles: On the cause of the trouble with quantitative studies. Functions of Language, 2(1), 1-24. Retrieved from https://www.uni-trier.de/fileadmin/fb2/ANG/Linguistik/Stubbs/stubbs-1995cause-trouble.pdf

Stubbs, M. (1996). Text and corpus analysis: Computer-assisted studies of language and culture. Oxford: Blackwell.

Stubbs, M. (1997). Whorf's children: Critical comments on critical discourse analysis (CDA). In A. Ryan \& A. Wray (Eds.), Evolving models of language: Papers from the annual meeting of the British Association for Applied Linguistics held at the University of Wales, Swansea, September 1996 (pp. 100-116). Philadelphia, PA: Multilingual Matters.

Stubbs, M. (2001). Texts, corpora and problems of interpretation: A response to Widdowson. Applied Linguistics, 22(2), 149-172.

Stubbs, M. (2001). Words and phrases: Corpus studies of lexical semantics. Oxford: Blackwell. Stubbs, M. (2004). Human and inhuman geography: A comparative analysis of two long texts and a corpus. In C. Coffin, A. Hewings, \& K. O’Halloran (Eds.), Applying 
English grammar: Functional and corpus approaches (247-274). London, UK: Hodder Arnold.

Tarc, P. (2009). Global dreams, enduring tensions: International Baccalaureate program in a changing world. New York: Peter Lang.

Tarc, P., \& Beatty, L. (2012). The emergence of the International Baccalaureate Diploma in Ontario: Diffusion, pilot study and prospective research. Canadian Journal of Education, 35(4), 341-375.

Tarver, E. T. (2010). University admissions officers' perceptions of student performance within the International Baccalaureate Diploma Program (Unpublished doctoral dissertation). Louisiana State University.

Taylor, C. (2008). What is corpus linguistics? What the data says. ICAME Journal, 32, 179-200.

Taylor, C. (2010). Science in the news: A diachronic perspective. Corpora, 5(2), 221-250.

Taylor, M. L., \& Porath, M. (2006). Reflections on the International Baccalaureate Program: Graduates' perspectives. The Journal of Secondary Gifted Education, 17(3), 21-30.

Tenorio, E. H. (2011). Critical discourse analysis, an overview. Nordic Journal of English studies, 10(1), 183-210.

Teubert, W. (2005). My version of corpus linguistics. International Journal of Corpus Linguistics, 10(1), 1-13.

Thomas, P. B. (1988a). Students across frontiers. The Journal of College Admissions, 121, 7-10.

Thomas, P. B. (1988b). University destinations and performance of IB diploma holders. The Journal of College Admissions, 121, 11-14.

Titscher, S., Meyer, M., Wodak, R., \& Vetter, E. (2000). Methods of text and discourse analysis. London: Sage. 
Tognini-Bonelli, E. (2001). Corpus linguistics at work. Amsterdam: John Benjamins.

Tognini-Bonelli, E. (2004). Working with corpora: Issues and insights. In C. Coffin, A. Hewings, \& K. O’Halloran (Eds.), Applying English grammar: Functional and corpus approaches (pp. 11-24). London, UK: Hodder Arnold.

Torre-Halscott, C. R. (1992). Extent to which selected variables predict success among International Baccalaureate students (Unpublished doctoral dissertation). University of Florida.

Uy, V. (1988). Determining the relevance of the international baccalaureate program vis-a-vis the Third World countries (Unpublished doctoral dissertation). Columbia University Teachers College.

van Dijk, T. (2001). Multidisciplinary CDA: A plea for diversity. In R. Wodak \& M. Meyer (Eds.), Methods of critical discourse analysis (pp. 95-120). London, UK: Sage.

van Leeuwen, T. (1996). The representation of social actors. In C. R. Caldas-Coulthard \& M. Coulthard (Eds.), Texts and practices: Readings in critical discourse analysis (pp. 32-70). New York, NY: Routledge.

van Leeuwen, T., \& Wodak, R. (1999). Legitimizing immigration control: A discoursehistorical analysis. Discourse Studies, 1(1), 83-118.

van Oord, L. (2007). To westernize the nations? An analysis of the International Baccalaureate's philosophy of education. Cambridge Journal of Education, 37(3), 375390.

Verneuille, J. T. (2011). The potential impacts of implementing the International Baccalaureate program in the Sag Harbor Union Free School district (Unpublished master's thesis). State University of New York. 
Vessey, R. (2016). Language and Canadian media: Representation, ideologies, policies. London, UK: Palgrave Macmillan.

Vogt, W. P. (2007). Quantitative research methods for professionals. Boston, MA: Pearson. Wagner, J. D. (1978). An analysis of the origin and growth of the International Baccalaureate (Unpublished doctoral dissertation). University of Connecticut.

Walker, G. (2002). The language of international education. In M. Hayden, J. Thompson \& G. Walker (Eds.), International education in practice: Dimensions for national \& international schools (pp. 208-215). London: Kogan Page.

Walker, G. (2005). Looking back and looking forward: The next 30 years. Plenary Address to the IBNA Annual Regional Conference, Montreal, $9^{\text {th }}$ July. Retrieved from https://web.archive.org/web/20070930201614/http://www.ibo.org/dg/emeritus/s peeches/documents/ibna jul05.pdf

Whitehead, K. (2005). Advertising advantage. The International Baccalaureate, social justice and the marketisation of schooling. Paper presented at the Australian Association for Research in Education Annual Conference, University of Western Sydney, Parramatta. Retrieved from http://www.aare.edu.au/data/publications/2005/whi05426.pdf

Whitsitt, S. (2005). A critique of the concept of semantic prosody. International Journal of Corpus Linguistics, 10(3), 283-305.

Widdowson, H. G. (2000). On the limitations of linguistics applied. Applied Linguistics, 21(1), $3-25$.

Widdowson, H. G. (2004). Text, context, pretext: Critical issues in discourse analysis. Oxford, UK: Blackwell. 
Wilkerson, C. L. (2005). The instructional efficacy of the International Baccalaureate program based on Scholastic Aptitude Tests, American College Tests, Advanced Placement and International Baccalaureate examinations (Unpublished doctoral dissertation). South Carolina State University.

Wodak, R. (1996). The genesis of racist discourse in Austria since 1989. In C. R. CaldasCoulthard \& M. Coulthard (Eds.), Texts and practices: Readings in critical discourse analysis (pp. 107-128). New York, NY: Routledge.

Wodak, R. (1999). Critical discourse analysis at the end of the $20^{\text {th }}$ century. Research on Language and Social Interaction, 32(1\&2), 185-193.

Wodak, R. (2001). The discourse-historical approach. In R. Wodak \& M. Meyer (Eds.), Methods of critical discourse analysis (pp. 63-94). London: Sage.

Wodak, R. (2002). Aspects of critical discourse analysis. Zeitschrift fiir Angewandte Linguistik, 36, 5-31.

Wodak, R. (2007). Pragmatics and critical discourse analysis. Pragmatics \& Cognition, 15(1), 203-225.

Wodak, R. (2008). 'Us' and 'them': Inclusion and exclusion - discrimination via discourse. In G. Delanty, R. Wodak, \& P. Jones (Eds.), Identity, belonging and migration (pp. 54-77). Liverpool University Press.

Wodak, R. (2009). The semiotics of racism: A critical discourse-historical analysis. In J. Renkema (Ed.), Discourse, of course: An overview of research in discourse studies (pp. 311325). Philadelphia, PA: John Benjamins.

Wodak, R. (2011). Suppression of the nazi past, coded languages, discourses of silence: Applying the discourse-historical approach to post-war anti-semitism in Austria. In 
W. Steinmetz (Ed.), Political languages in the age of extremes (pp. 351-379). London: Oxford University Press.

Wodak, R. (2012). Politics as usual: Investigating political discourse in action. In J. P. Gee \& M. Handford (Eds.), The Routledge handbook of discourse analysis (pp. 525-540). New York, NY: Routledge.

Wodak, R. (2014). Analyzing interaction in meetings: Perspectives from critical discourse studies and the discourse-historical approach. In F. Cooren, E. Vaara, A. Langley \& H. Tsoukas (Eds.), Language and communication at work (pp. 39-70). Oxford: Oxford University Press.

Wodak, R., de Cillia, R., Reisigl, M., \& Liebhart, K. (2009). The discursive construction of national identity (2 ${ }^{\text {nd }}$ ed.). Edinburgh: Edinburgh University Press.

Wodak, R., Krzyżanowski, M., \& Forchtner, B. (2012). The interplay of language ideologies and contextual cues in multilingual interactions: Language choice and code-switching in European Union institutions. Language in Society, 41, 157-186.

Wodak, R., Kwon, W., \& Clarke, I. (2011). “Getting people on board”: Discursive leadership for consensus building in team meetings. Discourse \& Society, 23(5), 592-644.

Wodak, R., \& Matouschek, B. (1993). "We are dealing with people whose origins one can clearly tell just by looking": Critical discourse analysis and the study of neo-racism in contemporary Austria. Discourse \& Society, 4(2), 225-248.

Wodak, R., \& Meyer, M. (Eds.). (2009). Methods of critical discourse analysis (2 ${ }^{\text {nd }}$ ed.). London, UK: Sage.

Wodak, R., \& Meyer, M. (Eds.). (2016). Methods of critical discourse studies (3 ${ }^{\text {rd }}$ ed.). London, UK: Sage. 
Wodak, R., \& Weiss, G. (2005). Analyzing European Union discourses: Theories and applications. In R. Wodak \& P. Chilton (Eds.), A new agenda in (critical) discourse analysis: Theory, methodology and interdisciplinarity (pp. 121-135). Philadelphia, PA: John Benjamins.

$\mathrm{Xi}, \mathrm{W}$. (2015). The discursive construction of intercultural understanding in China: A case study of an International Baccalaureate Diploma Program. New York, NY: Lexington Books.

Zethsen, K. K. (2006). Semantic prosody: Creating awareness about a versatile tool. Tidsskrift for Sprogforskning, 4(1), 275-294. Retrieved from ojs.statsbiblioteket.dk/index.php/tfs/ article/view/324 